BIOMECHANICS OF NORTH ATLANTIC RIGHT WHALE BONE: MANDIBULAR FRACTURE AS A FATAL ENDPOINT FOR BLUNT VESSEL-WHALE COLLISION MODELING

\author{
by \\ Regina Campbell-Malone \\ B.S., University at Buffalo, The State University of New York, 2000 \\ Submitted in partial fulfillment of the requirements for the degree of \\ Doctor of Philosophy \\ at the \\ MASSACHUSETTS INSTITUTE OF TECHNOLOGY \\ and the \\ WOODS HOLE OCEANOGRAPHIC INSTITUTION
}

September 2007

(C) 2007 Regina Campbell-Malone

All rights reserved.

The author hereby grants to MIT and WHOI permission to reproduce and to distribute publicly paper and electronic copies of this thesis document in whole or in part and to distribute them publicly.

Signature of Author,

Joint Proggram in Oceanography/Applied Ocean Science and Engineering Massachusetts Institute of Technology and Woods Hole Oceanographic Institution Certified by June 28, 2007

Michael J. Moore

Thesis Supervisor

Accepted by

Edward F. DeLong

Chyir, Joidt Committee for Biological Oceanography

Woods Hole Oceanographic Institution 


\title{
Biomechanics of North Atlantic Right Whale Bone: Mandibular Fracture as a Fatal Endpoint for Blunt Vessel-Whale Collision Modeling
}

\author{
by \\ Regina Campbell-Malone \\ Submitted to the MIT Department of Biology and the WHOI Biology Department in \\ partial fulfillment of the requirements for the degree of \\ Doctor of Philosophy
}

\begin{abstract}
The North Atlantic right whale, Eubalaena glacialis, one of the most critically endangered whales in the world, is subject to high anthropogenic mortality. Vessel-whale collisions and entanglement in fishing gear were indicated in $27(67.5 \%)$ of the 40 right whales necropsied between 1970 and December 2006. Of those, at least 9 deaths (22.5\%) resulted from blunt contact with a vessel. To reduce the likelihood of fatal collisions, speed restrictions are being considered for vessels traversing critical habitat, although the effects of speed on collision outcomes have not been specifically evaluated from a biomechanics perspective.

The ultimate goal of a larger collaborative project is to evaluate the efficacy of speed restrictions for reducing blunt collision mortality using a multi-scale finite element model. Complete, transverse fracture of the right whale mandible, an injury seen only in right whales killed by vessels, is used as a proxy for mortality in the model. Vital for that model are the material properties and biomechanical behavior of the right whale mandible.

Here, the internal structure and physical properties of right whale jawbone tissue are reported. The average apparent densities, $0.4258 \mathrm{~g} / \mathrm{cc} \pm 0.0970$ and $1.2370 \mathrm{~g} / \mathrm{cc} \pm 0.0535$ for trabecular and cortical bone respectively, indicate that the bone is of relatively low density. Average ash content for trabecular bone $(64.38 \% \pm 1.1330)$ is comparable with values from other species, indicating that low density results from a reduction of bone mass, not mineralization.

Mechanical properties of right whale bone (Young's modulus of elasticity and Poisson's ratio) were determined via uniaxial compression testing. These data are incorporated into the finite element model simulating different loading conditions (e.g. vessel speeds) that likely lead to mandibular failure and thereby mortality from blunt vessel collisions. Model results (e.g. risk of fracture) are used to determine the effect of speed restrictions on collision outcomes.
\end{abstract}




\section{ACKNOWLEDGEMENTS}

I am grateful for the opportunity to thank the many individuals and institutions that have supported this endeavor along the way. Without you this volume would not have been possible.

First and foremost, I'd like to express heartfelt thanks to my family for their unconditional love and support - now, then and always. Madness, Martini and Mandolin - I love you.

I'd also like to thank my advisor, Michael J. Moore for his intellectual and personal contributions toward the development of this body of work. Though I may never learn how to tie your bowline, the lessons I have learned from you will last a lifetime. Special thanks to my labmates, Andrea Bogomolni and Nadine Lysiak for their angelic dispositions. Your patience, warmth and energy are positively contagious.

To Lorna Gibson (MIT) and Igor Tsukrov (UNH) - your technical guidance and personal support were invaluable. I'd like to thank Moira Brown and the right whale research group at the New England Aquarium for providing me with a home and stress-free data access. Your work focuses on an endangered species whose population is rivaled by the number of researchers working to protecting them. Your dedication is an inspiration. Sue Barco, Jerry Conway and Amy Knowlton for making logistical necropsy support look effortless - though we all know better!

Thank you to my MIT/WHOI Joint Program peers, especially Eric Montie, Gareth Lawson, Nathalie Fairbank Goodkin Emami and Benjamin Walther. Special thanks to Andrea Thorrold and Lauren Mullineaux (WHOI) for teaching Communicating Ocean Sciences - I wish I had learned half as much my first time through $4^{\text {th }}$ grade!

I would like to acknowledge the invaluable assistance of contributors without whom this interdisciplinary ship would not have sailed - Bill McLellan (UNCW), Dave Rotstein (UTenn), Pierre-Yves Daoust (UPEI, Canada), Vicke Starczak (WHOI), Roberto Fajardo, John A. Muller, Nipun Patel, and Brian Snyder (Beth Israel Deaconess Medical Center). Technical assistance provided by Darlene Ketten, Julie Arruda and Scott Cramer (WHOI) Robin Fail (University of North Carolina Chapel Hill), Don Duncan, Patrick Barthelemy and Kathy Tinoco (Mercury Computer Systems) was also vital and appreciated. Special thanks to Ken Baldwin, Judson DeCew and Jason Raymond of the University of New Hampshire, Phil Clapham (NOAA Fisheries) and the Cape Cod Stranding Network (Buzzard's Bay, MA).

Personal thanks to Valerie Caron, Marsha Gomes, Shona Vitelli and Julia Westwater for going above and beyond the call of duty. Your dedication and personal touch have taught me that there is nothing that you can't make better with a smile, a hug, and a hot cup of tea. For that lesson (and so much more) I love you. To Blanche Staton (MIT), Ambrose Jearld (NOAA Fisheries), and Ashanti Pyrtle (USF) for being there in ways that only you could.

Funding for this work was provided by the National Science Foundation (Graduate Research Fellowship Program, Campbell-Malone), the National Oceanic and Atmospheric Administration (Right Whale Grants Program, 2004, PI Campbell-Malone, Award number NA04NMF4720402), the Ocean Life Institute (PI Campbell-Malone and PI Moore), the Quebec Labrador Foundation (PI Campbell-Malone), WHOI SeaGrant (PI Campbell-Malone), and an MIT (Presidential Fellowship, Campbell-Malone). All right whale samples were collected under National Marine Fisheries Service No. 932-1489-05.

And finally, I would like to thank my husband Kenneth M. Schopf for his unwavering support through a year filled with so much promise, preparation and planning. I am grateful for your patience and feel so blessed to have you in my life. 


\section{TABLE OF CONTENTS}

ABSTRACT 3

ACKNOWLEDGEMENTS _.............................................................................

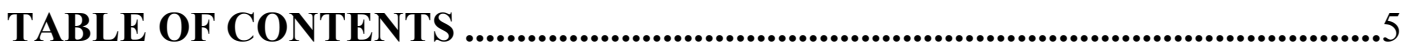

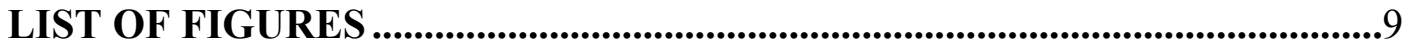

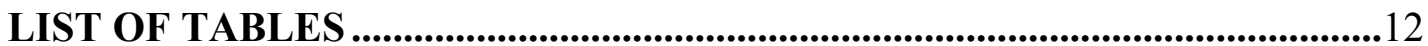

LIST OF ABBREVIATIONS ..................................................................................13

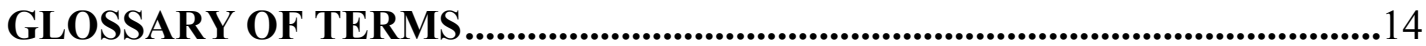

\section{CHAPTER 1: INTRODUCTION}

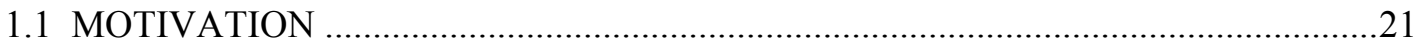

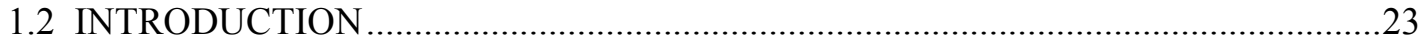

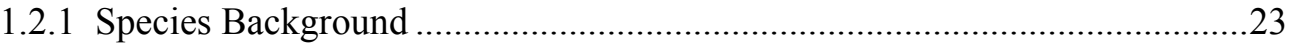

1.2.2 Biology, population size and trends …………………………………......24

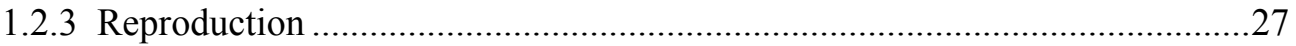

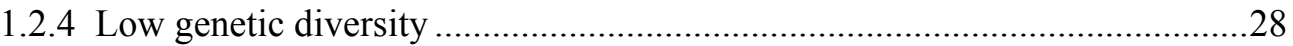

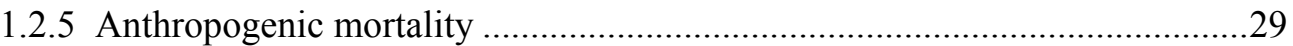

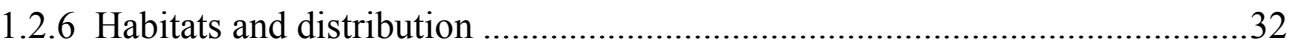

1.2.7 Protection and management …………………………………………….......

1.2.8 American and Canadian recovery plans .......................................................43

1.2.9 Vessel-whale collision modeling ...............................................................45

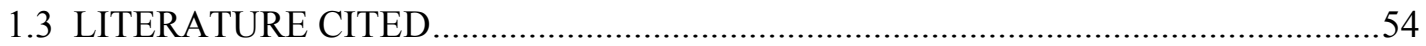

CHAPTER 2: GROSS AND HISTOLOGIC EVIDENCE OF SHARP AND BLUNT

TRAUMA IN NORTH ATLANTIC RIGHT WHALES (Eubalaena glacialis)

KILLED BY VESSELS

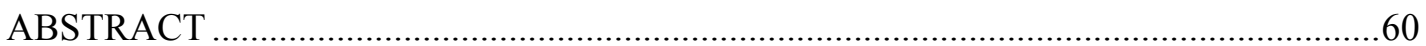

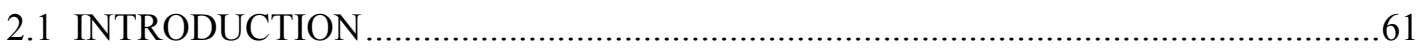

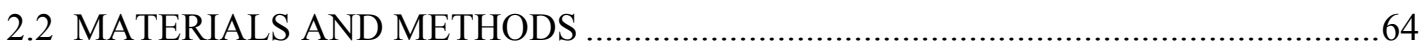

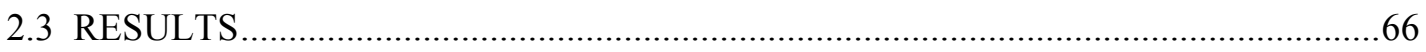

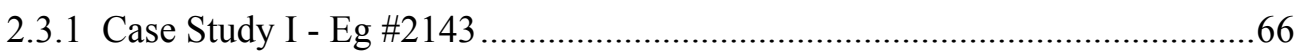

2.3.2 Case Study II - Eg \#1909 .............................................................................

2.3.3 Case Study III - Eg \#1004 ………………………………………………....75 


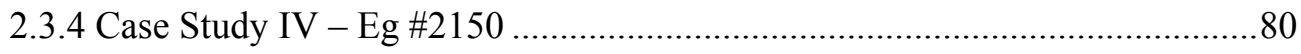

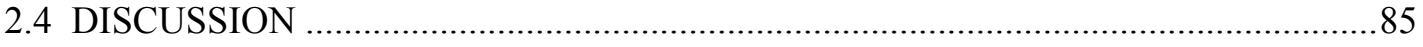

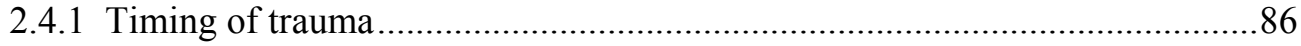

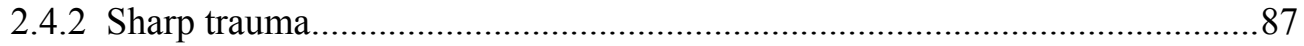

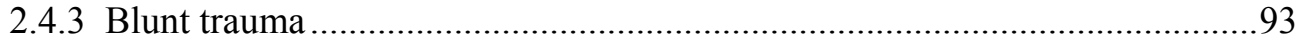

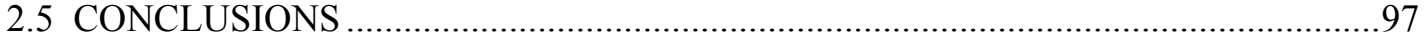

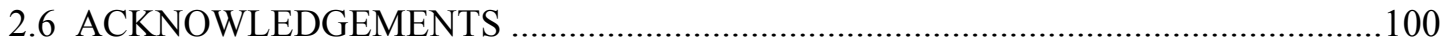

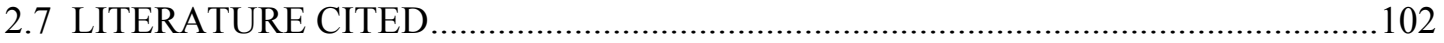

\section{CHAPTER 3: GEOMETRY, INTERNAL MORPHOLOGY AND DENSITOMETRY OF THE RIGHT WHALE MANDIBLE}

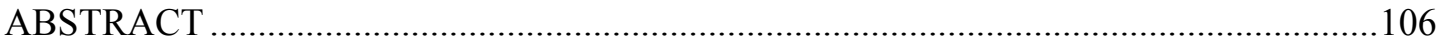

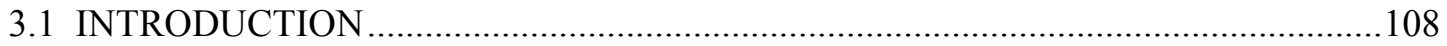

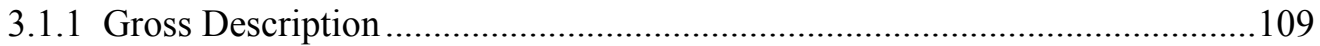

3.1.2 Mandibular bone tissue structure and physical properties.............................111

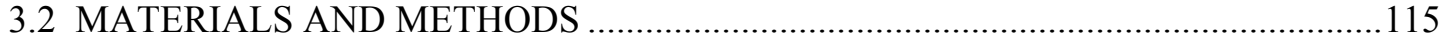

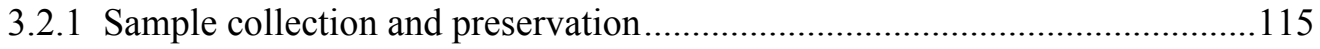

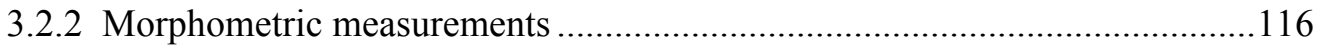

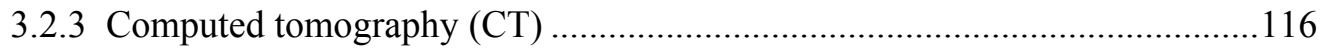

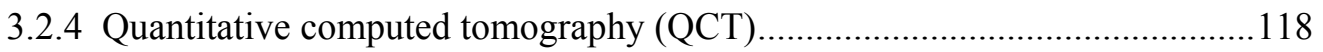

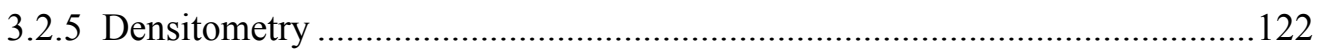

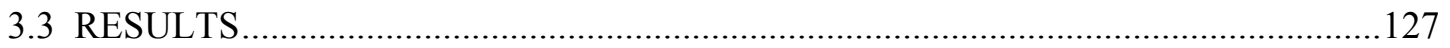

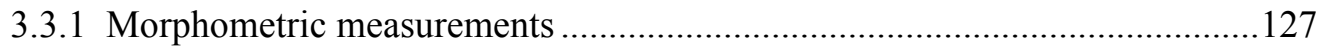

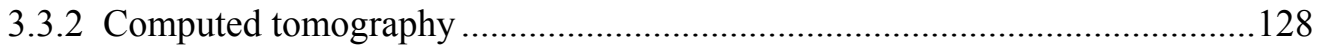

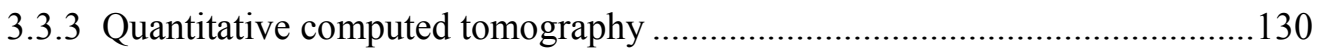

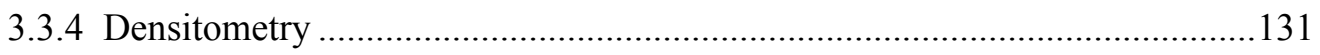

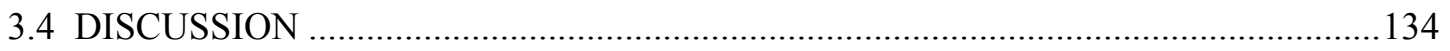

3.4.1 Right whale bone density and internal structure .........................................134

3.4.2 Comparing patterns in bone density - structure vs. function ........................136

3.4.3 Comparison of densitometry techniques ................................................... 138

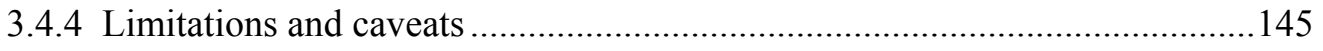

3.4.5 Implications for fracture risk .............................................................. 149

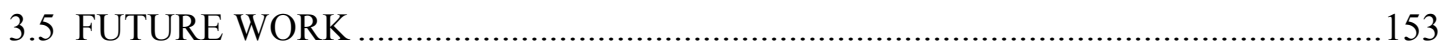

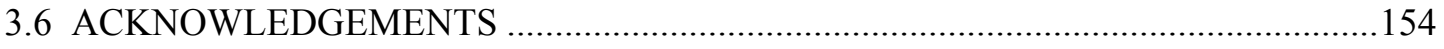




\section{CHAPTER 4: MATERIAL PROPERTIES OF THE NORTH ATLANTIC RIGHT WHALE MANDIBLE: A FATAL ENDPOINT FOR VESSEL-WHALE COLLISION MODELING}

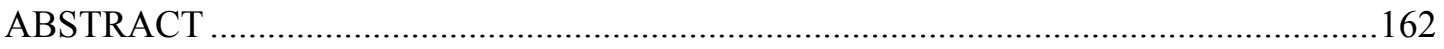

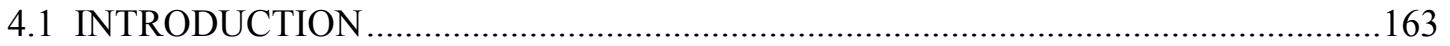

4.1.1 Mandibular fracture as a proxy for fatality from vessel-whale collisions ......164

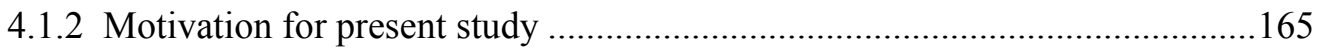

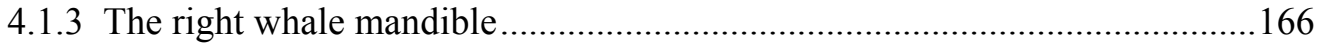

4.1.4 Physical properties as a predictor of material properties in bone ...................167

4.1.5 Apparent density as a predictor of Young's modulus and ultimate compressive

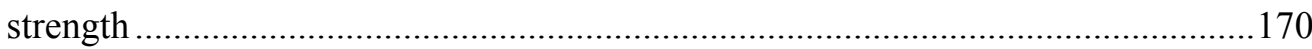

4.1.6 Predicting Young's modulus using quantitative computed tomography (QCT)

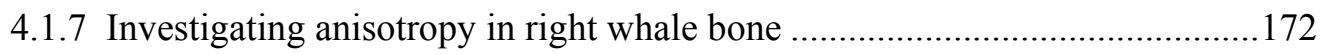

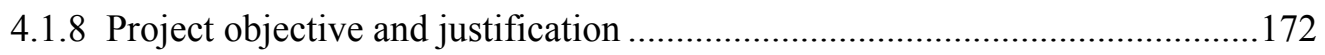

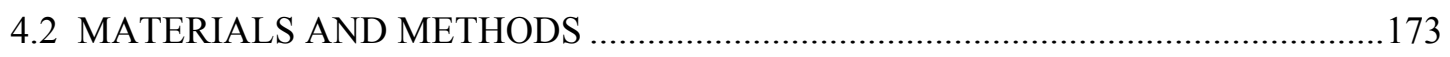

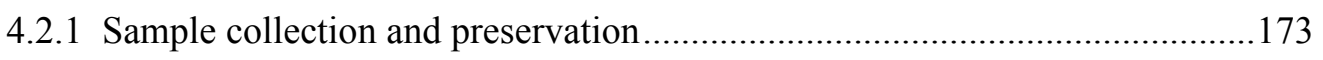

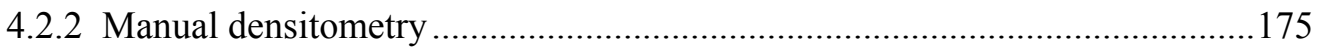

4.2.3 Evaluating QCT apparent density as a predictor of apparent density and Young's

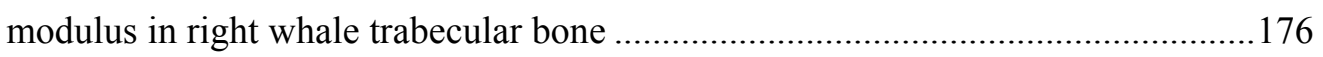

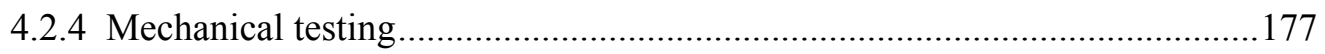

4.2.5 QCT apparent density and estimated Young's modulus ..............................183

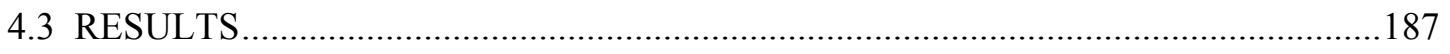

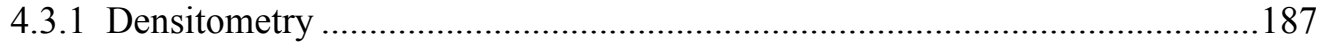

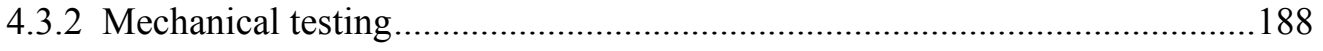

4.3.3 QCT apparent density and estimated Young's modulus ...............................199

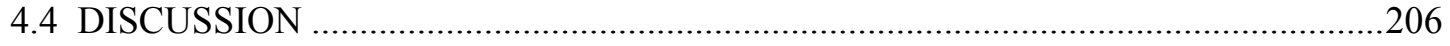

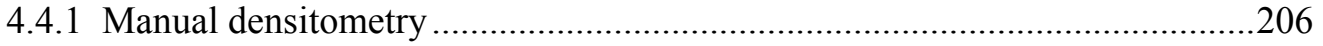

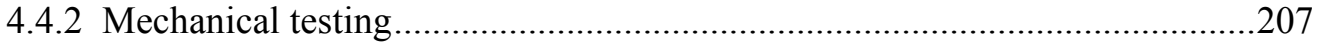

4.4.3 Estimating apparent density and Young's modulus using QCT ....................211

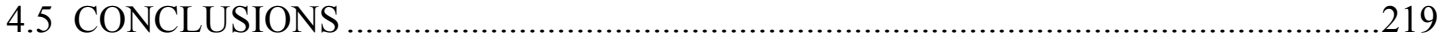

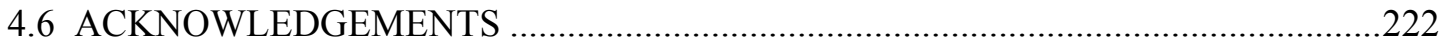




\section{CHAPTER 5: THESIS SUMMARY}

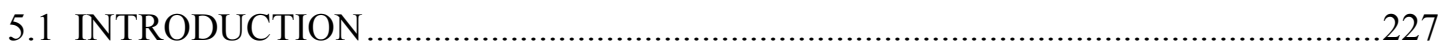

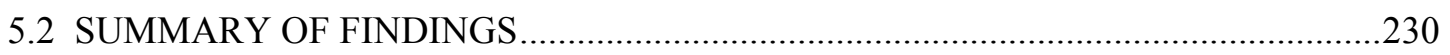

5.2.1 Chapter 2 - Gross and histologic evidence of sharp and blunt trauma in North Atlantic right whales (Eubalaena glacialis) killed by vessels .230

5.2.2 Chapter 3 - Geometry, internal morphology and densitometry of the North Atlantic

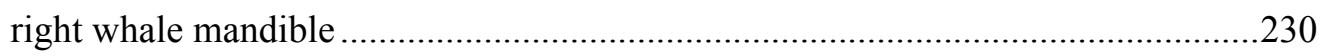

5.2.3 Chapter 4 - Material properties of the right whale mandible: a fatal endpoint for vessel-whale collision modeling .........................................................................23

5.3 THE FINITE ELEMENT MODEL OF THE MANDIBLE ..........................................235

5.3.1 Considerations for a vessel-whale collision model ......................................235

5.3.2 Finite element model of mandibular failure: design and preliminary results ..241

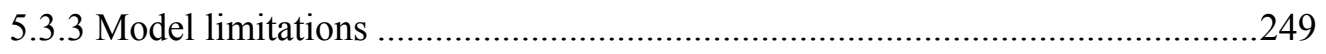

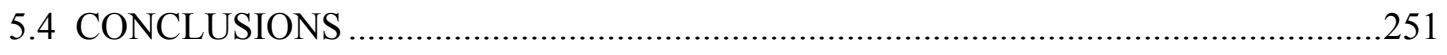

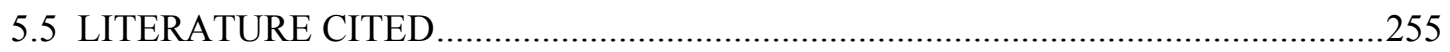




\section{LIST OF FIGURES}

Figure 1.1. Image of a mature North Atlantic right whale. 25

Figure 1.2. Relative mortality statistics from post-mortem examination of 40 carcasses retrieved between 1970 - December 2006. 30

Figure 1.3. Detailed map of North Atlantic right whale distribution in the Western North Atlantic. 36

Figure 1.4. Spatial location of right whales in the Central Early Warning System Survey Area of the Southeastern U.S. critical habitat during the winter 2005-2006 field season

Figure 1.5. Spatial location of commercial vessels $\geq 300$ gross tons in the Central Early Warning System Survey Area of the Southeastern U.S. critical habitat, collected from AIS beacon signals received over a 64-day period in the winter 2005-2006 field season

Figure 2.1. Characteristic propeller trauma in live and dead whales 65

Figure 2.2. Close up of caudal (left) and central (right) propeller scars on left flank of right whale Eg \#2143 69

Figure 2.3. Epithelium from propeller scar. 70

Figure 2.4. Dermis from propeller scar. 71

Figure 2.5. Extensive soft tissue damage to fluke and peduncle of right whale Eg \#1909 . .73

Figure 2.6. View of right side of post-cranial cross-section of Eg \#1004 after beheading reveals the first signs of extensive blunt trauma 77

Figure 2.7. Schematic representation of sub-dermal hemorrhage and edema in right whale $\mathrm{Eg} \# 1004$. .78

Figure 2.8. Evidence of significant blood loss in oral cavity of right whale Eg \#1004 . .79

Figure 2.9. Caudal view of skull of right whale Eg \#2150 81

Figure 2.10. Internal signs of hemorrhage and a complete fracture of the right mandible of right whale $\mathrm{Eg} \# 2150$. 82 
Figure 2.11. Histology of the fracture plane of the jaw bone revealed the presence of woven bone and islands of cartilage consistent with new bone formation in Eg \#2150

Figure 3.1. Digital reconstruction of the right mandible of right whale Eg \#1004...111

Figure 3.2. Computed tomography (CT) cross-section of the mandible from Eg \#1004

Figure 3.3. Calibration curves for CT number (Hounsfield unit)s vs. mineral density $(\mathrm{g} / \mathrm{cc})$

Figure 3.4. Calibration curves for CT number (Hounsfield units) vs. apparent density $(\mathrm{g} / \mathrm{cc})$

Figure 3.5. The depth of soft tissue overlying the right whale jawbone plotted as a function of distance from the symphysis (yellow triangles).

Figure 3.6. Close-up of soft tissue stratification overlying the mandible in Eg \#1004

Figure 4.1. Right whale mandibles: a) fractured right mandible of Eg\# 2150. b) reconstruction of right mandible of Eg\# 1004 .....

Figure 4.2. Schematic of three orthogonal axes of the right whale jawbone

Figure 4.3 Mechanical testing apparatus and sample orientation

Figure 4.4. Engineering stress vs. engineering strain plot from uniaxial compression testing of a representative $\mathrm{x}$-axis sample

Figure 4.5. Engineering stress vs. engineering strain plots for 16 trabecular bone specimens from the $\mathrm{x}$-axis

Figure 4.6. Engineering stress vs. engineering strain plots for 24 trabecular bone specimens from the y-axis

Figure 4.7. Engineering stress vs. engineering strain plots for 36 trabecular bone specimens from the z-axis.

Figure 4.8. Engineering stress vs. engineering strain plots for 11 cortical bone specimens

Figure 4.9. Interspecies comparison of Young's modulus values vs. apparent density 
Figure 4.10. Interspecies comparison of ultimate compressive strength vs. apparent

density 201

Figure 4.11. Apparent density vs. Young's modulus as a function of bone orientation .202

Figure 4.12. Apparent density vs. ultimate compressive strength as a function of bone orientation 203

Figure 4.13. Graph of apparent density ( $\left.\rho_{\text {app }}, \mathrm{g} / \mathrm{cc}\right)$ vs. Young's modulus ( $\left.\mathrm{E}_{\text {est }}, \mathrm{MPa}\right)$ predicted from published regression equations 206

Figure 5.1. Three-dimensional laser scan of right whale mandible produces CADcompatible point cloud detailing the external geometry of the bone.....

Figure 5.2. Preliminary finite element model of right whale jaw bone 245

Figure 5.3. Finite element model simulating loading at 4,000 lbf. 246

Figure 5.4. Finite element model simulating loading at 7,000 lbf. 247

Figure 5.5. Finite element model simulating loading at 19,600 lbf. 248 


\section{LIST OF TABLES}

Table 2.1. Life history and necropsy findings from four right whales killed by vessels

Table 2.2. Definition and appearance of ante-mortem, perimortem \& post mortem pathology of a traumatic origin

Table 3.1. Morphometric measurements are presented for 5 North Atlantic right whales

Table 3.2. Computed Tomography (CT) volume measurements for the right mandible from right whale Eg \#1004

Table 3.3. Average apparent and mineral densities of five segments of right whale jawbone from Eg \#1004 as determined via QCT and physical measurements..........132

Table 3.4. The average tissue density, apparent density, percent fat and average ash content measured for mandibular bone extracted from an adult female right whale.133

Table 3.5. Percent difference between average QCT density values and physical measurements of their apparent density and mineral density counterparts

Table 4.1. Results of manual densitometry of right whale trabecular bone samples from the mandible of Eg\# 1004 .

Table 4.2. Results of manual densitometry of right whale cortical bone samples from the mandible of Eg\# 1004

Table 4.3. Material properties of right whale trabecular bone as determined via uniaxial compression testing.

Table 4.4. Material properties of right whale cortical bone determined via uniaxial compression testing.

Table 4.5. Average Young's modulus of elasticity and ultimate strength of trabecular and cortical bone from the right whale jaw bone 198

Table 4.6. Percent difference between average QCT apparent density and the measured apparent density ( $\rho a p p)$ from segment B . 204

Table 4.7. Average QCT apparent density for right whale trabecular bone and corresponding values for estimated Young's modulus of elasticity (Eest)..... 205 


\section{LIST OF ABBREVIATIONS}

$\boldsymbol{\varepsilon}$ - engineering strain

$\boldsymbol{\mu C T}$ - microscale computed tomography

$\mathbf{v}$ - Poisson's ratio

$\boldsymbol{\rho}_{\boldsymbol{\alpha}}$ - apparent mineral (ash) density

$\boldsymbol{\rho}_{\text {app }}$ - apparent density (g/cc)

$\boldsymbol{\rho}_{\text {dry }}$ - apparent dry density

$\boldsymbol{\rho}_{\text {QCTapp }}-$ QCT apparent density (g/cc)

$\boldsymbol{\rho}_{\text {tissue }}$ - tissue density (g/cc)

$\boldsymbol{\sigma}$ - engineering stress

$\boldsymbol{\sigma}_{\text {ult }}-$ ultimate compressive strength (in $\mathrm{MPa}$ )

CT - computed tomography

E - Young's modulus of elasticity, as determined via mechanical testing (in $\mathrm{MPa}$ )

$\mathbf{E}_{\text {est }}$ - estimated Young's modulus of elasticity, as determined by QCT (in MPa)

Eg - Eubalaena glacialis, the scientific name for the North Atlantic right whale

$\mathbf{F}_{\mathbf{t f}}$ - force of (tissue) fracture

H.U. - Hounsfield units

knot - one nautical mile per hour

$\mathbf{m}_{\text {ash }}$ - ash weight

$\mathbf{m}_{\text {dry }}$ - dry mass

MPa - megapascals, $10^{6}$ Pascals or $10^{6} \mathrm{~N} / \mathrm{m}^{2}$

QCT - quantitative computed tomography 


\section{GLOSSARY OF TERMS*}

Ante-mortem lesions - lesions occurring more than six hours prior to death, thus allowing sufficient time for initiation of tissue response

Apparent ash density - mineral content of a specimen multiplied by its apparent dry density. Unites are in $\mathrm{g} / \mathrm{cc}$.

Apparent density - the mass of a defatted bone specimen divided by the volume of the same defatted bone specimen. The volume of the specimen is calculated from measurements of the specimen dimension (e.g. for a cubic specimen the volume would equal the length multiplied by the width and the height) which thus includes spaces devoid of mineral. For general use, apparent density equals the mass of an object divided by its volume. Units are in $\mathrm{g} / \mathrm{cc}$ unless otherwise specified.

Apparent dry density - dry mass of a dehydrated, defatted bone specimen divided by the volume of the specimen. For trabecular bone specimens the volume used to calculate the apparent dry density is the mineral volume as measured using a gas pycnometer. Thus, the volume of inter-trabecular void space in each specimen is not included in this measurement. Units are in $\mathrm{g} / \mathrm{cc}$ unless otherwise specified.

Ash content - the ash weight divided by the dry mass, then multiplied by 100 . This value is given as a percent $(\%)$.

Ash fraction - the ash weight (in grams) divided by the dry mass (in grams). This term is also known as the mineral content and may be expressed in grams/gram.

Ash weight - the mass of a bone specimen following dehydration $\left(\right.$ at $\left.65^{\circ} \mathrm{C}\right)$ and ashing $\left(\right.$ at $600^{\circ} \mathrm{C}$ ) until no appreciable change in mass was detectable. Units are in grams unless otherwise specified.

Autolysis - the disintegration of cells or tissues by endogenous enzymes. ${ }^{\dagger}$ This process is a part of postmortem decomposition.

Boat - A small vessel. The term is often modified to indicate the means of propulsion, such as a motorboat, rowboat, steamboat, sailboat, and sometimes to indicate the intended use, such as lifeboat, fishing boat, etc. ${ }^{\dagger \dagger}$

Callosities - raised cornified skin patches located in various locations on the heads of right whales, including on the rostrum, behind the paired blowholes, above the eye, on the ventral margin of the lower lip, and along the chin. Callosities form distinctive patterns that are unique to individuals and are used to identify members of the population. 
*Units given in the glossary of terms are used throughout this document unless otherwise specified.

Cancellous bone - low density bone with large pores and a lattice-work of supportive struts known as trabeculae. Cancellous bone is found internal to the compact bone cortex and at the ends of long bones. Generally, the change from compact to cortical bone occurs over rapidly over a small spatial scale and the demarcation between the two is obvious to the naked eye. The term cancellous bone is used synonymously with trabecular bone and spongy bone and is often specifically contrasted with compact bone.

Computed tomography $(\mathbf{C T})$ - a radiological imaging technique that produces images of "slices" through [an object]..$^{\dagger}$ This technique can be used to determine the internal structure, detailed morphology, relative density, and volume of objects. The CT scanner used for this study was capable of scanning objects up to 1 meter in length and $50 \mathrm{~cm}$ in diameter. Objects can be assessed using a slice thickness (inter-slice distance) as low as $0.1 \mathrm{~mm}$.

Compact bone - dense bone with relatively few pores and very low fat/marrow content. In long bones, the diaphysis and the thin cortex of the metaphyses are composed of compact bone. Compact bone is distinguished from trabecular bone based on the relative density of the bone tissue (see definition below). ${ }^{\S}$ The relative density of cortical bone ranges from about 0.7 to $0.95 .^{\S}$ Compact bone is often used synonymously with cortical bone or solid bone.

Cortical bone - the compact bone tissue of the shaft of a bone. ${ }^{\dagger}$ In most mammals, this bone surrounds the marrow cavity of long bones.

Density of the calcified bone matrix - the mass of defatted, hydrated bone divided by the volume of bone tissue that does not include pore spaces. Also known as the mineral matrix density.

Dry mass - the mass of a bone sample dried at $65^{\circ} \mathrm{C}$ until no change in mass due to water loss was observed. Units are in grams unless otherwise stated.

Edema - the abnormal accumulation of fluid in interstitial tissue spaces.

Engineering strain ( $(\varepsilon)$ - the change in gauge length of a specimen divided by the initial gauge length of the specimen. In standard notation, the change in gauge length is the length under load minus the original length. Engineering strain is reported here in $\mathrm{mm} / \mathrm{mm}$, and may also be considered as a quantity without units (e.g. when determining units for Young's modulus of elasticity).

Engineering stress $(\boldsymbol{\sigma})$ - the applied load divided by the original cross-sectional area over which it is applied. This is also referred to as the force per unit area. Engineering stress is reported in megapascals $(\mathrm{MPa})$ or $10^{6}$ Newtons per square meter. 
Estimated Young's modulus of elasticity - values for Young's modulus of elasticity calculated using regression equations. Experimental measurements of Young's modulus are determined during mechanical testing in uniaxial compression. Regression equations are then created, correlating the experimentally measured values for Young's modulus of elasticity $(\mathrm{MPa})$ to physical measurements of apparent density $(\mathrm{g} / \mathrm{cc})$. The apparent density of samples not subjected to mechanical testing is then used to predict the Young's modulus using the regression equations. Young's modulus is reported here in megapascals $(\mathrm{MPa})$ or $10^{6}$ Newtons per square meter.

Force of (tissue) fracture $\left(\mathbf{F}_{\mathbf{t f}}\right)$ - The force required to overcome the ultimate compressive strength of a tissue when applied across a given area. This parameter is reported here in Newtons.

Hematoma - a localized collection of extravasated blood, usually clotted, in an organ, space or tissue. Hematomas can occur almost anywhere on the body; they are almost always present with a fracture and are especially serious when they occur inside the skull, where they may produce local pressure on the brain. ${ }^{\dagger}$

Hemorrhage - the escape of blood from a ruptured vessel. Hemorrhage can be external, internal or into the skin or other tissues. ${ }^{\dagger}$

Hounsfield units - a normalized unit of measure assigned to a given pixel in a computed tomography reconstruction. The unit is based on the X-ray attenuation coefficient of the material occupying the physical space in the scanned specimen.

Each pixel is assigned a numerical value (CT number), which is the average of all the attenuation values contained within the corresponding voxel. ${ }^{\S \S}$ This number is compared to the attenuation value of water and displayed on a scale of arbitrary units named Hounsfield units (HU) after Sir Godfrey Hounsfield. $\$ \S$

The CT number is $\mathrm{K}([\mu-\mu \mathrm{w}] / \mu \mathrm{w})$, where $\mathrm{K}=$ a magnifying constant, which depends on the make of CT scanner, $\mu=$ linear attenuation coefficient of pixel being observed, and $\mu \mathrm{w}=$ linear coefficient of water. ${ }^{\mathrm{d}}$

The calculation of Hounsfield units by the CT scanner and supporting software results in a standardized scale such that Hounsfield units between scanners and between X-ray beam energy spectra are more comparable. The scale spans approximately 2000 Hounsfield units, with -1000 H.U. representing air, 0 H.U. representing water and 1000 H.U. roughly corresponding to compact bone.

Inter-birth interval - the period of time between parturition of one calf and the next. This parameter has implications regarding the reproductive capacity and growth rate of a population. All else being equal, an increase in the inter-birth interval will result in a decrease in the reproductive potential for a population. 
Knot - unit of speed used primarily by mariners. A knot is one nautical mile per hour, which is equal to 1.852 kilometers per hour and 1.150779 statute mile per hour and 0.5144444 meters per second.

Matrix material density - the mass of defatted, hydrated bone divided by the volume of bone tissue that does not include pore spaces. This parameter is also known as the density of the calcified bone matrix.

Mineral content - specific measures of mineral density, defined one of two ways. Mineral content $(\mathrm{g} / \mathrm{g})$ can be determined as the ash weight divided by the mass of dry bone (dry mass) and is also referred to as the ash fraction. As calcium is the primary mineral species in bone, mineral content ( $\mathrm{mg} \mathrm{Ca} / \mathrm{g}$ dry bone) may also be determined colorimetrically as the mass of calcium (mg) per gram of dried defatted bone. Though they share the same name, it should be noted that these two measures do not produce comparable values and are not generally compared to one another directly in the literature.

Mineral density - is generally taken as the mass of bone per unit volume of bone. However, there are many measures of "mineral density," with some being measures of mineral per unit volume, while others are measures of mineral (ash) mass per unit dry bone mass. Imaging techniques exist for determining bone mineral density (BMD) as measurements of mineral mass "per unit length $(\mathrm{g} / \mathrm{cm})$, area $\left(\mathrm{g} / \mathrm{cm}^{2}\right)$ or volume $\left(\mathrm{g} / \mathrm{cm}^{3}\right)$ " of a bone sample including dual-X-ray absorptiometry and quantitative computed tomography. ${ }^{\text {ad }}$ Mineral content (in $\mathrm{mg} \mathrm{Ca} / \mathrm{g}$ dry bone) is another measure of mineral density and can be determined colorimetrically.

Microscale computed tomography $(\boldsymbol{\mu C T})$ - fine-scale computed tomography performed on objects up to $8 \mathrm{~mm}$ in length by $36 \mathrm{~mm}$ in diameter. Objects can be scanned at slice thicknesses as low as 9 microns. Like quantitative computed tomography, standards of known density are scanned so that Hounsfield units can be converted to absolute density values.

Necropsy - the systematic dissection of a carcass with the goal of determining the cause of death. Also known as a post-mortem examination.

Peri-mortem lesions - lesions created just prior to or immediately following death

Poisson's ratio (v) - the ratio of transverse strain to axial strain. The ratio is negated to yield a positive value for Poisson's ratio. Poisson's ratio is expressed without units.

Post-mortem lesions - lesions that are created after death and generally lacking evidence of tissue reaction

Prosector - one who performs a systematic post-mortem examination 
QCT apparent density - values for apparent density obtained via quantitative computed tomography (QCT). These values are calculated using regression equations created by correlating the apparent density of known standards to point measurements of x-ray attenuation (in Hounsfield units) from a computed tomography scan of the standards. QCT apparent density is given in grams per cubic centimeter $(\mathrm{g} / \mathrm{cc})$.

QCT mineral density - values for mineral density obtained via quantitative computed tomography (QCT). These values are calculated using regression equations created by correlating the mineral density of known standards to point measurements of X-ray attenuation (in Hounsfield units) from a computed tomography scan of the standards. QCT mineral density is given in grams per cubic centimeter $(\mathrm{g} / \mathrm{cc})$.

Quantitative computed tomography (QCT) - a calibrated radiological imaging technique. Computed tomography (CT) is conducted on specimens and standards of known density allowing the conversion of the Hounsfield units output by standard CT into absolute physical density values. In this way the absolute physical density of internal structures can be calculated non-invasively in vivo and non-destructively in precious specimens.

Relative density - the ratio of the density of a bone specimen to the density of solid cortical bone. The density of solid cortical bone is taken as $1.8 \mathrm{~g} / \mathrm{cc}$. The ratio is reported without units. Trabecular bone has a relative density that ranges from $0.05-0.7 \mathrm{~g} / \mathrm{cc}$, while cortical bone relative density ranges from $0.7-0.95 \mathrm{~g} / \mathrm{cc} .{ }^{\S}$ There is a rather subjective distinction between low density cortical bone and high-density trabecular bone.

Right whale conservation areas - two regions designated by the Canadian government as right whale habitat. These areas include the Grand Manan Basin of the Lower Bay of Fundy (referred to as Bay of Fundy) and Roseway Basin (an area $\sim 50 \mathrm{~km}$ south of Nova Scotia).

Right whale critical habitat areas - three regions recognized by the United States government via the National Marine Fisheries Service as current seasonal habitat in U.S. waters. These include":

1) The Great South Channel. The area bounded by $41^{\circ} 40^{\prime} \mathrm{N} / 69^{\circ} 45^{\prime} \mathrm{W} ; 41^{\circ} 00^{\prime}$ $\mathrm{N} / 69^{\circ} 05^{\prime} \mathrm{W}$; $41^{\circ} 38^{\prime} \mathrm{N} / 68^{\circ} 13^{\prime} \mathrm{W}$; and $42^{\circ} 10^{\prime} \mathrm{N} / 68^{\circ} 31^{\prime} \mathrm{W}$,

2) Cape Cod Bay, Massachusetts. The area bounded by $42^{\circ} 04.8^{\prime} \mathrm{N} / 70^{\circ} 10^{\prime} \mathrm{W}$; $42^{\circ} 12^{\prime} \mathrm{N} / 70^{\circ} 15^{\prime} \mathrm{W} ; 42^{\circ} 12^{\prime} \mathrm{N} / 70^{\circ} 30^{\prime} \mathrm{W} ; 41^{\circ} 46.8^{\prime} \mathrm{N} / 70^{\circ} 30^{\prime} \mathrm{W}$ and on the south and east by the interior shore line of Cape Cod, Massachusetts,

3) Southeastern United States. The coastal waters between $31^{\circ} 15^{\prime} \mathrm{N}$ and $30^{\circ} 15^{\prime} \mathrm{N}$ from the coast out 15 nautical miles; and the coastal waters between $30^{\circ} 15^{\prime} \mathrm{N}$ and $28^{\circ} 00^{\prime} \mathrm{N}$ from the coast out 5 nautical miles.

Ship - originally a sailing vessel with three or more masts, square-rigged on all. The term is now generally applied to any large, ocean-going vessel, except submarines which are called boats regardless of size. ${ }^{\dagger}$ In 1999, Mandatory Ship Reporting Systems were established by the United States Coast Guard and the National Marine Fisheries Service 
requiring all commercial ships, 300 gross tons or larger, entering specified regions in the coastal waters of the United States to report the vessel name, speed, destination and true course (among other data) to land-based stations at the time of entry. As this rule was implemented specifically to address the issue of vessel-whale collisions in right whale critical habitat it is appropriate for research concerning these events to define a ship as any commercial or non-commercial vessel 300 gross tons or larger.

Ship strike - term used as a colloquial synonym for vessel-whale collisions. This term is considered imprecise and inappropriate by the shipping industry as it implies that all vessel-whale collisions involve ships. Strictly defined using the technical definition of a "ship," contact between a whale and a vessel 300 gross tons or larger is considered a ship strike. This document is the first published literature to address this concern and to appropriately draw a distinction between the two terms.

Tissue density - the bulk tissue mass of a specimen (e.g. for bone this includes the mass of fat, water, mineral content as well as mass contributed by organics) divided by the bulk sample volume as measured from the sample dimensions (i.e. including nonmineralized tissues and pore spaces). Tissue density is reported here as grams per cubic centimeter $(\mathrm{g} / \mathrm{cc})$.

Trabecular bone - low density bone organized into a lattice of bony struts called trabeculae, with inter-trabecular regions lacking mineral (and in the case of the right whale these regions are filled with inter-trabecular fat). This bone type is also known as cancellous or spongy bone and is found internal to the compact bone cortex and at the ends of long bones. The term trabecular bone is often specifically contrasted with cortical bone.

Ultimate compressive strength $\left(\boldsymbol{\sigma}_{\text {ult }}\right)$ - the peak engineering stress measured during a compression test. The ultimate compressive strength is also known as the ultimate strength and is reported here in megapascals or $10^{6}$ Newtons per square meter.

Vessel - Any type of craft which can be used for transportation on water. ${ }^{\dagger \dagger}$ Any structure designed to float upon and traverse the water for the carriage of persons or goods; a craft or ship of any kind, now usually one larger than a rowing-boat. ${ }^{*}$

Vessel-whale collision - contact between a vessel and a whale. Contact may result from blunt impact with the hull or may involve the propeller.

Young's modulus of elasticity (E) - the stress/strain in the linear region of the curve of an ordinary tensile or compressive test. ${ }^{* *}$ This is the equivalent of the slope of the linear region of the stress vs. strain curve in a tensile or compressive test. Uniaxial compressive tests were used here to determine the Young's modulus. Young's modulus is a uniaxial measure of the stiffness of a material. $\mathrm{E}$ is reported here in megapascals $(\mathrm{MPa})$ or $10^{6}$ Newtons per square meter. 


\section{Symbols in text denote technical definitions as defined in the following references:}

$\dagger \quad$ Blood, D.C. and V.P. Studdert, 1999. Saunders Comprehensive Veterinary

Dictionary. 2nd Edition, WB Saunders. New York. 1380 pages.

i† - Bowditch, N., 1995. American practical navigator: an epitome of navigation. Defense Mapping Agency Hydrographic/Topographic Center. Bethesda, MD.

$\S_{-} \quad$ Huiskes, R. and B. van Rietbergen, 2005. Biomechanics of Bone. In: Mow, V. C. and Huiskes, R., Eds. Basic Orthopaedic Biomechanics and Mechano-Biology. Lippincott, Williams \& Wilkins. New York. pp. 123-179.

$\S \S$ - Jackson, S. and R. Thomas, 2004. Cross-sectional Imaging Made Easy. Churchill Livingstone.

- Mull, R. T., 1984. Mass estimates by computed tomography: physical density

from CT numbers. American Journal of Roentgenology. 143 (5), pp. 1101-1104.

- Tabensky, A. D., J. Williams, V. DeLuca, E. Briganti and E. Seeman, 1996. Bone mass, areal, and volumetric bone density are equally accurate, sensitive, and specific surrogates of the breaking strength of the vertebral body: an in vitro study. Journal of Bone and Mineral Research 11 (12), pp. 1981-1988.

«- $\quad$ National Marine Fisheries Service, 2005. Critical habitat for northern right whales. National Oceanic and Atmospheric Administration, Editor. 2005, Department of Commerce. 70 FR 1832 §226.204. p. 189-190.

* $\quad$ Anonymous, 1989. Oxford English Dictionary. Second edition. Oxford University Press.

** - Currey, J.D., 2002. Bones: structure and mechanics. Princeton University Press. Princeton, NJ. 436 pages.

\section{Species of Interest}

Balaena mysticetus, Bowhead whale Balaenoptera acutorostrata, Minke whale Balaenoptera musculus, Blue whale Balaenoptera physalus, Fin whale Calanus finmarchicus, Calenoid copepod Dugong dugong, Dugong Eubalaena australis, Southern right whale Eubalaena glacialis, North Atlantic right whale Eubalaena japonica, North Pacific right whale Megaptera novaeangliae, Humpback whale Mesoplodon densirostris, Beaked whale Phocoena phocoena, Harbor porpoise Physeter macrocephalus, Sperm whale Trichechus manatus, West Indian manatee 


\section{Chapter 1}

\section{Introduction}

\subsection{MOTIVATION}

The North Atlantic right whale (Eubalaena glacialis) is a robust baleen whale that is considered one of the most endangered large whale species (Clapham, et al., 1999, International Whaling Commission, 2001b). With fewer than 400 individuals remaining in this well-studied population, a major target for conservation and management is reducing significant sources of mortality, particularly threats from human activities (COSEWIC, 2003, Kraus, et al., 2005, National Marine Fisheries Service, 2005a, 2006, Right Whale Consortium, 2005). Seventy five North Atlantic right whale deaths have been recorded between 1970 and January 2007 (Knowlton and Kraus, 2001, Moore, et al., 2005, Right Whale Consortium, 2005. Of these, twenty eight were linked to ship strikes, eight were attributed to entanglement in fishing gear and eighteen were considered neonatal deaths. Twenty-one remaining deaths were of unknown cause. The total number of deaths is unknown as some animals are never seen dead, but are simply never seen again. Similarly, the total number of deaths resulting from specific mortality 
factors (e.g. human activities) are unknown, however, current mortality statistics represent minimum values.

The most conservative estimates of mortality factors are those that consider cases that were examined postmortem. Direct threats from anthropogenic activities include entanglement in fishing gear and collisions with vessels, which together have resulted in $27(67 \%)$ of the 40 mortalities assessed by post-mortem examination of right whale remains. Of those, 21 (52.5\%) of the 40 animals examined post-mortem were killed by vessels. As such, government agencies charged with species management and population recovery are considering speed restrictions as a means of reducing the frequency of vessel-whale collisions and the degree of injury to whales struck by vessels (National Marine Fisheries Service, 2006).

Data presently used to justify the proposed implementation of speed restrictions include historical accounts of vessel-whale collisions detailing vessel size, vessel speed and mortality or injury outcome where available (Laist, et al., 2001, Vanderlaan and Taggart, 2007). Analysis of these data relies heavily upon circumstantial correlation and extrapolation from a limited (albeit carefully compiled) dataset which, while appropriate for elucidating general trends, are insufficient to directly address the influence of vessel speed on the biomechanics of a dynamic collision (Jensen and Silber, 2003, Laist, et al., 2001). In addition, few studies have explored the influence of speed on vessel-whale collision events and no research to date has focused on the biomechanics of vessel-whale collisions (Knowlton, et al., 1995, Korsmeyer and Hynes, 1995, National Marine Fisheries Service, 2004). 
The studies included in this thesis represent a comprehensive analysis of the biomechanics of vessel whale collisions. The first of the studies detailed here resulted in the characterization of trauma resulting from vessel-whale collisions and identification of the right whale mandible as an appropriate fatal endpoint for finite element models of vessel-whale collisions (Chapter 2). The morphology, internal structure and physical properties of the right whale jawbone were also investigated (Chapter 3). Mechanical testing was used to determine the material properties of right whale bone tissue from the mandible in order to assess how the right whale mandible behaves under loading (Chapter 4). Finally, thesis findings, preliminary modeling results and the implications of this work are presented (Chapter 5).

\subsection{INTRODUCTION}

\subsubsection{Species background}

The North Atlantic right whale, Eubalaena glacialis, is one of the three right whale species recognized by the International Whaling Commission following a comprehensive review of genetic and morphological data in the year 2000 (Rosenbaum, et al., 2000). The other species include the North Pacific right whale, E. japonica and the Southern right whale, E. australis.

The North Atlantic right whale population is believed to be divided into two distinct stocks inhabiting the Eastern North Atlantic and the Western North Atlantic respectively (Clapham, et al., 1999). Despite genetic evidence demonstrating a degree of 
relatedness (as assessed by mitochondrial DNA), the stocks are managed as two distinct critically endangered populations (International Whaling Commission, 2001b).

Though dedicated research and sighting efforts have not been conducted in the Eastern North Atlantic, the rare occurrence of opportunistic sightings of right whales in this region leaves little doubt that this stock is either severely reduced or extinct (with sightings representing Western North Atlantic right whales that have strayed from their known habitat) (Clapham, et al., 1999). As such, subsequent references to the North Atlantic right whale, Eubalaena glacialis, or 'right whale' in this thesis refer to the Western North Atlantic stock unless otherwise noted.

\subsubsection{Biology, population size and trends}

The North Atlantic right whale is a robust mysticete that measures approximately 16 meters in length at maturity (Figure 1.1) (Perrin, et al., 2002). The 200-270 baleen plates that hang from each side of the upper jaw are used for filtering dense aggregations of planktonic prey, primarily the copepod (Calanus finmarchicus), from seawater during feeding bouts where the mouth remains open for extended periods (Baumgartner, et al., 2007, Perrin, et al., 2002). 
Figure 1.1: Image of a mature North Atlantic right whale. Unique patterns formed by callosities (horny protrusions on the head, upper margin of the lower lip, and chin) permit identification of individuals in this small population. Image by Scott Landry (used with permission).

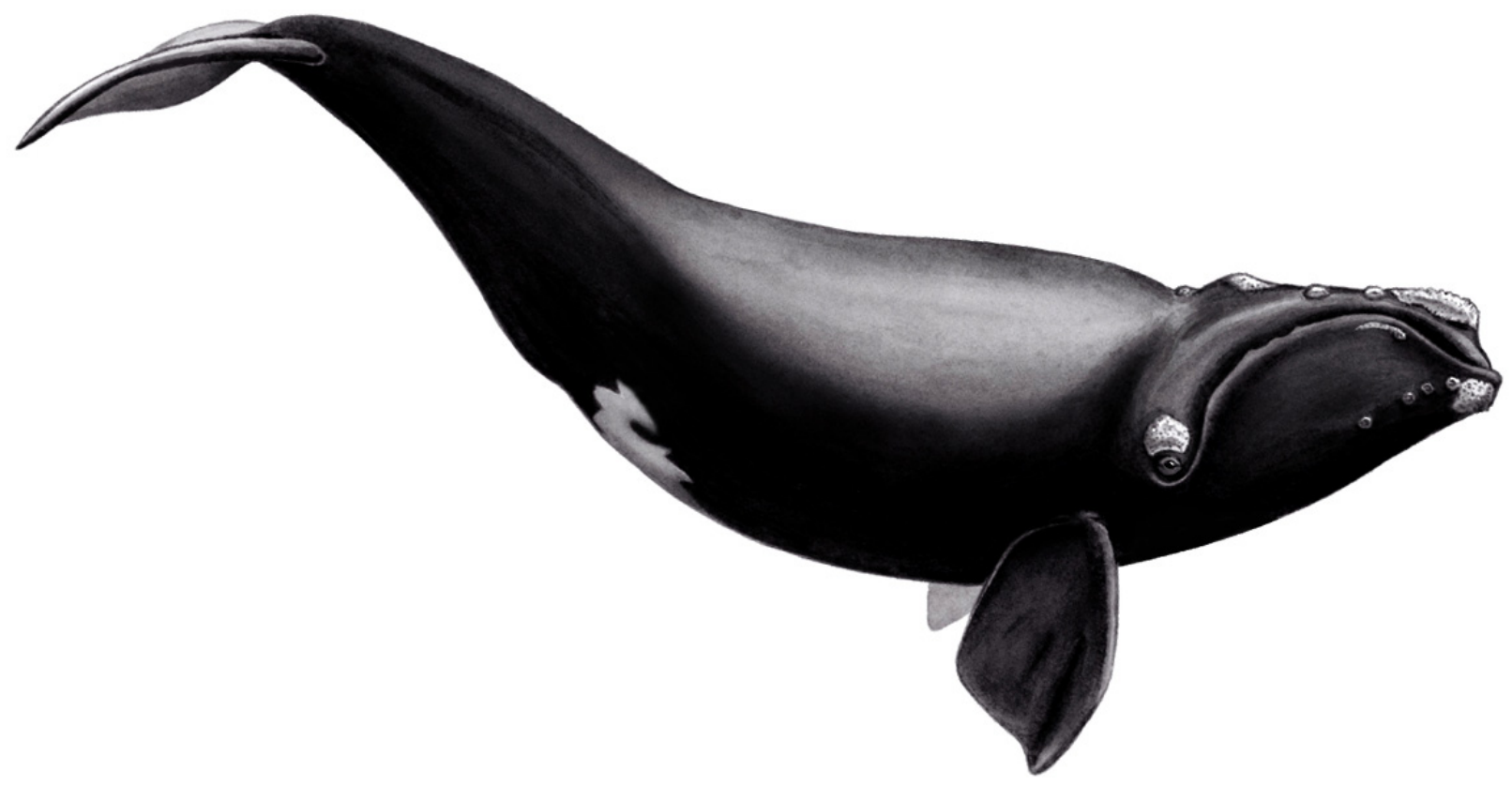

The right whale has black coloration, though some individuals have patches of white on the ventral surface and/or chin. The upper margin of the lower lip is crenulated and the patterns of lip ridges varies between individuals (Hamilton, et al., 2007). Right whales also have raised cornified skin patches called callosities located in various locations on the heads of individuals, including on the rostrum, behind the paired blowholes, above the eye, on the ventral margin of the lower lip, and along the chin, forming distinctive patterns that are unique to individuals (Hamilton, et al., 2007).

Callosity patterns, along with distinguishing scars, lip ridges and white skin patches, have been used to identify, track, and maintain records from opportunistic 
sightings of individuals dating back to 1935 (Kraus and Rolland, 2007a). The photoidentification and tracking of individuals via systematic aerial and vessel-based surveys for over 25 years makes this species one of the most well-studied cetacean populations (Hamilton, et al., 2007).

With such a small population of individually identifiable members under intense scientific scrutiny, estimating the population size and general trends in growth are possible. The most recent estimates suggest that the population contains around 400 individuals (Right Whale Consortium, 2005). The highest recorded annual rate of population growth for this species assessed between 1980-1992 (3.4\%) was much lower than the growth rate seen for Southern right whales (6-7\%) (Best, et al., 2001a, Knowlton, et al., 1994). Estimates of the annual growth rate of the population range from $-2 \%$ to $3.4 \%$ and average $2.5 \%$, but the consensus is clear - the North Atlantic right whale is recovering slowly (if at all) from commercial overexploitation (Fujiwara and Caswell, 2001, Knowlton, et al., 1994).

Several factors are likely limiting the recovery of the species, including intrinsic factors (e.g. reproduction and low genetic diversity) and extrinsic factors (e.g. direct anthropogenic mortality from entanglement in fishing gear and vessel-whale collision, and habitat degradation as a result of pollution and climate change) (COSEWIC, 2003). While anthropogenic mortality is responsible for the largest identified losses to the population, each of these factors likely contribute to the lack of recovery of this species and as such are addressed in subsequent sections (Campbell-Malone, et al., 2007, Moore, et al., 2005). 


\subsubsection{Reproduction}

While evidence suggests that Southern right whales have a gestation period of 12 months, the gestation period for the North Atlantic right whale has yet to be determined convincingly (Best, 1994). Females give birth to a single calf between December and March (Kraus, et al., 2007). The seasonality of calving suggests that conception or implantation may also be seasonal events (Parks, 2003). While delayed implantation is a potential factor confounding accurate estimates, there is no evidence among the balaenids and thus the gestation period for North Atlantic right whales is presently estimated to be about twelve months (Best, 1994).

As a result of a relatively long gestation period, lactation for approximately 11 months and an inter-birth interval ranging from 3 to 5 years, maternal investment in reproduction appears to be substantial (Kraus, et al., 2007). It is likely that costly metabolic activities such as reproduction and lactation are affected during times of limited prey abundance, leading to variable reproductive rates and changes in the interbirth interval (Moore, et al., 2001). Low genetic diversity, pollutants, marine biotoxins and infectious diseases may be additional factors directly limiting successful reproduction of this population (International Whaling Commission, 2001b, Kraus, et al., 2007).

While some females calve at regular intervals, others successfully produce calves sporadically while still others have never reproduced despite being considered sexually mature according to their size or age (Kraus, et al., 2007). The number of calves 
produced in a given year is also highly variable, ranging from 1-31 calves between 19802004 (Kraus, et al., 2001, National Marine Fisheries Service, 2005a).

This low and variable reproductive output in response to ecological and environmental parameters would likely have a limited effect on the long-term contributions of individuals to the population, instead accounting for short term variation (Kraus, et al., 2007). However, in the face of high anthropogenic mortality, low and variable reproductive success represents a real challenge to the recovery of the species.

\subsubsection{Low genetic diversity}

Analyses of the genetic variability of the North Atlantic right whale population using minisatellite and microsatellite loci, as well as mitochondrial DNA, have led to a greater understanding of current and historic levels of genetic diversity (Frasier, et al., 2007). Low levels of genetic variability have been found in extant right whales and it is clear from recent studies of right whale bones from Basque whaling sites that the population (or at lease the sub-population taken in the hunting grounds utilized) had slightly greater genetic variability prior to the Basque whaling era (Frasier, et al., 2007).

Genetic variation is also higher in calves than would be expected under the assumption of random mating (Frasier, et al., 2007). Comparative genetic analyses of right whale parents and their offspring revealed that calves have significantly higher levels of genetic variation than could be explained by random mating (Frasier, et al., 2007). Subsequent studies of the relatedness of mating pairs revealed that the higher level 
of genetic variation in right whale calves did not result from selective mating with "genetically dissimilar individuals" (Frasier, et al., 2007).

It is thus hypothesized that the majority of mating pairs were in fact genetically similar (as expected due to random mating in a population with low genetic diversity), which likely results in decreased reproductive success. The current hypothesis regarding the contribution of low genetic variability to the low reproductive success of the population is being explored (Frasier, et al., 2007).

\subsubsection{Anthropogenic mortality}

Entanglement in fishing gear: The two primary sources of anthropogenic mortality identified in this population include entanglement in fishing gear and vesselwhale collisions (Anonymous, 2002, Knowlton and Kraus, 2001, Kraus, 1990, Kraus, et al., 2005, Moore, et al., 2005). Together, these two factors account for 27 (67.5\%) of the 40 deaths investigated post-mortem between 1970-December 2006 (Figure 1.2) (Campbell-Malone, et al., 2007, Right Whale Consortium, 2005).

Six $(15 \%)$ of the forty necropsied animals died as a result of entanglement. A far greater number of animals were last seen entangled and in poor health and if not seen for six consecutive years they are presumed dead (Knowlton, et al., 1994, Right Whale Consortium, 2005). These are considered minimum numbers and underestimates of entanglement mortality, as $31(43.7 \%)$ of the 71 reported right whale carcasses from 1970 through December 2006 were not examined (Right Whale Consortium, 2005). 
Figure 1.2: Relative mortality statistics from post-mortem examination of 40 carcasses retrieved between 1970 - December 2006. Anthropogenic mortality including entanglement (15\%) and vessel-whale collisions (52\%) resulted in $67 \%$ of deaths investigated. Only $15 \%$ of the deaths investigated were classified as unknown cause of death. Cause of death is generally characterized as perinatal or neonatal when involving a newborn calf when no other cause is identifiable.

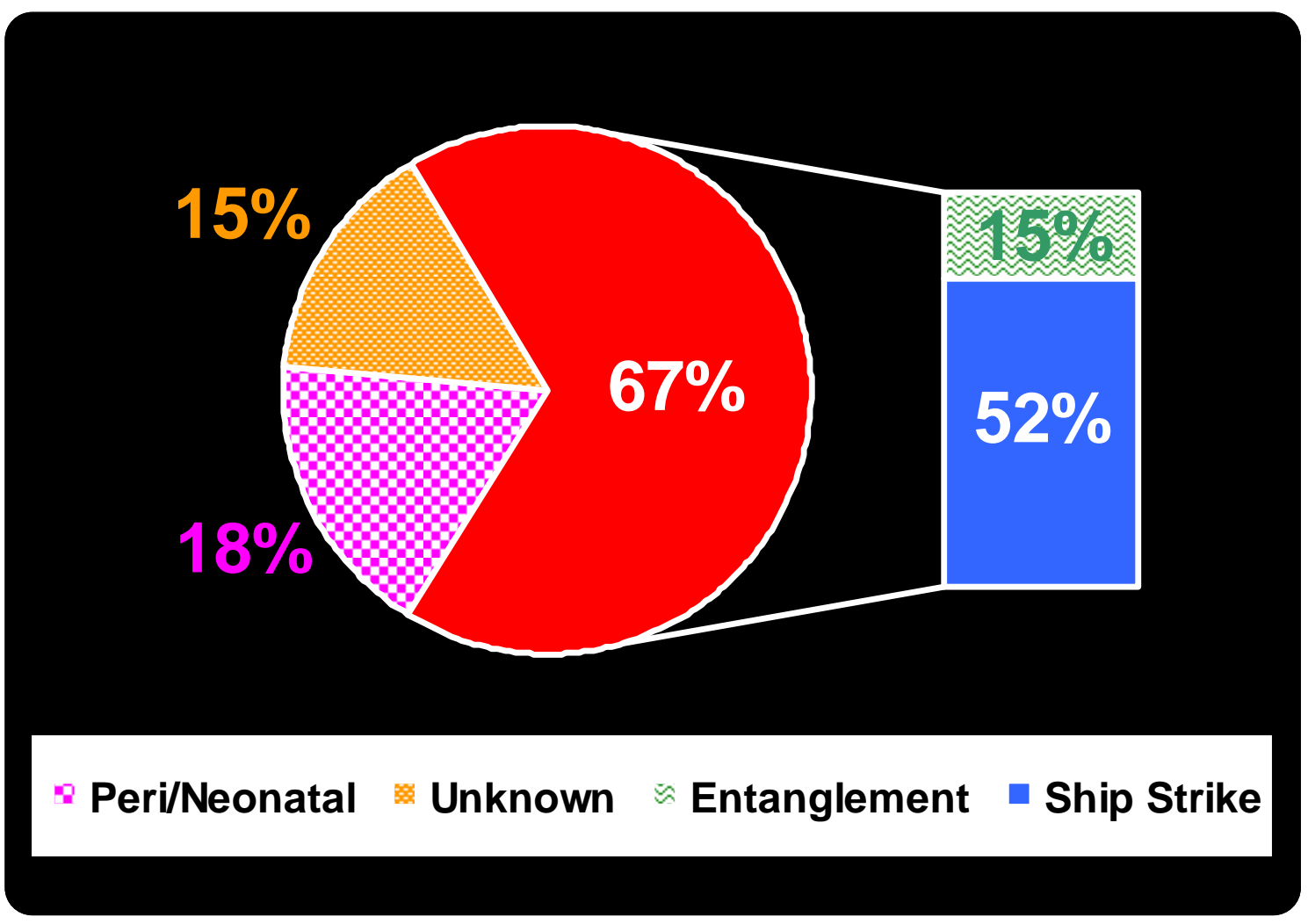

Chronic health effects associated with infection, reduced mobility and impaired feeding result in the metabolism of blubber stores and the loss of positive buoyancy. The body condition of animals with chronic entanglements or poor health result in a negatively buoyant carcass that is prone to sinking and is thereby likely lost (Knowlton and Kraus, 2001, Moore, et al., 2005, Right Whale Consortium, 2005). As such, statistics 
regarding the relative contribution of entanglements to right whale mortality are certainly underestimated (Moore, et al., 2005).

Sighting data and studies of scarification reveal that many whales become entangled in fishing gear (Hamilton, et al., 1998, Right Whale Consortium, 2005). Studies using photographs of extant individuals provide evidence of scars on $220(61.6 \%)$ of over 350 individuals suggesting that most entangled whales are able to self-disentangle (Hamilton, et al., 1998). Additional findings indicate that some 62 individuals (17.7\%) had scars from two or more entanglements. While these data suggest that most entanglements are successfully shed and do little lasting damage, additional data from observations of entangled animals over time and necropsy data reveal that some entanglements prove deadly (Moore, et al., 2005).

Entanglement fatality can be acute (i.e. when a whale becomes sufficiently entangled such that it is prevented from reaching the surface to breathe), or chronic. Chronic entanglement may result from gear getting entwined through baleen plates, or wrapped around the peduncle, axilla, or over the rostrum (Moore, et al., 2007). Extremely serious entanglements result in line embedded below the skin, necrosis, reduced mobility, impaired feeding and infection (Moore, et al., 2005).

Continued growth of the animal, drag on the line from trailing gear, or the wrapping of multiple extremities in the same gear, can result in line that becomes embedded beneath the epidermis - sometimes constricting to the point of involving bone (Moore, et al., 2005). Though the losses to the population from entanglement are considerable, the underlying issue of animal welfare in the face of such chronic, 
debilitating trauma resulting from human activity is equally significant (Moore, et al., 2007).

Vessel-whale collisions: The impact of vessel-whale collision on right whales has been well demonstrated. Massive wounds (e.g., fractured skulls and vertebrae, severed tails, and propeller cuts) on right whale carcasses show that vessel-whale collisions can be, and clearly are often, lethal (Campbell-Malone, et al., 2007, Knowlton and Kraus, 2001, Moore, et al., 2005). Vessel-whale collisions are the primary source of right whale mortality identified by post-mortem examination. These events have resulted in at least $21(29.6 \%)$ of the 71 known deaths since 1970 (Campbell-Malone, et al., 2007). The direct impacts of vessel-whale collisions on the right whale population are addressed in Chapter 2.

Anthropogenic mortality from both entanglement and vessel-whale collisions is in part a result of the substantial overlap between human activities and the coastal distribution of right whales (Knowlton and Brown, 2007). The discovery of the habitats utilized by the North Atlantic right whale was a critical step toward determining ways of reducing the fatal consequences of a shared ocean environment between marine mammal and man.

\subsubsection{Habitats and distribution}

Five regions have been identified as conservation areas or critical habitats by the fisheries management entities in Canadian and U.S. waters. These are 1) the southeastern U.S. calving ground (off the coast of Florida and Georgia), 2) Cape Cod Bay, 3) the Great 
South Channel, northeast of Nantucket 4) Grand Manan Basin in the Lower Bay of Fundy (between New Brunswick and Nova Scotia) and 5) the Roseway Basin region of the Scotian Shelf (south of Nova Scotia) (Figure 1.3) (Anonymous, 2004, International Whaling Commission, 2001b).

The regions within the Exclusive Economic Zone of the United States - including the southeastern calving grounds, Cape Cod Bay and the Great South Channel - were designated as critical habitat areas by the United States government in 1994 as required by the Endangered Species Act (National Marine Fisheries Service, 2005a, United States Congress, 1973). Right whales utilize the Cape Cod Bay habitat in most months with peak use occurring between February and May (COSEWIC, 2003). The Great South Channel is highly utilized in the spring, while the southeastern calving grounds are utilized by a portion of the population during the winter months (COSEWIC, 2003). Among the individuals inhabiting the southeastern calving area seasonally are primarily pregnant females, their calves of the year, and juveniles. Adult males are conspicuously absent, as are many non-breeding adult females, leaving questions regarding the regions used by this demographic in the winter months (COSEWIC, 2003).

The regions in the Exclusive Economic Zone of Canada - including the Grand Manan Basin (Lower Bay of Fundy) and Roseway Basin were given official status as Right Whale Conservation Areas in 1993 by the Canadian government (COSEWIC, 2003). These habitats are primarily utilized during the summer and autumn when socializing and feeding are commonly observed activities in both areas. The Lower Bay 
of Fundy also serves as a summer nursery for many cow/calf pairs that migrate there from calving grounds (National Marine Fisheries Service, 2005a).

Though these seasonal habitats are used by over $60 \%$ of the known population, questions remain regarding the distribution of the subpopulation that does not migrate to the winter calving grounds (Kraus and Rolland, 2007a). Similarly approximately onethird of the females that calve do not bring their offspring to the Bay of Fundy (Kraus and Rolland, 2007a). Yet the location of this alternate nursery ground is presently unknown. Genetic evidence from calf paternity analyses suggests that additional right whales are being "missed" by present surveys of critical habitats. Despite the fact that nearly $70 \%$ of all known males in the population have been sampled, $55 \%$ of the calves genetically tested to infer paternity did not match the subset of sampled fathers (Frasier, 2005). This indicates that additional fathers are contributing to the gene pool slightly more than the known and sampled males from right whale critical habitats and may be indicative of a population of males that do not regularly inhabit any of these areas (Frasier, et al., 2007).

Despite the outstanding questions regarding the winter habitat utilized by much of the population, the nursery grounds used by cows that do not bring their calves to the Bay of Fundy and the location/identity of these males, the whereabouts of the majority of the catalogued population have been well established. The details of their distribution contribute to the current understanding of the threats that face the population. The coastal distribution and coastal migration corridor (regions utilized for travel between the seasonal calving grounds and spring feeding grounds) results in substantial 
overlap between right whale habitats and high concentrations of fishing gear and vessels approaching and departing port or making coastal excursions (Clapham, 1999, Johnson, et al., 2007, Kraus, et al., 1986). The probability of a whale encountering one of these threats is presumably increased where the co-occurrence of whales and the specific threat is high. The severity of the problem is highlighted by an example from the southeast U.S. calving ground where it is particularly apparent when right whale distribution (Figure 1.4) is compared to vessel tracks from commercial vessels of 300 gross tons and above over a 64-day period during the winter 2005-2006 field season (Figure 1.5).

In Figure 1.4, the number of right whales seen at a given location is represented by circles whose size (small, medium, large) indicates the number of individuals observed (1, 2, 3-5 respectively). Stars enclosed by a circle represent mother-calf pair sightings. In Figure 1.5, the density of vessels is shown as obtained from Automatic Identification System (AIS) ship beacon signals from vessels 300 gross tons or greater. Clearly, any positive relation between the probability of vessel-whale collision and the co-occurrence of whales and vessel traffic would make such a dramatic overlap troubling. 
Figure 1.3: Detailed map of North Atlantic right whale distribution in the Western North Atlantic. Three critical habitats in U.S. waters (Cape Cod Bay, the Great South Channel and the Southeastern U.S. calving grounds) and two conservation areas in Canadian waters (the Lower Bay of Fundy and Roseway Basin) are shown. Adapted from (Kraus and Rolland, 2007b) by Kerry Lagueux, New England Aquarium.

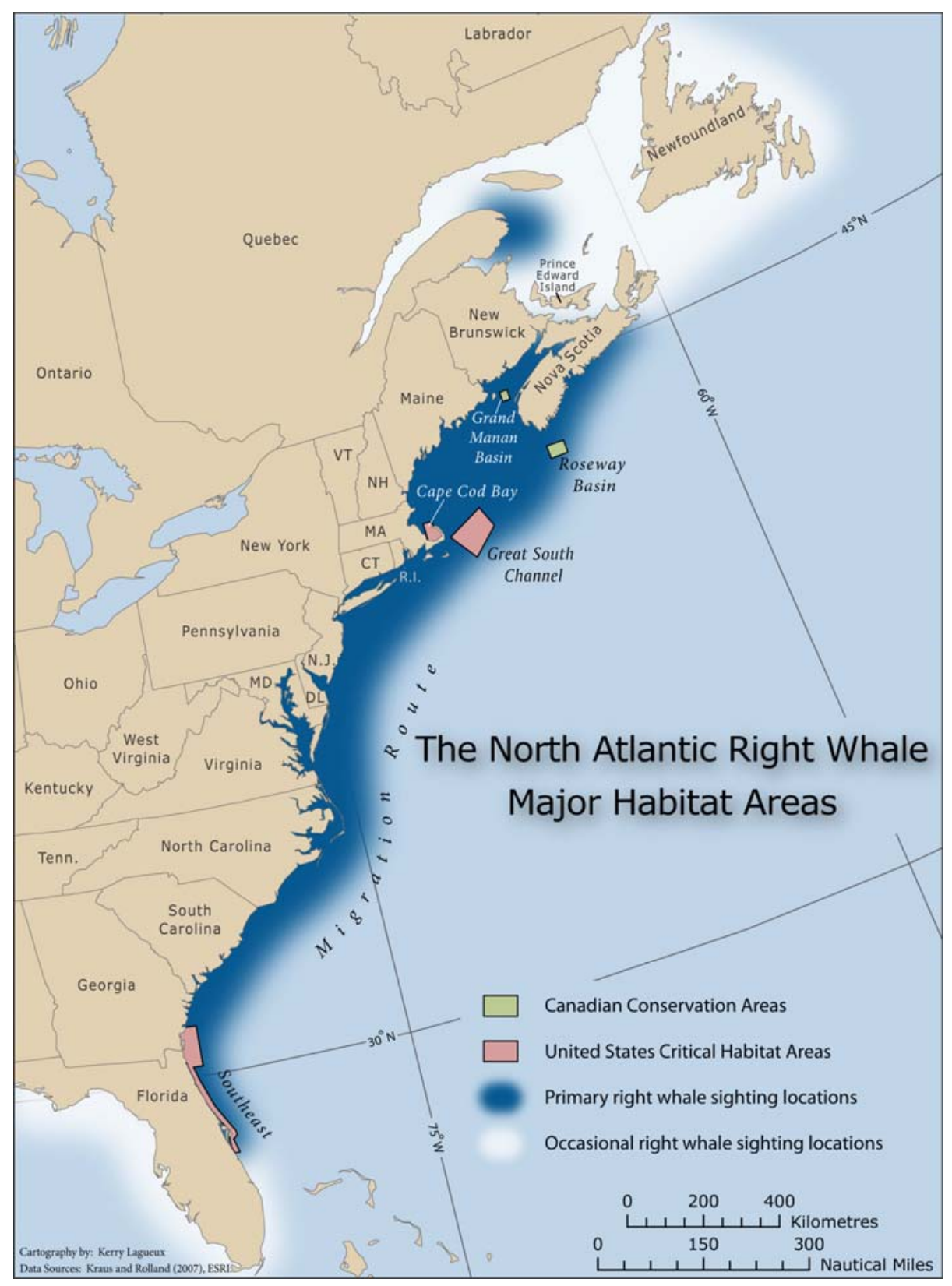


Figure 1.4: Spatial location of right whales in the Central Early Warning System Survey Area of the Southeastern U.S. critical habitat during the winter 2005-2006 field season. Whale distribution is shown as small, medium and large circles representing 1, 2, and 3-5 animals respectively. A star enclosed by a circle represents a mother-calf pair. Image courtesy of Kerry Lagueux, New England Aquarium (Lagueux, et al., 2007).

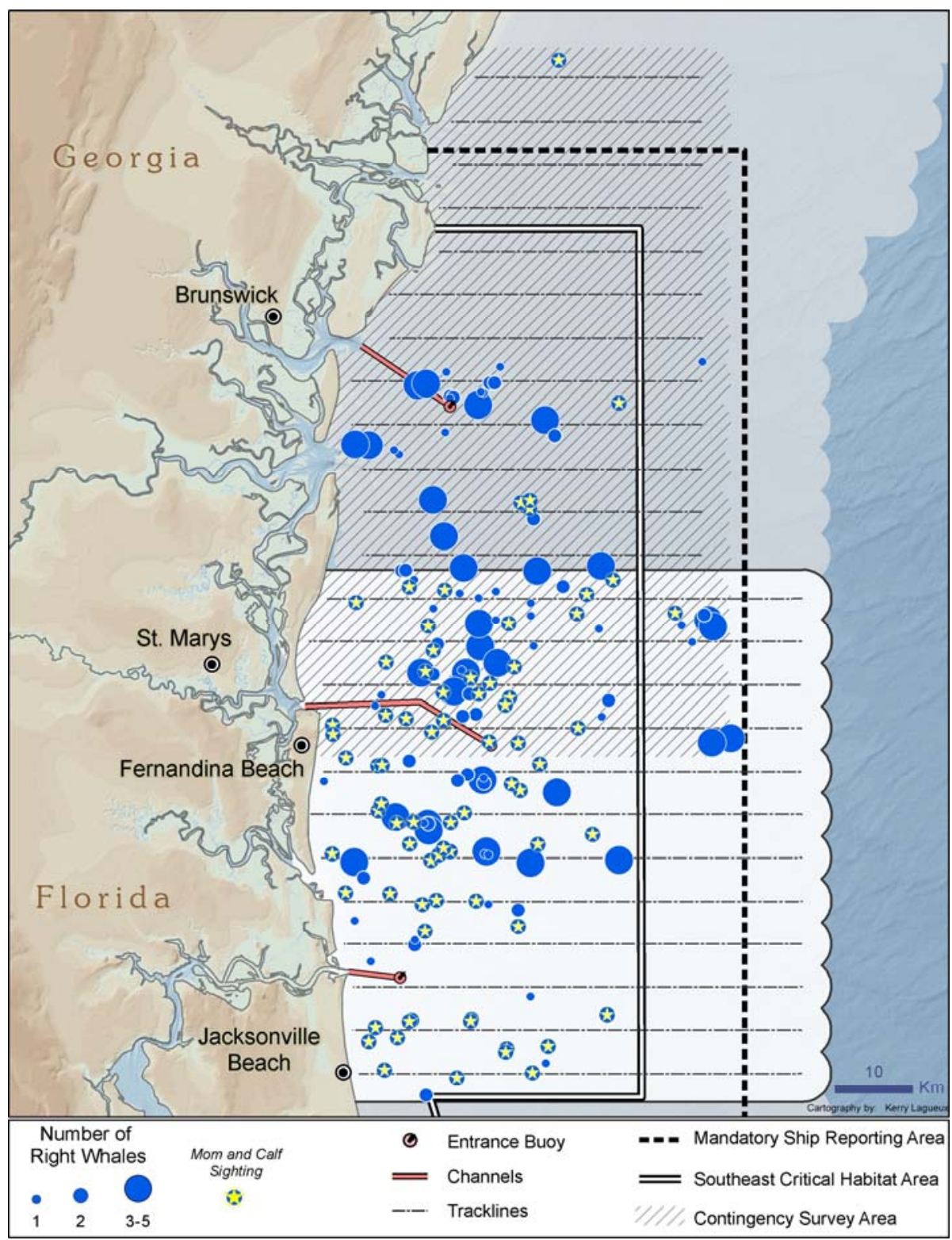


Figure 1.5: Spatial location of commercial vessels $\geq 300$ gross tons in the Central Early Warning System Survey Area of the Southeastern U.S. critical habitat, collected from AIS beacon signals received over a 64-day period in the winter 2005-2006 field season. Image courtesy of Kerry Lagueux, New England Aquarium (Lagueux, et al., 2007).

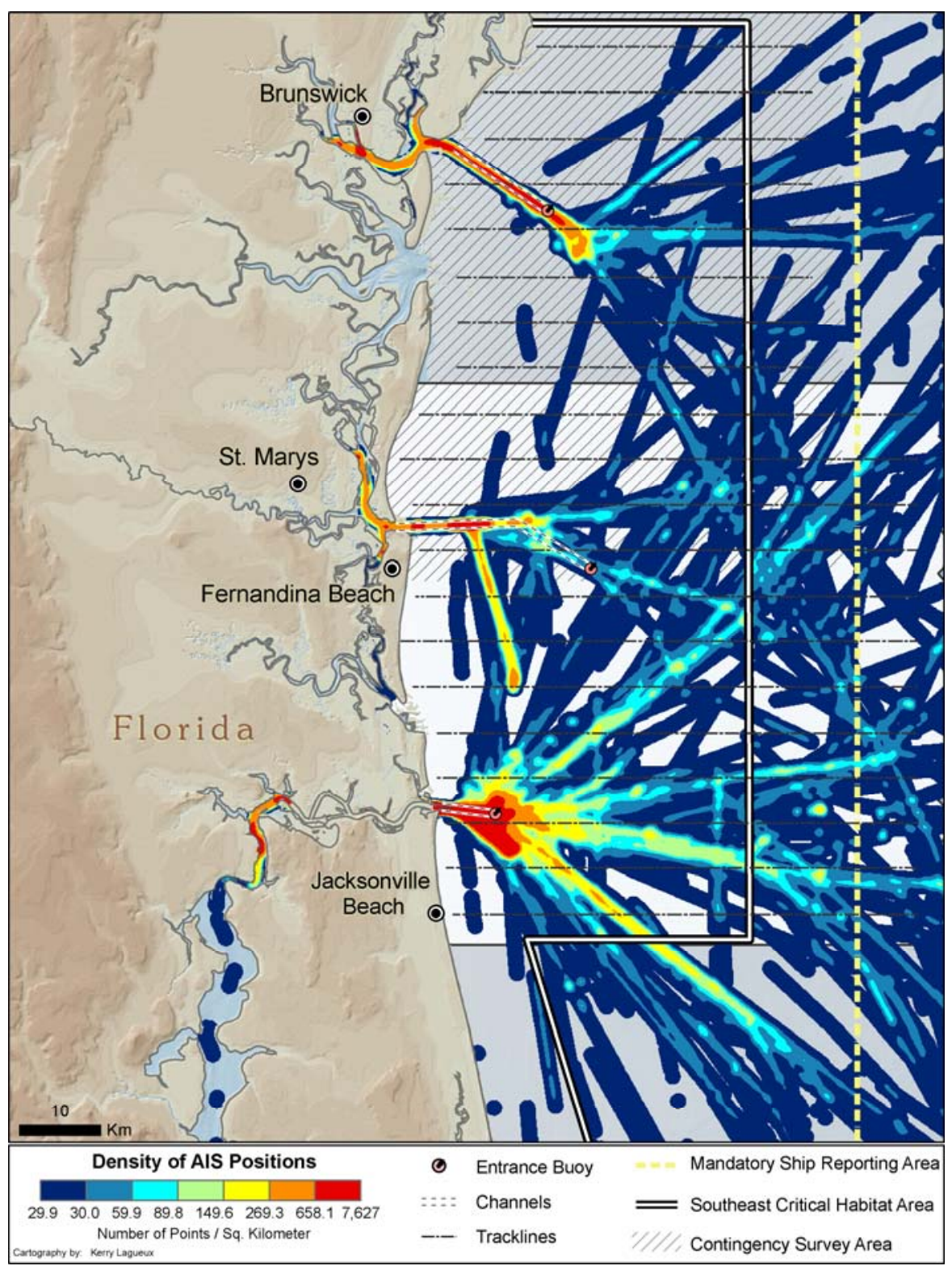




\subsubsection{Protection and management}

At the dawn of the modern whaling era, in the mid to late nineteenth century, "right whales" (a category at the time including the bowhead whale, Greenland right whale and pygmy right whale) had already been overexploited and no longer were a significant portion of the landed take (International Whaling Commission, 2001a, Tønnessen and Johnsen, 1982). Initial protection measures, including international limits on whaling take, were enacted in the early 20 th century and were created primarily by whaling nations in an effort to self-regulate the whaling industry to prevent the collapse of the lucrative whale fisheries (Tønnessen and Johnsen, 1982).

Unlike its southern hemisphere counterpart, E. australis, the North Atlantic right whale has failed to recover from severe population depletion due to whaling (International Whaling Commission, 2001a). This is true, despite international protection from whaling since 1935 as per the 1931 Convention for the Regulation of Whaling (International Whaling Commission, 2001a). Additional protection for the species has come in the form of international agreements (including the Convention on International Trade in Endangered Species of Wild Fauna and Flora 1975, and the International Convention for the Regulation of Whaling, 1946) and national laws (including the United States Marine Mammal Protection Act of 1972 and Endangered Species Act of 1973, and the Canadian Species at Risk Act, 2003) (Kraus and Rolland, 2007a, United States Congress, 1972, 1973). 
Monitoring and mortality statistics: In the United States, the Department of Commerce (DOC) is the agency with the primary responsibility of enforcing the Marine Mammal Protection Act (United States Congress, 1972). The National Oceanic and Atmospheric Administration's National Marine Fisheries Service (NMFS) is a division of the DOC charged with managing marine mammal stocks within the Exclusive Economic Zone of the United States. Long-term monitoring of important population parameters including the size, demography, distribution and health of the right whale population is one of the main action items of the management plan developed by the NMFS (National Marine Fisheries Service, 2005a). Management approaches have included:

1. conducting aerial surveys (to determine critical habitat use and to monitor the movements of right whales individually and on the population level),

2. funding scientific research (including acoustic surveys, genetic analyses, habitat-use monitoring, feeding studies, behavioral observations, population modeling, and photo-identification of individuals),

3. encouraging the development and testing of fishing gear modifications to reduce entanglement,

4. seasonal and spatial advisories and restrictions for mariners and commercial fishermen in areas occupied by right whales, and

5. supporting necropsy efforts to investigate the cause of death following carcass retrieval (Caswell, et al., 1999, Kenney, 2001, Knowlton and Kraus, 2001, Right Whale Consortium, 2005, Winn, et al., 1986). 
Together with non-governmental funding and activities which have contributed in large part to right whale research, these management-approved approaches have supported the right whale recovery plan by approaching the multi-faceted problem from various directions. However, it is the latter effort - federal support for post-mortem examination of retrieved right whale carcasses - that has provided valuable statistics and estimates regarding the mortality factors facing the right whale.

Examination of carcasses retrieved between 1970 and December 2006 reveals that vessel-whale collisions were the ultimate cause of death in 21 (52.5\%) of the 40 right whales examined post-mortem (Campbell-Malone, et al., 2007). Even more striking are statistics for recent years. Between 2001 and 2006, 11 (68.8\%) of the 16 right whales examined were precipitated by a collision with a vessel. These losses, deemed unsustainable and a threat to the population according to demographic models, lead to a published call for action from the right whale research community (Fujiwara and Caswell, 2001, Kraus, et al., 2005).

Necropsy mortality statistics, while incomplete, certainly represent minimum values regarding the factors responsible for losses in this population. These statistics have inherent biases that lead to skewed estimates of the proportion of deaths resulting from the various causes of death (Moore, et al., 2005). The most striking bias stems from the fact that not all dead right whales are seen, identified or retrieved - making the necropsy database a subset of individuals that died.

The robust body condition and lack of substantial healing in carcasses hit by vessels indicates that vessel-whale collision trauma often results in the acute demise of 
the animal. In right whales, a thick blubber coat leaves a carcass positively buoyant and (in their coastal habitat) more prone to being discovered and reported by mariners or aerial survey teams.

Similarly, the contribution of deaths from chronic entanglement in fishing gear to the mortality statistics may be underestimated as was previously discussed (Moore, et al., 2005). Severe entanglements that prevent the whale from resurfacing also contribute to the underestimation of the relative proportion of entanglement deaths.

It is important to note that the tissues most resistant to decomposition (i.e. bone and blubber) are amongst the tissues that present signs of blunt trauma, specifically fractures and hemorrhage respectively. Therefore, standard soft tissue diagnostics for the multiple causes of natural mortality are ineffective or of limited use in the typically autolyzed soft tissues of right whales - particularly in easily decomposed neural tissues, viscera and muscle. Thus, non-traumatic disease processes that do not affect the bone or blubber are certainly under-reported.

Despite the caveats concerning their relative contribution to mortality, it is clear that recent vessel-whale collision deaths (numbering nearly 2 per year on average for the past six years) pose a clear threat to the survival of this population of fewer than 400 individuals and must be reduced to allow for the recovery of the species (Kraus, et al., 2005). 


\subsubsection{American and Canadian recovery plans}

In 1991, the National Marine Fisheries Service created the "Recovery Plan for the North Atlantic Right Whale," a strategic plan detailing specific goals, present threats and current and planned conservation efforts aimed at reducing mortality and supporting the recovery of the species (National Marine Fisheries Service, 1991). This plan provided a framework upon which management measures were laid out, balancing the interests of stakeholders, current knowledge and the need for further monitoring and scientific input.

Fisheries and Oceans, Canada, the agency responsible for marine mammal protection within the Canadian Exclusive Economic Zone, also recognized the need for a recovery plan and active management to establish threats and management strategies to promote population growth. In 2000, in collaboration with the World Wildlife Fund, Canada, Fisheries and Oceans, Canada released the Canadian North Atlantic Right Whale Recovery Plan detailing planned and potential steps that management could take to protect the right whale population in Canadian waters (COSEWIC, 2003).

This plan included a recommendation to introduce a shift in the Traffic Separation Scheme servicing the Bay of Fundy (Anonymous, 2004). The original configuration provided a route for vessels headed north toward the port of Saint John, New Brunswick, Canada that traversed a region of high right whale density (Brown, 2003). The movement of the shipping lanes was justified by spatial probability modeling predictions indicating a substantial reduction in the probability of vessel-collisions with right whales (Taggart and Vanderlaan, 2003). 
In addition, Fisheries and Oceans, Canada, initiated a mariner education program to inform mariners transiting the region about right whale distribution and to provide "practical advice on how to avoid collisions" (Anonymous, 2002). Regular advisories are transmitted to vessels traveling through the Bay of Fundy during right whale residency (June through November) providing mariners with the last known whereabouts of right whales in the bay. Detailed information on right whales is also printed on relevant nautical charts issued by the Canadian Hydrographic Service.

In 2005, the National Marine Fisheries Service released a revised recovery plan for the North Atlantic right whale, establishing collisions with vessels as the "greatest known current cause of death" in this population and identifying the reduction of anthropogenic mortality from vessel-whale collisions and commercial fishing as the "most significant need" (National Marine Fisheries Service, 2005a). Under the recovery plan several management activities have been initiated in an effort to reduce both fatal and non-fatal impact of vessels on right whales over the last decade. These include:

1) Prohibiting vessels and aircraft from approaching within 500 yards of a right whale,

2) Conducting aerial surveys to determine near real-time coastal right whale distribution in selected areas,

3) Broadcasting spatial locations of right whales to mariners,

4) Educating stakeholders and the general public on right whales, management efforts and regulations, 
5) Funding of necropsies to develop a better understanding of threats to the survival of individuals and thereby the population,

6) Requesting port access route studies from the United States Coast Guard to establish safe "recommended shipping routes for vessels entering or departing ports" in right whale critical habitat including Jacksonville and Fernandina, FL, Brunswick, Georgia and Cape Cod Bay,

7) Reviewing the current Traffic Separation Scheme servicing Boston, MA, and traffic traversing the Great South Channel habitat, while evaluating the effects of a shift in shipping lanes (Boston) and creating an Area to be Avoided by ships greater than 300 gross tons (Great South Channel),

8) Developing speed restrictions for vessels in right whale critical habitat and migratory corridors (National Marine Fisheries Service, 2005a, 2006, Russell, 2001).

\subsubsection{Vessel-whale collision modeling}

In an effort to determine the efficacy of altering vessel traffic as proposed by the last two activities, recommendations regarding the impact of these actions on the likelihood of fatal vessel collisions were sought from vessel-whale collision modeling studies (National Marine Fisheries Service, 2005b). Four basic types of vessel-whale collision models are presently used - 1) incident-informed models 2) spatial probability models, 3) behavioral response models, and 4) biomechanical models. Each model 
utilizes specific data inputs, assumptions and modeling methods to address a specific aspect of vessel-whale collision risk.

The incident-informed modeling approach involves the analysis of available data regarding vessel-whale collision events seeking patterns linking collision parameters (e.g., vessel size, speed, species, life-history of the whale, location) to the collision outcome (e.g., lethal, severe injury, minor injury, no apparent injury, unknown) (Jensen and Silber, 2003, Laist, et al., 2001). Correlations between collision parameters and outcomes are then used to broadly predict the likelihood of a lethal injury given specific conditions. The records used include reports from whale strandings, observed accounts of collisions at sea; reports of dead whales draped on the bows of ships, published historical accounts and unpublished anecdotal evidence. The dataset includes records from 11 large whale species including the North Atlantic right whale. Collision outcomes are classified according to the observed or presumed fate of the whale. Outcomes include:

$\checkmark$ "killed" where the death of the animal or its carcass were observed,

$\checkmark$ "severe injury" where bleeding wounds were reported or blood was seen in the water,

$\checkmark$ "minor injury" where a "non-bleeding wound or sign of distress" was observed without blood in the water,

$\checkmark$ "no apparent effect" when no visible wounds or disturbance were apparent and the animal reportedly resumed behaviors observed before the collision

$\checkmark$ "unknown" where the animal was not seen after the collision but no blood was observed in the water following the collision (Laist, et al., 2001). 
The incident-informed model draws logical conclusions from a composite dataset composed of information from collisions with multiple species (11), accounts of varying completeness, in a 148-year record (1850-1998) with a relatively small number of collision descriptions before 1951 (15 of 58). These conclusions are then used to predict the vessel sizes, vessel speeds, spatial locations, and species of whale that are likely to be involved in a fatal vessel-whale interaction.

Though the conclusions drawn are valid based on the dataset, there are inherent biases in the data that limit the strict application of these conclusions to the entire vesselwhale collision problem. One limitation is that it is difficult to determine whether the underlying cause of correlations between collision parameters and outcomes is based on the collision parameters themselves, biological differences or factors affecting the overall sighting effort that thereby results in reporting. For example, Laist et al. contend that "A great majority of ship strikes... occur over or near the continental shelf." While the data indeed demonstrate a higher number of reports of collisions in coastal waters it is unclear whether this is due to increased vessel traffic on the continental shelf resulting in increased collisions, or increased reports of collisions due to increased sighting effort or reporting bias toward near shore events or increased collisions due to increased numbers of whales in shelf waters.

In some cases, species-specific biases may be playing a role in the patterns seen in the collision reports and stranding data. These data may actually reflect differences in the distribution of species, post-mortem buoyancy, anatomy (in terms of being structurally 
prone to being pinned to a bulbous bow), and mariner education as opposed to real differences in vessel collision mortality between species. For example, the coastal distribution, post-mortem buoyancy, and major efforts aimed at educating mariners on how to recognize and report the location of live and dead right whales may lead to positive reporting bias regarding this species over open-ocean dwelling species, species that are negatively buoyant or whose populations are less threatened.

Finally, the collision outcome categories are severely biased toward incidents involving propeller trauma and would thereby underestimate fatalities or serious injury due to blunt trauma. Blunt trauma injuries rarely result in external signs of trauma (Campbell-Malone, et al., 2007, Moore, et al., 2005). In fact, prosectors have flensed the entire postcranial elements of a carcass with no obvious signs of trauma only to find a fractured skull and mandible indicative of a vessel-collision event (Right Whale Consortium, 2005). This would result in the misclassification of blunt trauma cases that were not acutely fatal being misclassified as a minor injury, no apparent effect, or unknown outcome despite the presence of skeletal fractures, extensive hemorrhage and soft tissue trauma that is not visible.

An example of this is seen in one of the cases in the incident-informed study by Laist, where both a collision report and a stranding report were available for the same animals involved in the reported collision. The anecdotal report stated that the South African twin-screw ferry was unable to take action when nine Southern right whales were seen ahead of the vessel. They reportedly felt "impact with at least one animal" and noted blood in the water (Best, et al., 2001b). According to the study criteria this report was a 
documented case resulting in the death of a single animal. However, the stranding records indicate that three days later two carcasses were discovered - one having externally visible propeller wounds, the other lacking external signs of injury (Best, et al., 2001b).

The obvious bias toward appropriate classification of propeller trauma results in some question of whether or not the conclusions regarding the influence of speed on vessel-whale collision outcomes are applicable to both sharp and blunt trauma cases. With vastly different mechanisms of trauma being considered, it is likely that the influence of speed also varies between the sharp and blunt trauma scenarios. Studies specifically designed to address the relative influence of speed in blunt trauma events would be better suited to determine if this is true.

Spatial probability models utilize data regarding the distribution of whales and vessel traffic to determine the likelihood of interaction as a proxy of vessel collision risk (Garrison, 2005, Nichols and Kite-Powell, 2005, Taggart and Vanderlaan, 2003, Vanderlaan and Taggart, 2007). Spatial probability studies have been performed using data from three of the five critical habitats that right whales frequent, including Cape Cod Bay, the southeastern U.S. calving grounds, and the Bay of Fundy (Garrison, 2005, Nichols and Kite-Powell, 2005, Taggart and Vanderlaan, 2003, Vanderlaan and Taggart, 2007). Studies rely upon data from the Mandatory Ship Reporting System (MSRS) or the United States Army Corps of Engineers (USACE) that collect routine data regarding vessel traffic in the regions of interest.

The MSRS is a management tool implemented in 1999 by the United States Coast Guard and the National Marine Fisheries Service following adoption by the International 
Maritime Organization that requires ships of 300 gross tons and greater to report their vessel speed, heading and destination upon entering the region (Ward-Geiger and Silber, 2005). At that time the reporting vessel also receives an automated report detailing recent right whale sightings in the area. Similarly, the USACE records data regarding vessels passing through the Cape Cod Canal which are greater than 65 feet (20 meters) in length (Nichols and Kite-Powell, 2005). Collected data include the type of vessel, where it originated as well as its destination. Vessels in the dataset were fitted into the following categories: "tanker, dry cargo or passenger, tug, tank barge, dry cargo barge or commercial fishing vessel" (Nichols and Kite-Powell, 2005).

Data regarding the distribution of whales (standardized per unit effort) was obtained from sighting records maintained by the New England Aquarium (Right Whale Consortium, 2005). The studies then describe the spatial and temporal overlap between right whale sightings and vessel tracks. In some cases various vessel routing schemes are compared to determine the relative risk of a vessel-whale encounter for various routes available to vessels (Garrison, 2005, Taggart and Vanderlaan, 2003).

The limits of the spatial models are well known and include acknowledgement by at least one study that the calculated estimates of a vessel-whale encounter do not translate directly to estimates of vessel-whale collisions (Nichols and Kite-Powell, 2005) and all studies acknowledge that avoidance behavior on the part of the whale or the vessel are not addressed by the data (Garrison, 2005, Nichols and Kite-Powell, 2005, Taggart and Vanderlaan, 2003, Vanderlaan and Taggart, 2007). One model in particular, makes the necessary, albeit gross simplification that the probability of lethal injury is 1 
when a vessel is traveling at or above 23 knots in the same area occupied by a whale (Taggart and Vanderlaan, 2003). The probability of lethal injury at a given speed was extrapolated from anecdotal records of vessel-whale collisions utilized in incident informed models (Taggart and Vanderlaan, 2003, Vanderlaan and Taggart, 2007).

Certainly speed plays a role, but the relative rarity of lethal vessel collisions compared to the speed capabilities of modern vessels traversing right whale habitat precludes this assumption from being wholly valid (Laist, et al., 2001). It is likely that detection and behavioral avoidance play a critical part in reducing the probability of collisions occurring.

Fortunately, a model is being developed to address the impact that the right whale's stimulus detection and behavioral avoidance abilities have on reducing the risk of vessel-whale collisions (Kite-Powell, et al., 2007). The model is based upon studies monitoring the behavior of right whales in response to approaching vessels. Several vessel characteristics and whale behavioral parameters were examined in order to determine which factors play a role in a potential collision scenario. Factors explored include:

-the vessel range, distance to the whale when a response was initiated -the angle of avoidance response, the angle taken by the whale with respect to the vessel path -the dive angle, with respect to the surface - and the speed of the whale (Kite-Powell, et al., 2007). 
By incorporating observed avoidance behavior conditions and typical behavioral responses into the model, Kite-Powell et al. were able to determine the "strike fraction" or likelihood of the whale's path crossing into that of the vessel. The authors also discuss the effects that detection distance has on the probability of vessel-whale collision. They note a dramatic decrease in vessel-whale collision risk with increased detection ability (e.g. with a detection distance increased from $100 \mathrm{~m}$ to $150 \mathrm{~m}$ the probability of a collision with a vessel traveling 15 knots decreases from $40 \%$ to a negligible risk). While this study certainly takes care to incorporate the important parameters of whale response behavior into the model, the outcome (i.e. strike fraction) is an estimate of the likelihood of the vessel and the whale occupying the same place in space and time, much like the spatial probability models previously described.

The largest gap in the predictions made by the aforementioned models is undoubtedly the fact that each of them fails to address the actual collision event itself. The lack of biologically- relevant information regarding what happens when a vessel traveling at a given speed does in fact come into contact with a whale led to the studies detailed in the chapters that follow. These studies together approach the vessel-whale collision event from a holistic point of view.

In chapter two, four case studies of vessel-whale collision trauma are explored, providing insight into common suites of trauma, gross and histological findings, as well as injuries that may serve as characteristic vessel-whale collision injuries appropriate for modeling. These cases are compared to forensic evidence of trauma to provide a paradigm for specifically evaluating carcasses for signs of vessel interaction in the future. 
In chapter three, the gross morphology, internal structure and physical properties of the right whale mandible are explored in detail using computed tomography. The jawbone was examined as a commonly fractured skeletal element that has been broken in one-third of all whales that died as a result of blunt vessel-whale collision trauma (Campbell-Malone, et al., 2007). Physical properties of this bone, including the apparent density of the bone tissue, were explored as important factors for predicting the mechanical behavior of the whole bone during a collision.

The material properties of jawbone samples were determined in chapter four. These data are vital parameters for the creation of a finite element model of a vesselwhale collision event and jawbone fracture. The resulting finite element models, created in collaboration with Igor Tsukrov, Ken Baldwin, Jud DeCew and Jason Raymond of the University of New Hampshire, will aid in the prediction of fracture risk given specific vessel collision parameters (Raymond, 2007).

While the modeling studies will be reported in detail in future publications, preliminary results are presented in chapter five as they apply to this body of work and the problem of vessel-whale collisions in the highly endangered right whale population. The material properties of right whale bone (determined in chapter four) are incorporated into a finite element model capable of predicting the likelihood of bone failure in response to stress applied to simulate a vessel-whale collision event. The preliminary outcomes of the model are discussed in the context of management efforts to impose speed restrictions upon vessels traversing right whale critical habitat to reduce the risk of vessel-whale collision mortality. 
Prior studies have focused on using scarce historical records of observed collisions to extrapolate and predict the outcome of collisions under given conditions. Additional models have combined the distribution of whales and vessels to determine the probability of the two occupying the same parcel of water. This thesis provides the first data regarding the biomechanical response of right whale tissue to applied stress and is a first step in modeling a dynamic vessel-whale collision event. As such it represents the first time that the actual biological tissues and their inherent material properties have been examined and used to predict the outcome of a collision using experimental data from mechanical testing. Rather than approaching the issue of vessel-whale collision modeling obliquely, these data address the issue head on using reasonable assumptions and laboratory testing protocols developed for human orthopedic medicine and thus provides the most biologically relevant predictions of vessel-whale collision mortality risk to date.

\subsection{LITERATURE CITED}

Anonymous, 2002. Routeing of ships, ship reporting and related matters; amendment of the traffic separation scheme in the Bay of Fundy and approaches. Subcommittee on Safety of Navigation, 48th session. International Maritime Organization, Submitted by Canada. 9 pages.

Anonymous, 2004. Species At Risk Act Legal listing consultation workbook (North Atlantic Right Whale). Department of Fisheries and Oceans, Canada, 22 pages.

Baumgartner, M. F., C. A. Mayo and R. D. Kenney, 2007. Chapter 5: Enormous Carnivores, Microscopic Food, and a Restaurant That's Hard to Find. In: Kraus, S. D. and Rolland, R. M., Eds. The Urban Whale: North Atlantic Right Whales at the Crossroads. Harvard University Press. Cambridge, MA. pp. 138-173.

Best, P. B., 1994. Seasonality of reproduction and the length of gestation in southern right whales Eubalaena australis. Journal of Zoology 232 (2), pp. 175-189. 
Best, P. B., A. Brandao and D. S. Butterworth, 2001a. Demographic parameters of southern right whales off South Africa. Journal of Cetacean Research and Management Special Issue 2, pp. 161-169.

Best, P. B., V. M. Peddemors, V. G. Cockcroft and N. Rice, 2001b. Mortalities of right whales and related anthropogenic factors in South African waters, 1963-1998. Journal of Cetacean Research Management Special Issue 2 (Special Issue 2), pp. 171-176.

Brown, M. W., 2003. Guide the Implementation of Stewardship Measures to Reduce Interactions Between Vessels and Right Whales in two Right Whale Conservation Areas in the waters of Atlantic Canada. Final Report for Habitat Stewardship Program, Environment Canada. 20 pages.

Campbell-Malone, R., S. G. Barco, P.-Y. Daoust, A. R. Knowlton, W. A. McLellan, D. S. Rotstein and M. J. Moore, 2007. Sharp and blunt trauma in North Atlantic right whales killed by ships. Journal of Zoo and Wildlife Medicine, in press.

Caswell, H., M. Fujiwara and S. Brault, 1999. Declining survival probability threatens the North Atlantic right whale. Proceedings of the National Academy of Sciences 96, pp. 3308-3313.

Clapham, P. J., 1999. Predicting right whale distribution. Report of the workshop in Woods Hole, Massachusetts.

Clapham, P. J., S. B. Young and R. L. Brownell, 1999. Baleen whales: conservation issues and the status of the most endangered populations. Mammal Review 29 (1), pp. 37-62.

COSEWIC, 2003. COSEWIC assessment and update status report on the North Atlantic right whale Eubalaena glacialis in Canada. Committee on the Status of Endangered Wildlife in Canada. Ottawa, Ontario, Canada. vii +28 pages.

Frasier, T. R., 2005. Integrating genetic and photo-identification data to assess reproductive success in the North Atlantic right whale (Eubalaena glacialis). Ph.D. Thesis. Mcmaster University. Hamilton, Ontario, Canada.

Frasier, T. R., B. A. McLeod, R. M. Gillett, M. W. Brown and B. N. White, 2007. Chapter 7: Right Whales Past and Present as Revealed by Their Genes. In: Kraus, S. D. and Rolland, R. M., Eds. The Urban Whale: North Atlantic Right Whales at the Crossroads. Harvard University Press. Cambridge, MA. pp. 200-231.

Fujiwara, M. and H. Caswell, 2001. Demography of the endangered North Atlantic right whale. Nature 414, pp. 537-541.

Garrison, L. P., 2005. Applying a spatial model to evaluate the risk of interactions between vessels and right whales in the southeast United States critical habitat. National Marine Fisheries Service, Southeast Fisheries Science Center. Miami, FL. 23 pages.

Hamilton, P., M. K. Marx and S. D. Kraus, 1998. Scarification Analysis of North Atlantic Right Whales (Eubalaena glacialis) as a Method of Assessing Human Impacts. New England Aquarium. Boston, Massachusetts.

Hamilton, P. K., A. R. Knowlton and M. K. Marx, 2007. Chapter 3: Right Whales Tell Their Own Stories: The Photo-Identification Catalog. In: Kraus, S. D. and 
Rolland, R. M., Eds. The Urban Whale: North Atlantic Right Whales at the Crossroads. Harvard University Press. Cambridge, MA. pp. 75-104.

International Whaling Commission, 2001a. Introduction. Journal of Cetacean Research and Management Special Issue 2, pp. v-vi.

International Whaling Commission, 2001b. Report of the Workshop on Status and Trends of Western North Atlantic Right Whales. Journal of Cetacean Research and Management Special Issue 2, pp. 61-87.

Jensen, A. S. and G. K. Silber, 2003. Large Whale Ship Strike Database. U.S.

Department of Commerce, National Oceanic and Atmospheric Administration. 37 pages.

Johnson, A. J., S. D. Kraus, J. F. Kenney and C. A. Mayo, 2007. Chapter 13: The Entangled Lives of Right Whales and Fishermen: Can They Coexist? In: Kraus, S. D. and Rolland, R. M., Eds. The Urban Whale: North Atlantic Right Whales at the Crossroads. Harvard University Press. Cambridge, MA. pp. 380-408.

Kenney, R. D., 2001. Anomalous 1992 Spring and Summer Right Whale (Eubalaena glacialis) distributions in the Gulf of Maine. Journal of Cetacean Research and Management Special Issue 2, pp. 209-223.

Kite-Powell, H. L., A. R. Knowlton and M. W. Brown, 2007. Modeling the effect of vessel speed on Right Whale ship strike risk. Report to NOAA/NMFS. WHOI Marine Policy Center. Woods Hole, Massachusetts.

Knowlton, A. R. and M. W. Brown, 2007. Chapter 14: Running the Gauntlet: Right Whales and Vessel Strikes. In: Kraus, S. D. and Rolland, R. M., Eds. The Urban Whale: North Atlantic Right Whales at the Crossroads. Harvard University Press. Cambridge, MA. pp. 409-435.

Knowlton, A. R., F. T. Korsmeyer, J. E. Kerwin, H.-Y. Wu and B. Hynes, 1995. The Hydrodynamic Effects of Large Vessels on Right Whales. New England Aquarium \& Department of Ocean Engineering. Woods Hole, Ma. 93 pages.

Knowlton, A. R. and S. D. Kraus, 2001. Mortality and serious injury of northern right whales (Eubalaena glacialis) in the western North Atlantic Ocean. Journal of Cetacean Research and Management Special Issue 2, pp. 193-208.

Knowlton, A. R., S. D. Kraus and R. Kenney, 1994. Reproduction in North Atlantic right whales (Eubalaena glacialis). Canadian Journal of Zoology 72, pp. 1297-1305.

Korsmeyer, F. T. and B. Hynes, 1995. Hydrodynamic Effects of Ships on Right Whales. MIT. 8 pages.

Kraus, S. D., 1990. Rates and potential causes of mortality in North Atlantic right whales (Eubalaena glacialis). Marine Mammal Science 6 (4), pp. 278-291.

Kraus, S. D., M. W. Brown, H. Caswell, C. W. Clark, M. Fujiwara, P. K. Hamilton, R. D. Kenney, A. R. Knowlton, S. Landry, C. A. Mayo, W. A. McLellan, M. J. Moore, D. P. Nowacek, D. A. Pabst, A. J. Read and R. M. Rolland, 2005. North Atlantic Right Whales in Crisis. Science 309 (5734), pp. 561-562.

Kraus, S. D., P. K. Hamilton, R. D. Kenney, A. R. Knowlton and C. K. Slay, 2001. Reproductive parameters of the North Atlantic right whale. Journal of Cetacean Research Management Special Issue 2, pp. 231-236. 
Kraus, S. D., R. M. Pace III and T. R. Frasier, 2007. Chapter 6: High Investment, Low Return: The Strange Case of Reproduction in Eubalaena glacialis. In: Kraus, S. D. and Rolland, R. M., Eds. The Urban Whale: North Atlantic Right Whales at the Crossroads. Harvard University Press. Cambridge, MA. pp. 172-199.

Kraus, S. D., J. H. Prescott, A. R. Knowlton and G. S. Stone, 1986. Migration and calving of western North Atlantic right whales, (Eubalaena glacialis). Report of the workshop on the status of right whales.

Kraus, S. D. and R. M. Rolland, 2007a. Chapter 1: Right Whales in the Urban Ocean. In: Kraus, S. D. and Rolland, R. M., Eds. The Urban Whale: North Atlantic Right Whales at the Crossroads. Harvard University Press. Cambridge, MA. pp. 1-38.

Kraus, S. D. and R. M. Rolland, Eds. 2007b. The Urban Whale: North Atlantic Right Whales at the Crossroads. Harvard University Press. Cambridge, MA. 576 pages.

Lagueux, K. M., M. A. Zani and A. R. Knowlton, 2007. Using Automatic Identification System (AIS) to Characterize Ship Traffic and Response to the Early Warning System in the Southeast Right Whale Critical Habitat Area (in prep) New England Aquarium. Boston, MA.

Laist, D. W., A. R. Knowlton, J. G. Mead, A. S. Collet and M. Podesta, 2001. Collisions between ships and whales. Marine Mammal Science 17 (1), pp. 35-75.

Moore, M. J., A. R. Knowlton, S. D. Kraus, W. A. McLellan and R. K. Bonde, 2005. Morphometry, gross morphology and available histopathology in North Atlantic right whale (Eubalaena glacialis) mortalities (1970 to 2002). Journal of Cetacean Research and Management 6 (3), pp. 199-214.

Moore, M. J., W. A. McLellan, P.-Y. Daoust, R. K. Bonde and A. R. Knowlton, 2007. Chapter 12: Right Whale Mortality: A Message from the Dead to the Living. In: Kraus, S. D. and Rolland, R. M., Eds. The Urban Whale: North Atlantic Right Whales at the Crossroads. Harvard University Press. Cambridge, MA. pp. 358379.

Moore, M. J., C. A. Miller, M. S. Morss, R. Arthur, W. Lange, K. G. Prada, M. K. Marx and E. A. Frey, 2001. Ultrasonic measurement of blubber thickness in right whales. J. Cetacean Research and Management Special Issue 2, pp. 301-309.

National Marine Fisheries Service, 1991. Recovery Plan for the Northern Right Whale (Eubalaena glacialis). National Marine Fisheries Service. 86 pages.

National Marine Fisheries Service, 2004. Large Whale Ship Strikes Relative to Vessel Speed. Jensen, A. S., Ed. http://www.nmfs.noaa.gov/pr/pdfs/shipstrike/ss_speed.pdf. 19 pages.

National Marine Fisheries Service, 2005a. Recovery Plan for the Northern Right Whale (Eubalaena glacialis) Revision. National Marine Fisheries Service. 137 pages.

National Marine Fisheries Service, 2005b. Right Whale Research Grant Program (RWRGP) Full Funding Opportunity. http://www.nefsc.noaa.gov/psb/grantforms/.

National Marine Fisheries Service, 2006. Proposed Rule to Implement Speed Restrictions to Reduce the Threat of Ship Collisions with North Atlantic Right Whales. Department of Commerce, 50 CFR Part 224. 15 pages. 
Nichols, O. C. and H. L. Kite-Powell, 2005. Analysis of Risk to North Atlantic Right Whales (Eubalaena glacialis) from Shipping Traffic in Cape Cod Bay. NOAA Fisheries. Provincetown, MA. 20 pages.

Parks, S. E., 2003. Acoustic Communication in the North Atlantic right whale (Eubalaena glacialis). . Ph.D. Thesis. Massachusetts Institute of Technology. Woods Hole, MA.

Perrin, W., B. Wursig and J. G. M. Thewissen, 2002. Encyclopedia of Marine Mammals. Academic Press. Boston.

Raymond, J. R., 2007. Development of a Numerical Model to Predict Impact Forces in a North Atlantic Right Whale During Collision with a Vessel. Master of Science. University of New Hampshire. Durham, NH. 100 pages.

Right Whale Consortium, 2005. North Atlantic Right Whale Consortium Photo-ID, Sightings, Genetics, Contaminants and Necropsy Database. New England Aquarium, Boston, MA, USA.

Rosenbaum, H. C., R. L. Brownell, M. W. Brown, C. Schaeff, V. Portway, B. N. White, S. Malik, L. A. Pastene, N. J. Patenaude, C. S. Baker, M. Goto, P. B. Best, P. J. Clapham, P. K. Hamilton, M. J. Moore, R. Payne, V. Rowntree, C. T. Tynan, J. L. Bannister and R. Desalle, 2000. World-wide genetic differentiation of Eubalaena: questioning the number of right whale species. Molecular Ecology 9 (11), pp. 1793-1802.

Russell, B. A., 2001. Recommended measures to reduce ship strikes of North Atlantic right whales. National Marine Fisheries Service. 30 pages.

Taggart, C. T. and A. S. M. Vanderlaan, 2003. Regional Time/Space Conflicts in Vessel Traffic with Right Whales in the Bay of Fundy. Final Project Report, Habitat Stewardship Program for Species at Risk. Dalhousie University. Halifax, Nova Scotia, Canada. 16 pages.

Tønnessen, J. N. and A. O. Johnsen, 1982. The History of Modern Whaling. University of California Press. Los Angeles.

United States Congress, 1972. Marine Mammal Protection Act of 1972. United States, 16 U.S.C. 1361-1362, 1371-1421.

United States Congress, 1973. Endangered Species Act of 1973. 16 U.S.C. 1531-1544.

Vanderlaan, A. S. M. and C. T. Taggart, 2007. Vessel Collisions with Whales: The probability of lethal injury based on vessel speed. Marine Mammal Science 23 (1), pp. 144-156.

Ward-Geiger, L. I. and G. K. Silber, 2005. Characterization of Ship Traffic in Right Whale Critical Habitat. Coastal Management 33, pp. 263-278.

Winn, H. E., C. A. Price and P. W. Sorensen, 1986. The distributional biology of the right whale (Eubalaena glacialis) in the western North Atlantic. Reports of the International Whaling Commission Special Issue 10, pp. 129-138. 


\section{Chapter 2}

Gross and histologic evidence of sharp and blunt trauma in North Atlantic right whales (Eubalaena glacialis) killed by vessels*

*This chapter is currently in press as:

Campbell-Malone, R., Barco, Susan G., Daoust, Pierre-Yves, Knowlton, Amy R., McLellan, William A., Rotstein, David S., Moore, Michael J., 2007. Sharp and blunt trauma in North Atlantic right whales killed by vessels, in press. Journal of Zoo and Wildlife Medicine. 


\section{ABSTRACT}

Vessel-whale collision events represented the ultimate cause of death for 21 (52.5\%) of the 40 North Atlantic right whales (Eubalaena glacialis) necropsied between 1970 and December 2006. Injuries seen in vessel-struck whales fall into two distinct categories; 1) sharp trauma, resulting from contact with the propeller and 2) blunt trauma, presumably resulting from contact with a vessel’s hull. Here we analyze four trauma cases resulting from vessel-whale collisions, which together provide a framework for a more critical understanding of lethal blunt and sharp trauma resulting from vessel collisions with right whales.

In case \#1, contact with a propeller resulted in three deep lacerations to the body. The animal survived acute trauma only to succumb nearly fourteen years later when the scars reopened and became infected. In case \#2, anecdotal reports linked the laceration of large arteries of the peduncle and histologic evidence of perimortem trauma at a bone fracture site to vessel-whale collision trauma. Case \#3 had a laceration of the oral rete and fracture of the rostrum, both displaying histologic evidence of perimortem blunt trauma. Finally, in case \#4, an antemortem mandibular fracture, two additional skull fractures and widespread hemorrhage were indicative of severe blunt trauma.

Evidence from each case, including the timing of trauma relative to the time of death and identifying characteristics of both trauma types are presented. Prior to this study, no detailed comparative analysis of trauma pathology resulting from lethal interactions between vessels and right whales had been made. This study demonstrates 
the importance of detailed gross and histologic examination in determining the significance and timing of traumatic events.

\subsection{INTRODUCTION}

The North Atlantic right whale (Eubalaena glacialis) population of approximately 400 known individuals is inhibited from recovery by low reproductive success and high anthropogenic mortality that may contribute to the extinction of the species within 200 years (Caswell, et al., 1999, Fujiwara and Caswell, 2001, Knowlton and Kraus, 2001, Kraus, 1990, Kraus, et al., 2005). The two primary sources of anthropogenic mortality identified in this population include entanglement in fishing gear and vessel-whale collisions (International Maritime Organization, 2002, Knowlton and Kraus, 2001, Kraus, 1990, Kraus, et al., 2005, Moore, et al., 2005). Between 1970 and December 2006, 21 right whales were involved in fatal vessel-whale collisions as determined by necropsies of varying degrees of completeness (Moore, et al., 2005, New England Aquarium, 19862005). As this represents the cause of death of over half (52.5\%) of the 40 individuals necropsied during that time period, the reduction of vessel-whale collision mortality has been identified by United States and Canadian governmental agencies as an important goal of their respective right whale management programs (Department of Fisheries and Oceans, 2000, Kraus, et al., 2005, National Marine Fisheries Service, 1991, 2004).

Trauma seen in right whales struck by vessels falls into two distinct (though not mutually exclusive) categories - sharp trauma and blunt trauma. Sharp trauma is caused 
when sharp underwater protuberances including propellers and rudders come into contact with the animal. Propeller trauma occurs when the rotating blades of the vessel's screw incise the soft tissue and sometimes bone of the animal and leaves the most obvious external evidence of injury. Blunt trauma results when the animal is struck by the hull of the vessel. These events typically leave little external evidence of the injury even in the most severe cases due to the thickness of soft tissue and the dark pigment of much of the epidermis which tends to obscure evidence of swelling and bruising (Moore, et al., 2005).

Though the earliest confirmed case of lethal sharp trauma in right whales is from 1976, propeller injury in large whales of known and unspecified species (which therefore may have included right whales) can be found in the literature dating as far back as 1877 (Laist, et al., 2001). Sharp trauma results in peracute tissue damage with variable levels of severity ranging from mild, non-fatal "knicks" to severe, immediately lethal wounds. Damage from a turning propeller is often distinct in that it leaves a characteristic series of more or less parallel, evenly spaced, curved (s-shaped or z-shaped) cuts that deepen at the center and become shallow toward the margin as seen in Figure 2.1 (Wood, James L. 2005. Personal Communication) (Lightsey, et al., 2006).

Analysis of epidermal scarring reveals that $7 \%$ of the population carries evidence of healed wounds that can be attributed to sub-lethal sharp trauma (Hamilton, et al., 1998, Kraus, 1990). In minor cases this can lead to blood loss, a compromised epidermis, exposure to infection via open wounds, scarring, and presumably pain (Knowlton and Kraus, 2001, Laist, et al., 2001, Moore, et al., 2005). In more severe cases, sharp trauma leads to incision of the integument and underlying soft tissue, extensive blood loss, and 
dismemberment. Lethal cases may involve severe damage to the vertebral column or axial muscle resulting in reduced locomotor function, or, in extreme cases, the complete separation of the animal into two parts.

Blunt trauma resulting from a vessel-whale collision is marked by hemorrhage, edema and often concomitant pre-mortem fracture of skeletal elements. Generally, the epidermis is not damaged in such a way as to indicate the presence or the extent of subdermal injury, although swelling and bruising are at times evident externally. For this reason, complete necropsy including flensing of soft tissue is the only true diagnostic tool available to rule out a vessel strike as the primary cause of death where a collision was not documented (McLellan, et al., 2004, Moore, et al., 2005). Findings from the necropsies of two animals displaying evidence of blunt trauma will be reviewed as case studies in lethal blunt trauma.

Previously, the standard classification of injury from vessel collisions with right whales included four somewhat overlapping and often coincident categories, namely 1) acute propeller trauma, 2) severed fluke, 3) bone fracture, and 4) hemorrhage and hematoma (Knowlton and Kraus, 2001). At this time there has been no detailed analysis of the nature or timing of trauma pathology resulting from lethal interactions with sharp and blunt vessel structures. This study analyses four such cases, providing a framework for a more critical definition of lethal blunt and sharp trauma in right whales. The characterization of injuries seen in right whales struck by vessels will aid prosectors in linking future necropsy findings of tissue trauma to their underlying causes and timing relative to time of death. These determinations will help inform managers of the impact 
of vessel-whale collision mitigation efforts. This analysis will also permit evaluation of the adequacy of previous assessments of presumed trauma from contact with a vessel.

\subsection{MATERIALS AND METHODS}

The examination of the four animals discussed here was conducted according to the currently accepted right whale necropsy protocol to the extent practical (McLellan, et al., 2004). Lesions, including affected and unaffected margins, were sampled for histology.

The condition of the carcass was evaluated according to standard condition codes for marine mammals (Geraci and Lounsbury, 1993). The condition of the remains is not

directly proportional to the time since death, but instead categorizes the appearance of the carcass. Code two is fresh, Code three is moderately decomposed, Code four is significantly decomposed, and code five is mummified or skeletonized.

The necropsy reports for these animals include the known history of the animal in life, carcass discovery and retrieval, and gross necropsy process. Each report culminates with the findings of post-necropsy laboratory analyses and ultimate diagnosis. These reports can be obtained via a request for data access to the Right Whale Consortium (New England Aquarium, 1986-2005). 
Figure 2.1: Characteristic propeller trauma in live and dead right whales. a) Propeller wounds to the left fluke of right whale Eg \#2425. Note the series of parallel curved cuts that are typical of propeller wounds. Photographer: Monica Zani, New England Aquarium. b) Right whale calf RKB1424, was reportedly struck by a 25 meter vessel with twin screws turning to make 15 knots. Two series of deep propeller cuts were observed. Photograph from (Moore, et al., 2005). Photographer: Robert Bonde, U.S. Geological Survey.
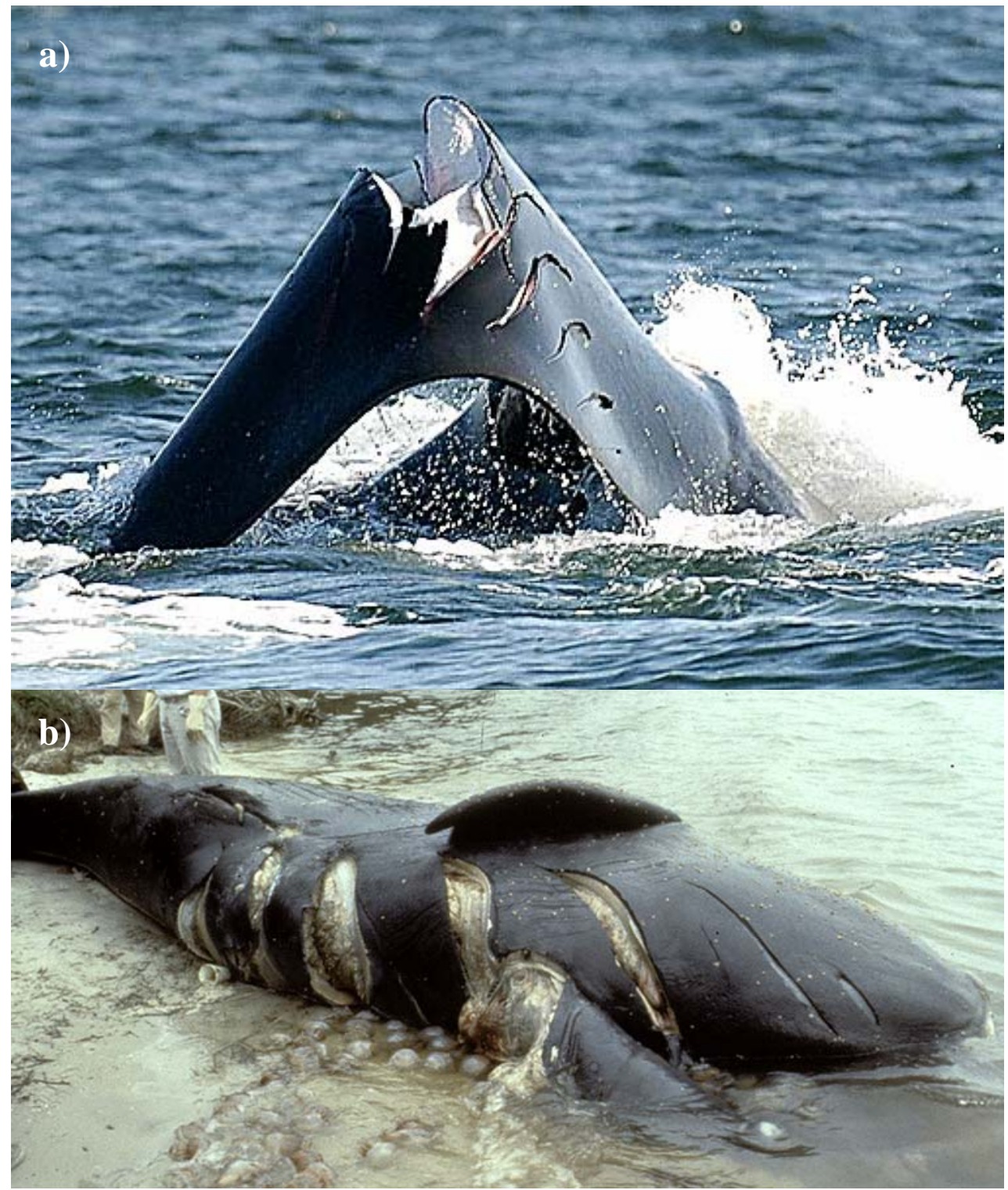


\subsection{RESULTS}

The diagnostic necropsy results of four individual North Atlantic right whales which suffered trauma from vessel strikes and were examined between October 2003 and January 2005 are presented below, beginning with the most recent case. Table 1 summarizes available life history data for each case.

\subsubsection{Case study I - Eg \#2143}

Sighting history: Eg \#2143 was first sighted in 1991 as a calf with its mother in the right whale calving grounds off the southeastern U.S. coast. At that time, it had three deep, open wounds on its left flank that had the characteristic parallel pattern and curvature of propeller wounds. Despite the severity of these wounds and a poor prognosis for survival, Eg \#2143 was re-sighted in the Bay of Fundy six months later and was observed each consecutive year through 2003. It was last seen alive on 5 January 2005 off the Florida coastline. At the time of its death the animal was pregnant with its first known fetus.

Necropsy observations: The code three carcass of Eg \#2143 was found $30 \mathrm{~km}$ east of Cumberland Island, Georgia on 12 January 2005.

External examination- Three large, healed propeller wounds were visible on the left abdominal wall (Figure 2.2). Other than the propeller wounds there were no 
Table 2.1: Life history and necropsy findings from four right whales killed by vessels.

\begin{tabular}{|c|c|c|c|c|c|c|}
\hline Case ID & $\begin{array}{c}\text { Necropsy location } \\
\text { and date }\end{array}$ & Sex & Age $^{a}$ & Pregnant? & $\begin{array}{c}\text { Condition } \\
\text { code }\end{array}$ & Comments \\
\hline Eg \#2143 & $\begin{array}{c}\text { Cumberland Island, } \\
\text { Georgia } \\
\text { Jan } 2005\end{array}$ & $\mathrm{~F}$ & 13 & Yes & 3 & $\begin{array}{l}\text { Sharp Trauma. Succumbed to } \\
\text { sequelae of propeller trauma nearly } 14 \\
\text { years after injury. }\end{array}$ \\
\hline Eg \#1909 & $\begin{array}{l}\text { Ocean Sands, } \\
\text { North Carolina } \\
\text { Nov } 2004\end{array}$ & $\mathrm{~F}$ & 14 & Yes & 3 & $\begin{array}{l}\text { Blunt Trauma. Left fluke blade } \\
\text { completely severed, presumably by } \\
\text { propeller. }\end{array}$ \\
\hline Eg \#1004 & $\begin{array}{l}\text { Nags Head, } \\
\text { North Carolina } \\
\text { Feb } 2004\end{array}$ & $\mathrm{~F}$ & $29+$ & Yes & 3 & $\begin{array}{l}\text { Blunt Trauma. Extensive hemorrhage } \\
\text { seen in subdermal sheath. Fractured } \\
\text { rostrum, premaxilla, and vomer. } \\
\text { Laceration of oral rete. }\end{array}$ \\
\hline Eg \#2150 & $\begin{array}{l}\text { Culloden Cove, } \\
\text { Nova Scotia, } \\
\text { Canada } \\
\text { Oct } 2003\end{array}$ & $\mathrm{~F}$ & $12+$ & No & 4 & $\begin{array}{l}\text { Blunt Trauma. } 1.5 \mathrm{~m} \text { long fracture of } \\
\text { caudal aspect of cranium. Complete } \\
\text { fracture of right jawbone. Fracture of } \\
\text { left rear vomer. }\end{array}$ \\
\hline
\end{tabular}

${ }^{a}$ Numbers followed by a “+” represent the “minimum age” for individuals first identified as juveniles or adults. 
significant findings of human interaction, massive blunt trauma or evidence of broken bones.

Internal examination- The cervix and uterus appeared normal and a full-term female fetus was found in the thoracic cavity and necropsied separately.

The most remarkable findings involved the three healed propeller scars. The caudal scar was opened from the epidermis through the sub-dermal sheath, leaving deep axial muscle clearly visible. The caudal scar was between the dorsal and lateral lines at the level of the genital slit. It included an open wound exuding large amounts of green pus. Though the axial muscle examined in other parts of the body appeared normal, the muscle deep to this wound was liquefied in a cranially-oriented cone shape and when opened it explosively released approximately $5 \mathrm{~L}$ of tan pus. Torn tendons and muscle fibers were associated with both the cranial and caudal margins of the wound. The lesions and exudate were surrounded by hard connective and scar tissue approximately $0.5 \mathrm{~m}$ thick.

Histopathology: Examination of cranial and caudal scar tissue revealed irregular and undulating superficial epithelium and neutrophilic infiltration of the papillary and superficial reticular dermis (Figure 2.3). There was extensive fibrosis with little associated inflammation in the middle and deep dermis and adipose tissue (Figure 2.4).

Diagnosis: Findings indicate that severe, sublethal propeller trauma had delayed but ultimately fatal complications. Secondary intention wound healing may have resulted 
in decreased strength and compromised integrity of tissues injured by the propeller.

Potential complications, including sepsis secondary to bacteremia via the open caudal propeller scar, likely arose as a result of girth expansion during pregnancy which led to loss of scar tissue integrity, wound re-opening, and severe infection.

Figure 2.2: Close up of caudal (left) and central (right) propeller scars on left flank of right whale Eg \#2143. The whale is oriented with the caudal end to the left of the image, cranial end to the right, lying on its dorsum with its ventral surface facing up. The caudal scar was opened from the epidermis through the sub-dermal sheath. Copious ectoparasitic cyamids were associated with the wounds and are visible here as small beige dots. The cranial-most scar is out of the frame. Photographer: Alicia Windham-Reid, Florida Fish and Wildlife Conservation Commission.

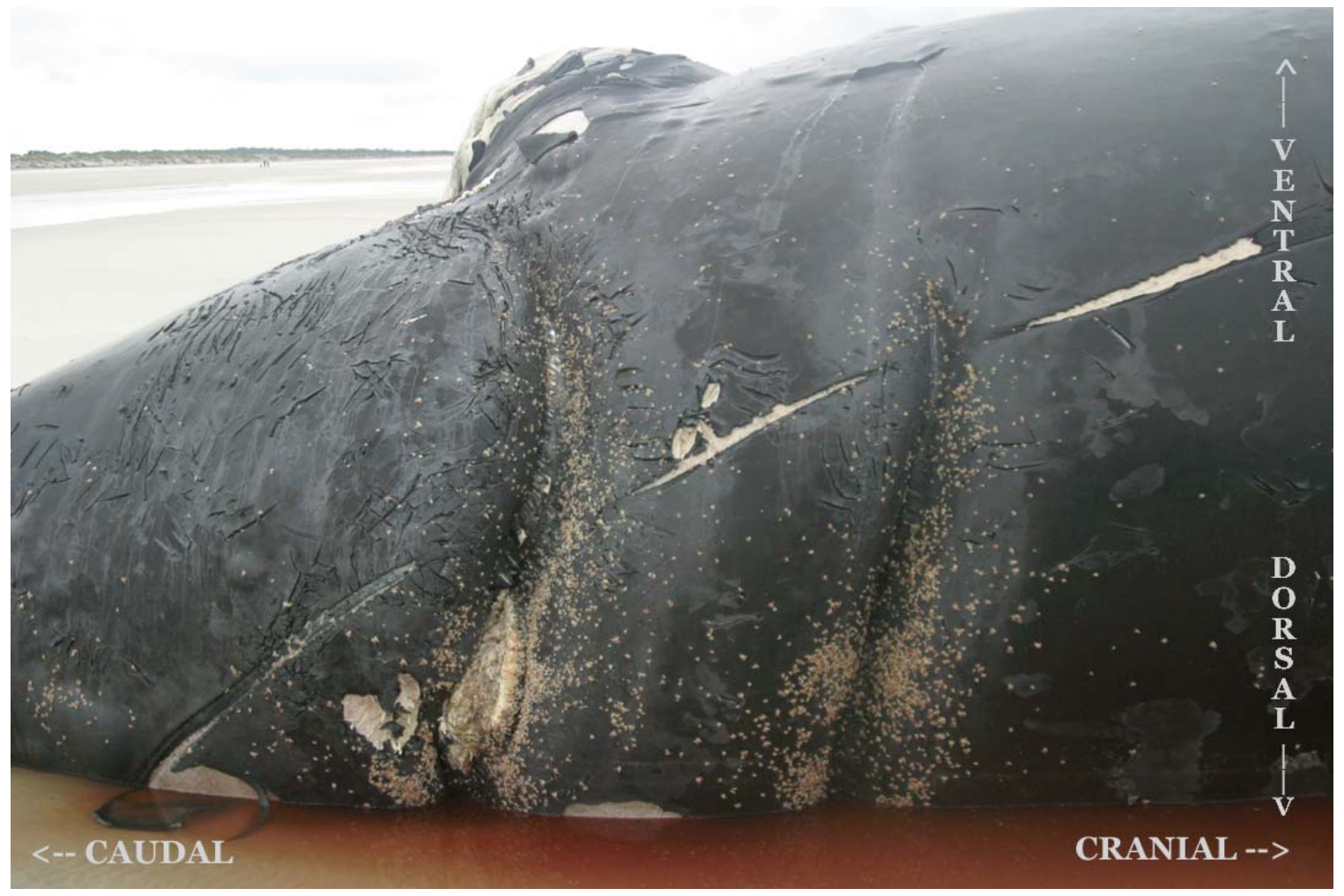


Figure 2.3: Epithelium from propeller scar. Neutrophils are present in small aggregates and can be seen transmigrating through the epithelium (NT). Epithelial cells (EC) with intracytoplasmic melanin are also visible. Photographer: David Rostein, University of Tennessee.

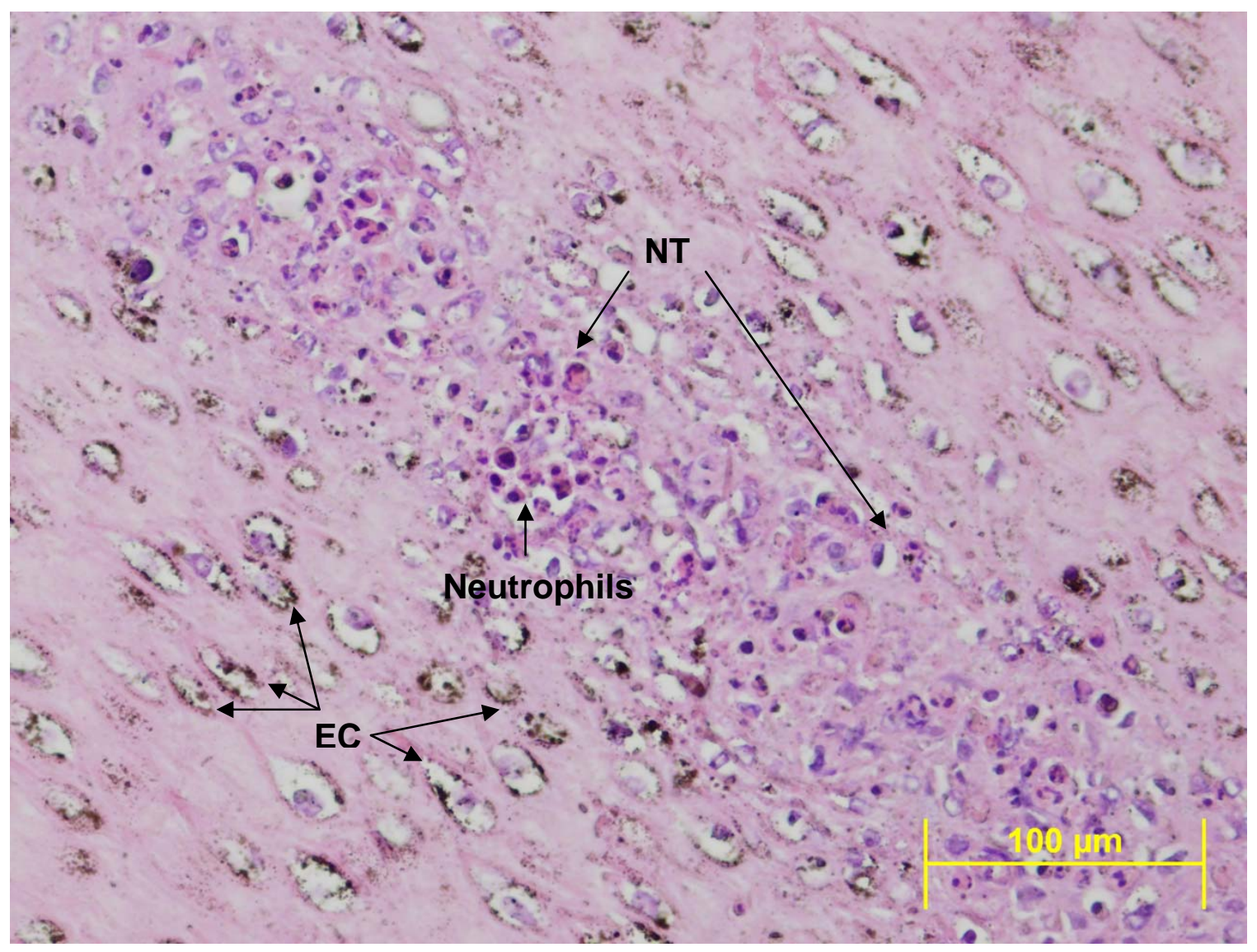


Figure 2.4: Dermis from propeller scar. Within the superficial dermis, there is deposition of abundant mature collagen with few entrapped adipocytes. Photographer: David Rotstein, University of Tennessee.

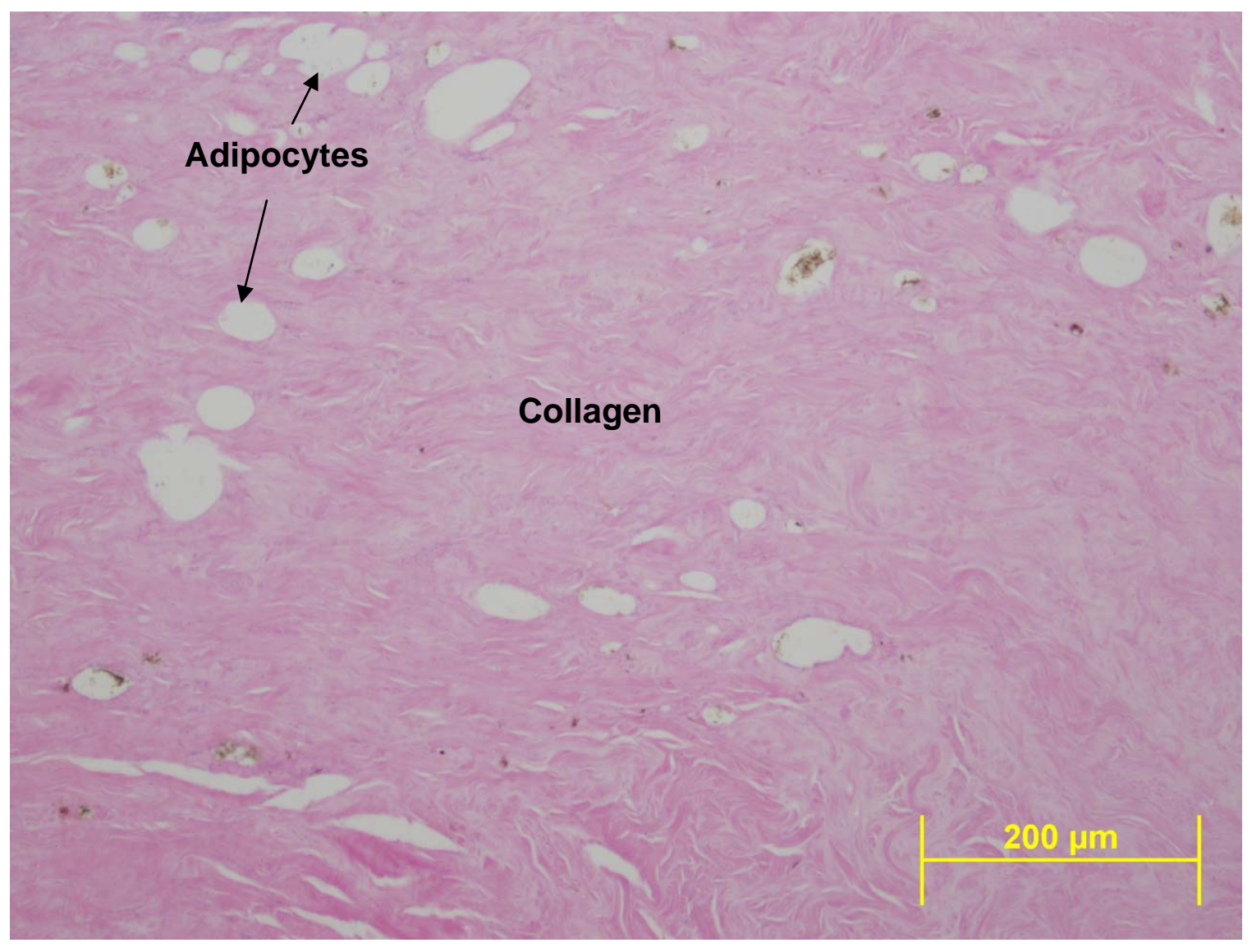


2.3.2 Case study II - Eg \#1909

Sighting history: Eg \#1909 was first sighted as a calf in 1989. It was seen each consecutive year from 1989 - 2003. It was last seen on 21 April 2003 in the Great South Channel. At the time of its death the cow was pregnant with its first known fetus.

Necropsy observations: The code three carcass was found on shore 24 November 2004, in Ocean Sands, North Carolina.

External examination- The left fluke blade was completely severed and large dorsal and ventral arteries (2-3 cm in diameter) originating in the tail stock were lacerated and exposed along the midline (Figure 2.5).

A shallow linear wound was found in the soft tissue superficial to the left caudal third of the rostrum. The laceration extended through the epidermis, dermis and soft tissue and into the premaxilla.

Internal examination- Examination of the blubber layer and post-cranial skeletal elements revealed no additional evidence of trauma. Minor, albeit deep, linear soft tissue wounds were seen through the rostrum and premaxilla. A near-term female fetus between 3-4 $\mathrm{m}$ in length was found in the thoracic cavity and was necropsied separately.

Histopathology: Analysis of soft tissue taken from the wound overlying the premaxilla revealed marked necrotizing and hemorrhagic panniculitis. Also evident were mild, multifocal hemorrhage in adipocyte lobules and mild, multifocal to coalescing intermysial edema with separation of fine collagen bundles indicative of traumatic 
Figure 2.5: Extensive soft tissue damage to fluke and peduncle of right whale Eg \#1909. Note that the entire left fluke and soft tissue of the left lateral and ventral peduncle were missing. Three or four of the caudal vertebrae were lost as well as the proximal quarter of the ventral right fluke, which was also lacerated. Photographer: Virginia Aquarium Stranding Program.

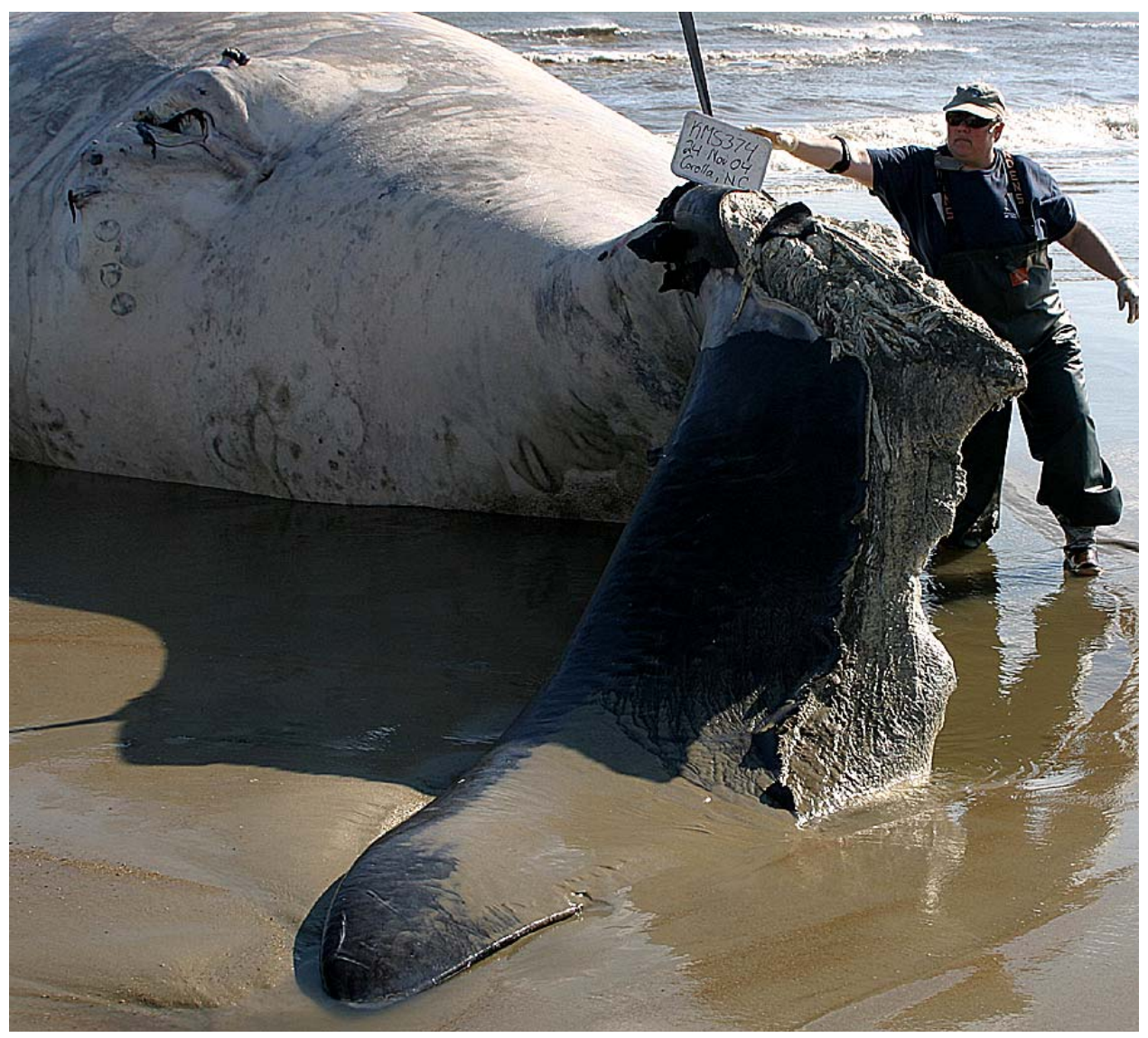


'stretching.' A bone sample from the damaged premaxilla had a comminuted fracture. Microscopic examination of decalcified bone revealed bone fractures involving individual or multiple trabeculae. The fracture margins were irregular and the margin surface was covered with extravasated erythrocytes and small amounts of eosinophilic substance consistent with fibrin.

Diagnosis: Laceration of large vessels of the peduncle suggest extensive trauma to both the fluke and head, with significant blood loss leading to traumatic, hypovolemic shock. Extravasated erythrocytes, fibrin deposition and trabecular fracture of the premaxilla support the acute, perimortem nature of these injuries as opposed to post-mortem or chronic lesions.

These findings are consistent with two reports regarding a bleeding whale seen on 17 November 2004 received later by the Virginia Aquarium \& Marine Science Center Stranding Program. A general public report described a whale with a fresh wound to its tail moving slowly just off the coast of North Carolina. At that time, the whale was reportedly bleeding and was missing a large portion of its fluke. A second report received from the Navy five days later detailed a vessel-whale collision event involving a Navy Amphibious Assault Ship on 17 November 2004. Global Positioning System coordinates from the public report placed the whale four nautical miles southwest of the Naval whale strike coordinates. The close proximity (in both time and space) make it likely that the same whale was seen by both vessels and was in all probability Eg \#1909 who washed ashore seven days later. 


\subsubsection{Case study III - Eg \#1004}

Sighting history: Eg \#1004 was first seen as an adult in 1975. Eg \#1004 was last seen alive in the Great South Channel on 29 May 2003 and was pregnant with its sixth known offspring at the time of its death.

Necropsy observations: The early code three carcass of Eg \#1004 was necropsied in February 2004, in Nags Head, North Carolina.

External examination- There was no evidence of fresh or recent human interaction visible on the epidermis, though white, healed scarring from old fishing line entanglements was found. There was a slight discoloration and bulging near the caudal insertion of the left mandible, potentially indicative of sub-dermal edema.

Internal examination- The internal examination began with a deep incision through the epidermis, blubber, and muscle just caudal to the skull down to the atlantooccipital joint with the animal lying on its dorsum. This incision revealed substantial hemorrhage and edema in the sub-dermal sheath extending from the nuchal crest through the right lateral midline to the ventral sub-dermal sheath (Figure 2.6).

Examination deep to the blubber revealed additional regions of hemorrhage on both the ventral and dorsal aspects of the animal. Edema, consistent with the externally apparent localized swelling, was found in the sub-dermal sheath and muscle overlying the left mandible. Samples of edematous tissue were collected for histology. A schematic representation of areas of major sub-dermal edema and hemorrhage can be seen in Figure 2.7. Dorsal edema extended along the dorsal midline from the blowhole, caudally to the 
anus, and measured $5 \mathrm{~cm}$ in depth. Dorsal edema extended laterally to the midline near the axilla and crosses the dorsal midline to the right lateral midline. Ventral edema extended from the posterior insertion of the left flipper caudally to insertion of peduncle. Ventral edema extended laterally to the midline just caudal to the anus.

Examination of the oral cavity revealed a laceration in the oral rete overlying a fracture of the rostrum (Figure 2.8). The area of baleen surrounding the oral rete laceration was coated in a thick mustard-brown fluid in a spray-like pattern emanating from the laceration. Complete fracture of the rostrum, maxilla, premaxilla, and vomer was evident at the site of the laceration upon removal of soft tissue. The fracture plane of each bone was sampled for histology.

Post-cranial skeletal elements were robust and showed no signs of fracture or damage. The fetus was necropsied separately.

Histopathology: Hemorrhagic tissue, irregular margins of fracture plane, and adherent fibrillar material localized at the vomer fracture site were suggestive of perimortem fractures of the vomer, premaxilla, maxilla, and rostrum. 
Figure 2.6: View of right side of post-cranial cross-section of Eg \#1004 after beheading reveals the first signs of extensive blunt trauma. The animal is lying ventral side up. The black epidermis (right), overlying the creamy white blubber layer, is superficial to a gelatinous layer of hemorrhagic tissue and brown (autolysed) muscle (all tissue to the left of the blue scale bar in hand). The $5 \mathrm{~cm}$ thick hemorrhagic tissue indicated perimortem blunt trauma. Photographer: Regina Campbell-Malone, Woods Hole Oceanographic Institution.

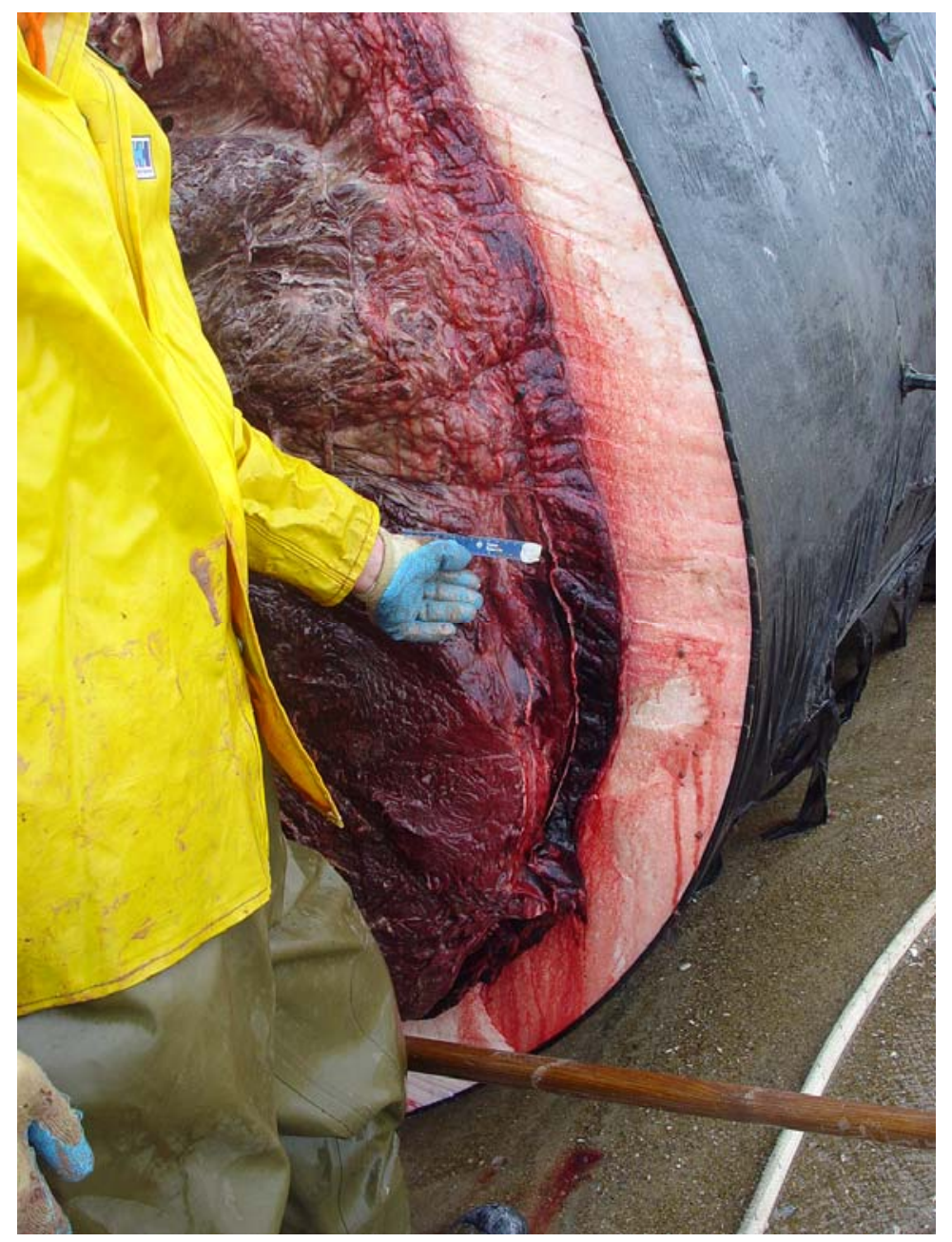


Figure 2.7: Schematic representation of sub-dermal hemorrhage and edema in right whale Eg \#1004. Both the dorsal and ventral surfaces were extensively bruised. Except for bruising overlying the left mandible, bruising seen on right side (not shown) mirrored that seen on the left side. Image from Eg \#1004 necropsy report adapted from standard right whale necropsy protocol (McLellan, et al., 2004, New England Aquarium, 1986-2005).

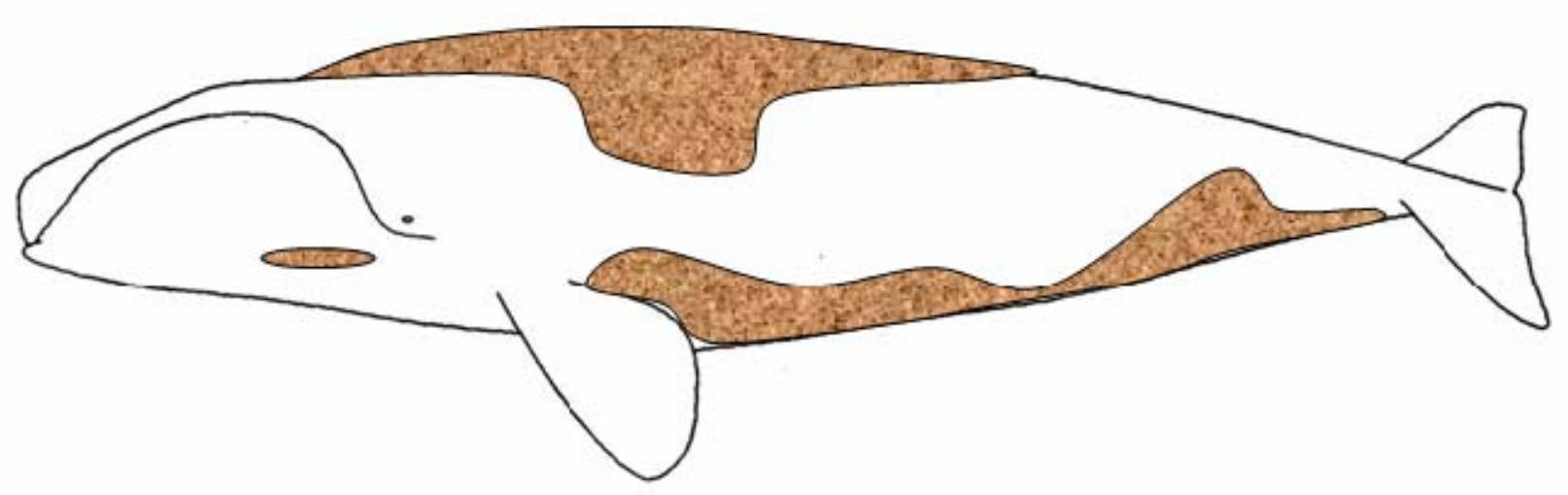

Diagnosis: A combination of severe sub-dermal bruising found in dorsal and ventral tissues, complete fracture of the rostrum involving the maxilla, premaxilla, and vomer and severe laceration of oral rete resulting in rapid loss of blood directly contributed to the death of Eg \#1004. This evidence indicates death resulting from catastrophic impact during a vessel collision event. 
Figure 2.8: Evidence of significant blood loss in oral cavity of right whale Eg \#1004. Inspection of the roof of the mouth revealed a laceration to the oral rete (between two arrows) and apparent "blood-spatter" staining (traced by gray curve) on the lingual surface of baleen plates. The tongue and black lip can be seen at the bottom of the photo. Removal of soft tissue revealed a complete fracture of the rostrum, vomer, and premaxilla. Staining pattern indicates that vessel contents were under pressure when the laceration occurred, thereby providing evidence of perimortem trauma. Photographer: Regina Campbell-Malone, Woods Hole Oceanographic Institution.

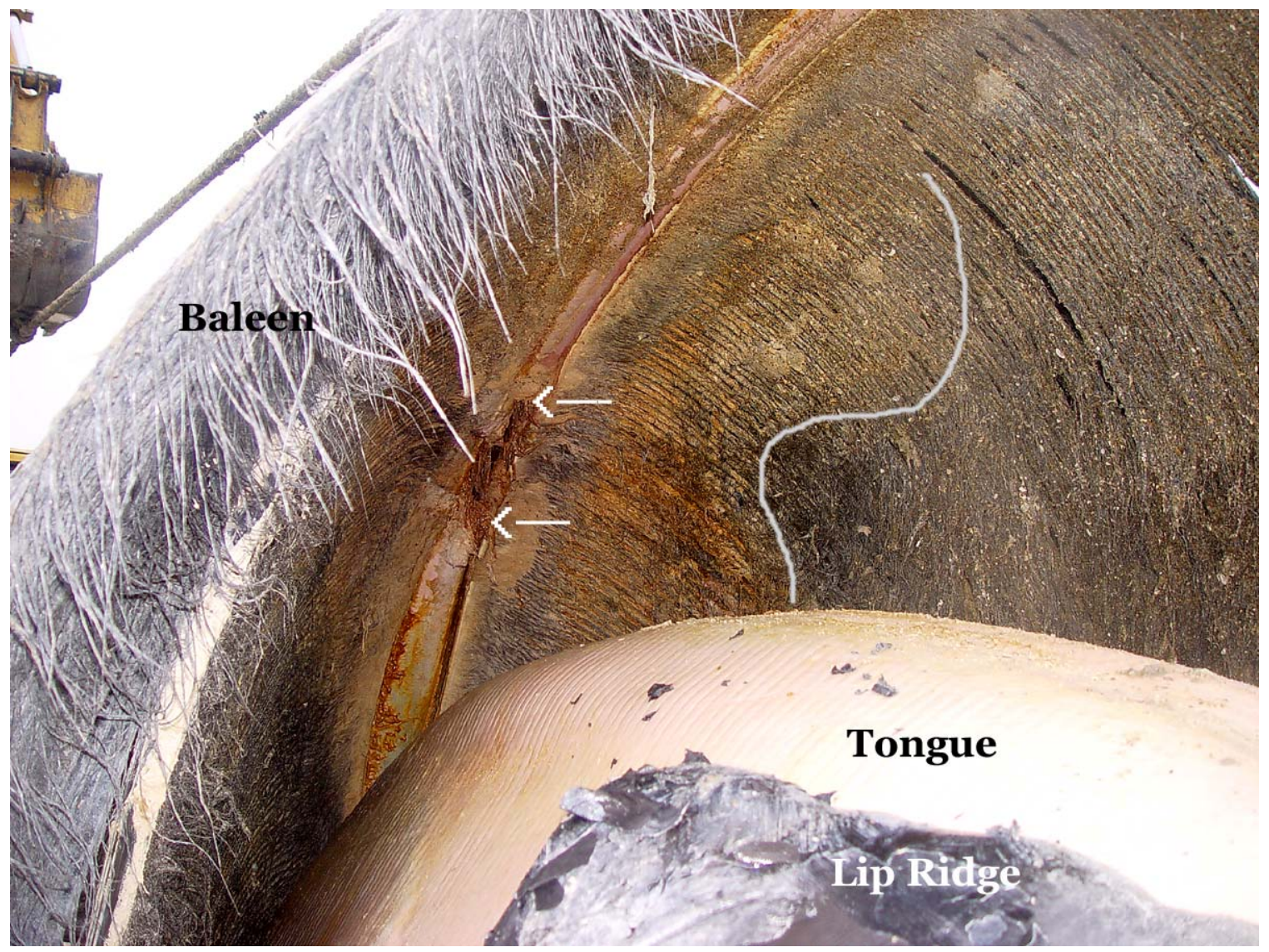


2.3.4 Case study IV - Eg \#2150

Sighting history: Eg \#2150 was first sighted as an animal of unknown age in Massachusetts Bay in 1991. It was last seen alive off the coast of Georgia in February 2002.

Necropsy observations: The code four carcass of Eg \#2150 was necropsied in Culloden Cove, Nova Scotia, Canada, in October 2003.

External examination- Photographs taken during the initial encounter on 2 October 2003 were viewed after the necropsy. The images revealed a large area of epidermal discoloration and swelling overlying the right mandible, although most of the epidermis was absent when the animal was necropsied.

Internal examination- Despite extreme autolysis, the main findings upon internal examination included sub-dermal bruising, abnormal fluids and substances noted in the abdominal and thoracic cavities, and three distinct fractures in the skull.

The most striking fracture, found in the caudal aspect of the cranium, partitioned the rear of the skull into two distinct sections (Figure 2.9). The fracture measured approximately $1.5 \mathrm{~m}$ in length and communicated with the brain case. Severe bruising was noted in the connective tissue and muscle overlying a fractured right lower jaw (Figures 2.10.a and 2.10.b), though the blubber layer was unremarkable. All post-cranial skeletal elements were intact. Disarticulated right ribs were associated with hemorrhage near the axilla of the right flipper. There were three distinct fractures in the cranial skeleton. The right mandible was completely fractured approximately $1.5 \mathrm{~m}$ from the 
mandibular symphysis. A fracture of the left rear of the vomer was also found (not pictured).

Figure 2.9: Caudal view of skull of right whale Eg \#2150. The dorsal aspect of the cranium is resting on soft tissue seen at the bottom of the photograph. The foramen magnum is visible (vertical arrow) as is a $1.5 \mathrm{~m}$ fracture (horizontal arrow) involving the brain case. The fracture divided the skull into two distinct sections. Photographer: Andrea Bogomolni, Cape Cod Stranding Network.

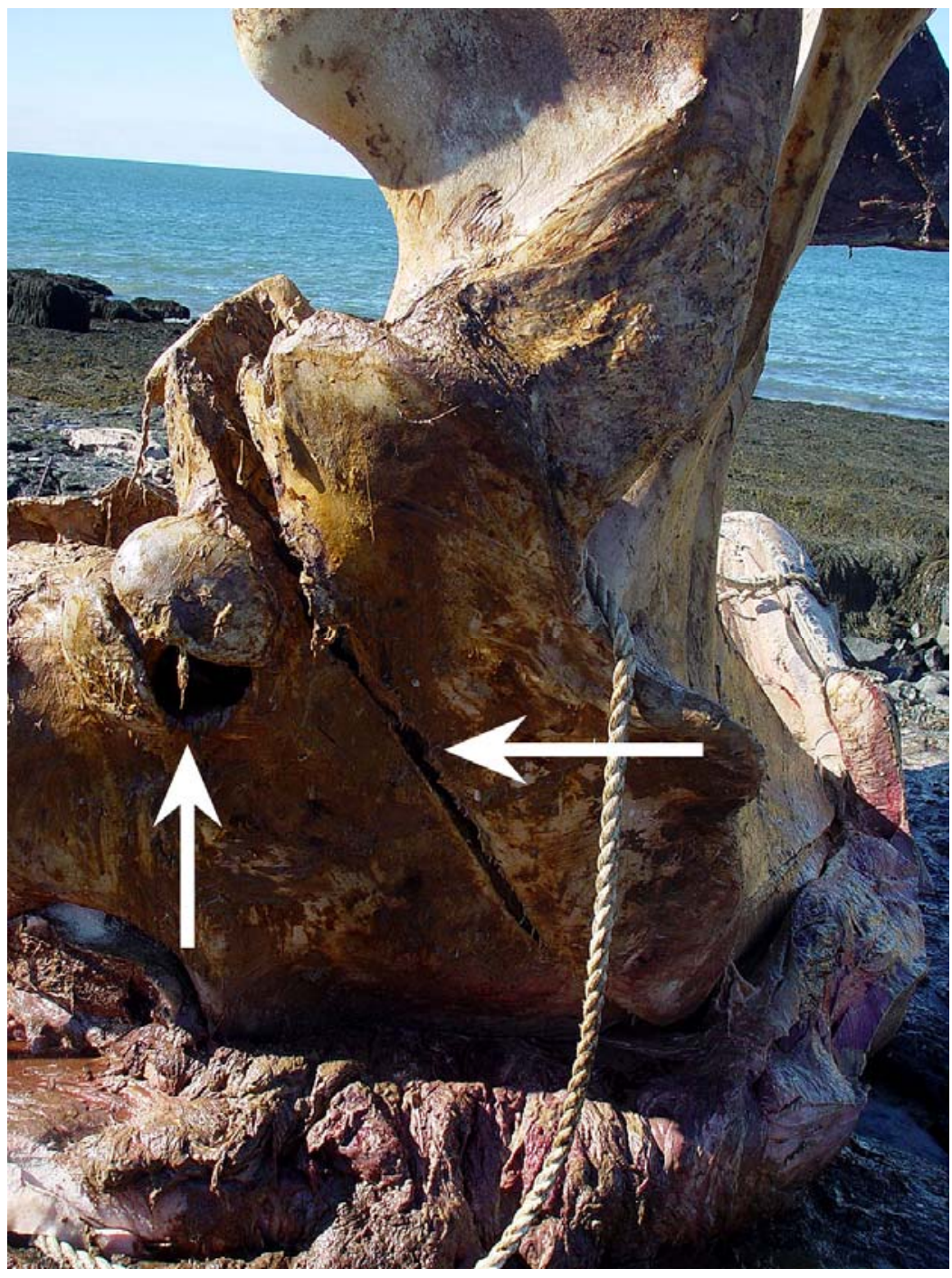


Figure 2.10: Internal signs of hemorrhage and a complete fracture of the right mandible of right whale Eg \#2150. a) Hemorrhage discovered upon reflection of skin and blubber layer. A knife penetrates the plane of the complete transverse fracture of the right mandible (seen in b). Photographer: Andrea Bogomolni, Cape Cod Stranding Network.

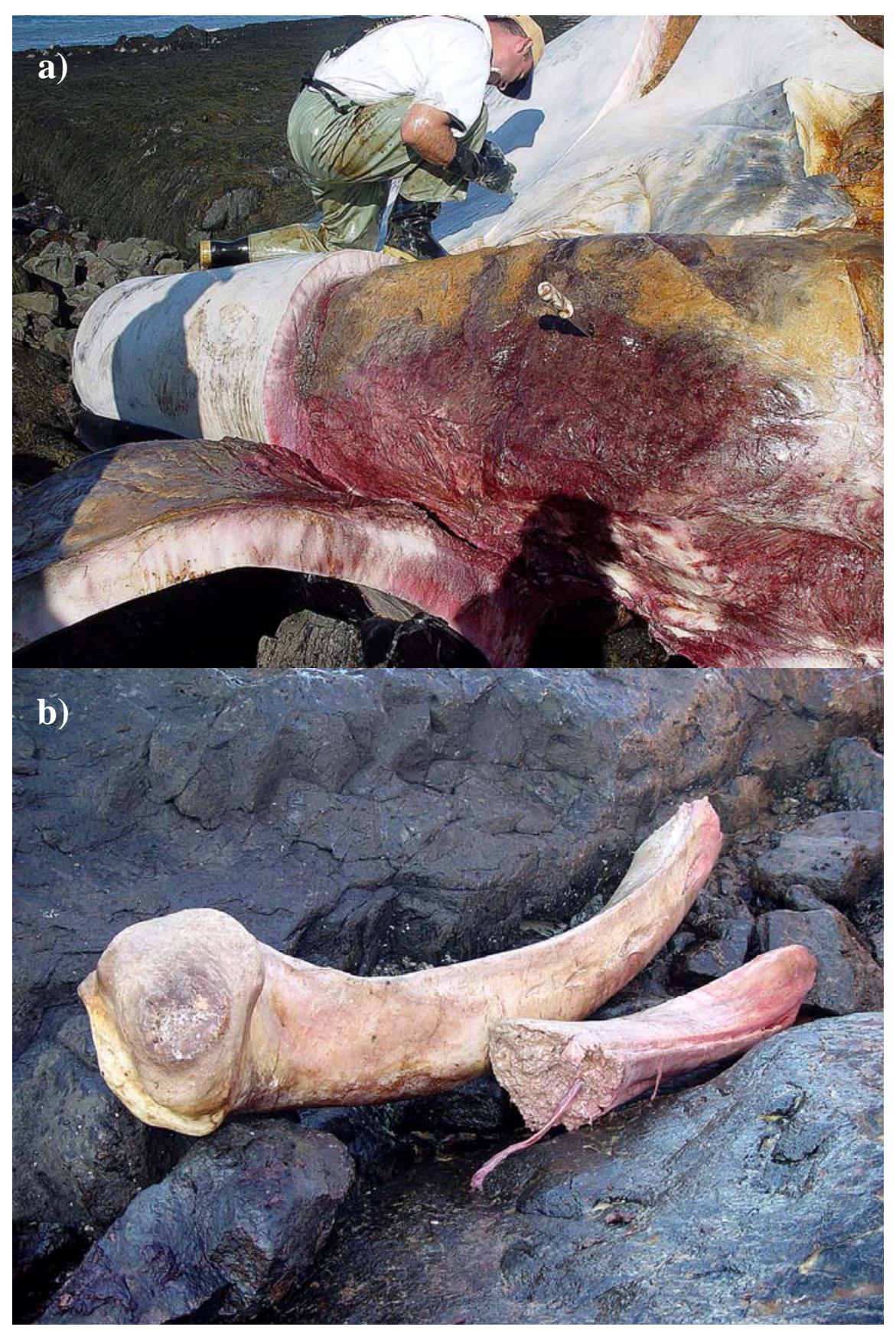


Figure 2.11: Histology of the fracture plane of the jaw bone revealed the presence of woven bone, islands of cartilage, and fibrous tissue consistent with attempt at bone repair in Eg \#2150. Hematoxylin and eosin stain. a) Normal bone trabeculae at 2X magnification. b) The upper image shows the fracture margin with normal bone trabeculae (T) on the left and abundant fibrous tissue of repair (F) on the right (2X). c) The lower image shows islands of cartilage (C), also indicative of attempt at bone repair (20X). Photographer: Pierre-Yves Daoust, University of Prince Edward Island.

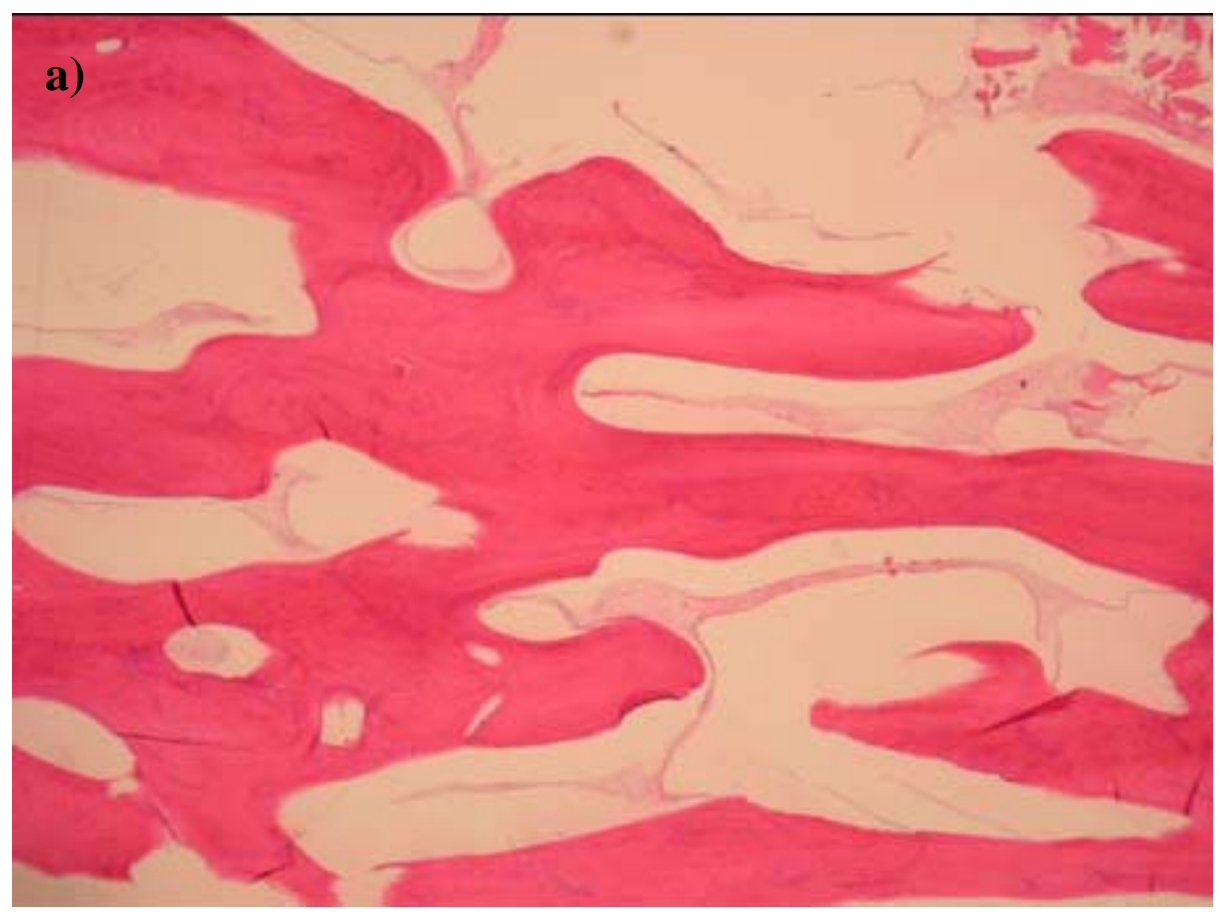




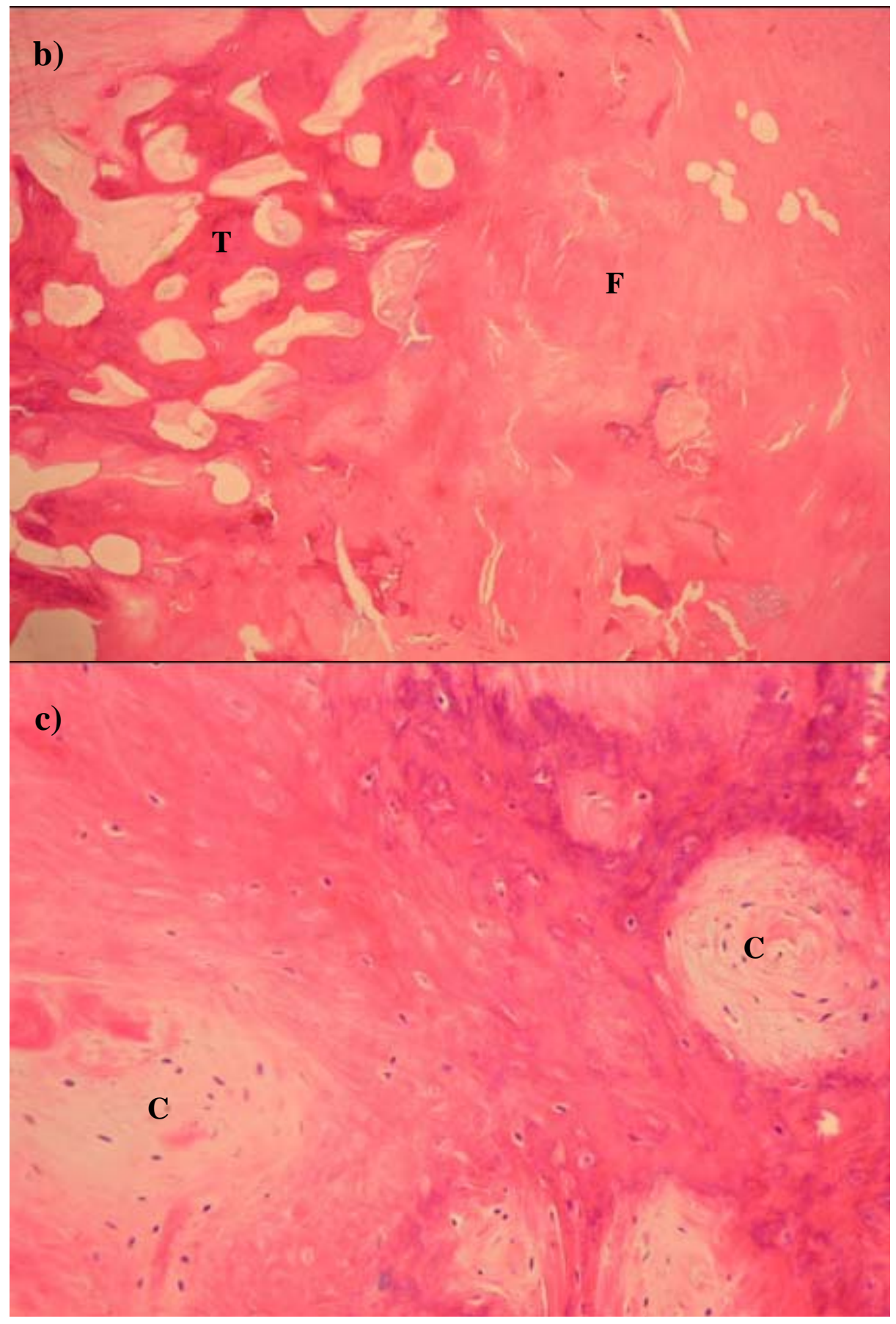


Histopathology: Histologic analysis of bone fragments revealed that the mandibular fracture plane contained regions of necrotic and woven bone (Figure 2.11). These were considered abnormal and indicative of bone healing and potentially an antemortem disease process. Histologic analysis of the bone fragments from the fractured vomer and cranium revealed no evidence of immune response. Gross evidence of hemorrhage in the soft tissue overlying these fractures would allow them to be conservatively classified as perimortem trauma.

Diagnosis: The ultimate cause of death was fracture of the skull involving the brain case resulting from a vessel-whale collision. The blunt force was sufficient to create a fissure along the caudal aspect of the skull, breaking it into two pieces. Histologic evidence indicates that this lethal strike may have been preceded either by an earlier, nonfatal strike that fractured the right mandible or a perimortem mandibular fracture of a section of the jawbone weakened by pre-existing disease.

\subsection{DISCUSSION}

These four cases present evidence of traumatic and ultimately lethal encounters between vessels and whales. The types of tissue damage identified during necropsy can be evaluated and categorized using the diagnostic characteristics of sharp and blunt trauma, thus creating an effective field standard to which future necropsy cases can be compared. Findings that are important to the discussion include the categorization of 
sharp trauma wounds seen in whales and the timing of skeletal fractures as compared to the time of death of the animal. Accepted criteria used for diagnosing sharp and blunt trauma will now be applied to evaluate the post-mortem findings in these cases (DiMaio and DiMaio, 2001, Lightsey, et al., 2006, Ortner, 2003).

\subsubsection{Timing of trauma}

It is important, albeit challenging, to distinguish between pre- and post-mortem trauma. The characteristics of ante-mortem, perimortem and post-mortem trauma were considered when analyzing a carcass and interpreting findings (Burke, et al., 1998, DiMaio and DiMaio, 2001, Galloway, et al., 1999, Kibayashi, et al., 1993). For this analysis an ante-mortem lesion is taken as one that occurs more than 6 hours prior to death, thus allowing sufficient time for the initiation of tissue response. For example, acute hematoma and coagulation at a fracture site occurs within 6-8 hours of the injury and is followed by inflammatory cell localization and differentiation (Aufderheide and Rodriguez-Martin, 1998). These changes are detectable upon gross or histologic examination of fresh samples; however, they may become less evident as tissue quality declines.

Perimortem lesions are those occurring near the time of death, be it just prior to or immediately following death (Aufderheide and Rodriguez-Martin, 1998). Post-mortem lesions occur after the death of the animal and generally lack evidence of tissue reaction, particularly with increased time between death and injury. Distinguishing between antemortem and post-mortem processes is not always a simple task (DiMaio and DiMaio, 
2001, Galloway, et al., 1999, Ortner, 2003). Cases lacking definitive evidence of antemortem or post-mortem injury are conservatively classified as perimortem. Table 2 contains characteristics and examples of relevant ante-mortem, perimortem and postmortem bone pathology (Galloway, et al., 1999, Lowell, 1997). Carcasses displaying evidence of perimortem bone fracture co-occurring with extensive sub-dermal edema and hemorrhage are believed to result from blunt trauma attributed to vessel-whale collisions.

It is particularly difficult to distinguish between perimortem and post-mortem fractures without necropsy records detailing the direct examination of accompanying soft tissue (Ortner, 2003). Histologic examination revealing inflammatory response is sufficient to determine that the wounds occurred prior to death (Kibayashi, et al., 1993).

\subsubsection{Sharp trauma}

The three categories of sharp trauma are stab wounds, incised wounds, and chop wounds. Stab wounds, once common in the whaling era, are now rarely found, given the ban on harvesting right whales. A recent source of stab wounds is the implantable tag, a subdermal transmitter used by researchers to track whales. None of the four animals examined had been tagged (New England Aquarium, 1986-2005).

Incised wounds occur when a body comes into contact with a sharp-edged object. These wounds have characteristically smooth, straight edges and the length of the wound is generally much greater than its depth (DiMaio and DiMaio, 2001). There are no abrasions or contusions associated with incised wounds and the tissue is cut clean through to the base of the wound (Ongley and Wright, 1990). The length and depth of an 
incised wound provide no clues as to what type of object created it (DiMaio and DiMaio, 2001).

Chop wounds are seen when a relatively heavy object, with a cutting edge, contacts soft tissue and often the underlying bone (Ongley and Wright, 1990). These wounds are typically incised, but they may also have some characteristics of a laceration, a blunt trauma injury defined below. As with incised wounds, the depth of the wound may vary, presenting as relatively superficial at the margins and deepening toward the center of the wound. Unlike incisions, the morphology of a chop wound may provide significant clues as to the object that created it (DiMaio and DiMaio, 2001). When boat propellers contact soft tissue they create a chop wound in the form of a series of more or less parallel, curved, evenly spaced s-shaped, or z-shaped gashes that are often deeper in the center than at the margins (DiMaio and DiMaio, 2001, Lightsey, et al., 2006). The angle to the line of travel, shape, spacing, depth, and length of cuts provide evidence of the rotation and approximate diameter and pitch of the screw, although the number of blades has to be assumed. Propeller trauma is usually acute and ranges in severity from mild, superficial epidermal wounds to more severe damage to the underlying blubber, muscle, viscera, and bone, and even complete dismemberment (Knowlton and Kraus, 2001, Kraus, 1990, Moore, et al., 2005). Histologic analysis of tissue sampled from the wounds may provide evidence of hemorrhage and or repair, a definitive feature of ante-mortem trauma. 
Table 2.2: Definition and appearance of ante-mortem, perimortem \& post-mortem bone pathology of a traumatic origin.

\begin{tabular}{|c|c|c|c|}
\hline Timing of pathology & Ante-mortem & Perimortem & Post-mortem \\
\hline Examples & $\begin{array}{l}\text { Healed or healing fractures } \\
\text { Osteoarthritis } \\
\text { Pitting } \\
\text { Accretion }\end{array}$ & $\begin{array}{l}\text { Unhealed fractures noticed } \\
\text { during necropsy. }\end{array}$ & $\begin{array}{l}\text { Unhealed fractures due } \\
\text { to post-mortem vessel } \\
\text { strike, surf trauma, } \\
\text { machinery during } \\
\text { necropsy, damage in } \\
\text { storage. }\end{array}$ \\
\hline Characteristics & $\begin{array}{l}\text { Abnormal density or } \\
\text { morphology, possible } \\
\text { asymmetry when } \\
\text { comparing paired bones. } \\
\text { Organizing and organized } \\
\text { hematoma. }\end{array}$ & $\begin{array}{l}\text { Obvious lack of complete } \\
\text { healing. Often } \\
\text { accompanied by soft tissue } \\
\text { edema and hemorrhage. } \\
\text { Unorganized coagulation. }\end{array}$ & $\begin{array}{l}\text { Specific detail in } \\
\text { necropsy report that no } \\
\text { fractures were evident } \\
\text { in bones examined. }\end{array}$ \\
\hline Fracture margins & $\begin{array}{l}\text { Potential osteoblast repair } \\
\text { (smoothing or rounding at } \\
\text { margin) with some post- } \\
\text { fracture survival. }\end{array}$ & Irregular margins. & $\begin{array}{l}\text { Jagged, linear or } \\
\text { squared edges, and } \\
\text { splintering particularly } \\
\text { seen when dry bone is } \\
\text { broken. }\end{array}$ \\
\hline Signs of healing & Variable depending on & Absent. & Absent. \\
\hline
\end{tabular}




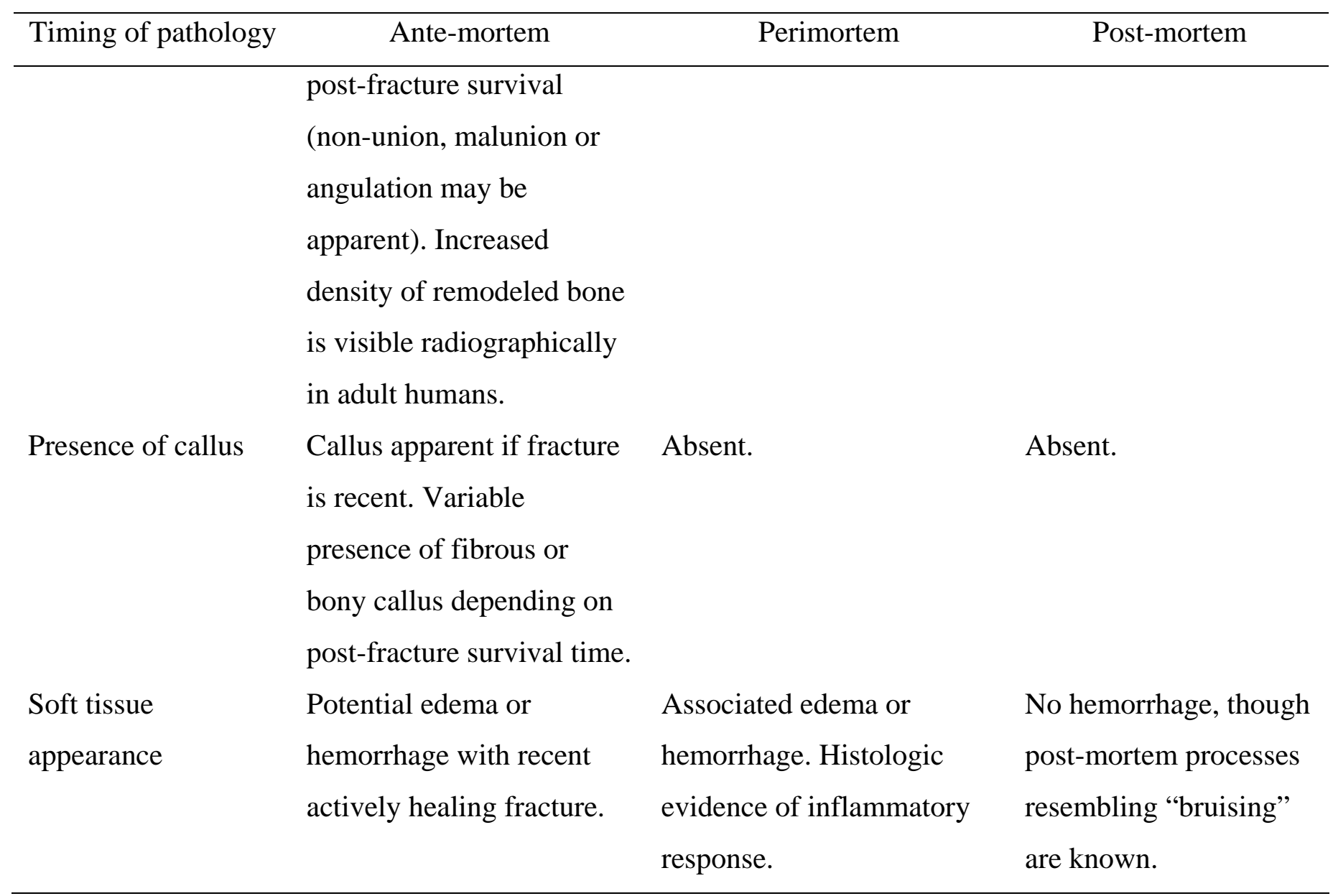


Wounds or scars from propeller trauma have been documented in both dead and living right whales (Hamilton, et al., 1998, Knowlton, 1997, Knowlton and Kraus, 2001, Moore, et al., 2005, New England Aquarium, 1986-2005). Fifteen of the seventy one (21.1\%) right whale mortalities since 1970 displayed wounds consistent with propeller trauma (Moore, et al., 2005, New England Aquarium, 1986-2005). As diagnostic necropsy is presently the only method permitting other causes of mortality to be ruled out, a more conservative estimate would eliminate mortality cases that were not necropsied, despite the presence of "propeller gashes.” Thus of the 40 necropsied carcasses, 11 (27.5\%) were fatalities resulting from sharp trauma (Knowlton, 1997, Moore, et al., 2005, New England Aquarium, 1986-2005). Studies of live animals shed further light on the prevalence of non-fatal propeller trauma in the species.

Two separate photographic studies of right whale epidermal scarring indicate that approximately 7\% of the whales examined have scars from vessel propellers (Hamilton, et al., 1998, Kraus, 1990). Animals that have survived even massive sharp trauma have been documented. The most recent documented case of sharp trauma involved an adult right whale (Eg \#2425) hit by the propeller of a 43 foot yacht traveling at 20 knots in March 2005 (Zani, M. 2005. Personal Communication). The propeller struck the submerged whale resulting in a series of propeller incisions and the incomplete severance of half of the animal's left fluke (Figure 2.1.a). It is important to note that the margins of the deepest wound are irregular and would be classified as a laceration (defined below), much like the distal margin of the wound seen in Eg \#1909. Eg \#2425 was sighted alive 
but in very poor condition in August 2005. While the fate of this animal remains unclear, other propeller strikes, such as RKB 1424 (Figure 2.1.b), have proven immediately fatal.

The first case study animal (Eg \#2143) initially survived particularly severe and invasive propeller wounds, only to succumb nearly fourteen years later to complications stemming from those injuries during the stress of pregnancy. The presence of neutrophils within the supporting stroma confirmed that these injuries were ante-mortem in nature (Figure 2.3). This leads to the consideration of sepsis secondary to bacteremia associated with the open caudal propeller scar (concomitant with increased abdominal pressure resulting from pregnancy) as the cause of death of the animal.

The second case, Eg \#1909, represents a more common outcome of severe propeller trauma. The animal had extensive tissue damage and the laceration of major vessels leading to impaired locomotor function and rapid exsanguination. These injuries, combined with the post-necropsy Naval report of a whale strike and a second report of a whale seen in the vicinity of the strike, bleeding from its tail, and missing a fluke lobe, leave little doubt that the trauma resulted from contact with a vessel.

The laceration of the entire left fluke blade and a portion of the proximal right fluke blade may have resulted in the loss of direct evidence of propeller trauma. Though the precise mechanism of vessel-whale collision trauma is unclear in this case it is important that prosectors are aware of the concrete anecdotal link between a vessel collision and this suite of severe trauma. As such, future cases displaying a similar cryptic laceration without anecdotal evidence may be interpreted in light of the precedent set by this case and conservatively classified as a "possible ship strike”. 
A few notable individuals have survived the acute effects of massive fluke damage involving mostly connective tissue and peripheral blood supply (Figure 2.1.a). Composed mostly of connective tissue and a countercurrent blood vessel supply, damage to small peripheral vessels and distal fluke tissue may not be as lethal as trauma to the proximal flukes and peduncle with involvement of large bore vessels that leads to rapid loss of blood volume.

Thus it seems that the severity of the trauma (depth, length, and surface area involved) as well as the anatomical location of the wound, are important in determining the immediate lethality of sharp trauma injury, while chronic sequelae from infection, improper healing, or reduced function, may prove lethal in a far less predictable manner.

\subsubsection{Blunt trauma}

Injuries that occur in response to a mechanical stress being applied to a body are known as blunt force trauma. To cause a blunt force injury, stress applied to the tissue must be great enough to deform the elastic or visco-elastic tissue beyond its ability to recover or maintain integrity (Fierro and Ongley, 1990, Galloway, 1999). This can occur in situations where: 1 ) the magnitude of the applied stress is greater than the ultimate strength of the tissue; 2) the stress is imparted in an unnatural direction, loading the tissue in a direction with weaker material properties; or 3) the stress is applied to mechanicallyinferior pathological tissue.

The severity of the injury is dependent upon many factors including the magnitude of the force, the area across which it is applied, the angle of contact, tissue 
elasticity and plasticity, and the contact time, which together influence the amount of energy transferred to the animal (DiMaio and DiMaio, 2001, Fierro and Ongley, 1990, Galloway, 1999). A first order estimate of the ultimate strength ( $\left.\sigma_{\text {ult }}\right)$ can be found using the equation

$$
\sigma_{\text {ult }}=\mathrm{F} / \mathrm{A}_{\mathrm{i} .}
$$

where $\mathrm{F}$ is the load at failure and $\mathrm{A}_{\mathrm{i}}$ is the initial cross-sectional area of the tissue. Thus even a relatively small force applied over a very small area can result in severe injury.

In general, blunt force injuries are classified into four categories: 1) abrasions, 2) lacerations, 3) contusions, and 4) skeletal fractures (DiMaio and DiMaio, 2001, Fierro and Ongley, 1990). Abrasions are produced as a result of friction leading to scraping or scuffing of the epidermis. Lacerations are tears or fissures in the tissue due to shear stresses and stretching forces across a tissue plane. Lacerations are more likely to occur in tissue superficial to bone than in tissue overlying additional soft tissue layers. Typically, lacerations have irregular margins and tissue bridging - when select intact remnants of more resilient tissue (e.g. vessels and nerves) traverse the wound (DiMaio and DiMaio, 2001, Ongley and Wright, 1990).

Contusions are bruises or areas of soft tissue hemorrhage. They result when an applied stress causes blood vessels to rupture, releasing blood into surrounding tissues. Hematoma can follow tissue hemorrhage. Skeletal fractures occur when bones break in response to mechanical stress. In large whales hit by vessels it is common to find fractures in the mandibles, cranium, rostrum, or vomer, disarticulated vertebrae, and tympanic bullae (De Guise and St. Aubin, 1999, New England Aquarium, 1986-2005). 
Anecdotal and forensic evidence of blunt trauma have been established in both dead and living right whales (Knowlton, 1997, Knowlton and Kraus, 2001, Laist, et al., 2001, New England Aquarium, 1986-2005). The number of fatal versus non-fatal vesselwhale collisions that occur each year is unknown. Unlike vessel collisions involving sharp trauma from propeller damage, non-fatal interactions between a whale and the hull of a vessel leave little immediate or lasting external evidence.

As diagnostic necropsy is presently the only reliable method that both exposes externally obscure sub-dermal evidence of blunt trauma and permits other causes of mortality to be investigated, a conservative estimate would consider only those animals which were thoroughly necropsied. Thus of the 40 necropsied carcasses, 9 (22.5\%) were fatalities resulting from blunt trauma (Knowlton, 1997, Moore, et al., 2005, New England Aquarium, 1986-2005) ${ }^{1}$.

The necropsy findings from Eg \#1004 revealed extensive hemorrhage and edema which suggests widespread contact with an object before death (Figure 2.7). The laceration to the oral rete occurred prior to death as evidenced by the blood-spray pattern on the lingual surface of baleen and roof of the mouth. This would not have been apparent if it was indeed a post-mortem injury. Histologic analysis of the broken rostrum revealed irregular bone margins and no signs of healing in the form of woven bone. Both of these findings are consistent with a perimortem fracture induced by blunt trauma.

\footnotetext{
${ }^{1}$ One additional case could not be classified as sharp or blunt trauma. The animal was struck by a vessel and was seen swimming away with a large portion of its tail torn away. The mechanism of trauma was not apparent following necropsy.
} 
In the case of Eg \#2150, the substantial black tarry substance found in the thoracic cavity provided evidence of massive trauma and blood loss into this region. Similarly, the hemorrhage found overlying the fractured left vomer, around disarticulated ribs and in soft tissue surrounding the fractured mandible also implicated a perimortem vessel-whale collision event. However, histologic analysis of the fracture plane of the right mandible revealed the presence of necrotic and woven bone, as well as cartilaginous tissue, indicative of a healing process occurring at least several days prior to death. Gross examination and computed tomography revealed an area of pitted bone flanking both sides of the fracture plane and extending a total length of approximately $45 \mathrm{~mm}$.

There are two possible interpretations of these findings. Either 1) The woven bone may be taken as a sign that the animal survived for a period of days to weeks following an initial vessel-whale collision event from which the animal was recovering (jaw fracture). This would lead to the conclusion that Eg \#2150 may have ultimately expired from a second collision that resulted in the massive skull fracture involving the brain case; or 2) Healing indicated by the presence of woven bone may have preceded the fracture, where bone disease in the right mandible may have predisposed the area to fracture when the animal was hit by a single vessel, resulting in all of the perimortem fractures and bruising found upon necropsy. While neither interpretation is exceptionally parsimonious, both implicate a vessel-whale collision event as the underlying cause of mortality. Further analysis of the pathological region of bone surrounding the fracture plane may improve diagnostic conclusions. 


\subsection{CONCLUSIONS}

The documentation of the number of deaths and sources of mortality in the highly endangered right whale population is an obvious goal of right whale biologists and species managers. The characterization of deaths resulting from human interactions, including vessel-whale collision events and entanglement in fishing gear, provides valuable statistics to those agencies responsible for the protection of right whales. The direct classification of wounds and the identification of indicators of disease process or human interaction are essential for future necropsies, accurate diagnoses, and precise mortality statistics.

Here, four carcasses were examined and classified by comparing the type of tissue damage identified during necropsy to the diagnostic characteristics of sharp and blunt trauma. These cases present evidence of traumatic and ultimately lethal encounters between vessels and whales. This study does not include all of the right whales that died or were necropsied during this time, however, in their thoroughness and rigor these cases are representative of necropsy results reported over the past decade (Moore, et al., 2005).

A critical assessment of these cases proves that diagnostic necropsy remains the key to determining the cause of death. This is particularly important in cases of whales sustaining blunt force injuries, as external evidence of internal trauma is generally obscured. It is also essential to document injuries seen during necropsy of animals anecdotally tied to ship strike (as in the case of Eg \#1909). Here gross findings lacking an identifiable source of trauma were linked to vessel-whale collisions and as such may serve as precedent for comparison to future cases lacking anecdotal evidence of a vessel- 
whale collision event. The classification of these cases provides an effective field standard to which future necropsy cases can be compared for the appropriate characterization of traumatic injury suites typically encountered during right whale necropsy.

As more than half (52.5\%) of the 40 right whales necropsied to date display evidence of vessel-whale collision trauma, and additional right whales that were not necropsied showed signs of serious injury and scarring from encounters with vessels, reducing the occurrence or lethality of vessel-whale collisions was identified as a key component in the management plan by NOAA Fisheries (Hamilton, et al., 1998, Knowlton and Kraus, 2001, NOAA, 2004). Along this vein efforts to mitigate vesselwhale collisions by implementing coastal speed restrictions and routing changes in right whale critical habitat and migratory corridors in the U.S. are being considered (Balsiger, 2006, Russell, 2005). Past efforts, including the re-routing of shipping channels to avoid right whale feeding grounds between New Brunswick and Nova Scotia and two Mandatory Ship Reporting Systems are presently being evaluated for efficacy.

Furthermore, studies relying on samples obtained during necropsy are vital to ongoing research regarding vessel-whale interactions. For example, the extraction of the tympanic bullae and subsequent computed tomography imaging has provided insight into the auditory range and ability of right whales to detect vessel noise (Parks, 2003). Additionally, necropsy records indicate that the right whale mandible has been fractured in one-third of the cases displaying evidence of blunt trauma due to vessel collisions, yet healed mandibular fractures have never before been seen in right whale skeletal remains 
(Right Whale Consortium, 2005). As such mandibular fracture represents an appropriate fatal endpoint for vessel-whale collision modeling. Material property analyses of mandibular bone and soft tissue overlying the right whale mandible will be used to model the stresses capable of fracturing right whale bone (Campbell-Malone, et al., 2006). When combined with potential stresses presented by vessels traveling at a given speed, speed restrictions may be evaluated as a means of reducing vessel-whale collision fatality. The aforementioned studies, along with data obtained from future necropsies and the appropriate characterization of trauma findings will continue to inform ongoing efforts to reduce vessel-whale collision mortality. 


\subsection{ACKNOWLEDGEMENTS}

The authors would especially like to thank Blair Mase Guthrie and Dana Hartley (both of NOAA/NMFS), Andrea Bogomolni (WHOI), Denise Boyd and Jamison Smith (FFWCC), Tod Leighfield and Gretchen Lovewell (NOAA), D. Ann Pabst (UNCW), Mark Swingle (VAMSC), David Taylor, NEAq SEUS survey team, VAMSC Stranding Response Team, Katie Moore (USCG), Department of Fisheries and Oceans Canada, the many volunteers that necropsy efforts somehow manage to attract, and to the many institutions and individuals that contribute sighting records to the North Atlantic Right Whale Consortium.

This report was prepared by the authors indicated under award numbers NA04NMF4720402 (Campbell-Malone/Moore) and NA04NMF4720392 (Moore/McLellan) from the National Oceanic and Atmospheric Administration (NOAA), U.S. Department of Commerce (U.S. DOC) and a National Science Foundation (NSF) Graduate Research Fellowship (Campbell-Malone). The statements, findings, conclusions and recommendations are those of the authors and do not necessarily reflect the views of the NOAA, U.S. DOC or the NSF. 
This chapter was accepted for publication in the Journal of Zoo and Wildlife Medicine as a co-authored manuscript. Co-authors and their affiliations are as follows:

Regina Campbell-Malone, Woods Hole Oceanographic Institution, MS\#50, Woods Hole, MA 02543 USA.

Susan G. Barco, Virginia Aquarium \& Marine Science Center, Virginia Beach, Virginia 23451, USA.

Pierre-Yves Daoust, University of Prince Edward Island, 550 University Avenue, Charlottetown, PEI, C1A 4P3 Canada.

Amy R. Knowlton, New England Aquarium, Boston, Massachusetts 02110, USA.

William A. McLellan, University of North Carolina Wilmington, Wilmington, North Carolina 28403, USA.

David S. Rotstein, University of Tennessee, Knoxville, Tennessee 37996, USA.

Michael J. Moore, Woods Hole Oceanographic Institution, MS\#50, Woods Hole, MA 02543 USA 


\subsection{LITERATURE CITED}

Aufderheide, A. C. and C. Rodriguez-Martin, 1998. The Cambridge Encyclopedia of Human Paleopathology. Cambridge University Press. Cambridge, Massachusetts.

Balsiger, J. W., 2006. Federal Register 50 CFR Part 224: Proposed Rule to Implement Speed Restrictions to Reduce the Threat of Ship Collisions with North Atlantic Right Whales. NOAA/NMFS. [Docket No. 040506143-6016-02. I.D.101205B] RIN 0648-AS36. 71, 122, 15 pages. http://www.nmfs.noaa.gov/pr/pdfs/fr/fr7136299.pdf

Burke, M. P., A. K. Olumbe and K. Opeskin, 1998. Postmortem extravasation of blood potentially simulating antemortem bruising. American Journal Of Forensic Medicine and Pathology 19 (1), pp. 46-49.

Campbell-Malone, R., J. Arruda, J. A. Muller, I. Tsukrov, D. R. Ketten and M. J. Moore, 2006. Achilles’ Jaw: Morphology and Mechanical Properties of the Right Whale Mandible as a Model Bone for Ship Strike Mortality. American Society of Mammalogists 86th Annual Meeting, Amherst, Massachusetts.

Caswell, H., M. Fujiwara and S. Brault, 1999. Declining survival probability threatens the North Atlantic right whale. Proceedings of the National Academy of Sciences 96, pp. 3308-3313.

De Guise, S. and D. St. Aubin, 1999. A non-union chronic fracture in a North Atlantic right whale: the importance of histopathology. 13th Biennial Conference of the Biology of Marine Mammals, Maui, Hawaii.

Department of Fisheries and Oceans, 2000. A Canadian Recovery Plan for the North Atlantic Right Whale. Prepared by the World Wildlife Fund for the Department of Fisheries and Oceans. Dartmouth, Nova Scotia, Canada. 104 pages.

DiMaio, V. J. M. and D. J. DiMaio, 2001. Forensic Pathology. CRC Press. New York.

Fierro, M. F. and J. P. Ongley, 1990. Chapter 21: Blunt Force Injuries. In: Froede, R. C., Ed. Handbook of Forensic Pathology. College of American Pathologists. Northfield, Illinois. pp. 171-180.

Fujiwara, M. and H. Caswell, 2001. Demography of the endangered North Atlantic right whale. Nature 414, pp. 537-541.

Galloway, A., 1999. Chapter 2: The Biomechanics of Fracture Production. In: Galloway, A., Ed. Broken Bones: Anthropological Analysis of Blunt Force Trauma. Charles C Thomas. Springfield, Illinois. pp. 35-62.

Galloway, A., S. A. Symes, W. D. Haglund and D. L. France, 1999. Chapter 1: The Role of Forensic Anthropology in Trauma Analysis. In: Galloway, A., Ed. Broken Bones: Anthropological Analysis of Blunt Force Trauma. Charles C Thomas. Springfield, Illinois. pp. 5-31.

Geraci, J. R. and V. J. Lounsbury, 1993. Marine Mammals Ashore: a field guide for strandings. Sea Grant College Program Texas A\&M University. Galveston, Texas.

Hamilton, P. K., M. K. Marx and S. D. Kraus, 1998. Scarification Analysis of North Atlantic Right Whales (Eubalaena glacialis) as a Method of Assessing Human Impacts. New England Aquarium. Boston, Massachusetts. 
International Maritime Organization, 2002. Routing of ships, ship reporting and related matters; amendment of the traffic separation scheme in the Bay of Fundy and approaches. Submitted to the International Maritime Organization by Canada. 9 pages.

Kibayashi, K., K. Hamada, K. Honjyo and S. Tsunenari, 1993. Differentiation between bruises and putrefactive discolorations of the skin by immunological analysis of glycophorin A. Forensic Science International 61, pp. 111-117.

Knowlton, A. R., 1997. The Regulation of Shipping to Protect North Atlantic Right Whales: Need and Feasibility. Master of Marine Affairs. University of Rhode Island. Kingston, Rhode Island. 188 pages.

Knowlton, A. R. and S. D. Kraus, 2001. Mortality and serious injury of northern right whales (Eubalaena glacialis) in the western North Atlantic Ocean. Journal of Cetacean Research and Management Special Issue 2, pp. 193-208.

Kraus, S. D., 1990. Rates and potential causes of mortality in North Atlantic right whales (Eubalaena glacialis). Marine Mammal Science 6 (4), pp. 278-291.

Kraus, S. D., M. W. Brown, H. Caswell, C. W. Clark, M. Fujiwara, P. K. Hamilton, R. D. Kenney, A. R. Knowlton, S. Landry, C. A. Mayo, W. A. McLellan, M. J. Moore, D. P. Nowacek, D. A. Pabst, A. J. Read and R. M. Rolland, 2005. North Atlantic Right Whales in Crisis. Science 309 (5734), pp. 561-562.

Laist, D. W., A. R. Knowlton, J. G. Mead, A. S. Collet and M. Podesta, 2001. Collisions between ships and whales. Marine Mammal Science 17 (1), pp. 35-75.

Lightsey, J. D., S. A. Rommel, A. M. Costidis and T. D. Pitchford, 2006. Methods used during gross necropsy to determine watercraft-related mortality in the Florida manatee (Trichechus manatus latirostris). Journal of Zoo and Wildlife Medicine 37 (3), pp. 262-275.

Lowell, N. C., 1997. Trauma Analysis in Paleopathology. Yearbook of Physical Anthropology 40, pp. 139-170.

McLellan, W. A., S. Rommel, M. J. Moore and D. A. Pabst, 2004. Right Whale Necropsy Protocol. Final Report to NOAA Fisheries for contract \# 40AANF112525. U.S. Department of Commerce, National Oceanic and Atmospheric Administration, National Marine Fisheries Service, Office of Protected Resources. Silver Spring, Maryland. 51 pages.

Moore, M. J., A. R. Knowlton, S. D. Kraus, W. A. McLellan and R. K. Bonde, 2005. Morphometry, gross morphology and available histopathology in North Atlantic right whale (Eubalaena glacialis) mortalities (1970 to 2002). Journal of Cetacean Research and Management 6 (3), pp. 199-214.

National Marine Fisheries Service, 1991. Recovery Plan for the Northern Right Whale (Eubalaena glacialis). Prepared by the Right Whale Recovery Team for the National Marine Fisheries Service. Silver Spring, Maryland. 86 pages.

National Marine Fisheries Service. 2004. "NOAA Fisheries Releases Recovery Plan For Endangered North Atlantic Right Whales." August 31, 2004. Retrieved Feb 8, 2004, from http://www.nero.noaa.gov/shipstrike/whatsnew/04080_north_atlantic_right_whale_recovery_plan.pdf. 
New England Aquarium, 1986-2005. Photo-identification, Sightings, Tagging history, Genetics, Contaminant Analyses and Necropsy reports. .

NOAA. 2004. "NOAA Fisheries Releases Recovery Plan For Endangered North Atlantic Right Whales." August 31, 2004. Retrieved Feb 8, 2004, from http://www.nero.noaa.gov/shipstrike/whatsnew/04080_north_atlantic_right_whale_recovery_plan.pdf.

Ongley, J. P. and R. K. Wright, 1990. Chapter 28: Cutting and Stabbing. In: Froede, R. C., Ed. Handbook of Forensic Pathology. College of American Pathologists. Northfield, Illinois. p. 344 pp.

Ortner, D. J., 2003. Identification of Pathological Conditions in Human Skeletal Remains. Academic Press. Boston, Massachusetts.

Parks, S. E., 2003. Acoustic Communication in the North Atlantic Right Whale (Eubalaena glacialis). Ph.D. Thesis. Massachusetts Institute of Technology. Cambridge, Massachusetts.

Right Whale Consortium, 2005. North Atlantic Right Whale Consortium Photo-ID, Sightings, Genetics, Contaminants and Necropsy Database. New England Aquarium, Boston, MA, USA.

Russell, B., 2005. Report on Nine Industry Stakeholder Meetings 30 September 2004 through 27 October 2004 in Support of Advanced Notice of Proposed Rulemaking (ANPR) on NOAA Fisheries' Strategy to "Reduce Mortalities to North Atlantic Right Whales (NARW) as a Result of Vessel Collisions." JS\&A Environmental Services. Chevy Chase, Maryland. 59 pages. 


\section{Chapter 3}

\section{Geometry, Internal Morphology and Densitometry of the}

\section{North Atlantic Right Whale (Eubalaena glacialis) Mandible*}

*This chapter is currently in prep as:

Campbell-Malone, R., Arruda, J., Ketten, D. R., Moore, M. J., 2007. Geometry, Internal Morphology and Densitometry of the North Atlantic Right Whale Mandible. 56 pages. 


\section{ABSTRACT}

Fractures of the mandible are common blunt trauma injuries seen in North Atlantic right whales (Eubalaena glacialis) that are involved in fatal vessel-whale collisions. With vessel-whale collisions responsible for at least 21 fatalities of the 40 right whales examined post-mortem between 1970 and December 2006, and fewer than 400 individuals remaining in the population the reduction of vessel-whale collision mortality is a primary goal of Canadian and American management agencies. As such, biomechanical studies are presently underway to determine the biomechanical response of the right whale mandible to applied stress as a model for a vessel-whale collision event. Toward that end, the present study examines the anatomy of the right whale mandible and the basic physical properties of right whale jawbone tissue.

Comparative morphometrics were used to determine that the straight length of the right whale mandible (standardized to body length) ranges from $0.2183-0.2796$, and as such falls within the range of values seen in other large whales. Computed tomography (CT) was used to determine the relative volume of internal mandibular structures including bone tissue $(95.6 \%)$, the mandibular canal (4.1\%) and void spaces $(0.07 \%)$. The apparent and mineral densities of the right whale mandible were determined using quantitative computed tomography (QCT) and physical measurements.

The average QCT apparent density ranged from 0.9489 - $1.1694 \mathrm{~g} / \mathrm{cc}$ for trabecular bone. A statistically significant longitudinal density gradient (increasing rostrally) was detected using ANOVA $(\alpha=0.05, \mathrm{p}<0.001)$. The average QCT apparent density for cortical bone ranged from $1.3500-1.5939 \mathrm{~g} / \mathrm{cc}$ and had a similar pattern of 
increasing density from the caudal apex toward the rostral apex. Average QCT mineral density also increased rostrally ranging from $98.90-230.10 \mathrm{mg} / \mathrm{cc}$ (trabecular) and $492.23-865.32 \mathrm{mg} / \mathrm{cc}$ (cortical).

Physical measurements were recorded for the average apparent density for trabecular $(0.4258 \mathrm{~g} / \mathrm{cc} \pm 0.0970)$ and cortical bone $(1.2370 \mathrm{~g} / \mathrm{cc} \pm 0.0535)$. These measurements were comparable to QCT measurements of apparent density only at high densities due to the effect of porosity on the apparent density of low density bone. Methods of standardizing QCT measurements of density are presented which should decrease the percent difference between QCT and physical measurements of apparent density.

The determination of the internal structure and bone density variation using QCT reconstruction is the first step toward a finite element model of a right whale mandible capable of responding to applied load simulating a vessel-whale collision event. The novel data reported here serve as the foundation of a collaborative project aimed at evaluating speed restrictions for various vessel classes as a mechanism of reducing vessel-whale collision mortality in this highly endangered species. 


\subsection{INTRODUCTION}

The North Atlantic right whale, Eubalaena glacialis, is a highly endangered baleen whale that is subjected to high anthropogenic mortality from vessel-whale collisions (Knowlton and Kraus, 2001, Kraus, et al., 2005, Moore, et al., 2005). Over half $(52.5 \%)$ of the 40 North Atlantic right whales examined post mortem between 1970 and December 2006 were hit and ultimately succumbed to traumatic injuries resulting from vessel-whale collisions (Campbell-Malone, et al., 2007, Moore, et al., 2005, Right Whale Consortium, 2007). Of the animals killed by vessels, 11 deaths resulted from sharp trauma injuries while 9 deaths resulted from blunt trauma injuries. ${ }^{1}$

Evidence of blunt trauma includes hemorrhage and broken or disarticulated bones in which the fracture margins are consistent with perimortem trauma (Campbell-Malone, et al., 2007). Fractures of the mandible, skull, and vertebrae are common injuries in blunt trauma cases. The vessel mass, vessel speed and applied stresses sufficient to produce the injuries seen in blunt trauma cases have been the subject of prior study but remain unclear (Laist, et al., 2001, Vanderlaan and Taggart, 2007).

The physical and material properties of many structural elements of the right whale (i.e. bone, muscle, blubber and the animal as a whole) have not been the subject of prior biomechanical studies, leaving the biology and biomechanical response of the animal out of prior predictive vessel-whale collision models. In contrast to the skull,

\footnotetext{
${ }^{1}$ One additional case was classified as neither sharp nor blunt trauma. The animal was struck by a vessel and was seen swimming away with a large portion of its tail torn away. The mechanism of trauma was not apparent following necropsy. Though lacerations or tearing of tissue are considered blunt trauma, it was thought more appropriate to classify this vessel-whale collision event as 'unknown' to avoid any implications regarding how the trauma was produced.
} 
which is comprised of many bones, each half of the mandible represents the largest single bone in a right whale. It measures approximately $25 \%$ of the length of the body and as such is a large target of concern for approaching vessels, especially given its craniolateral location in an air-breathing marine animal that often presents its head first when surfacing (Kraus and Rolland, 2007). Given that fractures of the jawbone have been observed in at least 3 of the 9 cases (33.3\%) which were definitively classified as blunt trauma mortalities, the present study was conducted to determine the external morphology, internal structure and physical properties of the right whale jaw bone, that has a 'beam-like geometry' which lends itself well to modeling. Specifically, the gross morphometry, volume, mineral density, apparent density, and internal structure are examined.

Once defined, these parameters can be incorporated into a finite element (FE) model to predict the biomechanical response of skeletal elements as well as the likelihood and location of fractures resulting from applied stress (Raymond, 2007). The findings of this study combined with biomechanical testing and modeling exercises will provide the first predictions regarding the biomechanical effects of decreased vessel speed on the outcome of a vessel-whale collision involving blunt trauma.

\subsubsection{Gross description}

Like the jaws of ruminants, carnivores, and other whale species, the lower jaw of the North Atlantic right whale is composed of two halves that meet at the mandibular symphysis, a fibrous joint around which the bone can rotate slightly (Lambertsen, et al., 
2005, Miller, et al., 1964, Philo, et al., 1990). The mandible is enclosed in relatively thin soft tissue composed of multiple layers including skin, fibroelastic connective tissue, and a layer of muscle papillae that extends to the basal muscle layer which is immediately superficial to the fibrous sheath surrounding the bone.

For the purposes of this paper the right and left halves of the mandible will simply be referred to as the right and left mandible. Each half of the mandible is composed of a horizontal bowed segment, known as the corpus mandibulae, and a rounded caudal end, the ramus, which articulates at the temporomandibular joint (Miller, et al., 1964). The ramus of the right whale has a low vertical profile, lacking the characteristic "L-shape" of the articular process in a typical mammalian jaw (Miller, et al., 1964). The right whale ramus instead resembles the "ball" of a ball and socket joint (Figure 3.1).

The mandible of this baleen whale contains neither teeth nor tooth sockets. Externally visible features include several foramina which allow blood vessels and nerves to enter and exit the mandible thereby vascularizing and innervating the facial tissue. The largest, the mandibular foramen, is located on the caudo-medial surface of each mandible. The smaller anterior mental foramen is located on the lateral face at the rostral end of each mandible. There are additional lesser mental foramina through which blood vessels and nerves exit between the mandibular foramen and the anterior mental foramen.

The mandibular foramen is the caudal opening of the mandibular canal, a mineralfree channel through which vessels and nerves travel to respectively vascularize and innervate the rostral facial tissue. The mandibular canal is structured such that the main body (the largest continuous lumen void of mineral) diverges approximately a dozen 
times, resulting in the formation of branches that exit individually through mental foramina.

Figure 3.1: Digital reconstruction of the right mandible of right whale Eg\# 1004. The lingual surface of the 3-D image is shown. The straight length (SL) was measured as the distance between the rostral apex of the mandible and the apex of the ramus. The external curved length was measured between the same two points, with the measuring tape in contact with the surface of the bone along the buccal midline. (Image adapted from J. DeCew, UNH, used with permission).

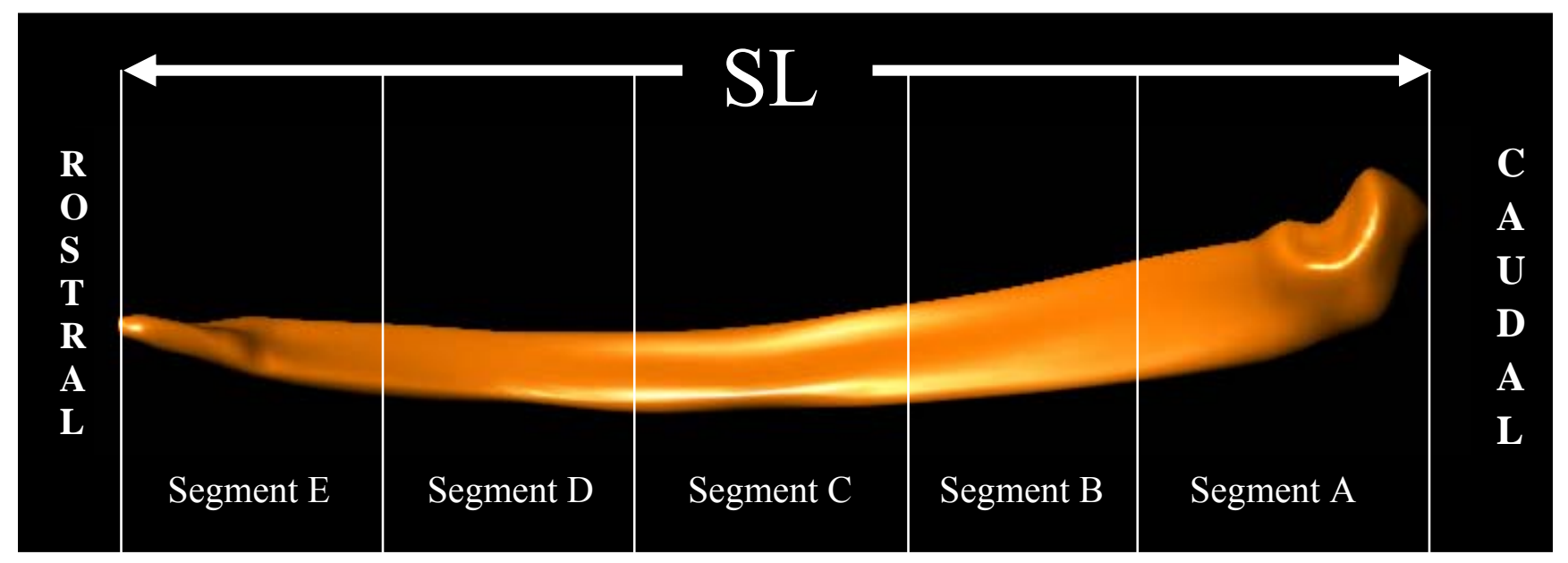

3.1.2 Mandibular bone tissue structure and physical properties

The mammalian mandible is composed of trabecular and cortical bone which vary distinctly in structure and distribution, but have the same basic components of typical mammalian bone tissue - an organic collagen matrix, the mineral dahllite (also referred to as carbonated apatite or calcium hydroxyapatite), and water (Weiner and Wagner, 1998).

Trabecular bone is organized into a lattice of bony struts called trabeculae which are filled with inter-trabecular fat, making it relatively low-density bone (Weiner and 
Wagner, 1998). Cortical bone, on the other hand, is a dense mineralized solid with relatively few pores and low fat or marrow content (Currey, 2002). Structural organization and density analyses permit the differentiation of cortical and trabecular bone. While these bone types are generally well-classified, the absolute distinction between highly dense trabecular bone and low density cortical bone is somewhat subjective (Huiskes and van Rietbergen, 2005). The density and distribution of each bone type throughout the entire mandible are important factors that will significantly affect the biomechanical response of the intact mandible to applied stress (Wang, et al., 1998).

One measure of density that is often correlated to the measured mechanical properties of bone is the apparent density of bone (Carter and Hayes, 1977, Keller, 1994). In the field of orthopaedic biomechanics, the apparent density of bone is equal to the mass of a defatted bone specimen divided by the volume of the same defatted bone specimen (Hayes and Bouxsein, 1997). ${ }^{2}$ The volume of the specimen is calculated from measurements of the geometric dimensions of a specimen (e.g. for a cubic specimen the volume would equal the specimen length multiplied by the specimen width and height) which thus includes the volume devoid of mineral as well.

Another measure of density that has been correlated to the mechanical properties of bone is the mineral density or mass of bone per unit volume of bone (Tabensky, et al., 1996). Several specifically defined standard terms related to mineral density are commonly used in the literature, including the "bone mineral density" (BMD) which is

\footnotetext{
2 There are various modifiers used with the term 'density' that define the actual parameters measured. These include tissue density, mineral density, and apparent dry density which are defined in the glossary. Some authors use the term 'density' without providing details necessary to specifically determine the measurement being reported. This practice should be avoided as it precludes the use of these data for comparative analysis.
} 
equal to the mineral mass "per unit length $(\mathrm{g} / \mathrm{cm})$, area $\left(\mathrm{g} / \mathrm{cm}^{2}\right)$ or volume $\left(\mathrm{g} / \mathrm{cm}^{3}\right)$ " of a bone sample (Tabensky, et al., 1996). This parameter is generally measured noninvasively using radiographic imaging techniques such as dual-energy X-ray absorptiometry (DXA) or quantitative computed tomography (QCT) (Guglielmini, et al., 2002, Tabensky, et al., 1996). Another standard measure found in the literature is the calcium content ${ }^{3}$ which can be measured colorimetrically to determine the mass of calcium per gram of dehydrated, defatted bone (Currey, 2004, Sarkar and Chauhan, 1967). Ash fraction (mass of ash per unit bone mass, also known as mineral content), or ash content (ash fraction multiplied by 100 and expressed as a percentage) are alternative measures of the mineral density per unit mass (Keller, 1994). Additionally, the apparent mineral (ash) density (g/cc), or mass of ash per unit volume quantification of mineral density, may be determined via ashing (Keller, 1994).

Each of these measures is slightly different and is thus only directly comparable to identical measures, though relative values and trends between datasets may be considered when appropriate. Mineral density was explored here using two techniques QCT and direct measurement of the apparent mineral (ash) density - so that comparisons could be made with values of mineral density from prior studies where appropriate.

Quantitative computed tomography (QCT) is an important tool used to determine the apparent density and mineral density of bone on a fine scale (QCT) and at the microscale $(\mu \mathrm{CT})$ (Lind, et al., 2003). The QCT and $\mu \mathrm{CT}$ scanners used are capable of accommodating samples up to 1 meter in length by $50 \mathrm{~cm}$ diameter and $8 \mathrm{~mm}$ in length

\footnotetext{
${ }^{3}$ As calcium is the primary mineral component in bone tissue, this measure is also referred to simply as the mineral content.
} 
by $36 \mathrm{~mm}$ in diameter respectively. Slice thickness may be as low as $0.1 \mathrm{~mm}(\mathrm{QCT})$ and 9 microns $(\mu \mathrm{CT})$ depending upon specimen dimensions and the scanning protocol used.

QCT is used to generate relative x-ray attenuation coefficients for bone tissue in a given specimen. This value is known as the CT number and is reported in Hounsfield units. ${ }^{4}$ These values are then compared to values obtained from CT scans of hydroxyapatite standards of known apparent and mineral densities. The comparison results in the calibration of the $\mathrm{CT}$ numbers (in Hounsfield units) to physical measurements of apparent and mineral densities. This permits the development of a fine scale density map detailing the internal density variation of a bone in a non-destructive manner (Ciarelli, et al., 1991, Hong, et al., 2004, Mull, 1984). Quantitative computed tomography was used here to explore the internal structure and density variation in the right whale jawbone for the first time.

The density of bone, as determined by QCT, is known as the QCT apparent density and can be used to estimate the value of Young's modulus of elasticity - an important material property of a given material. Young's modulus of elasticity, also known as Young's modulus, is experimentally determined as the slope of the linear elastic regime of a plot of stress vs. strain during compressive or tensile loading tests. Young's modulus offers a quantitative assessment of the "stiffness" of a material, such that materials characterized by a large modulus are resistant to changes in their original length, while those with a small modulus are more compliant.

\footnotetext{
${ }^{4}$ Hounsfield units are a normalized unit of measure assigned to a given pixel in a computed tomography reconstruction. The unit is based on the X-ray attenuation coefficient of the material occupying the physical space in the scanned specimen.
} 
Though it can be directly determined via mechanical testing (e.g. during uniaxial compression tests), Young's modulus can also be estimated for bone specimens without mechanical testing via regression equations derived from previous experimental QCT data. These regression equations are used to estimate the Young's modulus of a bone specimen based on its apparent density or mineral density.

The application of standard morphometric and computed tomography protocols to the right whale mandible will provide novel data that can be used to inform biomechanical models of fatal blunt trauma from vessel-whale collisions.

\subsection{MATERIALS AND METHODS}

\subsubsection{Sample collection and preservation}

Three pairs of mandibles were obtained from three adult female right whales necropsied between October 2003 and November 2004. Two of the three pairs (from Eg\# 1004 and Eg\# 1909) were frozen intact within days of the necropsy, with no appreciable loss of the internal oil and water that contribute to the bone's mass. The third pair (from Eg\# 2150) was frozen after appreciable loss of mass. ${ }^{5}$ While the quality of its gross structure was unaffected, the mandible from Eg\# 2150 was unsuitable for densitometry or mechanical testing.

\footnotetext{
${ }^{5}$ Following necropsy, the skeleton was stored outdoors without controlled temperature or humidity. A large slick of oil was visible when the bones were retrieved and the bones were noticeably lighter. The fractured right mandible was weighed and the two segments weighed $325 \mathrm{lbs}$ (70lbs and 225lbs respectively) compared to the fresh, intact right mandible of a mature female of comparable size (Eg\# 1004) which weighed $493.8 \mathrm{lbs}$ whole.
} 


\subsubsection{Morphometric measurements}

The straight length (SL) of the right whale mandible was measured as the maximum distance between the rostral apex of the mandible and the apex of the ramus with the tape held level above the surface of the bone (Figure 3.1). The external curved length of each mandible was measured as the length along the bone from the rostral apex to the apex of the ramus, such that the measuring tape rested on the surface of the bone along the buccal midline.

\subsubsection{Computed tomography (CT)}

A Siemens Somatom Volume Zoom computed tomography (CT) unit (www.siemensmedical.com, Munich, Germany) was used to scan the jawbone of Eg\# 1004 at the Computerized Scanning and Imaging Facility of the Woods Hole Oceanographic Institution (www.whoi.edu/csi).

CT scanning results in the production of a distribution map of a scanned object wherein each three-dimensional volume element, or voxel, is assigned a CT number on a Hounsfield unit (H.U.) scale (Jackson and Thomas, 2004). During image reconstruction, a CT number is assigned to a given picture element, or pixel, based on the average X-ray attenuation coefficient of its voxel of origin within the material (Jackson and Thomas, 2004). The calculation of Hounsfield units by the CT scanner and supporting software results in a standardized scale, normalized to water, such that Hounsfield units between scanners and between X-ray beam energy spectra are more comparable (Mull, 1984). Generally, the scale spans approximately 2000 Hounsfield units, with -1000 H.U. 
representing air, 0 H.U. representing water and +1000 H.U. roughly corresponding to compact bone (Jackson and Thomas, 2004). The scale used for this scanning protocol spanned over 5000 H.U., including a minimum possible value of -1023 H.U. (which corresponded to air) and a maximum possible value of 4096 H.U. Values measured for cortical bone averaged 772 H.U., though values upwards of 1800 H.U. were noted.

The right mandible of right whale Eg\# 1004 was cut into 5 segments, each approximately $90 \mathrm{~cm}$ in length, to accommodate length and weight limits of the medical scanner. Total volume, mandibular canal volume, void space volume, and total mineral volume were also determined using the image segmentation editor in Amira 3.1 software (Template Graphics Software, Inc. \& Mercury Computer Systems, San Diego, CA). Briefly, the region of interest was visually identified, selected, and assigned to a "material" (e.g. mandibular canal) in the image segmentation editor according to the specific volume definitions below. The tissue statistics module of Amira 3.1 was then used to compute the volume assigned to each "material."

Total volume $\left(\mathrm{V}_{\mathrm{t}}\right)$ was determined by measuring the volume within the periosteum or external surface of the bone. The volume of the main body of the mandibular canal $\left(\mathrm{V}_{\mathrm{m}}\right)$ was measured as the volume of the largest continuous lumen void of bone in cross-section. The volume of mandibular canal branches $\left(\mathrm{V}_{\mathrm{br}}\right)$ which permanently separate from the main body of the mandibular canal and open anteriorly via mental foramina were measured separately (Miller, et al., 1964). The volume of the entire mandibular canal $\left(\mathrm{V}_{\mathrm{c}}\right)$, including both the main body $\left(\mathrm{V}_{\mathrm{m}}\right)$ and the branches $\left(\mathrm{V}_{\mathrm{br}}\right)$ was calculated. The volume of void spaces $\left(\mathrm{V}_{\mathrm{v}}\right)$, or regions greater than $9 \mathrm{~mm}$ in diameter that 
contained a tissue-free lumen and were completely surrounded by bone, was also assessed. Total bone tissue volume $\left(\mathrm{V}_{\mathrm{bt}}\right)$ was calculated as:

$$
\mathrm{V}_{\mathrm{bt}}=\mathrm{V}_{\mathrm{t}}-\mathrm{V}_{\mathrm{c}}-\mathrm{V}_{\mathrm{v}}
$$

\subsubsection{Quantitative computed tomography (QCT)}

Computed tomography standards of known hydroxyapatite density (Computed Imaging Reference Systems, Inc., Norfolk, VA) were scanned along with each bone segment allowing a correlation between Hounsfield units and both mineral density and apparent density to be determined.

Mineral density: Cross-sections of the six calibration standards are visible with mineral densities of (left to right) 100, 200,500, 800, 1000, and $1250 \mathrm{mg} / \mathrm{cc}$ calcium hydroxyapatite (Figure 3.2). The mineral density of calibration standards was established on the basis of the amount of calcium hydroxyapatite suspended in a water-equivalent background matrix when the standards were manufactured.

A calibration curve for mineral density was created by determining the CT numbers, in Hounsfield units, at 10 points along each hydroxyapatite standard using the point probe in AMIRA 3.1. CT numbers were then plotted against the equivalent hydroxyapatite density for a given standard (Figure 3.3). ANOVA was used to determine that the mean CT numbers generated for each standard was statistically significantly different from those assigned to each of the other standards $(\alpha=0.05$ level of significance, $p<0.001$, data not shown). A linear regression of mineral density vs. Hounsfield units resulted in an equation relating these two parameters such that once the 
Hounsfield unit of measure for a given point is known its equivalent QCT mineral density can be calculated (Ciarelli, et al., 1991, Mull, 1984).

Figure 3.2: Computed tomography (CT) cross-section of the mandible from Eg\# 1004. $\mathrm{CT}$ provides a black and white visual representation with tone (black to white) corresponding to density, with high density bone appearing bright white and low density bone appearing darker. Cross-sections of 6 hydroxyapatite calibration standards are visible with mineral densities of (1 to r) 100, 200,500, 800, 1000 and $1250 \mathrm{mg} / \mathrm{cc}$ hydroxyapatite and apparent densities ranging from $1.091 \mathrm{~g} / \mathrm{cc}$ to $1.83 \mathrm{~g} / \mathrm{cc}$.

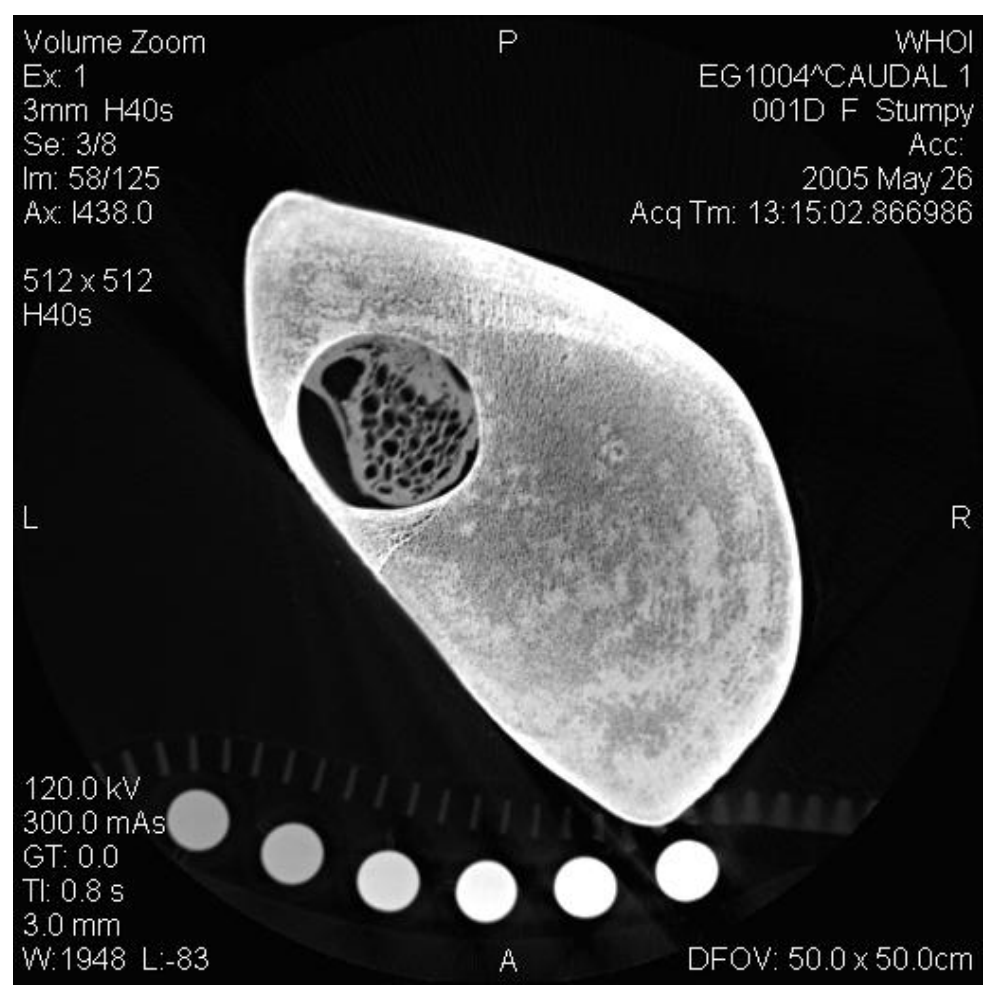

The linear, polynomial, and logarithmic regressions were calculated to relate mineral density to Hounsfield units. Correlation coefficients were calculated to evaluate the curve of best fit. The linear and polynomial regressions explained the data equally over the range of values examined with correlation coefficients $\left(\mathrm{r}^{2}\right)$ equal to 0.977 . For 
simplicity, the linear regression was adopted and used for mineral density QCT calibrations.

This calibration primarily takes into account the mineral content only. Calibrated mineral content values do not take into account the contribution of fat in natural bone and are thereby prone to error when fat is present. The degree of error for single energy QCT has been determined in previous studies to be "- $10 \mathrm{mg} / \mathrm{mL}$ per $10 \%$ fat by volume" at high CT energies (e.g. $140 \mathrm{kVp}$ ) and "-8 $\mathrm{mg} / \mathrm{mL}$ per $10 \%$ fat by volume" at low CT energies (e.g. $80 \mathrm{kVp}$ ) (Laval-Jeantet, et al., 1986). The present study utilized an intermediate energy $(120 \mathrm{kVp})$ and thus is expected to have an intermediate fat-induced error term.

Apparent density: Calibration standards ranging from $1.091 \mathrm{~g} / \mathrm{cc}$ to $1.83 \mathrm{~g} / \mathrm{cc}$ apparent density were scanned so that calibration curves could be made to relate CT Hounsfield units to apparent density. The apparent density of the calibration standards was determined by measuring the apparent density (mass divided by the measured geometric volume) of the calibration standards. This permitted the analysis of the contribution of both the hydroxyapatite mineral and the water-equivalent solid suspension media (for which CT numbers, in H.U., correspond to water) and comparison to manual densitometry and QCT apparent density data from whole bones.

A calibration curve for QCT apparent density was created by recording the CT numbers at 10 points along each hydroxyapatite standard, using the point probe in AMIRA 3.1, and plotting the Hounsfield units vs. apparent density for each of the standards (Figure 3.4). ANOVA was used to determine that the mean CT number 
determined for each hydroxyapatite rod was statistically significantly different from the mean CT number generated for each of the other rods. A linear regression of apparent density vs. Hounsfield values resulted in an equation relating these two parameters such that once the Hounsfield value for a given point is known its QCT apparent density can be calculated.

The calibrated scans and regression formula for apparent density were then used to determine the distribution of cortical and trabecular bone and QCT apparent density at various points along and across the mandible.

The linear and polynomial regressions relating apparent density to Hounsfield units explained the data to approximately the same degree over the range of values examined with correlation coefficients $\left(\mathrm{r}^{2}\right)$ equal to 0.9605 and 0.9608 respectively. For simplicity, the linear regression was adopted and used for apparent density QCT calibrations.

Additionally, a subset of cortical bone samples was scanned using a microscale computed tomography scanner ( $\mu$ CT40, Scanco Medical, Bassersdorf, Switzerland, $\underline{\text { www.scanco.ch) }}$ at $36 \mu \mathrm{m}$ slice thickness. These scans were used to calculate the $\mu \mathrm{CT}$ apparent density of cortical bone samples using a computed regression of Hounsfield units vs. the apparent density during weekly calibrations.

\subsubsection{Densitometry}


The mass and density of cortical and trabecular bone samples from the mandible were determined manually. Bone density has been explored extensively in human and animal models as a correlate for bone strength (Carter, 1976, Carter and Hayes, 1977, Currey, 1988, Ford and Keaveny, 1996, Hong, et al., 2004, Kabel, et al., 1999, Keller, 1994, Martin and Boardman, 1993, Ong and Bouazza-Marouf, 2000, Schaffler and Burr, 1988). The densities of right whale bone samples were measured using multiple methods to allow direct comparison of right whale bone to values in the literature for other species.

Sampling was restricted to extraction of bone from a single longitudinal segment from the right mandible of Eg\# 1004 in order to limit the damage to this museum quality skeleton. Segment "B" of the right mandible of Eg\# 1004 was selected as the representative segment of bone because it was composed of bone of moderate density (neither the highest nor the lowest density of the five segments as assessed by QCT) and it contained both cortical and trabecular bone (Figure 3.1). This segment included bone between 1-2 meters cranial to the apex of the ramus. Samples were drilled using a watercooled concrete corer with a 1-11/4" wood drill bit (Eibenstock, Eibenstock, Germany, http://www.ee-eibenstock.de/).

Tissue density: The wet mass $\left(\mathrm{m}_{\mathrm{wet}}\right)$ and caliper volume $\left(\mathrm{v}_{\text {caliper }}\right)$ of 95 trabecular and 27 cortical bone samples from Eg\# 1004 were measured. $\mathrm{V}_{\text {caliper }}$ was determined using a digital caliper to measure the height and diameter of each cylindrical sample 4-5 times per measurement. The average volume for a given sample was then used to calculate the tissue density ( $\rho_{\text {tissue }}$ ) according to the following equation: 
Figure 3.3: Calibration curves for CT number (Hounsfield units) vs. mineral density $(\mathrm{g} / \mathrm{cc})$. Regressions were made using phantom standards of known calcium hydroxyapatite densities ranging from 100-1250 $\mathrm{mg} / \mathrm{cc}$. Linear and polynomial expressions showed substantial overlap.

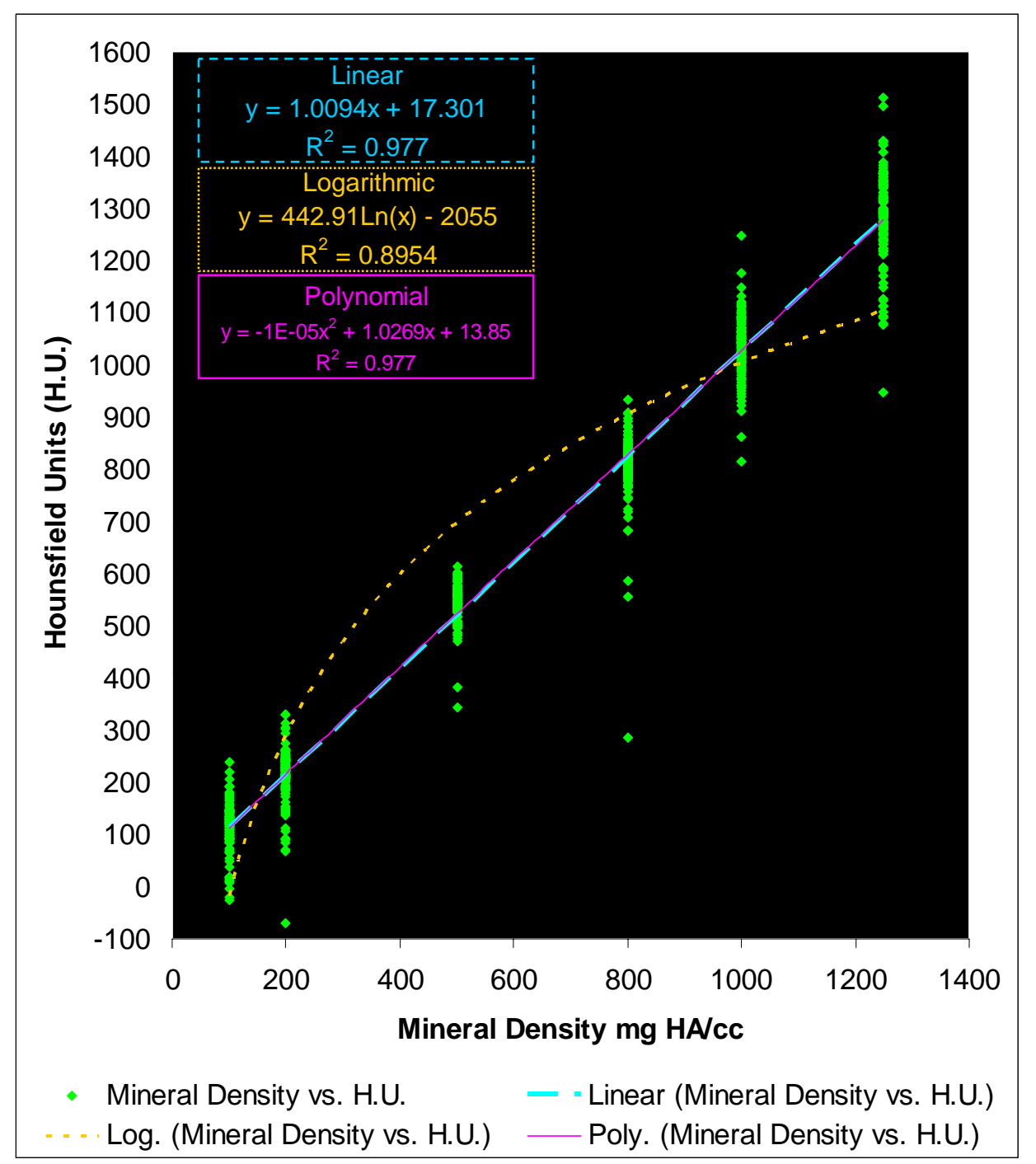


Figure 3.4: Calibration curve for CT numbers (Hounsfield units) vs. apparent density $(\mathrm{g} / \mathrm{cc})$. The regression was made using phantom standards of known apparent density ranging from $1.091-1.830 \mathrm{~g} / \mathrm{cc}$.

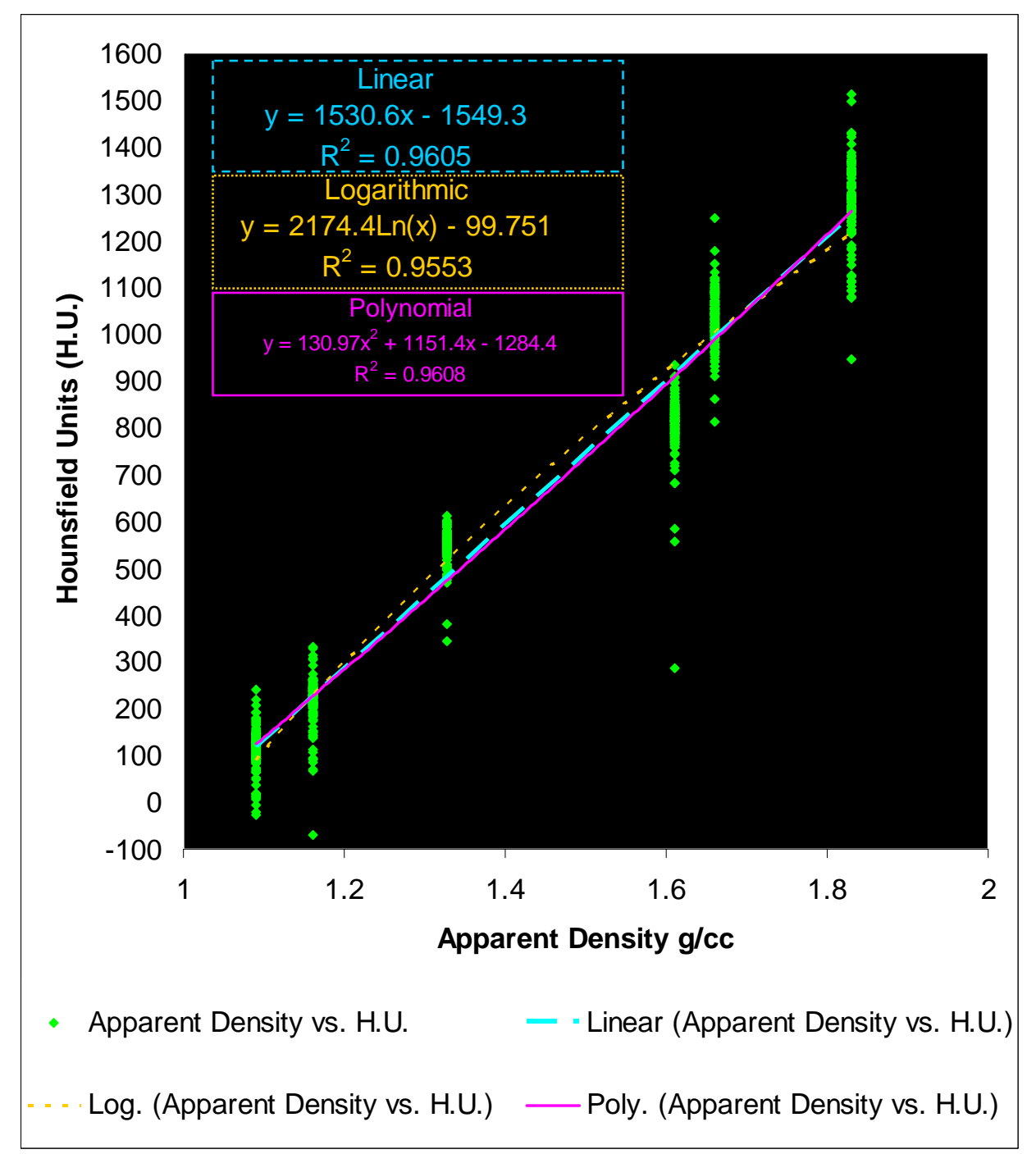

Apparent density: Apparent density was determined according to standard protocol (Carter and Hayes, 1977). Samples were subjected to a mechanical testing protocol for uniaxial compression of up to $10 \%$ strain. Following mechanical testing, samples were defatted in $0.85-0.9 \%$ saline in a sonicator with frequent saline changes, for 
approximately two weeks. Samples were placed into centrifuge tubes on absorbent paper and were spun at 13,000 rpm for five minutes to remove water from trabecular spaces. Samples were then flipped over and were spun at the same speed for 5 additional minutes. The defatted mass ( $\left.\mathrm{m}_{\text {defatted }}\right)$ was then measured to determine the apparent density ( $\left.\rho_{\text {app }}\right)$ and the percent fat using the formula:

$$
\begin{gathered}
\rho_{\text {app }}=\mathrm{m}_{\text {defatted }} / \mathrm{v}_{\text {caliper }} \\
\text { Percent Fat }(\%)=\left[\left(\mathrm{m}_{\text {wet }}-\mathrm{m}_{\text {defatted }}\right) / \mathrm{m}_{\text {wet }}\right] \times 100
\end{gathered}
$$

Percent difference was calculated between the average QCT measurements of apparent density (avg. QCT apparent density) for segment B and physical measurements of apparent density (avg. $\rho_{\text {app }}$ ) for samples extracted from segment B according to the following equation:

$$
\text { Percent difference } \left.(\%)=100 \times(\text { avg. QCT apparent density }) / \text { avg. } \rho_{\text {app }}\right)
$$

Apparent dry density: The apparent dry density of right whale jaw bone was determined using a standard protocol from Le and Liu (Le and Liu, 1997). Empty crucibles were weighed and assigned to individual samples. Each sample was then placed into its crucible and the mass of the crucible and sample combined was recorded.

Samples were then dried in their respective crucibles at $65^{\circ} \mathrm{C}$ until no change in mass due to water loss was observed. The dry mass $\left(\mathrm{m}_{\text {dry }}\right)$ was then determined from a protocol modified from Kriewall et al. (Kriewall, et al., 1981). An empty crucible was included to evaluate the change in mass due to crucible water loss or handling. There was no appreciable change in the mass of the blank crucible throughout the drying procedure. 
The volume of the dried, defatted trabecular bone samples ( $\left.\mathrm{v}_{\text {mineral }}\right)$ was determined using an AccuPyc 1330 gas pycnometer (Micromeritics, Norcross, Georgia). The volume of dried, defatted cortical bone seemed to change little, as evaluated by mass lost during sonication, thus $\mathrm{v}_{\text {caliper }}$ was used. The apparent dry density $\left(\rho_{\text {dry }}\right)$ was calculated for a subset of trabecular and cortical samples using the formulas:

$$
\begin{gathered}
\rho_{\text {dry trabecular }}=\mathrm{m}_{\text {dry }} / \mathrm{v}_{\text {mineral }} \\
\rho_{\text {dry cortical }}=\mathrm{m}_{\text {dry }} / \mathrm{v}_{\text {caliper }}
\end{gathered}
$$

where $\mathrm{m}_{\text {dry }}$ is the dry mass, $\mathrm{v}_{\text {mineral }}$ is the mineral volume and $\mathrm{v}_{\text {caliper }}$ is the caliper volume.

Apparent mineral (ash) density: The ash content of right whale jaw bone was determined using a modified protocol from Carter et al 1981 (Carter, et al., 1981). Following dehydration, samples were placed into a furnace at $600^{\circ} \mathrm{C}$ for 12 hours. Samples were allowed to cool for 1 hour and were weighed. The mass of each sample was determined at intervals over 60 hours until no change in mass was detectable. ${ }^{6}$ The mass at this point was taken as the ash weight. The ash fraction was then calculated as the ash weight divided by the dry mass. The ash content was then computed using the following equation:

$$
\text { Ash content }=\left(\mathrm{m}_{\mathrm{ash}} / \mathrm{m}_{\text {dry }}\right) \times 100
$$

Finally, the apparent mineral (ash) density $\left(\rho_{\alpha}\right)$ was calculated using the following equation:

\footnotetext{
${ }^{6}$ No appreciable change in mass occurred after 24 hours.
} 


$$
\rho_{\alpha}=\text { ash fraction } \mathrm{x} \text { apparent dry density }
$$

Percent difference (\%) between the average QCT mineral density (avg. QCT mineral density) for segment $B$ and the average apparent mineral (ash) density (avg. $\rho_{\alpha}$ ) for segment B was calculated as:

$$
\text { Percent difference } \left.(\%)=100 \times(\text { avg. QCT mineral density }) / \text { avg. } \rho_{\alpha}\right)
$$

\subsection{RESULTS}

\subsubsection{Morphometric measurements}

The right mandible of right whale Eg\#1004, an adult female right whale, measured 399.5 centimeters (13.11 feet) straight length and $449.5 \mathrm{~cm}$ (14.75 feet) external curved length. It weighed $224 \mathrm{~kg}$ (493.8 lbs.) intact. The left mandible measured $404.0 \mathrm{~cm}$ (13.25 feet) straight length and $4.445 \mathrm{~m}$ (14.58 feet) external curved length. It weighed $226 \mathrm{~kg}$ (498.2 lbs.) intact. Measurements were also taken from 4 additional right whales. Table 3.1 contains comparative values for mandibular length standardized by body length for other whales. The sex, total body length, mandibular straight length, and jaw bone condition of each whale were recorded for comparison. Entries followed by an asterisk were additive measurements from fragments and are considered estimates. Measurements preceded by “ ” were also estimated.

Note that the mandible of the right whale comprises approximately $25 \%$ of the length of the individual in all of the adult females sampled. Also of note is the lower 
value (21.8\%) obtained when a juvenile male was measured. It is unknown if sexual dimorphism or allometry were leading factors for the low value for this individual.

In addition, the relevant morphometrics for other baleen whales are included in the table for comparison. Bowhead whale (Balaena mysticetus), blue whale (Balaenoptera musculus) and fin whale (Balaenoptera physalus) data were adapted from Philo et al, 1990, Lambertsen et al. 1995 and Ridgeway \& Harrison, 1985 respectively, while minke whale (Balaenoptera acutorostrata) data appears courtesy of the Cape Cod Stranding Network (Buzzards Bay, MA) (Lambertsen, et al., 2005, Philo, et al., 1990, Ridgway and Harrison, 1985). Values listed represent either an individual for which total and mandibular lengths were measured or the range of total body length for physically mature adults of both sexes (the latter appears in parentheses).

Standardized mandibular length values from the blue whale (Balaenoptera musculus), fin whale (Balaenoptera physalus), minke whale (Balaenoptera acutorostrata) and the bowhead whale (Balaena mysticetus) demonstrate that the right whale mandible falls well within the range of values from other whale species.

\subsubsection{Computed tomography}

The results of bone volume assessment via CT can be seen in Table 3.2. The right mandible of right whale Eg\# 1004 measured 0.1570 cubic meters in total volume $\left(\mathrm{V}_{t}\right.$, including bone volume and internal void space) and 0.1501 cubic meters in total bone volume $\left(\mathrm{V}_{\mathrm{bt}}\right)$. The mandibular canal $\left(\mathrm{V}_{\mathrm{c}}\right)$, including canal branches, measured 6806.5 cubic centimeters $(\mathrm{cc})$ in volume. The lumen of the mandibular canal contains tissue 
Table 3.1: Morphometric measurements are presented for 5 North Atlantic right whales. Where applicable, measurements for right and left sides are included separated by a slash. Entries with an asterisk or " $"$ " are considered estimates. TBL, Total Body Length. SL, Straight Length. NE, not examined.

\begin{tabular}{|c|c|c|c|c|c|}
\hline \multirow[b]{2}{*}{ Whale ID, Sex } & \multirow{2}{*}{$\begin{array}{c}\text { Total } \\
\text { Body } \\
\text { Length, } \\
\text { TBL (m) }\end{array}$} & \multicolumn{4}{|c|}{ Mandible } \\
\hline & & $\begin{array}{c}\text { Straight } \\
\text { Length, SL } \\
(\mathrm{R} / \mathrm{L}, \text { in } \mathrm{cm})\end{array}$ & $\begin{array}{c}\text { External } \\
\text { Curved Length } \\
(\mathrm{R} / \mathrm{L}, \text { in } \mathrm{cm})\end{array}$ & $\begin{array}{c}\text { SL/TBL } \\
\text { Ratio }^{\dagger}\end{array}$ & Condition \\
\hline $\begin{array}{l}\text { Right Whale 1004, } \\
\text { to }\end{array}$ & $\begin{array}{c}16.0(16- \\
17)\end{array}$ & $399.5 * / 404.0$ & $449.5 * / 444.5$ & 0.2525 & $\begin{array}{c}\text { Frozen, } \\
\text { fresh }\end{array}$ \\
\hline Right Whale 1909, & 14.9 & -- & -- & -- & -- \\
\hline $\begin{array}{l}\text { Right Whale 1014, } \\
\end{array}$ & 13.7 & $394.2 * / 383.0$ & $412 * / 421.5$ & 0.2796 & $\begin{array}{c}\text { Defatted, } \\
\text { dried }\end{array}$ \\
\hline $\begin{array}{l}\text { Right Whale } \\
\text { MJM09042006, 우 }\end{array}$ & 14.65 & $372.8 / 371.1$ & $420.0 / 425.0$ & 0.2545 & Fresh \\
\hline 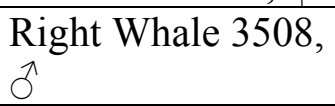 & 12.6 & $275 / 274$ & $297 / 295$ & 0.2183 & Fresh \\
\hline $\begin{array}{l}\text { Bowhead Whale } \\
1987 \text { Harvest, } q\end{array}$ & 11.4 & $\sim 350$ & $\mathrm{NE}$ & 0.3070 & Fresh \\
\hline $\begin{array}{l}\text { Blue Whale } \\
\text { (adults) }\end{array}$ & $(21-24)$ & (Over 500) & -- & $0.2083+$ & -- \\
\hline Fin Whale & $\begin{array}{c}19.8 \\
(22-27)\end{array}$ & 400 & -- & 0.2020 & -- \\
\hline $\begin{array}{l}\text { Minke Whale } \\
\text { CCSN03-174Ba }\end{array}$ & $\begin{array}{c}\sim 6.6 \\
(7.9-8.5)\end{array}$ & 161 & -- & 0.2349 & $\begin{array}{c}\text { Frozen, } \\
\text { Fresh }\end{array}$ \\
\hline
\end{tabular}

${ }^{\dagger}$ The straight length of the right or fragmented mandible was used preferentially over the left or fragmented mandible respectively for SL/TBL ratio.

whose appearance, CT numbers and structural architecture are consistent with blood vessels. The mandibular canal diverged resulting in the formation of 17 branches. Branches represented $334.0 \mathrm{cc}(0.21 \%)$ of the total volume of the jawbone. Combined, the mandibular canal and its branches represent $4.33 \%$ of the total volume of the jaw bone. Twenty-four void spaces were found within the periosteum (average volume - 
$4.42 \mathrm{cc})$. This represented a total of $106.0 \mathrm{cc}(<0.07 \%)$ of the total volume of the right mandible. All twenty-four void spaces were found in the caudal-most segment (Segment A).

\subsubsection{Quantitative computed tomography}

QCT apparent density: The QCT apparent density of the right whale jaw bone was determined using a regression equation relating Hounsfield numbers to apparent density $(\mathrm{g} / \mathrm{cc})$. The jaw was cut into five segments and the average apparent density of cortical and trabecular bone in each segment was determined. The average apparent density value $(\mathrm{g} / \mathrm{cc})$ for each segment can be found in Table 3.3 .

Table 3.2: Computed tomography (CT) volume measurements for the right mandible from right whale Eg\# 1004. The volume of the whole bone, mandibular canal, void space and total mineral volume were determined.

\begin{tabular}{|c|c|c|}
\hline & Volume $\left(\mathrm{m}^{3}\right)$ & \% Total Volume \\
\hline \hline Total Volume $\left(\mathrm{V}_{\mathrm{t}}\right)$ & 0.1570 & - \\
\hline Bone Tissue $\left(\mathrm{V}_{\mathrm{bt}}\right)$ & 0.1501 & $95.6 \%$ \\
\hline \hline Mandibular Canal, Main Body $\left(\mathrm{V}_{\mathrm{m}}\right)$ & 0.006473 & $4.1 \%$ \\
\hline Mandibular Canal, Branches $\left(\mathrm{V}_{\mathrm{br}}\right)$ & 0.0003340 & $0.21 \%$ \\
\hline Void spaces $\left(\mathrm{V}_{\mathrm{v}}\right)$ & 0.0001061 & $0.07 \%$ \\
\hline
\end{tabular}


Analysis of variance (ANOVA) was performed to determine if the average apparent density of trabecular bone from different segments was statistically different from each of the other segments at $\alpha=0.05$ level of significance. The same test was conducted for cortical bone as well. Significance was tested via ANOVA for average apparent density of hydrated bone only. An asterisk indicates that a given segment was statistically significantly different from all other segments. In the absence of an asterisk, a numeral will indicate which segment was not significantly different from a given segment as determined by post hoc pair-wise comparison test. Values for the average QCT apparent density for segment B were compared to physical measurements of apparent density for specimens extracted from segment B and can be found in Table 3.3.

QCT mineral density: The QCT mineral density of the right whale jawbone was determined using a regression equation relating Hounsfield numbers to hydroxyapatite mineral density $(\mathrm{mg} / \mathrm{cc})$. The average QCT mineral density was determined for each of the five segments scanned and can be found in Table 3.3.

\subsubsection{Densitometry}

The tissue density, apparent density, percent fat, and mineral density (as ash content) for right whale jawbone were determined and can be found in table 3.4. The values for average apparent density of hydrated bone were determined for comparison to QCT apparent density values.

Values for percent fat were included for comparison to percent fat in other bone tissues and for comparison to fat-induced error in QCT. Average apparent dry density can 
be compared to density studies of dried, defatted museum specimens (Lind, et al., 2003, Wall, 1983). Last but not least, the average ash content was determined for comparison to QCT mineral density determined here and ash content determined in other studies (Currey, 1975). Ash content represents the "gold standard" density measurement used often in the literature. Percent difference between average QCT mineral density and average apparent mineral (ash) density can be found in Table 3.5

Table 3.3: Average apparent and mineral densities of five segments of right whale jawbone from Eg\# 1004 as determined via QCT and physical measurements. An asterisk indicates that a given segment was significantly different from all other segments, while a letter in parentheses indicates the segment that was not significantly different from the segment indicated by the letter. Density measurements for average apparent density of hydrated bone was performed according to Sharp et al. 1990 (Sharp, et al., 1990).

\begin{tabular}{|c|c|c|c|c|}
\hline $\begin{array}{c}\text { Right Jawbone } \\
\text { Eg\# 1004 }\end{array}$ & \multicolumn{2}{|c|}{$\begin{array}{c}\text { Average Apparent } \\
\text { Density Hydrated Bone } \\
(\mathrm{g} / \mathrm{cc})\end{array}$} & \multicolumn{2}{c|}{ Average Mineral Density (mg/cc) } \\
\hline QCT & Trabecular & Cortical & Trabecular & Cortical \\
\hline Segment A & $0.9489^{\star}$ & $1.3500^{\star}$ & 98.90 & 492.23 \\
\hline Segment B & $1.0963^{*}$ & $1.4970^{\star}$ & 160.88 & 737.93 \\
\hline Segment C & $1.1127^{\star}$ & $1.562702(\mathrm{E})$ & 174.37 & 816.73 \\
\hline Segment D & $1.1426^{\star}$ & $1.5939^{\star}$ & 197.67 & 865.32 \\
\hline Segment E & $1.1694^{\star}$ & $1.5607(\mathrm{C})$ & 230.10 & 818.68 \\
\hline Segment A-E & 1.0940 & 1.5128 & 172.39 & 746.18 \\
\hline $\begin{array}{c}\text { Meas. Density } \\
\text { Segment B }\end{array}$ & Trabecular & Cortical & $\begin{array}{c}\text { Average Apparent Mineral (Ash) } \\
\text { Density (mg/cc) }\end{array}$ \\
\hline Tissue Density & 1.2291 & 1.5595 & Trabecular & Cortical \\
\hline Apparent Density & $\begin{array}{c}0.4258 \\
( \pm 0.0970)\end{array}$ & $\begin{array}{c}1.2370 \\
( \pm 0.0535)\end{array}$ & $\begin{array}{c}\text { Minimum: } 174.9 \\
\text { Maximum: } 378.0\end{array}$ & $\begin{array}{c}\text { Minimum: } 649.44 \\
\text { Maximum: } 781.8\end{array}$ \\
\hline Apparent Dry & $\begin{array}{c}0.4232 \\
( \pm 0.0961)\end{array}$ & $\begin{array}{c}1.2302 \\
( \pm 0.0561)\end{array}$ & 273.476 & 725.243 \\
\hline Density & & & \multicolumn{2}{c}{} \\
\hline
\end{tabular}


Table 3.4: The average tissue density, apparent density, percent fat and average ash content measured for mandibular bone extracted from an adult female right whale. Sample size indicated in brackets for average tissue density. For all others $n=5$ samples/axis. Standard deviation is shown in parentheses.

\begin{tabular}{|c|c|c|c|c|c|}
\hline $\begin{array}{c}\text { Right } \\
\text { Jawbone } \\
\text { Eg\# 1004 }\end{array}$ & $\begin{array}{c}\text { Average Tissue } \\
\text { Density (g/cc) }\end{array}$ & $\%$ Fat & $\begin{array}{c}\text { Avg. } \\
\text { Apparent } \\
\text { Density } \\
\text { Hydrated } \\
\text { Bone (g/cc) }\end{array}$ & $\begin{array}{c}\text { Average } \\
\text { Apparent Dry } \\
\text { Density (g/cc) }\end{array}$ & $\begin{array}{c}\text { Average Ash Content } \\
(\%)\end{array}$ \\
\hline Segment B & \multicolumn{5}{|c|}{ TRABECULAR BONE } \\
\hline $\begin{array}{c}\mathrm{X} \text {-axis } \\
\text { [n=16] }\end{array}$ & $1.2610( \pm 0.0633)$ & 57.7 & 0.5246 & $\begin{array}{c}0.4458 \\
( \pm 0.0899)\end{array}$ & $64.57( \pm 0.9400)$ \\
\hline $\begin{array}{c}\text { y-axis } \\
{[n=24]}\end{array}$ & $1.2445( \pm 0.0521)$ & 59.6 & 0.5025 & $\begin{array}{c}0.4264 \\
( \pm 0.0647)\end{array}$ & $64.89( \pm 1.1794)$ \\
\hline $\begin{array}{c}\text { Z-axis } \\
{[n=36]}\end{array}$ & $1.2046( \pm 0.0764)$ & 60.6 & 0.4831 & $\begin{array}{c}0.4022 \\
( \pm 0.1376)\end{array}$ & $63.67( \pm 1.1051)$ \\
\hline Average & $1.2367( \pm 0.0703)$ & 59.3 & $\begin{array}{c}0.5034 \\
( \pm 0.0970)\end{array}$ & $\begin{array}{c}0.4248 \\
( \pm 0.0962)\end{array}$ & $64.38( \pm 1.1330)$ \\
\hline
\end{tabular}

\begin{tabular}{|c|c|c|c|c|c|}
\hline $\begin{array}{c}\text { Right } \\
\text { Jawbone } \\
\text { Eg\# 1004 }\end{array}$ & $\begin{array}{c}\text { Average Tissue } \\
\text { Density (g/cc) } \\
{[\mathrm{n}=27]}\end{array}$ & $\%$ Fat & $\begin{array}{c}\text { Avg. } \\
\text { Apparent } \\
\text { Density } \\
\text { Hydrated } \\
\text { Bone (g/cc) }\end{array}$ & $\begin{array}{c}\text { Average } \\
\text { Apparent Dry } \\
\text { Density (g/cc) }\end{array}$ & $\begin{array}{c}\text { Average Ash Content } \\
(\%)\end{array}$ \\
\hline Segment B & n/a & 22.14 & 1.17 & 1.45 & 55.91 \\
\hline Min & n/a & 25.34 & 1.28 & 1.57 & 61.24 \\
\hline Max & $1.5416( \pm 0.1089)$ & 24.06 & $1.23( \pm 0.0535)$ & 1.51 & $58.89( \pm 2.00)$ \\
\hline Average &
\end{tabular}

Table 3.5: Percent difference between average QCT density values and physical measurements of their apparent density and mineral density counterparts.

\begin{tabular}{|c|c|c|c|}
\hline Value from QCT & $\begin{array}{c}\text { Value from physical } \\
\text { measurements }\end{array}$ & $\begin{array}{c}\text { Percent Difference QCT/Physical } \\
\text { Measurement (\%) }\end{array}$ \\
\hline From Segment B & From Segment B & Trabecular & Cortical \\
\hline $\begin{array}{c}\text { Average QCT } \\
\text { apparent density }\end{array}$ & Average apparent density & $257.5 \%$ & $121.0 \%$ \\
\hline $\begin{array}{c}\text { Average QCT } \\
\text { mineral density }\end{array}$ & $\begin{array}{c}\text { Average mineral (ash) } \\
\text { density }\end{array}$ & $58.8 \%$ & $110.0 \%$ \\
\hline
\end{tabular}




\subsection{DISCUSSION}

3.4.1 Right whale bone density and internal structure

Bone samples extracted directly from a North Atlantic right whale mandible were used to measure the apparent and mineral (ash) densities of cortical and trabecular bone. These data are critical for modeling the biomechanics of vessel-whale collisions that threaten the survival of this highly endangered species. The average apparent density of hydrated, defatted bone samples was $0.5034 \mathrm{~g} / \mathrm{cc}( \pm 0.0970)$ for trabecular and $1.23 \mathrm{~g} / \mathrm{cc}$ $( \pm 0.0535)$ for cortical bone. The values for trabecular bone are relatively low compared to the range of values for trabecular bone from human mandibles $(0.85-1.53 \mathrm{~g} / \mathrm{cc})(\mathrm{Misch}$, et al., 1999). Values for the average ash content of trabecular bone from the right whale mandible $(64.38 \% \pm 1.13)$ were on par with the average ash content measured in human femora $(64.9 \% \pm 1.4 \%)$ and human femora $(58.3 \% \pm 10.3 \%)$ and vertebrae $(61.0 \pm 2.2 \%)$ (Carter, et al., 1981, Keller, 1994). Taken together, these data indicate that the low density of right whale mandibular bone is due to a decrease in bone mass rather than a decrease in mineralization.

The relatively low apparent density of whale bone determined here was in accordance with reports from other whale bones (Currey, 2002, Perrin, et al., 2002, Wall, 1983). ${ }^{7}$ However, reports from different cetacean skeletal elements have demonstrated

\footnotetext{
${ }^{7}$ Though, only Wall provides even a single measure of cetacean bone density to substantiate the claim of diminution of bone density in cetaceans. Those data were from the forelimb of a single unidentified cetacean which had bone densities of 1.16, 1.26 and $1.25 \mathrm{~g} / \mathrm{cc}$ for the humerus, radius and ulna. These values were indeed lower than the average limb bone density found for terrestrial mammals $(1.2 \mathrm{~g} / \mathrm{cc})$ and considerably lower than values found for non-cetacean aquatic mammals $(1.46 \mathrm{~g} / \mathrm{cc})$ in that study (Wall, 1983).
} 
how much the physical properties of bone vary across cetacean taxa. For example, the tympanic bullae of the fin whale, Balaenoptera physalus, and harbor porpoise, Phocoena phocoena, represent some of the most dense bone tissue found in any mammal to date with an average density of 2.50 and $2.70 \mathrm{~g} / \mathrm{cc}$ respectively (Lees, et al., 1996). ${ }^{8}$ Similarly, the calcium content (another measure of mineral density) of the rostrum of the beaked whale, Mesoplodon densirostris, is also extremely high $(351 \mathrm{mg} \mathrm{Ca} / \mathrm{g}$ dry bone compared to the $311 \mathrm{mg} \mathrm{Ca} / \mathrm{g}$ dry bone seen in the fin whale bulla). However this bone type is notably compliant for its density (Zioupos, et al., 1997). The variation seen in the density of whale bones provided justification for specifically exploring the density of the right whale mandible.

Like the well-studied human mandible, the right whale mandible has a cortical bone cortex surrounding its trabecular core. However, the clear demarcation between trabecular and cortical bone that exists in human bone is absent in the whale jawbone. Instead, the trabecular bone appears to become progressively less porous at the boundary between cortical and trabecular bone, grading into the solid bone structure typical of cortical bone. Additional microscale computed tomography of right whale cortical bone in this transition zone revealed it to have the porous structure of trabecular bone (albeit lower porosity) and an average $\mu \mathrm{CT}$ apparent density of $0.501 \mathrm{~g} / \mathrm{cc}( \pm 0.0312)$. Individual trabeculae were extremely large, on the order of $1 \mathrm{~mm}$ in thickness and plate-like columns of trabecular bone were also visible.

\footnotetext{
${ }^{8}$ The "physical density" was determined for these bones. Though this loose term was not defined, it is presumably the specimen mass divided by the total specimen volume including pores. For high density bone, few pores are expected and thereby only a minute error would occur if the volume of the bony matrix was used here.
} 
Data in Table 3.3 demonstrate that the QCT apparent density for both trabecular and cortical bone varies longitudinally - with the caudal region being the least dense. Statistical analysis revealed a trend of increasing QCT trabecular bone apparent density from the ramus toward the rostral apex of the mandible. For cortical bone, the caudalmost segments (Caudal A \& B) were subtly, albeit statistically significantly $(\mathrm{p}<0.001)$, less dense than the more rostral regions (Caudal C-E). ${ }^{9}$

This trend of longitudinal density variation corresponds well to a similar trend in the human mandible. When the density of trabecular bone was investigated (via manual densitometry) in three regions of the human mandible - region 1, anterior-most (containing incisors and canines), region 2, central corpus (containing premolars) and region 3 , caudal corpus (containing molars) - the apparent density was significantly higher in the anterior-most region than in the other two regions (Misch, et al., 1999).

3.4.2 Comparing patterns in bone density - structure vs. function

Despite the absence of mastication function in the skim feeding North Atlantic right whale, the jaw bone density distribution pattern exhibited by this baleen whale seems to follow the same pattern seen in masticating humans. This possibly reflects ontogenetic control of development, which is thought to be a dominant factor (as opposed to function) determining the morphology of several features in mammals including vertebrate limb bud development (Gilbert, 1997, von Dassow and Munro, 1999).

\footnotetext{
${ }^{9}$ The same trend was found for QCT mineral density of both trabecular and cortical bone although significance was not tested.
} 
On the other hand, bone is a dynamic tissue that undergoes remodeling in response to applied stress (Currey, 2002, Huiskes and van Rietbergen, 2005). The stress concentrations experienced by feeding baleen whales may lead to the development and remodeling of bone in response to functional loading. Ram-feeding baleen whales swim open-mouthed through high density patches of their primary prey, the copepod Calanus finmarchicus (Baumgartner, et al., 2007). The hydrodynamic forces loading the baleen whale jaw may introduce loading schemes that result in patterns of bone structure resembling those seen in masticating animals.

The morphology and biomechanics of the baleen whale feeding apparatus during feeding have been explored previously (Bouetel, 2005, Brodie, 2001, Lambertsen, et al., 1995, Lambertsen, et al., 2005). Skim feeding in the family Balaenidae is thought to result in relatively minor forces on the lower jaw due to much slower forward movement during skim feeding (estimated $5 \mathrm{~km} /$ hour) compared to engulfment feeding speeds (40$50 \mathrm{~km} /$ hour) seen in Balenopterids (e.g. the Humpback whale, Megaptera novaeangliae) (Lambertsen, et al., 1995, Werth, 2004).

Biomechanical modeling would be a highly effective method for exploring the effect of functional loading regime differences between whales who utilize skim feeding vs. those that engulf their prey. Such a study may resolve the contribution of ontogeny vs. dynamic remodeling to the observed density distribution in the right whale jaw bone. 


\subsubsection{Comparison of densitometry techniques}

Imaging vs. physical measurements: In this study, quantitative computed tomography was used to determine the QCT apparent density and QCT mineral density of the right whale mandible non-destructively in parallel with physical measurements of apparent density and mineral density. Comparative analysis of the data reveals that the average QCT apparent density value for high density cortical bone is much closer to the average apparent density derived from physical measurements of cortical bone than the average QCT apparent density value for low density trabecular bone is to its physically measured counterpart. Average QCT apparent density for cortical bone was $21.0 \%$ greater than the physical measurements of apparent density, while the average QCT apparent density of trabecular bone was $257.5 \%$ greater than physical measurements. Similarly, the average QCT mineral density value for cortical bone was much closer to the average mineral density measurement $(+10 \%)$ than the average QCT mineral density value for trabecular bone ws to physical measurements of the average mineral density of trabecular bone (-41.2\%). The percent difference observed at the high end of the QCT apparent density range is reasonable, while that at the low end is unacceptably large for a valid predictor of a physical property.

The difference presumably results from the fact that hydroxyapatite density standards represent an intermediate range of values $(100-1250 \mathrm{mg} / \mathrm{cc}$ mineral density and $1.091-1.830 \mathrm{~g} / \mathrm{cc}$ apparent density) such that values above and below the range were derived via extrapolation. 
The linear relationship makes theoretical sense when extrapolating above 1.830 $\mathrm{g} / \mathrm{cc}$ up to the standard value for the apparent density of solid cortical bone $(2.0 \mathrm{~g} / \mathrm{cc})$, the theoretical limit of cortical bone density (Martin, et al., 1998). When the linear regression equation for deriving apparent density from H.U. is used inversely, the upper limit of bone density would correspond to a value of 1511.9 Hounsfield units - well within the Hounsfield unit scale of -1000 to +4096 . From this it would follow that extrapolation above $1.830 \mathrm{~g} / \mathrm{cc}$ returns values consistent with theoretical limits for both the Hounsfield unit scale and the known range of bone apparent density.

Similarly, when QCT mineral density is considered, the linear relationship makes theoretical sense when extrapolating above $1250 \mathrm{mg} / \mathrm{cc}$ up to the highest H.U. value seen for cortical bone in this study - roughly 1900 Hounsfield units. When the linear regression equation for deriving mineral density from H.U. is used, the upper limit of the H.U. scale would correspond to $1.935 \mathrm{~g} / \mathrm{cc}$. This is a value that makes theoretical sense when compared to the maximum value for the apparent mineral (ash) density measured in human vertebrae and femora $(1.885 \mathrm{~g} / \mathrm{cc})$ and the range of inter-species variation (Keller, 1994). From this it would follow that extrapolation above $1250 \mathrm{mg} / \mathrm{cc}$ QCT mineral density returns values consistent with theoretical limits for both the Hounsfield unit scale and the known range of bone mineral density and thereby should result in reasonably low differences in the predicted mineral density unless unpredicted changes in mineralization occur at the high end of the scale.

Extrapolating below the mineral density range of the calibration standards (e.g. to $0 \mathrm{mg} / \mathrm{cc}$ ) using the linear regression equation relating mineral density to Hounsfield units 
results in a value of 17.301 Hounsfield units. This is theoretically reasonable as the intertrabecular spaces are filled with soft tissue that is primarily water which would translate to approximately 0 on the Hounsfield unit scale (Martin, et al., 1998).

This is consistent with the physical properties of the calibration standards as well. The rods are made by mixing a known quantity of calcium hydroxyapatite powder into a fluid matrix known as plastic water. When hardened, this substance has the radiographic properties of water, such that a standard of $0 \mathrm{mg} / \mathrm{cc}$ should correspond to H.U. readings of about 0 .

Though the results for the lower limit of mineral density are theoretically sound, minor issues may still present themselves at the low end of the mineral density scale. For example, individual points representing measurements for a single hydroxyapatite standard occur across a range of H.U. values. If the same range occurs for lower density calibration standards then the range of H.U. values are also expected to extend below the theoretical limit of $\sim 0$ Hounsfield units. ${ }^{10}$ These minor issues may be easily resolved via QCT analysis of mineral density standards below $100 \mathrm{mg} / \mathrm{cc}$ to determine the appropriate regression equation inclusive of low mineral densities. Preliminary studies are presently underway to resolve this issue using standards measuring $0,25,50$, and $75 \mathrm{mg}$ calcium hydroxyapatite/cc.

When extrapolating below the $1.091 \mathrm{~g} / \mathrm{cc}$ QCT apparent density calibration standard, theoretical considerations complicate the interpretation of the established linear relationship. The most obvious conundrum is due to the fact that the range apparent

\footnotetext{
${ }^{10}$ This would be the theoretical limit for a calibration rod composed of $100 \%$ plastic water and $0 \mathrm{mg} / \mathrm{cc}$ hydroxyapatite.
} 
density of bone is fairly wide, ranging from $0.1-1.0 \mathrm{~g} / \mathrm{cc}$ in humans (Huiskes and van Rietbergen, 2005). Using the linear regression relating the QCT apparent density to Hounsfield units, QCT apparent density values at the lower limit of apparent density $(0.1$ g/cc) would correspond to a value of -1396.2 Hounsfield units. The Hounsfield unit scale is calibrated such that the density of water corresponds to $\sim 0$ H.U., while the density of air corresponds to $-1,000$ Hounsfield units. Thus, the lower limit of apparent density corresponds to a Hounsfield unit value that is much lower than air, which is of course problematic indeed!

This represents a technical flaw in the terminology used to describe the apparent density of bone. The standard definition of apparent density of bone from biomechanics literature is the mass of defatted, hydrated bone divided by the geometric volume of the specimen including pore spaces (Carter, 1976, Ford and Keaveny, 1996, Huiskes and van Rietbergen, 2005, Kopperdahl and Keaveny, 1998). For a non-porous solid this would permit direct comparison of the density of the solid and the density of water. However, for a porous solid, this introduces an error whose magnitude is directly related to the porosity of the material. The greater the porosity, the greater the percent difference between the apparent density of bone and the density of the calcified bone matrix ${ }^{11}$ which is measured as the mass of defatted, hydrated bone divided by the volume of the bony matrix and thereby takes into account only the density of the actual substance, excluding pore spaces (Martin and Boardman, 1993).

${ }^{11}$ This term is also discussed as the matrix material density by Rice et al., 1988. 
Consider for example the case of a real cylindrical specimen of trabecular bone (sample 1a-2) that when defatted has a mass of 0.2743 grams and a geometric specimen volume equal to 0.4730 cubic centimeters. Using the standard definition of apparent density from bone biomechanics (Equation 3.3) the apparent density of this specimen would equal $0.5799 \mathrm{~g} / \mathrm{cc}$. Thus, the specimen would be expected to be far less dense than water when measured using the same definition of apparent density or QCT apparent density. However, when dropped into water (which has an apparent density of $1 \mathrm{~g} / \mathrm{cc}$ at $4^{\circ} \mathrm{C}$ ) for additional experimentation, the observation was made that the specimen sunk, which led to the realization that the standard use of the term "apparent density" and the further application of this misleading term to the 'density' determined by QCT in bone literature is cause for serious concern.

Resolving disparities between QCT and physical measurements: A more appropriate measure of density would allow it to be compared to the reference value for water in a physically meaningful way. Use of the density of calcified bone matrix, defined as the mass of defatted, hydrated bone divided by the volume of bone tissue that does not include pore spaces, would resolve this issue (Martin and Boardman, 1993, Rice, et al., 1988). For the specimen discussed above, the volume of bone tissue was measured using a gas pycnometer $(0.1191 \mathrm{cc})$ and the density of the calcified bone matrix was calculated to be $2.30 \mathrm{~g} / \mathrm{cc}$ - which fully explains why the bone sunk! Unfortunately, the density of the calcified bone matrix is not often reported (in favor of reporting the apparent density as defined for biomechanics). 
It is clear when comparing the apparent density to the density of the calcified bone matrix that the former will vary as a function of porosity whereas the latter will remain constant with respect to porosity. With this in mind, one of two methods may be tested to remedy the extreme values for percent difference between QCT apparent density and measured apparent density. The first would incorporate measures of porosity into the regression equation used to correlate QCT apparent density with Hounsfield units. This could be done by determining the porosity of specimens that were previously scanned to obtain their QCT apparent density. The porosity (as a function of apparent density) may vary between anatomical sites, with age and between species (Goldstein, 1987, Schaffler and Burr, 1988, Weaver and Chalmers, 1966). Therefore, this calibration step may have to be carried out frequently to determine the range of variation in porosity values for given bone types.

This method maintains the accepted (albeit misleading) term QCT apparent density but adjusts its definition to make it more appropriate and comparable to physical measurements of apparent density.

The second possible method of eliminating low density error when relating QCT apparent density to Hounsfield units would be to instead adopt the term QCT matrix material density which could then be correlated to physical measurements of the matrix material density (mass of defatted, hydrated bone, divided by the volume of the bony matrix without pore spaces). In this way a regression function would be theoretically appropriate at low densities and could still be correlated to measurements of the apparent density if the porosity were also measured as the volume of the pore spaces divided by 
the total specimen volume as determined using the geometric dimensions of the specimen including pore spaces. The use of the latter technique is favored for simplicity and because it will facilitate the use of a preferred term over the current problematic terminology.

Regardless of the technique chosen to make QCT derived density more relevant to a measure of physical density, it is important that calibration standards representing the low end of the density spectrum (e.g. apparent densities ranging from $0.1 \mathrm{~g} / \mathrm{cc}$ to $1.0 \mathrm{~g} / \mathrm{cc}$ and mineral densities below $100 \mathrm{mg} / \mathrm{cc}$ ) are used to derive the regression equations. This is because they are physically relevant to the range of apparent densities seen in the literature and are in the range where porosity has a large effect on relation between QCT apparent density and Hounsfield units (Huiskes and van Rietbergen, 2005).

The term "QCT apparent density" is itself problematic as its name implies that it is comparable to the measured apparent density of bone yet this comparison seems inappropriate, particularly at low apparent densities. The results of this study strongly suggest that the density determined by QCT does not presently account for the porosity of bone tissue and as such significant error is observed when using it as an estimate of apparent density at the low end of the density continuum. Future studies exploring the inclusion of porosity as an explanatory variable in regression equations relating QCT apparent density to physical measurements of apparent density are warranted. 


\subsubsection{Limitations and caveats}

Three factors that may limit the general application of the data presented here to right whale bone biomechanics include: 1) the limited sample size, 2) gender bias of the sample set, 3) spatial limitations of sampling. The parameters considered with regard to these limitations are presented in detail.

Limited sample size: The morphometric dataset presented here is a compilation of data collected from five individual right whales, including 4 adult females and a juvenile male. A larger dataset composed of a greater number of individuals and a more equal sex ratio would provide increased confidence regarding the average values (and standard deviations) for standardized morphometric measurements in this population. Such a dataset may also provide insight into whether the disparity between the standardized mandibular lengths for the juvenile male and the mature females was a result of age, sex or individual variation.

Similarly, the internal structure and QCT apparent density obtained via computed tomography were derived from the right mandible of a single adult female. While a larger dataset composed of many individuals, including males and females of multiple age classes, would be ideal for determining the range of measurements found in the population, it is certainly precluded by the fact that the species being investigated is highly endangered. As such high quality specimens adequately preserved for such studies are rare. In fact, only two adult female right whale mandibles have been properly stored to meet the preservation standards required for these analyses. 
As mentioned earlier, the weight limits of the computed tomography scanner required that the mandible be cut into 5 segments. The skeletons of these individuals are well preserved and are of high educational value and are thus destined for museum collections. As such, destructive sampling is conducted only in the absence of a viable alternative or in the interest of the greater good (i.e. balancing the value of the scientific data obtained with the number of bones sacrificed). The statistical benefits of a dataset composed of two adult right whale females were not outweighed, in our subjective opinion, by the permanent destruction of a museum quality specimen. Similarly, the samples used for physical measurements of tissue density, apparent density and apparent dry density and ash content were all taken from the same segment and thus represent bone tissue from a region spatially representing only $20 \%$ of the volume of the mandible. Again, the decision was made that a first order estimate of these parameters in right whale mandible was sufficient to provide insight into the physical properties of the right whale mandible for comparison to other species.

Gender bias: This study proposes the use of the data presented as reasonable estimates of the physical properties and internal structure of mandibular bone for the North Atlantic right whale species, despite being determined for a single mature cow. Findings indicate that the measured apparent density of right whale trabecular bone tissue from the mandible of this adult female $(0.514 \mathrm{~g} / \mathrm{cc})$ was much lower than values seen in the human mandible (0.85-1.53 g/cc) (Misch, et al., 1999). Similarly, right whale cortical bone extracted from the mandible had an average apparent density of $1.23 \mathrm{~g} / \mathrm{cc}$ which was low compared to cortical bone extracted from human femora $(1.81 \mathrm{~g} / \mathrm{cc})$ and bovine 
tibia (2.01 g/cc) (Carter, et al., 1981, Martin and Boardman, 1993). Thus the implication for this study is that the apparent density of right whale mandibular bone tissue is lower than was expected based on prior studies of the apparent density of human and bovine bone.

While the use of a mature, pregnant, adult female (who had successfully reproduced at least 5 calves) raises questions regarding the potential for gender bias in this study, prior studies of pregnant and postpartum lactating females demonstrate only temporary decreases in bone density associated with pregnancy. Temporary decreases in bone mineral density are seen early in lactation in humans and rats (Karlsson, et al., 2001, Yildiz and Oral, 2006, Zeni, et al., 2003, Zeni, et al., 1999). These decreases are restored after 5 months of lactation and no significant difference in bone mineral density was associated with multiparity (i.e. women with two or fewer pregnancies did not have significantly higher bone mineral density than women with four or more pregnancies).

Assuming comparable metabolic effects in right whales, the pregnancy status and reproductive history of this female were not factors likely to influence the bone mineral density or other physical properties of this individual from other mature female whales of the population.

Gender parity, with respect to bone mineral density, has been observed in children, young adult and middle aged humans (Genant, et al., 1994). However, after onset of menopause, bone mineral density decreases linearly over time in the vertebrae and rapidly in the appendicular skeleton (Riggs, et al., 1981). Males on the other hand show little to no trend of decreased bone mineral density with age (Riggs, et al., 1981). 
Assuming comparable metabolic response to aging and reproduction in right whales, the age and active reproductive status of right whale Eg\#1004 offer no indication that bone mineral density in this individual would be abnormal when compared to mature females. Additionally, despite evidence of reproductive senescence in two species of toothed whales, convincing evidence of reproductive senescence has not been demonstrated for right whales so no differences in bone density are expected between this reproductively active female and older females of the species (Kraus, et al., 2007, Mann, et al., 2000). However, small differences due to decreased bone mineral density in females with age, compared to males, may result in the sampled bone having a slightly lower bone mineral density than a male of comparable age.

The decreased bone density (relative to other species) combined with differences in the internal structure of cortical and trabecular bone (i.e. the presence of transitional bone rather than a definitive demarcation between cortical and trabecular bone) are likely more significant than small differences between aging females and males of the same species. Together, the low relative bone density and marked differences in the internal structure of cortical and trabecular bone found in samples extracted from Eg\#1004 are taken as evidence of species-specific differences in bone structure. Therefore, it is reasonable to assume that this individual, for which postmortem findings and a 29 -year sighting record revealed no evidence of chronic disease, is representative of the larger population of right whales and was thus an appropriate specimen for this study (Right Whale Consortium, 2007). 


\subsubsection{Implications for fracture risk}

The apparent density of bone, above all other bone parameters investigated, is the primary predictor of the stiffness and strength of bone tissue (Keller, 1994). Bone failure results when the magnitude of applied stress exceeds the ultimate strength of a given region (Huiskes and van Rietbergen, 2005).

From this it follows that regions of lower density and thereby lower ultimate strength will be more susceptible to fracture (assuming all regions are protected from or exposed to equal load distribution). All else being equal, bone density data reported here indicate that the caudal segments (labeled A and B in this study) may be more susceptible to failure.

While this is a logical conclusion based on the data from the present study, it fails to explain contradictory evidence found in three whales with mandibular fractures resulting from vessel-whale collisions. Each of these animals had closed, complete, transverse mandibular fractures located approximately 1.5 meters caudal to the symphysis (Right Whale Consortium, 2007). The location of the fractures corresponds to segment D in Figure 3.1. This finding is in direct opposition to the outcomes predicted assuming that density was the primary factor influencing the ultimate strength of the jawbone.

One factor that may contribute to the pattern of fracture described is the thickness of the soft tissue overlying the jaw. In fact, increased soft tissue thickness has been shown to reduce peak force at loading of the human hip during experimental falls (Robinovitch, et al., 1991). There is clearly an inverse relationship between the density of 
mandibular bone and the thickness of the soft tissue overlying it (Figure 3.5). The density of the mandible increases longitudinally toward the symphysis, while the soft tissue thickness decreases toward the symphysis at all regions sampled. This soft tissue is composed of a thin layer of black skin $(\sim 1.0 \mathrm{~cm}$ thick) overlying white fibroelastic (FE) connective tissue, interdigitated by muscle papillae (MP) extending up from a basal muscle layer (BML) (Figure 3.6). Beneath the basal muscle layer lays a fibrous sheath directly surrounding the bone (not pictured). A small portion of the mandible is seen at the bottom of the image. As a viscoelastic material, this soft tissue would likely play the role of a "bumper" by absorbing and re-distributing applied loads.

The apparent density of right whale mandibular bone and the thickness of right whale soft tissue may likely play a cooperative role in providing the lower jaw of the right whale with the stiffness and strength that it needs, on a gross level, to function as a feeding apparatus. Bone mineral density and soft tissue thickness have been used as "predictors of fracture force" in studies of fracture in the human hip (Etheridge, et al., 2005). Ideally the apparent density of right whale jawbone tissue and right whale soft tissue thickness may be translated into units quantifying the fracture risk based upon how each of their specific material properties influence the results of applied loading (Robinovitch, et al., 1991). By incorporating contributions from both skin thickness and bone apparent density, with the common unit of fracture risk, the "additive fracture risk" could be expressed as a function of distance along the jawbone to reveal regions susceptible to failure when sufficient stress is applied. Ongoing work regarding the 
biomechanical behavior of right whale soft tissue overlying the mandible will inform

such an analysis.

Figure 3.5: The depth of soft tissue overlying the right whale mandible plotted as a function of distance from the symphysis (yellow triangles). Diamonds (blue) and squares (pink) represent QCT apparent density values for trabecular and cortical bone (g/cc). Soft tissue thickness was measured in right whale, Eg\# 1909 while QCT density was measured in Eg\# 1004.

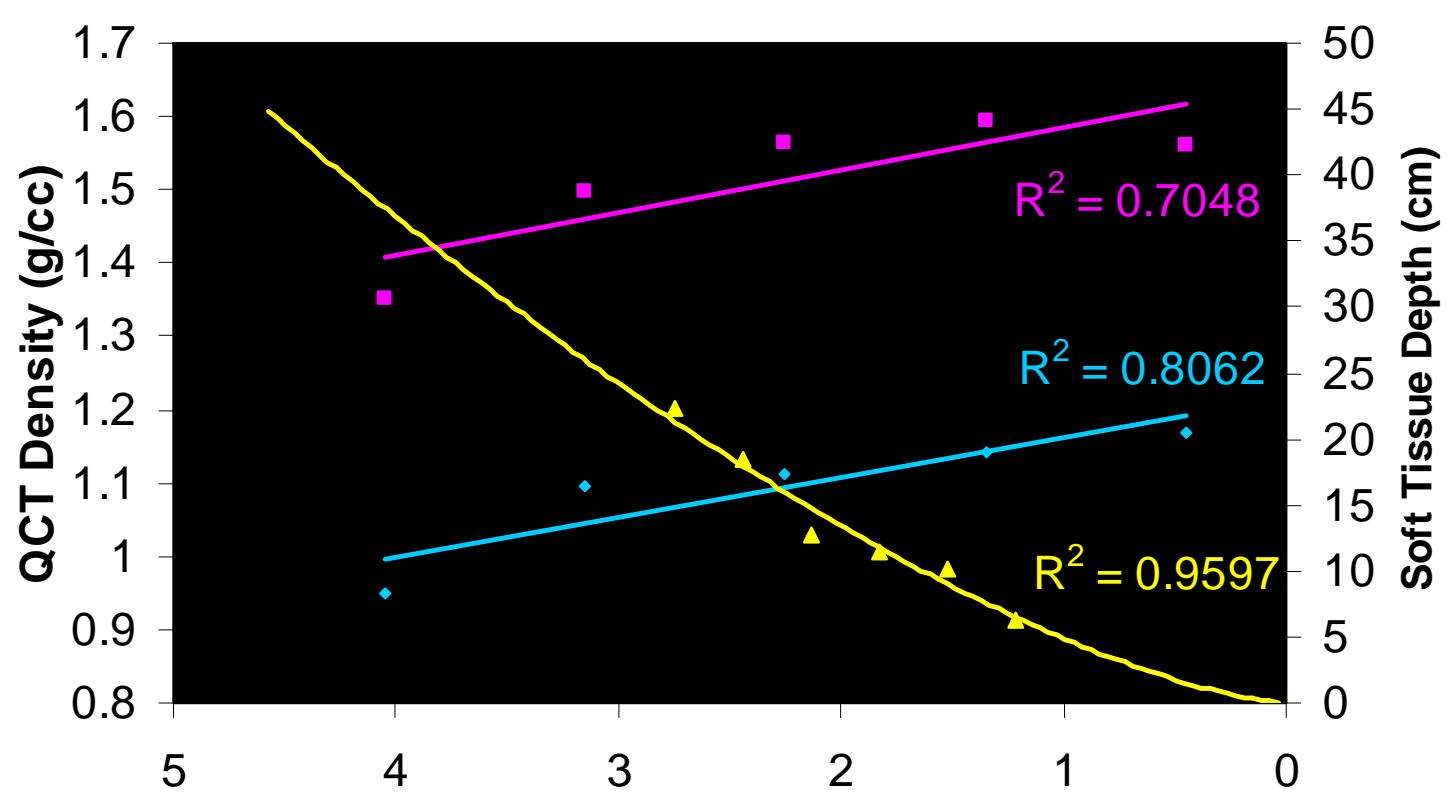

Distance from Symphysis $(\mathrm{m})$

$\checkmark$ Avg. Trabecular QCT Apparent Density ( $\mathrm{y}=-0.0576 \mathrm{x}+1.6424)$

- Avg. Cortical QCT Apparent Density $(\mathrm{y}=-0.0541 \mathrm{x}+1.2158)$

A Soft Tissue Depth $\left(\mathrm{y}=4.8806 \mathrm{x}^{1.4585}\right)$ 
Figure 3.6: Close-up of soft tissue stratification overlying the mandible in Eg\# 1004. Note the skin (top layer, black) overlying creamy, white fibroelastic (FE) connective tissue, grading into a transition zone (TZ) where muscle papillae (MP) interdigitate into the connective tissue layer superficial to the basal muscle. The soft tissue is separated from the bone by a thin sheath (not visible). Part of the mandible can be seen at the bottom of the image.

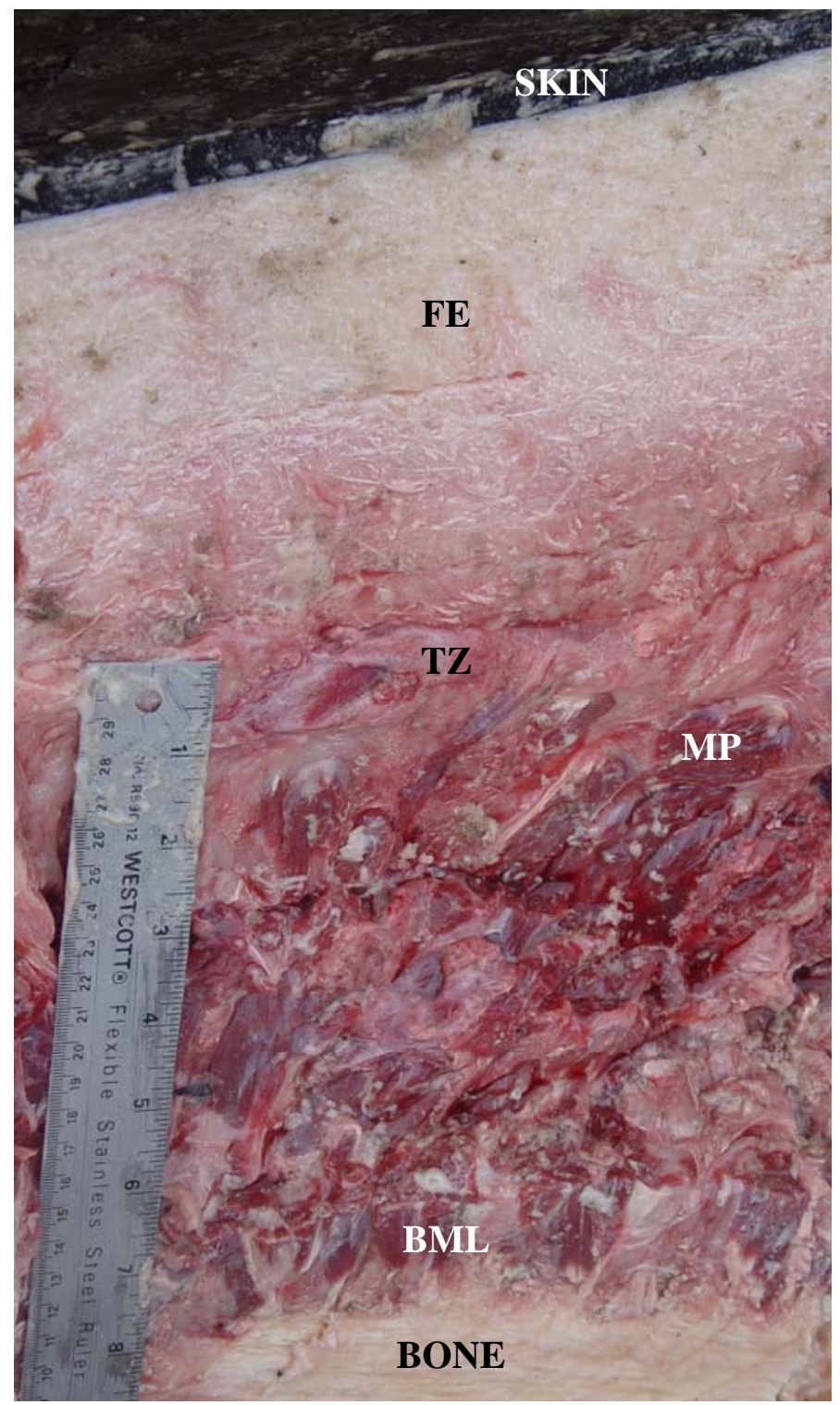




\subsection{FUTURE WORK}

The right whale jaw bone's physical and material properties revealed by this study will be used as the foundation of a biomechanical model of vessel-whale collisions. Specifically, the detailed density map of the mandible produced using QCT will be transformed into a detailed map of the material properties (e.g. Young's modulus and ultimate strength) once experimental testing is conducted to correlate these material properties to apparent density measurements. Young's modulus is a measure of the "stiffness" of a material, while the ultimate strength is the maximum applied stress before material failure (Currey, 2002). These material properties will serve as important parameters for predicting the mechanical response of the mandible to applied stress.

A finite element model, developed in collaboration with I. Tsukrov, K. Baldwin and J. DeCew of the University of New Hampshire (Durham, NH) was designed to return the magnitude and distribution of engineering stress resulting from applied load. The applied load in this case represents the load that would be imposed on the bone during a vessel-whale collision. By varying collision parameters such as vessel mass and speed, the model outcomes can be used to interpret the efficacy of speed restrictions for given vessel mass and speed combinations. The novel data reported here serve as a first step toward that overarching goal of evaluating speed restrictions for various vessel classes as a mechanism of reducing vessel-whale collision mortality in this highly endangered species. 


\subsection{ACKNOWLEDGEMENTS}

Co-authors would like to acknowledge the invaluable assistance of contributors without whom his interdisciplinary ship would not have sailed - Vicke Starczak (WHOI), Roberto Fajardo, John A. Muller, Nipun Patel, and Brian Snyder (Beth Israel Deaconess Medical Center). The technical assistance provided by Robin E. Fail (University of North Carolina Chapel Hill), Don Duncan, Patrick Barthelemy and Kathy Tinoco (Mercury Computer Systems) was also vital and appreciated. Special thanks to Judson DeCew of the University of New Hampshire and the Cape Cod Stranding Network (Buzzard's Bay, MA). Funding for this project was provided by the National Science Foundation (Graduate Research Fellowship Program, Campbell-Malone), National Oceanic and Atmospheric Administration (Right Whale Grants Program, 2004, PI Campbell-Malone, Award No. NA04NMF4720402), Ocean Life Institute (PI Campbell-Malone and PI Moore).

All right whale samples were collected under National Marine Fisheries Service No. 932-1489-05. 


\subsection{LITERATURE CITED}

Baumgartner, M. F., C. A. Mayo and R. D. Kenney, 2007. Chapter 5: Enormous Carnivores, Microscopic Food, and a Restaurant That's Hard to Find. In: Kraus, S. D. and Rolland, R. M., Eds. The Urban Whale: North Atlantic Right Whales at the Crossroads. Harvard University Press. Cambridge, MA. pp. 138-173.

Bouetel, V., 2005. Phylogenetic Implications of Skull Structure and Feeding Behavior in Balaenopterids (Cetacea, Mysticeti). Journal of Mammalogy 86 (1), pp. 139-146.

Brodie, P. K., 2001. Feeding mechanisms of rorquals (Balaenoptera sp.). In: Mazin, J.-M. and de Buffrenil, V., Eds. Secondary Adaptations of Tetrapods to Life in Water. Verlag Dr. Friedrich Pfeil. Munchen, Germany. pp. 345-352.

Campbell-Malone, R., S. G. Barco, P.-Y. Daoust, A. R. Knowlton, W. A. McLellan, D. S. Rotstein and M. J. Moore, 2007. Sharp and blunt trauma in North Atlantic right whales killed by vessels. Journal of Zoo and Wildlife Medicine, in press.

Carter, D. R., W. E. Caler, D. M. Spengler and V. H. Frankel, 1981. Uniaxial fatigue of human cortical bone. The influence of tissue physical characteristics. Journal of Biomechanics 14 (7), pp. 461-470.

Carter, D. R. and W. C. Hayes, 1977. The compressive behavior of bone as a two-phase porous structure. The Journal of Bone and Joint Surgery 59 (7), pp. 954-962.

Carter, D. R., Hayes, Wilson C., 1976. Bone Compressive Strength: The Influence of Density and Strain Rate. Science 194 (4270), pp. 1174-1176.

Ciarelli, M. J., S. A. Goldstein, J. L. Kuhn, D. D. Cody and M. B. Brown, 1991. Evaluation of orthogonal mechanical properties and density of human trabecular bone from the major metaphyseal regions with materials testing and computed tomography. Journal of Orthopaedic Research 9 (5), pp. 674-682.

Currey, J., 1988. The effects of porosity and mineral content on the Young's modulus of elasticity of compact bone. J. Biomechanics 21, pp. 131-139.

Currey, J., 2004. Tensile yield in compact bone is determined by strain, post-yield behaviour by mineral content. Journal of Biomechanics 37, pp. 549-556.

Currey, J. D., 1975. The effects of strain rate, reconstruction and mineral content on some mechanical properties of bovine bone. Journal of Biomechanics 8 (1), pp. 81-82.

Currey, J. D., 2002. Bones: structure and mechanics. Princeton University Press. Princeton, NJ. 436 pages.

Etheridge, B. S., D. P. Beason, R. R. Lopez, J. E. Alonso, G. McGwin and A. W. Eberhardt, 2005. Effects of Trochanteric Soft Tissues and Bone Density on Fracture of the Female Pelvis in Experimental Side Impacts. Annals of Biomedical Engineering 33 (2), pp. 248-254.

Ford, C. M. and T. M. Keaveny, 1996. The dependence of shear failure properties of trabecular bone on apparent density and trabecular orientation. Journal of Biomechanics 29 (10), pp. 1309-1317.

Genant, H. K., C. C. Gluer and J. C. Lotz, 1994. Gender differences in bone density, skeletal geometry, and fracture biomechanics. Radiology 190 (3), pp. 636-640. 
Gilbert, S. F., 1997. Chapter 18: Development of the tetrapod limb. In: Gilbert, S. F., Ed. Developmental Biology Sinauear Associates, Inc. Sunderland, Massachusetts. pp. 701-731.

Goldstein, S. A., 1987. The mechanical properties of trabecular bone: Dependence on anatomic location and function. Journal of Biomechanics 20 (11-12), pp. 10551061.

Guglielmini, C., A. Zotti, D. Bernardini, M. Pietra, M. Podestá and B. Cozzi, 2002. Bone density of the arm and forearm as an age indicator in specimens of stranded striped dolphins (Stenella coeruleoalba). The Anatomical Record 267 (3), pp. 225-230.

Hayes, W. C. and M. L. Bouxsein, 1997. Chapter 3: Biomechanics of Cortical and Trabecular Bone: Implications for Assessment of Fracture Risk. In: Mow, V. C. and Hayes, W. C., Eds. Basic Orthopaedic Biomechanics. Lippincott-Raven Publishers. New York. pp. 69-112.

Hong, J., G. D. Cabe, J. R. Tedrow, J. A. Hipp and B. D. Snyder, 2004. Failure of trabecular bone with simulated lytic defects can be predicted non-invasively by structural analysis. Journal of Orthopaedic Research 22, pp. 479-486.

Huiskes, R. and B. van Rietbergen, 2005. Biomechanics of Bone. In: Mow, V. C. and Huiskes, R., Eds. Basic Orthopaedic Biomechanics and Mechano-Biology. Lippincott, Williams \& Wilkins. New York. pp. 123-179.

Jackson, S. and R. Thomas, 2004. Cross-sectional Imaging Made Easy. Churchill Livingstone. 160 pages.

Kabel, J., B. van Rietbergen, A. Odgaard and R. Huiskes, 1999. Constitutive relationships of fabric, density, and elastic properties in cancellous bone architecture. Bone 25 (4), pp. 481-486.

Karlsson, C., K. J. Obrant and M. Karlsson, 2001. Pregnancy and Lactation Confer Reversible Bone Loss in Humans. Osteoporosis International 12 (10), pp. 828834.

Keller, T. S., 1994. Predicting the compressive mechanical behavior of bone. Journal of Biomechanics 27 (9), pp. 1159-1168.

Knowlton, A. R. and S. D. Kraus, 2001. Mortality and serious injury of northern right whales (Eubalaena glacialis) in the western North Atlantic Ocean. Journal of Cetacean Research and Management Special Issue 2, pp. 193-208.

Kopperdahl, D. L. and T. M. Keaveny, 1998. Yield strain behavior of trabecular bone. Journal of Biomechanics 31 (7), p. 601.

Kraus, S. D., M. W. Brown, H. Caswell, C. W. Clark, M. Fujiwara, P. K. Hamilton, R. D. Kenney, A. R. Knowlton, S. Landry, C. A. Mayo, W. A. McLellan, M. J. Moore, D. P. Nowacek, D. A. Pabst, A. J. Read and R. M. Rolland, 2005. North Atlantic Right Whales in Crisis. Science 309 (5734), pp. 561-562.

Kraus, S. D., R. M. Pace III and T. R. Frasier, 2007. Chapter 6: High Investment, Low Return: The Strange Case of Reproduction in Eubalaena glacialis. In: Kraus, S. D. and Rolland, R. M., Eds. The Urban Whale: North Atlantic Right Whales at the Crossroads. Harvard University Press. Cambridge, MA. pp. 172-199. 
Kraus, S. D. and R. M. Rolland, 2007. Chapter 1: Right Whales in the Urban Ocean. In: Kraus, S. D. and Rolland, R. M., Eds. The Urban Whale: North Atlantic Right Whales at the Crossroads. Harvard University Press. Cambridge, MA. pp. 1-38.

Kriewall, T. J., G. K. McPherson and A. C. Tsai, 1981. Bending properties and ash content of fetal cranial bone. Journal of Biomechanics 14 (2), pp. 73-79.

Laist, D. W., A. R. Knowlton, J. G. Mead, A. S. Collet and M. Podesta, 2001. Collisions between ships and whales. Marine Mammal Science 17 (1), pp. 35-75.

Lambertsen, R., N. Ulrich and J. Straley, 1995. Frontomandibular Stay of Balaenopteridae: A Mechanism for Momentum Recapture During Feeding. Journal of Mammalogy 76 (3), pp. 877-899.

Lambertsen, R. H., K. J. Rasmussen, W. C. Lancaster and R. J. Hintz, 2005. Functional morphology of the mouth of the bowhead whale and its implications for conservation. Journal Of Mammalogy 86 (2), pp. 342-352.

Laval-Jeantet, A. M., B. Roger, S. Bouysee, C. Bergot and R. B. Mazess, 1986. Influence of vertebral fat content on quantitative CT density. Radiology 159 (2), pp. 463466.

Le, H. M. and M. S. Liu, 1997. Standard Operating Procedure: Determination of Ash Content. Beth Israel Deaconess Medical Center. Boston, MA.

Lees, S., D. Hanson and E. Page, 1996. Some acoustical properties of the otic bones of a fin whale. Journal of the Acoustical Society of America 99 (4), pp. 2421-2427.

Lind, P. M., A. Bergman, M. Olsson and J. Orberg, 2003. Bone Mineral Density in Male Baltic Grey Seal (Halichoerus grypus). Ambio 32 (6), pp. 385-388.

Mann, J., R. C. Connor, P. L. Tyack and H. Whitehead, Eds. 2000. Cetacean Societies: Field Studies of Dolphins and Whales. The University of Chicago Press. Chicago. 433 pages.

Martin, R. B. and D. L. Boardman, 1993. The effects of collagen fiber orientation, porosity, density, and mineralization on bovine cortical bone bending properties. Journal of Biomechanics 26 (9), pp. 1047-1054.

Martin, R. B., D. B. Burr and N. A. Sharkey, 1998. Skeletal Tissue Mechanics. Springer. New York. 392 pages.

Miller, M. E., G. C. Christensen and H. E. Evans, 1964. Anatomy of the Dog. W.B. Saunders Company. Philadelphia. 941 pages.

Misch, C. E., Z. Qu and M. W. Bidez, 1999. Mechanical properties of trabecular bone in the human mandible: Implications for dental implant treatment planning and surgical placement. Journal of Oral and Maxillofacial Surgery 57 (6), pp. 700706.

Moore, M. J., A. R. Knowlton, S. D. Kraus, W. A. McLellan and R. K. Bonde, 2005. Morphometry, gross morphology and available histopathology in North Atlantic right whale (Eubalaena glacialis) mortalities (1970 to 2002). Journal of Cetacean Research and Management 6 (3), pp. 199-214.

Mull, R. T., 1984. Mass estimates by computed tomography: physical density from CT numbers. American Journal of Roentgenology 143 (5), pp. 1101-1104. 
Ong, F. R. and K. Bouazza-Marouf, 2000. Evaluation of bone strength: correlation between measurements of bone mineral density and drilling force. Proceedings of the Institution of Mechanical Engineers 214 (Part H), pp. 385-399.

Perrin, W., B. Wursig and J. G. M. Thewissen, 2002. Encyclopedia of Marine Mammals. Academic Press. Boston. 1414 pages.

Philo, L. M., C. Hanns and J. C. George, 1990. Fractured mandible and associated oral lesions in a subsistence-harvested bowhead whale (Balaena mysticetus). 26. 125128.

Raymond, J. R., 2007. Development of a Numerical Model to Predict Impact Forces in a North Atlantic Right Whale During Collision with a Vessel. Master of Science. University of New Hampshire. Durham, NH. 100 pages.

Rice, J. C., S. C. Cowin and J. A. Bowman, 1988. On the dependence of the elasticity and strength of cancellous bone on apparent density. Journal of Biomechanics 21 (2), pp. 155-168.

Ridgway, S. H. and R. J. Harrison, Eds. 1985. Handbook of Marine Mammals, Volume 3: The Sirenians and Baleen Whales Handbook of Marine Mammals. Academic Press. 330 pages.

Riggs, B. L., H. W. Wahner, W. L. Dunn, R. B. Mazess, K. P. Offord and L. J. Melton III, 1981. Differential changes in bone mineral density of the appendicular and axial skeleton with aging: relationship to spinal osteoporosis. The Journal of Clinical Investigation 67 (2), pp. 328-335.

Right Whale Consortium, 2007. North Atlantic Right Whale Consortium Photo-ID, Sightings, Genetics, Contaminants and Necropsy Database. New England Aquarium, Boston, MA, USA.

Robinovitch, S. N., W. C. Hayes and T. A. McMahon, 1991. Prediction of femoral impact forces in falls on the hip. Journal of Biomechanical Engineering 113: (4), pp. 366-74.

Sarkar, B. C. R. and U. P. S. Chauhan, 1967. A new method for determining micro quantities of calcium in biological materials. Analytical Biochemistry 20 (1), pp. 155-166.

Schaffler, M. B. and D. B. Burr, 1988. Stiffness of compact bone: Effects of porosity and density. Journal of Biomechanics 21 (1), pp. 13-16.

Sharp, D., K. Tanner and W. Bonfield, 1990. Measurement of the density of trabecular bone. J. Biomechanics 23, pp. 853-857.

Tabensky, A. D., J. Williams, V. DeLuca, E. Briganti and E. Seeman, 1996. Bone mass, areal, and volumetric bone density are equally accurate, sensitive, and specific surrogates of the breaking strength of the vertebral body: an in vitro study. Journal of Bone and Mineral Research 11 (12), pp. 1981-1988.

Vanderlaan, A. S. M. and C. T. Taggart, 2007. Vessel Collisions with Whales: The probability of lethal injury based on vessel speed. Marine Mammal Science 23 (1), pp. 144-156.

von Dassow, G. and E. Munro, 1999. Modularity in animal development and evolution: Elements of a conceptual framework for EvoDevo. The Journal of Experimental Zoology 285 (4), pp. 307-325. 
Wall, W. P., 1983. The Correlation between High Limb-Bone Density and Aquatic Habits in Recent Mammals. Journal of Paleontology 57 (2), pp. 197-207.

Wang, X., J. D. Mabrey and C. M. Agrawal, 1998. An interspecies comparison of bone fracture properties. Bio-Medical Material and Engineering 8, pp. 1-9.

Weaver, J. K. and J. Chalmers, 1966. Cancellous Bone: Its Strength and Changes with Aging and an Evaluation of Some Methods for Measuring its Mineral Content. Journal of bone and Joint Surgery 48 (2), pp. 289-299.

Weiner, S. and H. Wagner, 1998. The Material Bone: Structure-Mechanical Function Relations. Annual Review of Materials Science 28, pp. 271-298.

Werth, A. J., 2004. Models of hydrodynamic flow in the bowhead whale filter feeding apparatus. The Journal of Experimental Biology 207 (1), pp. 3569-3580.

Yildiz, M. and B. Oral, 2006. The effect of pregnancy and lactation on bone mineral density in fluoride-exposed rats. Toxicology and Industrial Health 22, pp. 217222.

Zeni, S., A. Weisstaub, S. Di Gregorio, P. Ronanre de Ferrer and M. L. d. Portela, 2003. Bone Mass Changes In Vivo During the Entire Reproductive Cycle in Rats Feeding Different Dietary Calcium and Calcium/Phosphorus Ratio Content. Calcified Tissue International 73 (6), pp. 594-600.

Zeni, S. N., S. Di Gregorio and C. Mautalen, 1999. Bone mass changes during pregnancy and lactation in the rat. Bone 25 (6), pp. 681-685.

Zioupos, P., J. D. Currey, A. Casinos and V. De Buffrenil, 1997. Mechanical properties of the rostrum of the whale Mesoplodon densirostris, a remarkably dense bony tissue. Journal of Zoology, London 241, pp. 725-737. 


\section{Chapter 4}

Material Properties of the North Atlantic Right Whale Mandible: a fatal endpoint for vessel-whale collision modeling*

*This chapter is currently in prep as:

Campbell-Malone, R., Muller, J. A., Tsukrov, I., Moore, M. J., 2007. Material

Properties of the North Atlantic Right Whale Mandible: a fatal endpoint for vesselwhale collision modeling. 66 pages. 


\section{ABSTRACT}

The North Atlantic right whale, Eubalaena glacialis, is one of the most critically endangered whales in the world and is subject to high anthropogenic mortality. Vesselwhale collisions and entanglement in fishing gear were indicated in 27 (67.5\%) of the 40 right whales necropsied between 1970 and December 2006. Of those, at least 9 deaths $(22.5 \%)$ resulted from blunt contact with a vessel. To reduce the likelihood of fatal collisions, speed restrictions are being considered for vessels traversing critical habitat, although the effects of speed on collision outcomes have not been specifically evaluated from a biomechanical perspective.

The ultimate goal of an on-going collaborative project is to evaluate the efficacy of speed restrictions for reducing blunt collision mortality using a finite element (FE) model. Complete, transverse fracture of the right whale mandible, an injury seen only in right whales killed by vessels, is used as a proxy for mortality for the model. Vital for that model are the material properties and biomechanical behavior of the right whale mandible. These are determined for the first time in the present study.

Here, the internal structure and physical properties of right whale jawbone tissue are reported. The average apparent density $(0.5140 \mathrm{~g} / \mathrm{cc}$, S.D. \pm 0.1041 and $1.2370 \mathrm{~g} / \mathrm{cc}$, S.D. \pm 0.0535 for trabecular and cortical bone respectively) indicate that the bone is of relatively low density. The value for trabecular bone is much lower than that predicted for trabecular bone using quantitative computed tomography (QCT) (1.0940 g/cc, S.D. \pm 0.1200). The difference between QCT and measured apparent density was nearly 2-fold, 
making QCT a poor estimate of apparent density when the methods utilized in this study are employed.

Material properties of right whale bone (Young's modulus of elasticity and the ultimate strength) were determined via uniaxial compression testing. Experimentally determined values for Young's modulus $\left(\mathrm{E}_{\mathrm{exp}}\right)$ were then compared to estimates of Young's modulus from QCT and were found to be 30-fold lower than QCT predictions. An alternative function utilizing CT numbers to predict Young's modulus proved more consistent with $\mathrm{E}_{\exp }\left(-18 \%\right.$ difference from $\left.\mathrm{E}_{\mathrm{exp}}\right)$.

These data, representing the first published account of the biomechanical behavior of right whale bone, can be incorporated into the FE model to determine loading conditions that likely lead to mandibular failure and thereby mortality from blunt vessel collisions. Data from this study are critical toward evaluating the efficacy of speed restrictions for vessels in right whale critical habitat.

\subsection{INTRODUCTION}

The North Atlantic right whale, Eubalaena glacialis, is one of the most critically endangered whales in the world (International Whaling Commission, 2001). Anthropogenic mortality, including deaths resulting from vessel-whale collisions and entanglement in fishing gear, accounted for 27 (67.5\%) of the 40 right whales examined postmortem between 1970 and December 2006 (Campbell-Malone, et al., 2007b, Moore, et al., 2005). Of those deaths, 21 (52.5\%) were attributed to vessel-whale collisions and at least $9(22.5 \%)$ of those resulted from blunt contact with the hull of a vessel. 
A thorough review of available necropsy reports for right whales examined during the same time period revealed common blunt trauma injuries seen in right whales killed by vessels. These included hemorrhage, broken bones (i.e. skulls, jaws and vertebrae) and disarticulated ribs (Campbell-Malone, et al., 2007b).

4.1.1 Mandibular fracture as a proxy for fatality from vessel-whale collisions

A previous study identified mandibular fracture as an appropriate fatal endpoint upon which a vessel-whale collision model could be based for several reasons (CampbellMalone, et al., 2007a). Firstly, a fractured mandible has been found in $3(33 \%)$ of the 9 right whales that succumbed as a direct result of blunt trauma from a vessel-whale collision (Figure 4.1a) (Campbell-Malone, et al., 2007a). Secondly, with appropriate failure criteria, bone fracture can be modeled as a binary condition (i.e. failure or no failure). In addition, no fully healed jaw fractures have been found to date in right whales, making mandibular fracture a reasonable proxy for fatality.

The simple geometry of this bone also makes it a practical structure to model when compared to the complex geometry of other skeletal components (e.g. the skull or vertebrae). Furthermore, the right whale mandible has relatively thin soft tissue protection (on the order of $20 \mathrm{~cm}$ total, compared to $20 \mathrm{~cm}$ of highly fibroelastic blubber overlying an even thicker layer of skeletal muscle covering the rest of the skeletal elements). Finally, the length of the mandible of large whales, measuring $25-30 \%$ of the total body length, represents one of the longest single bones in any extant group and is a 
relatively large target in the vessel-whale collision scenario (Campbell-Malone, et al., 2007a).

\subsubsection{Motivation for present study}

U.S. management entities responsible for the protection of the North Atlantic right whale are in the process of developing speed restrictions for vessels traveling through right whale critical habitat in an effort to reduce the likelihood of fatal collisions (Balsiger, 2006). The ultimate goal of an on-going collaborative project is to evaluate the efficacy of speed restrictions in terms of reducing the force of impact and thereby mortality due to vessel collisions. This will be done using a finite element (FE) model to compare the failure outcomes resulting from various loading conditions on whale skeletal components. Vital for that model are data regarding the material properties and biomechanical behavior of a right whale or its components.

The present study seeks to inform the finite element model of vessel-whale collisions by defining the material properties of the right whale jaw bone as determined via mechanical testing and quantitative computed tomography. Biomechanical studies of skeletal elements rely on the basic assumptions that bone fracture represents failure of a bone on two different scales - the tissue level and the structural or whole bone level (Hayes and Bouxsein, 1997). Here, the biomechanics of right whale bone tissue are reported for the first time. In the future, the finite element model will explore the biomechanical response of the whole bone to loading. 


\subsubsection{The right whale mandible}

The right whale mandible is composed of two bowed segments that articulate caudally at the temporomandibular joint and are joined rostrally by fibroelastic connective tissue at the mandibular symphysis (Miller, et al., 1964). The rounded caudal end, known as the ramus, has a low vertical profile and the articular process lacks the "Lshape" typical of the mammalian jaw (Miller, et al., 1964).

Computed tomography has been utilized in a prior study to explore the internal structure of the right whale mandible using computed tomography (CT) (CampbellMalone, et al., 2007a). CT image reconstruction revealed the bone to be composed of bone tissue ( $95.6 \%$ by volume), the mandibular canal ( $4.31 \%$ by volume) and internal void spaces $(0.07 \%$ by volume) (Campbell-Malone, et al., 2007a).

The bone tissue varies in structure from porous, low density trabecular bone to denser cortical bone. The density of bone in the right whale mandible was found to vary in cross-section and longitudinally. In cross-section, cortical bone composes the outer shell of the bone which then increases in porosity medially toward the inner medulla which is made up of trabecular bone (Campbell-Malone, et al., 2007a). Longitudinally, both cortical and trabecular bone show a subtle but statistically significant increase in apparent density from the caudal end toward the rostral apex (Campbell-Malone, et al., 2007a).

While some studies treat trabecular and cortical bone as the same material (albeit on opposite ends of the density continuum), others prefer to regard them separately as materials with their own unique physical and material properties (Currey, 2002, 
Hernandez, et al., 2001, Rice, et al., 1988). For this study, trabecular and cortical bone were investigated separately and were compared where appropriate.

Figure 4.1: Right whale mandibles: a) fractured right mandible of right whale Eg\# 2150. b) Reconstruction of the right mandible of right whale Eg\# 1004. This mandible was cut into 5 segments (identified A-E). The caudal end is at right, rostral to the left. Samples were extracted from segment B. Image b created in collaboration with Judson DeCew, University of New Hampshire.
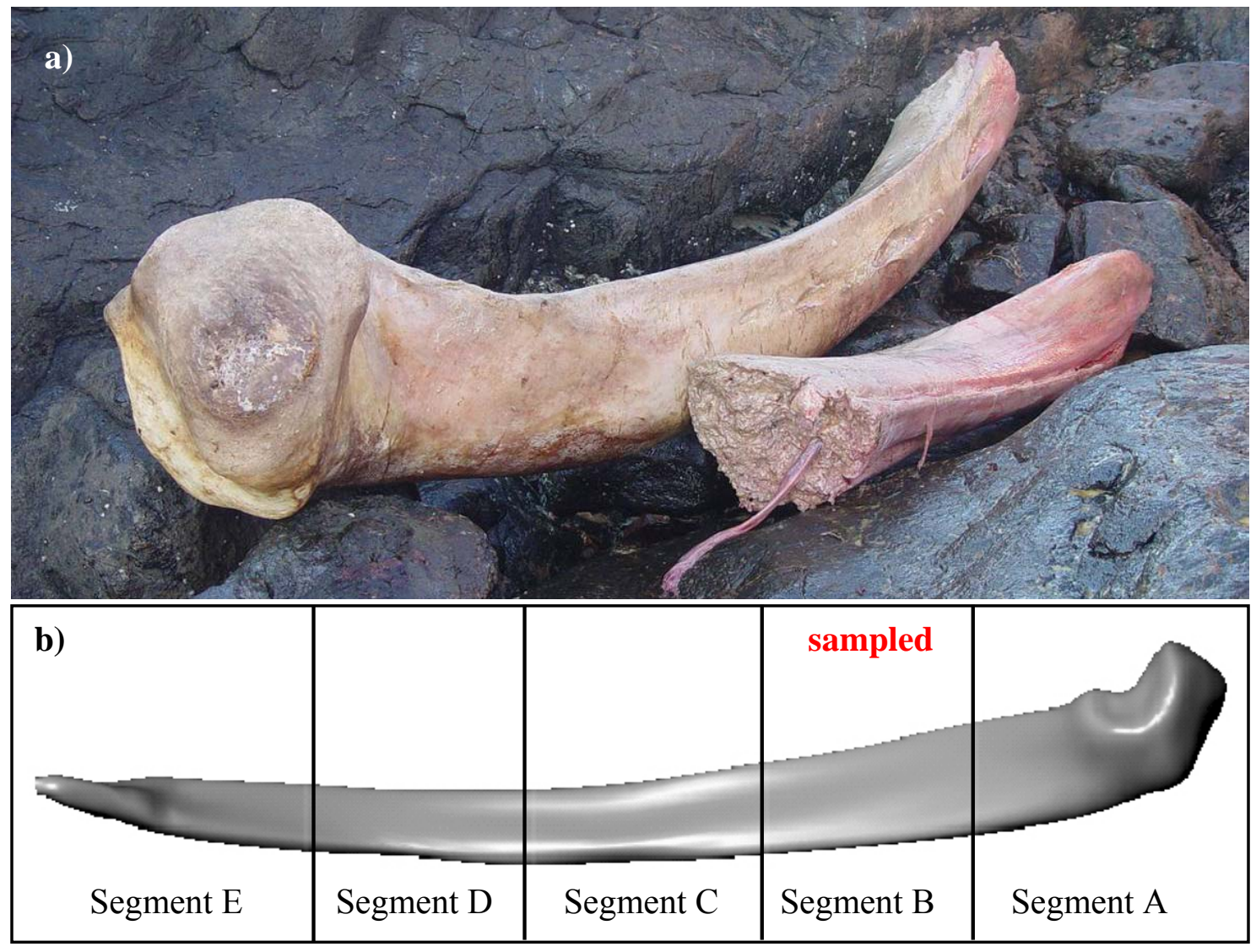

4.1.4 Physical properties as a predictor of material properties in bone

Predicting the risk of bone fracture has been a topic of extreme clinical interest as it relates to higher likelihood of fracture and their sequelae in the elderly (Gibson and 
Ashby, 1997, Hong, et al., 2004, Rice, et al., 1988). A plethora of experimental studies exist that have investigated the link between the physical properties of bone (i.e. mineral or ash density, bone volume fraction, relative composition, porosity and apparent density) and its material properties (i.e. Young's modulus of elasticity, shear modulus, yield stress, ultimate compressive strength, and fracture toughness) (Carter, 1976, Currey, 1988, 2004, Currey, 1975, Giesen, et al., 2004, Goulet, et al., 1994, Hodgskinson and Currey, 1990a, Hodgskinson and Currey, 1990b, Keller, 1994, Martin and Boardman, 1993, Misch, et al., 1999, Rice, et al., 1988, Uchiyama, et al., 1999, Yan, et al., 2006). Several studies have found that apparent density is the strongest predictor of select material properties, including Young's modulus and the ultimate strength (Ashby, 1983, Hodgskinson and Currey, 1990a, Hodgskinson and Currey, 1990b, Keller, 1994).

Correlations between physical and biomechanical properties in trabecular bone: A comprehensive review of studies investigating the relationship between the physical properties and biomechanical behavior of trabecular bone reveals correlations that are both species-specific and anatomically distinctive (Goldstein, 1987). While data are available from a wide variety of taxa, most studies regarding the mechanical behavior of trabecular bone focus primarily on the femur, tibia, vertebra, radius, humerus, and metacarpus (Currey, 2004, Currey, 2002, Hong, et al., 2004, Kabel, et al., 1999b, Keller, 1994, Les, et al., 2002, Ong and Bouazza-Marouf, 2000, Uchiyama, et al., 1999, Wang, et al., 1998). Comparisons with biomechanical studies of mandibles from other species were also explored where possible (Ashman, et al., 1985, Ashman and van Buskirk, 1987, Giesen, et al., 2004, Misch, et al., 1999). 
Correlations between physical and biomechanical properties in cortical bone:

Biomechanical studies of cortical bone have also revealed relationships between the basic physical properties of cortical bone (calcium content, apparent density, mineral volume fraction, etc.) and its material properties (yield stress, Young's modulus, ultimate stress, ultimate strain, etc.) (Carter, et al., 1981, Currey, 2004, Currey, 1998, 2002). A few factors have been explored in compact bone from across a wide array of taxa (Currey, 1988, 2004, Zioupos, et al., 1997).

Results from these inter-species studies show a clear correlation between physical parameters (e.g. calcium content) and mechanical properties (e.g. Young's modulus) with some scatter and few notable outliers (Currey, 2004). These data are from studies of compact bone from a variety of skeletal elements including the femur, tibia, metatarsus, radius, ulna, and humerus (Currey, 1988, 2004, Keller, 1994, Martin and Boardman, 1993, Schaffler and Burr, 1988).

The need for species-specific material properties: Even when standardized for bone type, studies of the biomechanical behavior of a given bone have revealed some inter-specific differences in the mechanical behavior of bone (Ashman, et al., 1985, Ashman and van Buskirk, 1987). Ultrasound studies have revealed canine mandibular bone tissue to be isotropic and homogenous, while human mandibular bone was characterized as anisotropic (Ashman, et al., 1985, Ashman and van Buskirk, 1987).

The surprising finding of homogeneity and isotropy in the dog was thought to be either a species-specific result or due to the lower relative age of the canine specimens used (Ashman, et al., 1985). Inter-specific differences in the mechanical properties of 
trabecular bone have been revealed in previous studies and generate caution against making cross-taxa generalizations or pooling data to develop cross-taxa trends without some validation in the species of interest (Rice, et al., 1988).

While trends may be apparent in other studies comparing bone tissue across taxa and in different bones, it is prudent to consider the dynamic nature of bone remodeling in response to loading, gross anatomy and functional morphology when inter-species comparisons are performed. Here, the mechanical behavior of right whale jaw bone tissue is investigated to provide species-specific and anatomically appropriate data regarding the material properties of this bone.

4.1.5 Apparent density as a predictor of Young's modulus and ultimate compressive strength

Apparent density has been shown to exhibit a positive correlation with two important material properties in bone and other porous materials - the compressive strength and Young's modulus of elasticity (Carter and Hayes, 1977, Galante, et al., 1970, Gibson and Ashby, 1997, Hong, et al., 2004). In fact, the apparent density of bone has been shown to have stronger correlations to mechanical properties than any other bone composition indicator analyzed (Keller, 1994).

Young's modulus of elasticity, also known simply as Young's modulus, is a measure of the stiffness of a given material. The ultimate compressive strength of a material is the peak stress measured during compression testing. 
The apparent density of right whale mandibular bone tissue was determined via manual densitometry so that both species-specific and mandible-specific relationships between apparent density and these two material properties could be examined following mechanical testing. Once the relationship between the apparent density and Young's modulus of right whale bone is determined empirically, it will be used as a standard to evaluate the use of quantitative computed tomography (QCT) as a non-destructive alternative for predicting Young's modulus indirectly.

\subsubsection{Predicting Young's modulus using quantitative computed tomography (QCT)}

Quantitative computed tomography, or QCT, is a non-invasive, calibrated, radiological imaging technology which permits the conversion of CT numbers (reported in Hounsfield units) into an estimate of the mineral or apparent density of a scanned object. Several studies have been conducted which correlate either the apparent density of bone specimens or CT numbers for scanned bone samples to Young's modulus as determined via mechanical testing (Carter and Hayes, 1977, Ciarelli, et al., 1991, Hong, et al., 2004, Rice, et al., 1988). The regression equations developed in these studies permit the estimation of Young's modulus for bone of known apparent density without the need for mechanical testing.

When used to examine skeletal elements, this technique has considerable advantages including the fact that it can be used both in vivo and on precious archival specimens without the destructive extraction of bone material required for standard densitometry techniques and mechanical testing. It can also be used to examine larger 
regions of bone (i.e. samples as large as 1 meter in length by $50 \mathrm{~cm}$ diameter) on a relatively fine scale without requiring the time consuming preparation of a large number of specimens.

Despite these advantages it is necessary to determine if any of the published regression equations, derived from human, bovine and whale trabecular bone, can be applied to right whales or if a species-specific relation must be determined. This will be evaluated via the direct comparison of estimated Young's modulus values from QCT to values derived from mechanical testing of right whale bone extracted from a limited area of the jaw representing a narrow range of apparent density values.

\subsubsection{Investigating anisotropy in right whale bone}

Trabecular orientation is an additional parameter known to directly influence the biomechanical behavior of bone tissue (Gibson and Ashby, 1997, Uchiyama, et al., 1999). In the present study, mechanical testing of right whale bone of known trabecular orientation was conducted to evaluate anisotropy in the right whale mandible. While the microstructure of trabecular bone has also been shown to be a factor influencing its material properties, exploring the substructure of right whale bone tissue is beyond the scope of this study (Gibson, 1985).

\subsubsection{Project objective and justification}

Together these data, regarding the mechanical response of right whale bone, represent species-specific values that were previously unknown. These are vital 
parameters that, once defined in this species, will aid in the assessment of fracture risk and the identification of vessel dynamics characteristics (e.g. vessel speed and vessel mass combinations) and collision scenarios (e.g. relative orientation of the whale and vessel) that promote or reduce the likelihood of vessel collision mortality in this critically endangered whale species. These data will enable future modeling exercises to evaluate the efficacy of proposed speed restrictions for vessels in right whale habitat.

\subsection{MATERIALS AND METHODS}

\subsubsection{Sample collection and preservation}

All samples used for biomechanical testing were extracted from the right mandible of right whale Eg\# 1004, a mature female right whale that died as a result of a vessel-whale collision (Right Whale Consortium, 2005). The animal measured $16.0 \mathrm{~m}$ in total length and was at least 29 years old, according to the sighting record maintained by the New England Aquarium (Right Whale Consortium, 2005).

At the time of necropsy, the animal's robust blubber coat and excellent skin condition indicated that it was in very good health prior to death and lacked obvious signs of chronic illness or starvation. Eg\# 1004 had also successfully reproduced at least five times and was pregnant with her sixth known offspring at the time of death (Right Whale Consortium, 2005).

After the animal was necropsied, the left and right halves of the mandible were retrieved and were frozen within days of the necropsy. These bones represent the freshest 
right whale mandibles available for study, with no appreciable loss of water or oil prior to sample preparation. Dehydration and degreasing of bone specimens can compromise the functional response of the bone to applied stress (Gibson and Ashby, 1997). The influence of marrow on the mechanical response of bone to loading has been demonstrated for high-strain loading conditions (Carter and Hayes, 1977).

The mandibles were wrapped in thick plastic sheeting and were stored at $-20^{\circ} \mathrm{C} \mathrm{(-}$ $4^{\circ} \mathrm{F}$ ) until samples were prepared for mechanical testing. The plastic sheeting was removed and the bone was then wrapped several times over in thin clear plastic wrap and was stored below room temperature $\left(60^{\circ} \mathrm{F}\right.$ or $\left.15.6^{\circ} \mathrm{C}\right)$ for one week during full-scale mechanical testing. During this time it was estimated that less than 4 ounces of fluid seeped from the entire bone. The bone was then re-wrapped in the plastic sheeting and was refrozen.

The whole bone was cut into five segments measuring approximately $90 \mathrm{~cm}$ straight length to conform to weight and length limits of the computed tomography (CT) scanner used for internal analysis. Segments were tightly wrapped in thin clear plastic as well as thick plastic sheeting to prevent desiccation and were frozen. Each segment was assigned a letter beginning at the caudal end (A) and ending at the rostral end (E) (Figure $4.1 b)$.

All bone samples used for densitometry and mechanical testing were extracted from segment B of the right mandible (Figure 4.1). This segment included bone between 1-2 meters cranial to the apex of the ramus. Destructive sampling was required for the preparation of specimens. Sampling was restricted to this region of the bone in 
recognition of the educational and aesthetic value of this museum quality skeleton.

Samples were drilled using a water-cooled concrete corer with a 1-11/4" wood drill bit (Eibenstock, Eibenstock, Germany, http://www.ee-eibenstock.de/). Samples were wrapped in saline-soaked gauze and were frozen. For biomechanical testing, samples were thawed and were maintained hydrated with physiological $(0.9 \%)$ saline at room temperature. Sample storage followed standard orthopedic biomechanics protocols that prior studies have shown do not influence biomechanical behavior to a significant extent (Hamer, et al., 1996).

\subsubsection{Manual densitometry}

Manual densitometry of trabecular and cortical bone was conducted according to standard protocols on a subset of specimens after mechanical testing (Campbell-Malone, et al., 2007a). Briefly, samples were defatted in $0.85-0.9 \%$ saline in a sonicator for approximately two weeks. Samples were centrifuged at 13,000 rpm for five minutes atop absorbent paper to remove water from pore spaces. Samples were then inverted and were spun for 5 additional minutes. The defatted mass $\left(\mathrm{m}_{\text {defatted }}\right)$ was then measured to determine the apparent density $\left(\rho_{\text {app }}\right)$ using the formula:

$$
\rho_{\text {app }}=\mathrm{m}_{\text {defatted }} / \mathrm{v}_{\text {caliper }}
$$

Apparent density was determined for a total of $58(69 \%)$ of the 84 trabecular and $5(45 \%)$ of the 11 cortical specimens tested in uniaxial compression.

\footnotetext{
${ }^{1}$ Tissue density was also determined for these samples as the specimen mass (including fat) divided by the specimen volume as determined by a digital caliper. These data are reported in the results section but are not discussed.
} 
4.2.3 Evaluating QCT apparent density as a predictor of apparent density and Young's modulus in right whale trabecular bone

Physical measurements of apparent density represent the standard for determining apparent density. To evaluate the use of QCT apparent density the deviation from the direct measurements of apparent density must be examined. Samples used for manual densitometry were extracted from segment B only and are thus compared to QCT measurements from segment B only. Percent difference was calculated between the average QCT measurements of apparent density (avg. QCT app. density) for segment B and physical measurements of apparent density (avg. $\rho_{\text {app }}$ ) according to the following equation:

$$
\% \text { difference }=100\left[\left(\text { avg. QCT app. density - avg. } \rho_{\text {app }}\right) / \text { avg. } \rho_{\text {app }}\right]
$$

Mechanical testing is a direct and appropriate method used to determine Young's modulus for a given material. To evaluate the use of QCT-derived values of Young's modulus the deviation from the mechanical testing data must be examined. Samples used for mechanical testing were extracted from segment B only and are thus compared to QCT-derived estimates of Young's modulus ( $\left.E_{\text {est }}\right)$ from segment B only. Percent difference was calculated between the average estimated Young's modulus (avg. E est $_{\text {) for }}$ segment B and experimentally derived values for Young's modulus (E) according to the following equation:

$$
\text { Percent difference }(\%)=100 \times\left[\left(\text { avg. } E_{\text {est }}-\text { avg. E }\right) / \text { avg. E }\right]
$$




\subsubsection{Mechanical testing}

Uniaxial compression testing was carried out on bone samples to determine the Young's modulus $(E)$ and ultimate strength $\left(\sigma_{\text {ult }}\right)$ for trabecular and cortical bone

Trabecular bone specimen preparation: The gross orientation of each trabecular specimen (with respect to the three primary axes of the jawbone) was preserved to coincide with the anatomy of the animal (Figure 4.2). This was done such that testing in compression along a given dimension could be correlated to the direction that an oncoming vessel would be traveling toward the whale in a hypothetical vessel-whale collision scenario. This step allowed trabecular bone to be evaluated for anisotropy.

Cylindrical specimens of trabecular bone were prepared from one-inch bone cores under constant irrigation with physiological saline using a 12" Delta drill press (Delta Machinery, Jackson, TN, www.deltamachinery.com) with a diamond-tipped coring bit. 84 specimens were machined and each measured approximately $7.5 \mathrm{~mm}$ in diameter and $10 \mathrm{~mm}$ in height.

Specimen orientation was determined based upon the presence of a primary direction of trabeculation during visual inspection and x-ray imaging. This confirmed the bone indeed had a well-organized microstructure with a distinct pattern of trabecular orientation. The three orthogonal axes (x-, y- and z-) were defined and were related back to the gross structure of the jawbone. These axes incidentally coincided with the gross axes indicated in Figure 4.2. A total of 16, 24 and 36 specimens were tested for the $x_{-}, y-$ and z-axes respectively. 
Figure 4.2: Schematic of three orthogonal axes of the right whale jawbone. Samples were extracted with directionality preserved such that compression testing simulated impact with a vessel traveling in the direction indicated by each arrow. Image adapted with permission from McLellan et al., 2004 (McLellan, et al., 2004) .

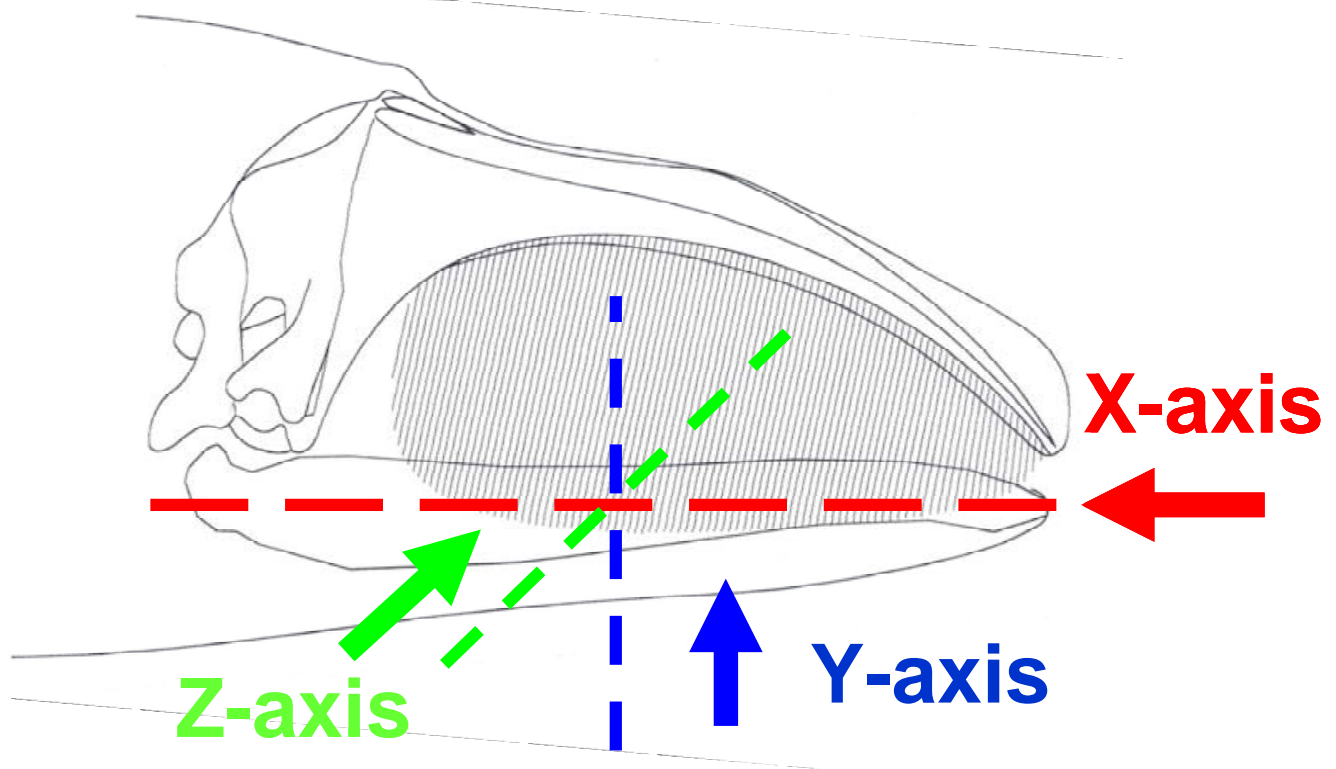

Cortical bone specimen preparation: Cortical bone was extracted from segment B from the right mandible of Eg\# 1004 using a handsaw. Eleven cylindrical specimens of cortical bone were machined using a Delta drill press following the same protocol used for the preparation of trabecular bone cylinders. Specimen orientation was not preserved for cortical bone, thus anisotropy could not be evaluated for this bone type.

Uniaxial compression testing: Trabecular bone samples were loaded between the platens of a MTS load frame (Eden Prairie, MN, USA, www.mts.com) with a momentrelief ball bearing above a mobile platen and a 1,000 N load cell. The testing apparatus can be seen in Figure 4.3a. Figures 4.3b and 4.3c show close up views of a specimen loaded on the lower platen before (b) and during (c) a uniaxial compression test. In 
Figure 4.3a the load frame can be seen complete with metal platens that exert force along the axis of loading as the distance between them is decreased. Each sample was compressed between the platens at a strain rate of $0.02 \mathrm{sec}^{-1}$ until one of three testing endpoints was reached:

1) the applied force reached the load cell limit $(1,000 \mathrm{~N})$

2) the sample was loaded to $10 \%$ strain

3) failure was detected, defined by a 50\% drop in supported force

Human and bovine bone studies have revealed that at typical strain rates (below $\left.10 \mathrm{sec}^{-1}\right)$, the relative influence of apparent density on the biomechanical properties of bone tissue greatly outweighs the contributions of strain rate (Carter and Hayes, 1977). For this reason, the strain rate was held constant (at $0.02 \mathrm{sec}^{-1}$ ) for all testing of both trabecular and cortical bone. Data regarding the typical strain rates experienced by cetacean bone during routine activities have not been reported in the literature. The chosen strain rates were taken from maximal strain rates recorded during running $(0.01$ $\left.\mathrm{sec}^{-1}\right)$ and estimates of the range of strain rates encountered during impact fractures (0.1$1.0 \mathrm{sec}^{-1}$ ) in humans (Carter and Hayes, 1977).

Samples were placed between the metal platens with the axis of interest oriented in line with the axis of loading (Figure 4.3b). During a test, a load was applied in the axial direction. In Figure 4.3b, a cylindrical sample with original gauge length, Lo and original diameter, $d_{0}$ is shown before loading. This diameter was used to calculate $A_{0}$. During testing, the distance between the platens is reduced at a specified rate, applying force in the axial direction over area $A_{o}$, resulting in a new gauge length at time $t\left(L_{t}\right)$ 
(Figure 4.3c). Over the course of each test of trabecular bone specimens the applied load was recorded by the load cell while the axial displacement was recorded via crosshead displacement.

Engineering stresses and strains were calculated according to a protocol by Keller (1994). Briefly, engineering stresses ( $\sigma$, in MPa) were determined according to the equation:

$$
\sigma_{\mathrm{x}}=\mathrm{F} / \mathrm{A}_{\mathrm{ox}}
$$

where F equals the axial load (in Newtons) applied with the specimen in the $\mathrm{x}$-axis orientation and $\mathrm{A}_{\mathrm{ox}}$ equals the original cross-sectional area $\left(\mathrm{mm}^{2}\right)$ of the specimen that is contacted by the platens. $A_{o x}$ was calculated using the average of five measurements of the original diameter $\left(\mathrm{d}_{\mathrm{o}}\right)$ for cylindrical specimens. All measurements were taken prior to testing using a digital caliper.

Engineering strains $(\varepsilon$, in $\mathrm{mm} / \mathrm{mm})$ were determined using the following equation:

$$
\varepsilon_{\text {axial-x }}=\left(\mathrm{L}_{\mathrm{t}}-\mathrm{L}_{\mathrm{o}}\right) / \mathrm{L}_{\mathrm{o}}
$$

where $\mathrm{L}_{\mathrm{t}}-\mathrm{L}_{\mathrm{o}}$ represents the change in gauge length (or corrected crosshead displacement) at time (t), while $\mathrm{L}_{\mathrm{o}}$ represents the original gauge length (height) of the specimen prior to testing and $\mathrm{L}_{\mathrm{t}}$ is the gauge length at time t. Gauge length $\left(\mathrm{L}_{\mathrm{o}}\right.$ and $\left.\mathrm{L}_{\mathrm{t}}\right)$ values are in reported in $\mathrm{mm}$.

For cylindrical specimens, the transverse engineering strain was also determined according to the equation:

$$
\varepsilon_{\text {trans }}=\left(\mathrm{d}_{\mathrm{t}}-\mathrm{d}_{\mathrm{o}}\right) / \mathrm{d}_{\mathrm{o}}
$$


where $d_{o}$ is the original diameter $(\mathrm{mm})$ and $d_{t}$ is the diameter $(\mathrm{mm})$ at time $\mathrm{t}^{2}$

Engineering stress and strain data were plotted and the Young's modulus of elasticity (E) was defined as the slope of the linear portion of each resulting curve (Figure 4.4). Ultimate compressive strength $\left(\sigma_{\mathrm{ult}}\right)$ was also determined as the maximum stress before specimen failure. Mechanical property data were determined for each specimen and averages were computed for pooled specimens extracted from each of the three anatomical axes.

Figure 4.3: Mechanical testing apparatus and sample orientation. A) Load frame with metal platens that exert force along the axis of loading. B) Samples loaded between platens prior to start of test. Lo represents the average original gauge length, while $d_{o}$ represents the average original diameter of the cylinder. C) During testing, force is applied as the distance between the platens is reduced resulting in a new gauge length at time $t\left(\mathrm{~L}_{\mathrm{t}}\right)$ and a new diameter $\left(\mathrm{d}_{\mathrm{t}}\right)$ at time $\mathrm{t}$. Image created in collaboration with Kenneth M. Schopf.

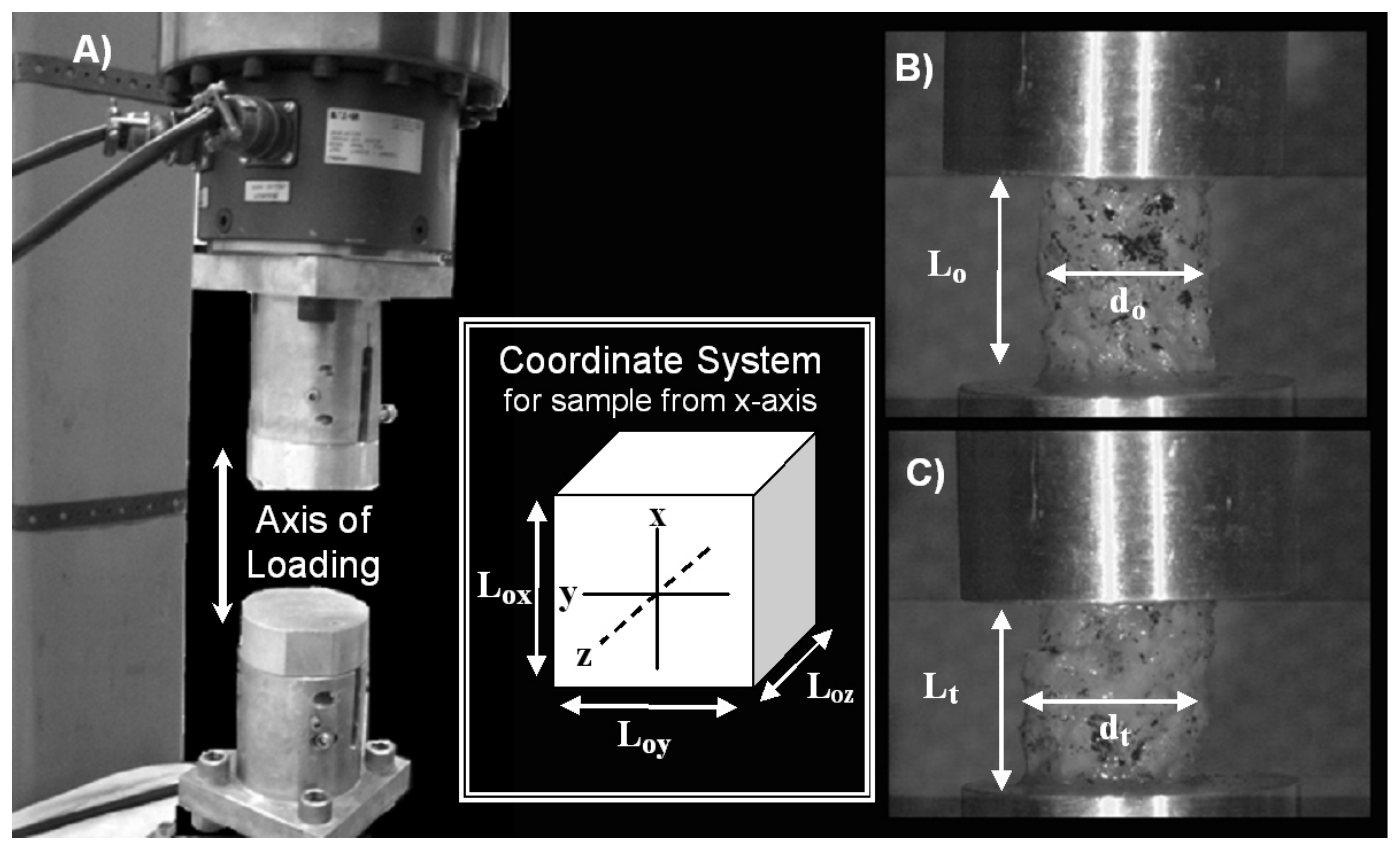

\footnotetext{
${ }^{2} L_{o}$ and $d_{o}$ were measured using a caliper, while $L_{t}$ was measured as the distance between platens at time $t$. $d_{t}$ was measured from digital images taken during the test, using an on-screen pixel caliper.
} 
Figure 4.4: Engineering stress vs. engineering strain plot from a representative $\mathrm{x}$-axis trabecular bone sample (Sample 1a-7). The linear region is highlighted in yellow. The slope of this curve (372.89 MPa) equals the Young's modulus. The star indicates the ultimate compressive strength (17.95 $\mathrm{MPa})$.

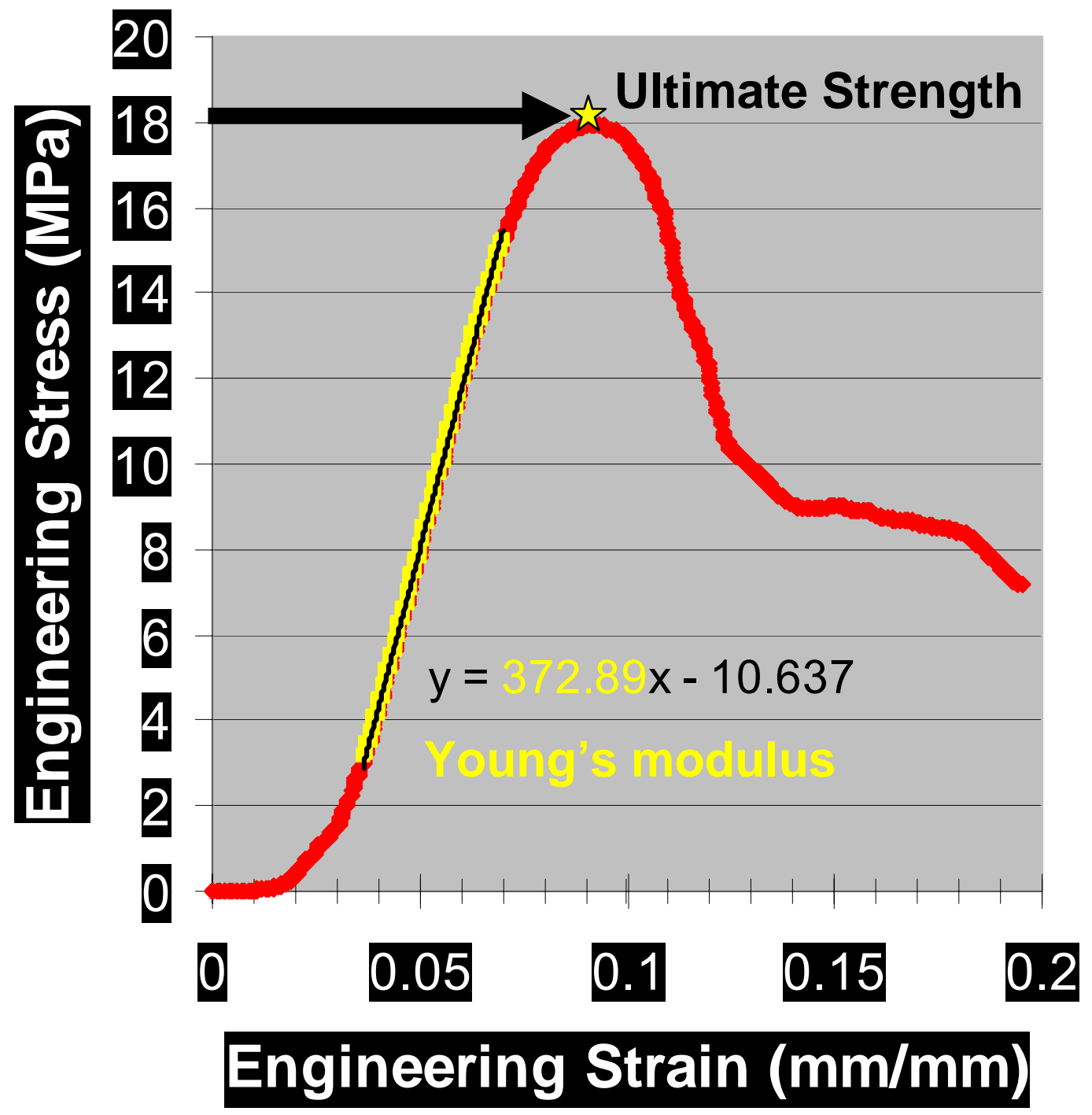


Compliance testing: In addition, compliance of the compact bone testing apparatus was determined and was used to correct cross-head displacement values. Compliance was evaluated by bringing the platens into contact, applying a load of over $10,000 \mathrm{~N}$ and observing the crosshead displacement during this process.

Ideally, the cross-head would not move, such that during actual testing the only component contributing to the observed crosshead displacement is the sample being tested. Even in simple set-ups, each component of the testing apparatus (the platens, the load cell, the fixtures holding the load cell in place, etc.) has a minute amount of compliance.

The objective of the compliance test is to ensure that 1) the compliance does not introduce a large and unacceptable amount of error into the data set, 2) to establish the error for reporting and/or correction. For the range of forces used during mechanical testing of cortical bone, the cross-head displacement during compliance testing was minimal (less than $0.05 \mathrm{~mm}$ ) representing up to $1.7 \%$ error in absolute displacement. This degree of error was deemed acceptable if reported and no further corrections were made to the dataset to compensate.

\subsubsection{QCT apparent density and estimated Young's modulus}

Quantitative computed tomography (QCT) was performed in a previous study to determine the distribution of trabecular bone density in the right whale mandible both longitudinally and in cross-section (Campbell-Malone, et al., 2007a). The QCT apparent density data from that study are used here to estimate the distribution of the Young's 
modulus of elasticity for trabecular bone found in the right whale mandible. This was done using regression equations from the literature to predict Young's modulus from physical measurements or proxies of apparent density derived from CT.

Briefly, QCT apparent density was determined in trabecular bone at 720 unique points by comparing CT numbers, in Hounsfield units, to a regression equation relating CT numbers to apparent density for hydroxyapatite standards of known density (Campbell-Malone, et al., 2007a). This calibration step was necessary as CT numbers provide relative density values which are neither absolute nor constant between scans (i.e. using the same scanner) or between scanners (e.g. two scans of the same make and model) (Levi, et al., 1982).

Four equations from the literature were used to transform the QCT apparent density data from the right whale mandible into estimates of Young's modulus of elasticity $\left(E_{\text {est }}\right)$ for trabecular bone. Where more than one equation was available from a study, the power-law equation was selected as these equations offer a) a higher correlation coefficient, b) a Young's modulus value of zero when density equals zero and 3) power-law equations correlating density and Young's modulus are often reported (Hodgskinson and Currey, 1990b, Rice, et al., 1988).

The equations, the variables used and the study details are noted.

From Hong et al. 2004

$$
E_{\text {est }}=4677 \rho_{\mathrm{QCT} \text { app }}{ }^{2.17}+169
$$


This equations provides estimates of Young's modulus from QCT apparent density ( $\rho_{\text {QCTapp }}$ ) and was derived from a dataset relating QCT apparent density measurements and experimentally derived Young's modulus of elasticity (E) for trabecular bone from three large whale species including the Sperm whale (Physeter macrocephalus), Bowhead whale (Balaena mysticetus), and Pygmy Sperm whale (ㅁogia breviceps) (Hong, et al., 2004).

Unfortunately, the publication contains no indication of the units for the apparent density or the predicted Young's modulus. ${ }^{3}$ An attempt was made to substitute commonly used units for apparent density and the resulting values of $\mathrm{E}$. The use of $\mathrm{g} / \mathrm{cc}$ for apparent density and MPa for Young's modulus resulted in the most reasonable estimates of E.

From Carter \& Hayes, 1977 (Carter and Hayes, 1977)

$$
E=3790 \times \bar{\varepsilon}^{0.06}\left(\rho_{\text {app }}\right)^{3}
$$

This equation relates the apparent density of trabecular bone $\left(\rho_{\text {app }}\right.$, in $\left.\mathrm{g} / \mathrm{cc}\right)$ and the strain rate $\left(\bar{\varepsilon}, \sec ^{-1}\right)$ to the measured Young's modulus of elasticity $\left(\mathrm{E}_{\text {est }}\right.$, in MPa) (Carter and Hayes, 1977). This study utilized both human and bovine trabecular bone specimens.

From Ciarelli et al., 1991 (Ciarelli, et al., 1991)

$$
E_{\text {est }}=-38.644+1.3665 \times(\text { H.U. })
$$

\footnotetext{
${ }^{3}$ When contacted, the first author could (understandably) not recall the implied units. He indicated that the data was contained in his lab notebooks, which will be explored as soon as they have been obtained.
} 
where CT numbers (in Hounsfield units, H.U.) are related to estimated Young's modulus ( $\mathrm{E}_{\text {est }}$, in $\mathrm{MPa}$ ) for human femora, humeri and radii. In that study anisotropy was explored in human cancellous bone (Ciarelli, et al., 1991). For this study, a single regression equation was used to relate apparent density to the average Young's modulus for all three directions. ${ }^{4}$ True correlation of QCT apparent density to Young's modulus in three different directions would require three different regression equations in this anisotropic material.

From Rice et al., $1988^{5}$ (Rice, et al., 1988)

$$
E=1000 \times\left[0.07+0.82\left(\rho_{\text {app }}\right)^{2}\right]
$$

where Young's modulus (E, in MPa) can be estimated from apparent density $(\mathrm{g} / \mathrm{cc})$. Equation 4.10, created from a dataset of human cancellous bone loaded in compression along its longitudinal axis, was used for this study although other equations from Rice et al. (1988) were equally valid for this comparison.

As sample extraction and subsequent testing was spatially limited in this museum quality specimen, these equations will hopefully provide reasonable estimates of the material properties of the bone. If so, QCT apparent density will allow fine-scale resolution of the variation of Young's modulus seen in cross-section and longitudinally in the right whale mandible.

\footnotetext{
${ }^{4}$ The average Young's modulus was determined by taking the average of all three measures of Young's modulus obtained when the three orthogonal axes of the same specimen were tested sequentially within the elastic range of the material.

${ }^{5}$ This meta-analysis utilized pooled data from several studies and is a valuable reference for predicting the Young's modulus, shear modulus and strength from apparent density in a variety of loading orientations.
} 
Despite its extensive use in predicting the mechanical properties of trabecular bone, there is at present some debate surrounding the validity of using non-invasive imaging techniques (e.g. computed tomography) to predict the mechanical properties of cortical bone (Snyder and Schneider, 1991). Thus, a parallel study involving QCT and cortical bone is not reported here. However, detailed studies are underway to assess the use of QCT as an appropriate predictor of mechanical properties in cortical bone.

\subsection{RESULTS}

\subsubsection{Densitometry}

Densitometry data for right whale trabecular bone specimens extracted from the mandible can be found in Table 4.1. The average apparent density for all specimens was $0.5140 \mathrm{~g} / \mathrm{cc}$, while the average for specimens extracted from the $\mathrm{x}-, \mathrm{y}$ - and $\mathrm{z}$-axes were $0.5558 \mathrm{~g} / \mathrm{cc}, 0.5249 \mathrm{~g} / \mathrm{cc}$, and $0.4614 \mathrm{~g} / \mathrm{cc}$ respectively. These values are within the range of apparent density values found in human trabecular bone $(0.1-1.0 \mathrm{~g} / \mathrm{cc})$.

Densitometry data for right whale cortical mandibular bone can be found in Table 4.2. While tissue density was measured for all specimens subjected to mechanical testing, the apparent density was only determined for a subset of the data. The apparent density of right whale cortical bone specimens analyzed here ranges from $1.17 \mathrm{~g} / \mathrm{cc}$ to $1.28 \mathrm{~g} / \mathrm{cc}$ with an average value of $1.24 \mathrm{~g} / \mathrm{cc}$. This is well below the standard apparent density value of cortical bone which is approximately $1.8 \mathrm{~g} / \mathrm{cc}$ (Huiskes and van Rietbergen, 2005). 


\subsubsection{Mechanical testing}

Biomechanical response to compressive loading was evaluated in right whale trabecular bone tissue of known bone orientation (as detailed in Figure 4.2). Engineering stress vs. engineering strain curves were created representing the range of data acquired from the quality-controlled dataset of 87 bone specimens ( 76 trabecular, 11 cortical) tested (Figures $4.5-4.8$ ).

Figure 4.4 is a representative plot of data from a trabecular bone sample (from the $\mathrm{x}$-axis) detailing the important features of a stress-strain curve. During low-level loading (below $0.5 \mathrm{MPa}$ ), strain increases to about $0.02 \mathrm{~mm} / \mathrm{mm}$. After this initial low-level loading phase, the bone enters the linear elastic region where the strain begins to respond more linearly to increasing stress. It is during this phase that Young's modulus is defined as the slope of the linear region of the stress-strain curve. Next, the specimen reaches the proportionality limit, the point where the specimen's response to loading becomes nonlinear, likely in response to failure of individual trabeculae. The curve finally peaks at a point defined as the ultimate compressive strength and the test ends with the unloading phase. All tests successfully loaded to failure - 72/76 (94.7\%) trabecular and 11/11 $(100 \%)$ cortical cylinders - demonstrated a smooth response during loading. 
Table 4.1: Results of manual densitometry of right whale trabecular bone samples from the mandible of Eg\# 1004.

\begin{tabular}{|c|c|c|c|c|c|c|c|c|}
\hline Tube\# & Sample\# & Axis & $\begin{array}{c}\text { Initial mass } \\
(\mathrm{g})\end{array}$ & $\begin{array}{l}\text { Defatted } \\
\text { mass }(\mathrm{g})\end{array}$ & $\begin{array}{c}\text { \%fat } \\
\text { (by mass) }\end{array}$ & Volume (cc) & $\begin{array}{c}\text { Tissue Density } \\
\text { (g/cc) }\end{array}$ & $\begin{array}{c}\text { Apparent density } \\
(\mathrm{g} / \mathrm{cc})\end{array}$ \\
\hline 1 & $1 a-1$ & $x$ & 0.6118 & 0.3064 & 49.92 & 0.4750 & 1.2879 & 0.6450 \\
\hline 2 & $1 a-2$ & $x$ & 0.5779 & 0.2743 & 52.54 & 0.4730 & 1.2218 & 0.5799 \\
\hline 3 & $1 a-3$ & $x$ & 0.5649 & 0.2306 & 59.17 & 0.4581 & 1.2330 & 0.5034 \\
\hline 4 & $1 a-4$ & $x$ & 0.5644 & 0.2244 & 60.24 & 0.4584 & 1.2311 & 0.4895 \\
\hline 5 & $1 a-5$ & $\mathrm{x}$ & 0.5785 & 0.2886 & 50.11 & 0.4696 & 1.2318 & 0.6145 \\
\hline 6 & $1 a-6$ & $x$ & 0.6075 & 0.2664 & 56.14 & 0.4733 & 1.2835 & 0.5629 \\
\hline 7 & $1 a-7$ & $x$ & 0.6262 & 0.3117 & 50.22 & 0.4699 & 1.3325 & 0.6633 \\
\hline 8 & $1 a-8$ & $x$ & 0.6582 & 0.3401 & 48.33 & 0.4759 & 1.3829 & 0.7145 \\
\hline 9 & $2 a-1$ & $y$ & 0.6141 & 0.2889 & 52.95 & 0.4718 & 1.3017 & 0.6124 \\
\hline 10 & $2 a-2$ & $y$ & 0.5902 & 0.2819 & 52.24 & 0.4705 & 1.2544 & 0.5991 \\
\hline 11 & $2 a-3$ & $y$ & 0.6018 & 0.2610 & 56.63 & 0.4732 & 1.2719 & 0.5516 \\
\hline 12 & $2 a-4$ & $y$ & 0.5963 & 0.2628 & 55.92 & 0.4710 & 1.2661 & 0.5581 \\
\hline 13 & $2 a-5$ & $y$ & 0.5852 & 0.2463 & 57.92 & 0.4778 & 1.2247 & 0.5154 \\
\hline 14 & $2 a-6$ & $y$ & 0.5594 & 0.2215 & 60.41 & 0.4402 & 1.2707 & 0.5031 \\
\hline 15 & $2 a-7$ & $y$ & 0.5880 & 0.2620 & 55.44 & 0.4693 & 1.2528 & 0.5583 \\
\hline 16 & $2 a-8$ & $y$ & 0.6281 & 0.3177 & 49.42 & 0.4662 & 1.3473 & 0.6814 \\
\hline 17 & $3 a-1$ & z & 0.5919 & 0.2765 & 53.29 & 0.4546 & 1.3020 & 0.6082 \\
\hline 18 & $3 a-2$ & $z$ & 0.5342 & 0.1732 & 67.57 & 0.4138 & 1.2911 & 0.4187 \\
\hline 19 & $3 a-3$ & $z$ & 0.5110 & 0.1732 & 66.11 & 0.4312 & 1.1852 & 0.4017 \\
\hline 20 & $3 a-4$ & $z$ & 0.5316 & 0.1882 & 64.59 & 0.4141 & 1.2838 & 0.4545 \\
\hline 21 & $3 a-5$ & $z$ & 0.5618 & 0.2090 & 62.79 & 0.4437 & 1.2662 & 0.4711 \\
\hline 22 & $3 a-6$ & $z$ & 0.5496 & 0.1954 & 64.44 & 0.4529 & 1.2136 & 0.4315 \\
\hline 29 & $4 a-1$ & $x$ & 0.6375 & 0.3243 & 49.13 & 0.4693 & 1.3585 & 0.6911 \\
\hline 30 & $4 a-2$ & $x$ & 0.6244 & 0.3035 & 51.39 & 0.4699 & 1.3288 & 0.6459 \\
\hline 31 & $4 a-3$ & $x$ & 0.5558 & 0.2119 & 61.87 & 0.4611 & 1.2053 & 0.4595 \\
\hline 32 & $4 a-4$ & $x$ & 0.5502 & 0.1907 & 65.34 & 0.4644 & 1.1847 & 0.4106 \\
\hline 33 & $4 a-5$ & $x$ & 0.5425 & 0.1926 & 64.50 & 0.4607 & 1.1775 & 0.4180 \\
\hline 34 & $4 a-6$ & $x$ & 0.5558 & 0.1964 & 64.67 & 0.4660 & 1.1928 & 0.4214 \\
\hline
\end{tabular}




\begin{tabular}{|c|c|c|c|c|c|c|c|c|}
\hline Tube\# & Sample\# & Axis & $\begin{array}{c}\text { Initial mass } \\
(\mathrm{g})\end{array}$ & $\begin{array}{l}\text { Defatted } \\
\text { mass }(\mathrm{g})\end{array}$ & $\begin{array}{c}\text { \%fat } \\
\text { (by mass) }\end{array}$ & Volume (cc) & $\begin{array}{c}\text { Tissue Density } \\
(\mathrm{g} / \mathrm{cc})\end{array}$ & $\begin{array}{c}\text { Apparent density } \\
(\mathrm{g} / \mathrm{cc})\end{array}$ \\
\hline 35 & $4 a-7$ & $x$ & 0.5868 & 0.2354 & 59.88 & 0.4677 & 1.2545 & 0.5033 \\
\hline 36 & $4 a-8$ & $x$ & 0.6079 & 0.2726 & 55.16 & 0.4789 & 1.2694 & 0.5692 \\
\hline 37 & $5 a-1$ & $y$ & 0.5758 & 0.2285 & 60.31 & 0.4794 & 1.2012 & 0.4767 \\
\hline 38 & $5 a-2$ & $y$ & 0.5567 & 0.1947 & 65.02 & 0.4836 & 1.1511 & 0.4026 \\
\hline 39 & $5 a-3$ & $y$ & 0.5504 & 0.1915 & 65.21 & 0.4647 & 1.1843 & 0.4121 \\
\hline 40 & $5 a-4$ & $y$ & 0.5602 & 0.2010 & 64.12 & 0.4737 & 1.1826 & 0.4243 \\
\hline 41 & $5 a-5$ & $\mathrm{y}$ & 0.5713 & 0.2234 & 60.90 & 0.4552 & 1.2552 & 0.4908 \\
\hline 42 & $5 a-6$ & $\mathrm{y}$ & 0.5920 & 0.2380 & 59.79 & 0.4853 & 1.2199 & 0.4905 \\
\hline 43 & $5 a-7$ & $y$ & 0.5903 & 0.2308 & 60.89 & 0.4803 & 1.2290 & 0.4806 \\
\hline 44 & $5 a-8$ & $y$ & 0.5922 & 0.2579 & 56.45 & 0.4781 & 1.2386 & 0.5394 \\
\hline 59 & $2 b-1$ & $y$ & 0.5306 & 0.2120 & 60.04 & 0.4418 & 1.2010 & 0.4799 \\
\hline 60 & $2 b-2$ & $y$ & 0.5308 & 0.1779 & 66.48 & 0.4408 & 1.2042 & 0.4037 \\
\hline 61 & $2 b-3$ & $y$ & 0.5366 & 0.1891 & 64.76 & 0.4327 & 1.2403 & 0.4371 \\
\hline 62 & $2 b-4$ & $y$ & 0.5446 & 0.2221 & 59.22 & 0.4230 & 1.2874 & 0.5250 \\
\hline 65 & $2 b-7$ & $y$ & 0.5780 & 0.2865 & 50.43 & 0.4672 & 1.2373 & 0.6133 \\
\hline 66 & $2 b-8$ & $y$ & 0.6435 & 0.3674 & 42.91 & 0.4635 & 1.3883 & 0.7926 \\
\hline 23 & $3 a-1 b$ & $z$ & 0.6185 & 0.3230 & 47.78 & 0.4563 & 1.3556 & 0.7079 \\
\hline 24 & $3 a-2 b$ & $z$ & 0.5925 & 0.2724 & 54.02 & 0.4589 & 1.2910 & 0.5936 \\
\hline 25 & $3 a-3 b$ & $z$ & 0.5873 & 0.2569 & 56.27 & 0.4532 & 1.2959 & 0.5668 \\
\hline 26 & $3 a-4 b$ & $z$ & 0.5991 & 0.2516 & 58.00 & 0.4574 & 1.3099 & 0.5501 \\
\hline 27 & $3 a-5 b$ & $z$ & 0.6195 & 0.2794 & 54.90 & 0.4616 & 1.3420 & 0.6053 \\
\hline 28 & $3 a-6 b$ & $z$ & 0.6052 & 0.2679 & 55.73 & 0.4569 & 1.3245 & 0.5863 \\
\hline 75 & $6 b-3$ & $z$ & 0.4989 & 0.1614 & 67.65 & 0.4635 & 1.0763 & 0.3482 \\
\hline 45 & $6 a-1$ & $z$ & 0.5166 & 0.1571 & 69.59 & 0.4479 & 1.1534 & 0.3507 \\
\hline 46 & $6 a-2$ & $z$ & 0.5150 & 0.1583 & 69.27 & 0.4482 & 1.1491 & 0.3531 \\
\hline 47 & $6 a-3$ & $z$ & 0.5077 & 0.1673 & 67.06 & 0.4516 & 1.1242 & 0.3703 \\
\hline 48 & $6 a-4$ & $z$ & 0.5154 & 0.1453 & 71.82 & 0.4303 & 1.1978 & 0.3376 \\
\hline 49 & $6 a-5$ & $z$ & 0.5187 & 0.1575 & 69.64 & 0.4627 & 1.1210 & 0.3404 \\
\hline 50 & $6 a-6$ & $z$ & 0.5205 & 0.1504 & 71.10 & 0.4537 & 1.1473 & 0.3316 \\
\hline 80 & $6 b-2 b$ & $z$ & 0.5314 & 0.1868 & 64.85 & 0.4664 & 1.1394 & 0.4005 \\
\hline
\end{tabular}


Table 4.2: Results of manual densitometry of right whale cortical bone samples from the mandible of Eg\# 1004.

\begin{tabular}{|c|c|c|c|c|c|c|}
\hline Sample\# & $\begin{array}{c}\text { Initial mass } \\
(\mathrm{g})\end{array}$ & $\begin{array}{l}\text { Volume } \\
\text { (cc) }\end{array}$ & $\rho_{\text {tissue }}(\mathrm{g} / \mathrm{cc})$ & Defat. mass $(\mathrm{g})$ & \%fat (by mass) & $\begin{array}{c}\rho_{\mathrm{app}} \\
(\mathrm{g} / \mathrm{cc})\end{array}$ \\
\hline $\mathrm{C}-1$ & 1.9986 & 1.2496 & 1.5994 & 1.4922 & 25.3377 & 1.1942 \\
\hline C-2 & 2.0501 & 1.2317 & 1.6645 & 1.5661 & 23.6086 & 1.2715 \\
\hline C-3 & 2.0290 & 1.2401 & 1.6361 & 1.5798 & 22.1390 & 1.2739 \\
\hline C-4 & 1.9995 & 1.1881 & 1.6829 & 1.5213 & 23.9160 & 1.2805 \\
\hline$C-5$ & 1.9466 & 1.2481 & 1.5596 & 1.4542 & 25.2954 & 1.1651 \\
\hline $\mathrm{C}-6$ & 2.0504 & 1.2333 & 1.6626 & & & \\
\hline C-7 & 2.0196 & 1.2471 & 1.6194 & & & \\
\hline C-8 & 2.0021 & 1.2249 & 1.6344 & & & \\
\hline C-9 & 2.0686 & 1.2206 & 1.6947 & & & \\
\hline C-10 & 1.9825 & 1.2077 & 1.6415 & & & \\
\hline$C-11$ & 2.1142 & 1.1604 & 1.8220 & & & \\
\hline
\end{tabular}

Seventy-six stress-strain curves for trabecular bone specimens taken from the x-, y- and z-axes appear in Figures 4.5, 4.6 and 4.7 respectively. In each figure, the different hues of red (Figure 4.5), blue (Figure 4.6) and green (Figure 4.7) were used to group individual test specimens extracted from the same bone core. Mechanical testing results for each bone type appear in Tables 4.3 (trabecular) and 4.4 (cortical).

Twenty four specimens were tested from the $\mathrm{x}$-axis (Figure 4.5). However, 8 samples were discarded after quality control, resulting in a total of 16 tests analyzed. ${ }^{6}$ Four of these trabecular bone specimens reached the load cell limit $(1000 \mathrm{~N})$ prior to failing. Data for these uncompromised specimens are seen as straight lines to the left side of the graph. As the linear portion of the stress-strain curve for the specimens was apparent, data for these four specimens were used in calculating the average Young's

\footnotetext{
${ }^{6}$ Samples from core $1 \mathrm{~b}$ were visually inspected and they appeared to have been cored off-axis. Photographs taken during the original core extraction from the mandible are consistent with findings from sample inspection.
} 
modulus for the x-axis. However, these specimens were not used in calculating the average ultimate compressive strength.

The average Young's modulus for specimens extracted from the $\mathrm{x}$-axis was 357.21 MPa (S.D. \pm 36.85$)$, with individual values ranging from $313.13-424.73 \mathrm{MPa}$. The ultimate compressive strength ranged from $12.00-21.59 \mathrm{MPa}$, with an average value of $15.56 \mathrm{MPa}$ (S.D. \pm 2.88 ). Note that the scale for the stress (ordinate) axis for Figure 4.5 is twice that of Figures 4.6 and 4.7.

Twenty four specimens were tested from the y-axis (Figure 4.6). The average Young's modulus for specimens extracted from the y-axis was 106.40 MPa (S.D. \pm 49.96 ), with values ranging from $47.27-259.74 \mathrm{MPa}$. The ultimate compressive strength ranged from $1.99-11.10 \mathrm{MPa}$ with an average of 4.34 MPa (S.D. \pm 1.99 ).

Thirty six specimens were tested from the z-axis (Figure 4.7). The Young's modulus for these specimens ranged from 47.95-136.27 MPa with an average value of 80.34 MPa (S.D. \pm 23.87$)$. The ultimate compressive strength ranged from $1.84-4.81$ $\mathrm{MPa}$ with an average of $3.22 \mathrm{MPa}(\mathrm{S} . \mathrm{D} . \pm 0.73)$.

Engineering stress-strain curves for the eleven cylindrical cortical bone specimens can be found in Figure 4.8. Young's modulus for cortical bone specimens of undetermined orientation ranged from 557.86 - 1360.4 MPa and averaged 854.21 MPa (S.D. \pm 259.5$)$. The ultimate compressive strength averaged 22.93 MPa (S.D. \pm 11.66 ) and ranged from $12.90-51.72 \mathrm{MPa}$.

Values for Young's modulus, and ultimate strength for both cortical and trabecular bone can be found in Table 4.5. Comparative values for trabecular bone from 
the human mandible (Giesen, et al., 2004), canine vertebrae (Martin, et al., 1998), human femur (Martin, et al., 1998) and sperm whale vertebrae ${ }^{7}$ (Kabel, et al., 1999a), as well as cortical bone from the equine metacarpal (Les, et al., 2002), human and bovine femora (Currey, 2004, Currey, 1998), dugong scapula (Currey, 2004), beaked whale rostrum (Zioupos, et al., 1997), and manatee ribs (Yan, 2002) are also included.

Figure 4.5: Engineering stress vs. engineering strain plots for 16 trabecular bone specimens from the $\mathrm{x}$-axis. Young's modulus and the ultimate strength averaged 357.21 and 15.56 MPa respectively. Specimens from the same core appear in like colors.

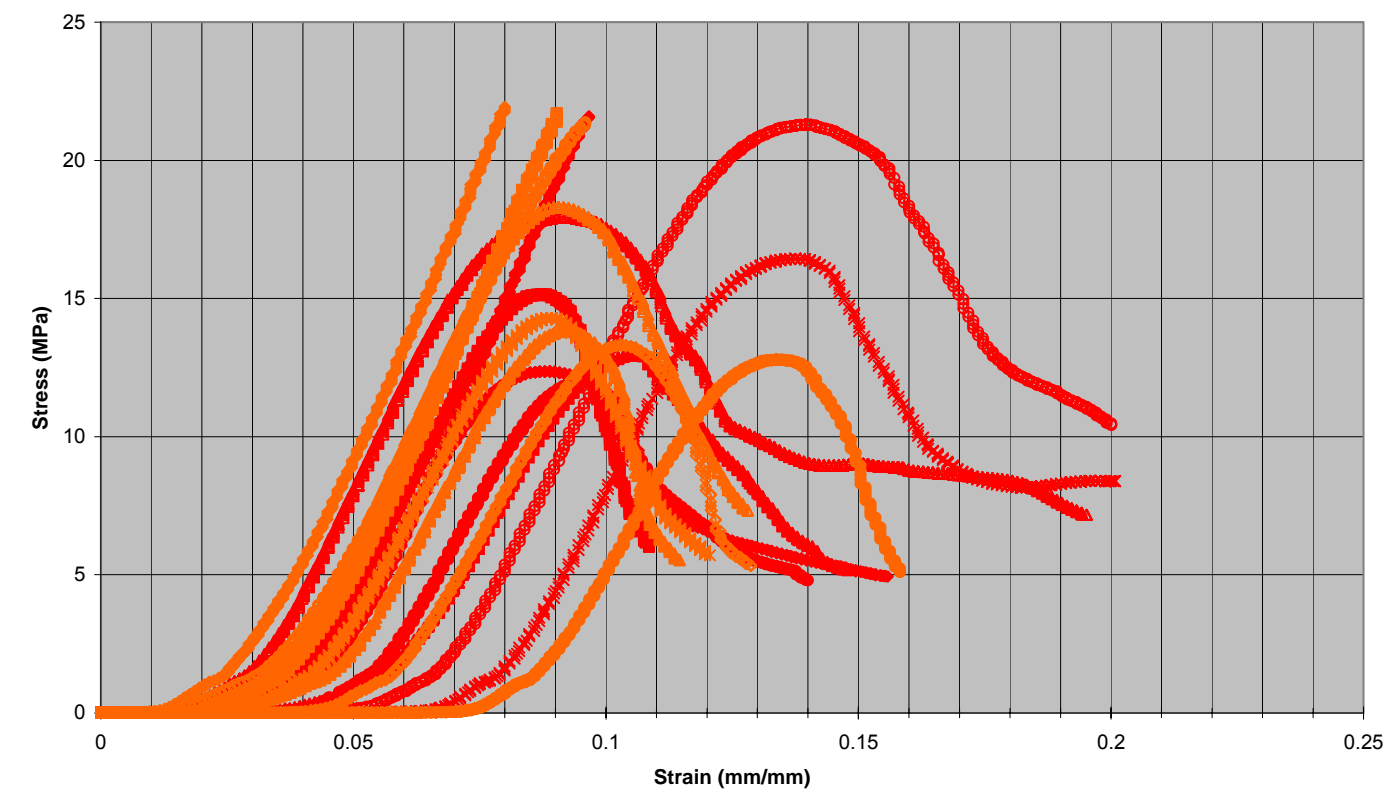

\footnotetext{
${ }^{7}$ The average value of specimens from the central, anterior and spinous processes of vertebrae is used here.
} 
Figure 4.6: Data plots of engineering stress vs. engineering strain for 24 trabecular bone test specimens from the y-axis. Young's modulus and the ultimate strength averaged $106.40 \mathrm{MPa}$ and $4.34 \mathrm{MPa}$ respectively.

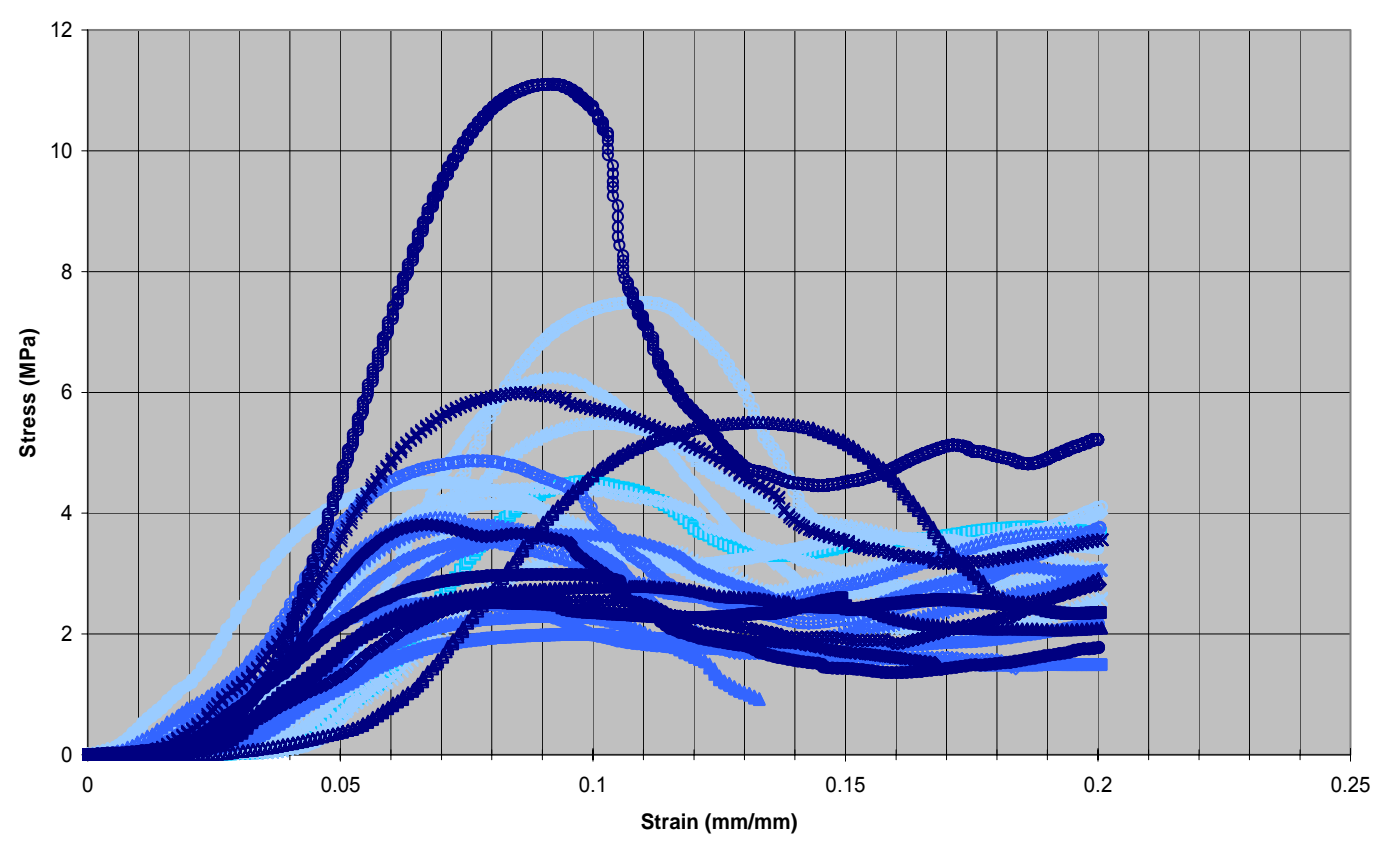

A subset of the mechanical testing results for trabecular bone is summarized in Table 4.3. These data include only samples for which the apparent density was also determined, however they are representative of the mechanical testing dataset as a whole. Mechanical testing results for cortical bone are summarized in Table 4.4. As this dataset was composed of fewer specimens all mechanical testing results are reported even in cases where the corresponding apparent density was not determined. 
Figure 4.7: Data plots of engineering stress vs. engineering strain for 36 trabecular bone test specimens from the z-axis. Young's modulus and the ultimate strength averaged $80.34 \mathrm{MPa}$ and $3.22 \mathrm{MPa}$ respectively.

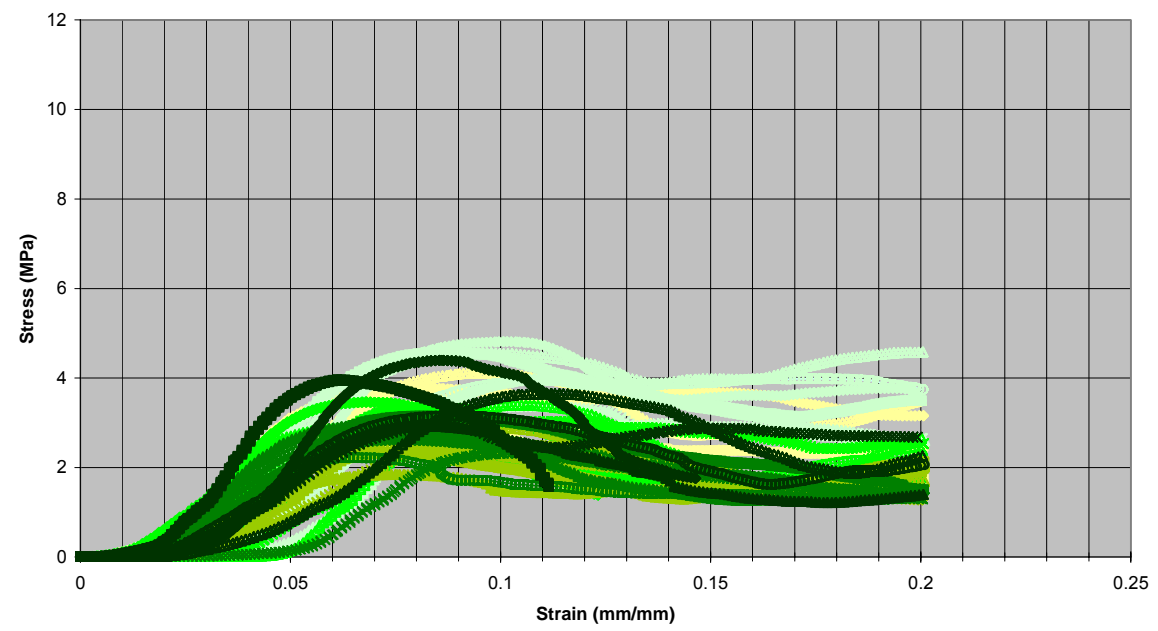

Figure 4.8: Engineering stress vs. engineering strain curves for 11 cortical bone specimens tested in uniaxial compression to $20 \%$ strain, failure or the load cell limit $(25,000 \mathrm{~N})$.

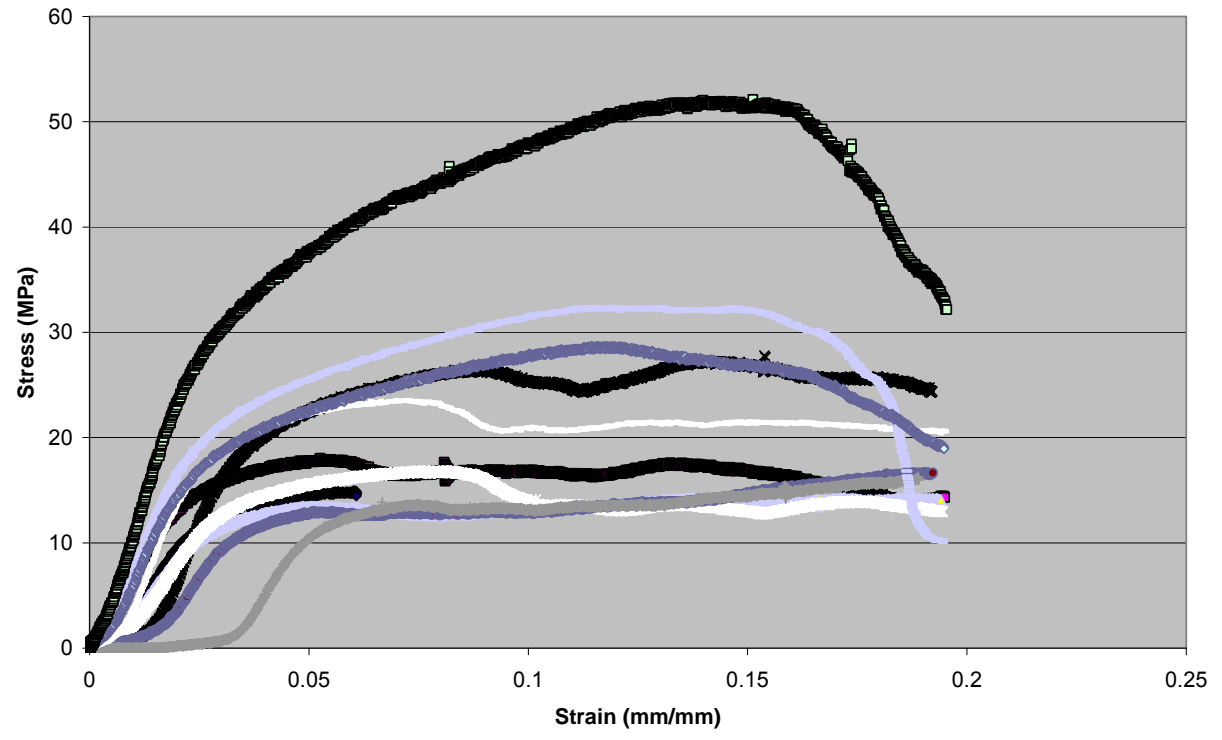


Table 4.3: Material properties of right whale trabecular bone as determined via uniaxial compression testing. Young's modulus $(E)$, the ultimate compressive strength $\left(\sigma_{\text {ult }}\right)$ and apparent density are reported for a subset of samples tested. The load cell limit $(1000 \mathrm{~N})$ was exceeded prior to failure of three samples for which $\sigma_{\text {ult }}$ is not reported below. ${ }^{8}$ The average $\rho_{\text {app }}$ for all axes (controlling for sample size) was $0.5140 \mathrm{~g} / \mathrm{cc}$.

\begin{tabular}{|c|c|c|c|c|c|c|}
\hline Tube\# & Sample\# & axis & $\rho_{\text {app }}(\mathrm{g} / \mathrm{cc})$ & $\rho_{\text {app }}\left(\mathrm{kg} / \mathrm{m}^{3}\right)$ & $\mathrm{E}(\mathrm{MPa})$ & $\sigma_{\text {ult }}(\mathrm{MPa})$ \\
\hline 1 & $1 \mathrm{a}-1$ & $\mathrm{x}$ & 0.6450 & 645.02 & 424.73 & 21.59 \\
\hline 2 & $1 \mathrm{a}-2$ & $\mathrm{x}$ & 0.5799 & 579.93 & 354.99 & 15.15 \\
\hline 3 & $1 \mathrm{a}-3$ & $\mathrm{x}$ & 0.5034 & 503.40 & 317.66 & 12.95 \\
\hline 4 & $1 \mathrm{a}-4$ & $\mathrm{x}$ & 0.4895 & 489.49 & 323.03 & 12.01 \\
\hline 5 & $1 \mathrm{a}-5$ & $\mathrm{x}$ & 0.6145 & 614.53 & 323.65 & 12.36 \\
\hline 6 & $1 \mathrm{a}-6$ & $\mathrm{x}$ & 0.5629 & 562.90 & 350.59 & 16.45 \\
\hline 7 & $1 \mathrm{a}-7$ & $\mathrm{x}$ & 0.6633 & 663.28 & 372.89 & 17.95 \\
\hline 8 & $1 \mathrm{a}-8$ & $\mathrm{x}$ & 0.7145 & 714.49 & 362.00 & 21.29 \\
\hline 9 & $2 \mathrm{a}-1$ & $\mathrm{y}$ & 0.6124 & 612.44 & 165.51 & 6.24 \\
\hline 10 & $2 \mathrm{a}-2$ & $\mathrm{y}$ & 0.5991 & 599.14 & 116.51 & 4.52 \\
\hline 11 & $2 \mathrm{a}-3$ & $\mathrm{y}$ & 0.5516 & 551.56 & 110.37 & 4.17 \\
\hline 12 & $2 \mathrm{a}-4$ & $\mathrm{y}$ & 0.5581 & 558.06 & 122.47 & 4.51 \\
\hline 13 & $2 \mathrm{a}-5$ & $\mathrm{y}$ & 0.5154 & 515.36 & 102.84 & 4.41 \\
\hline 14 & $2 \mathrm{a}-6$ & $\mathrm{y}$ & 0.5031 & 503.06 & 73.55 & 3.42 \\
\hline 15 & $2 \mathrm{a}-7$ & $\mathrm{y}$ & 0.5583 & 558.27 & 141.64 & 5.50 \\
\hline 16 & $2 \mathrm{a}-8$ & $\mathrm{y}$ & 0.6814 & 681.42 & 196.00 & 7.49 \\
\hline 17 & $3 \mathrm{a}-1$ & $\mathrm{z}$ & 0.6082 & 608.22 & 104.54 & 3.77 \\
\hline 18 & $3 \mathrm{a}-2$ & $\mathrm{z}$ & 0.4187 & 418.65 & 47.95 & 2.48 \\
\hline 19 & $3 \mathrm{a}-3$ & $\mathrm{z}$ & 0.4017 & 401.69 & 92.76 & 3.83 \\
\hline 20 & $3 \mathrm{a}-4$ & $\mathrm{z}$ & 0.4545 & 454.54 & 79.28 & 3.45 \\
\hline 21 & $3 \mathrm{a}-5$ & $\mathrm{z}$ & 0.4711 & 471.12 & 88.49 & 4.12 \\
\hline 22 & $3 \mathrm{a}-6$ & $\mathrm{z}$ & 0.4315 & 431.54 & 66.21 & 3.00 \\
\hline 29 & $4 \mathrm{a}-1$ & $\mathrm{x}$ & 0.6911 & 691.08 & 421.06 & $\mathrm{n} / \mathrm{a}$ \\
\hline 30 & $4 \mathrm{a}-2$ & $\mathrm{x}$ & 0.6459 & 645.86 & 414.73 & $\mathrm{n} / \mathrm{a}$ \\
\hline 31 & $4 a-3$ & $\mathrm{x}$ & 0.4595 & 459.52 & 337.28 & 13.84 \\
\hline 32 & $4 a-4$ & $\mathrm{x}$ & 0.4106 & 410.58 & 313.13 & 12.78 \\
\hline 33 & $4 a-5$ & $\mathrm{x}$ & 0.4180 & 418.05 & 320.81 & 13.31 \\
\hline 34 & $4 a-6$ & $\mathrm{x}$ & 0.4214 & 421.43 & 344.21 & 14.29 \\
\hline 35 & $4 a-7$ & $\mathrm{x}$ & 0.5033 & 503.28 & 377.54 & 18.31 \\
\hline 36 & $4 a-8$ & $\mathrm{x}$ & 0.5692 & 569.22 & 357.12 & $\mathrm{n} / \mathrm{a}$ \\
\hline 37 & $5 \mathrm{a}-1$ & $\mathrm{y}$ & 0.4767 & 476.74 & 97.06 & 3.65 \\
\hline 38 & $5 \mathrm{a}-2$ & $\mathrm{y}$ & 0.4026 & 402.62 & 47.27 & 1.99 \\
\hline 39 & $5 \mathrm{a}-3$ & $\mathrm{y}$ & 0.4121 & 412.06 & 52.95 & 2.30 \\
\hline 40 & $5 \mathrm{a}-4$ & $\mathrm{y}$ & 0.4243 & 424.34 & 65.76 & 2.52 \\
\hline 41 & $5 \mathrm{a}-5$ & $\mathrm{y}$ & 0.4908 & 490.82 & 79.67 & 3.60 \\
\hline & & & & & & \\
\hline
\end{tabular}

${ }^{8} \mathrm{~A}$ total of 4 samples exceeded the load cell limit - the fourth is not reported since $\rho_{\text {app }}$ was not determined. 
Table 4.3: (continued)

\begin{tabular}{|c|c|c|c|c|c|c|}
\hline Tube\# & Sample\# & axis & $\rho_{\text {app }}(\mathrm{g} / \mathrm{cc})$ & $\rho_{\text {app }}\left(\mathrm{kg} / \mathrm{m}^{3}\right)$ & $\mathrm{E}(\mathrm{MPa})$ & $\sigma_{\text {ult }}(\mathrm{MPa})$ \\
\hline 42 & $5 \mathrm{a}-6$ & $\mathrm{y}$ & 0.4905 & 490.46 & 103.60 & 3.80 \\
\hline 43 & $5 \mathrm{a}-7$ & $\mathrm{y}$ & 0.4806 & 480.62 & 83.77 & 3.93 \\
\hline 44 & $5 \mathrm{a}-8$ & $\mathrm{y}$ & 0.5394 & 539.41 & 135.41 & 4.86 \\
\hline 59 & $2 \mathrm{~b}-1$ & $\mathrm{y}$ & 0.4799 & 479.95 & 112.32 & 3.81 \\
\hline 60 & $2 \mathrm{~b}-2$ & $\mathrm{y}$ & 0.4037 & 403.70 & 63.46 & 2.52 \\
\hline 61 & $2 \mathrm{~b}-3$ & $\mathrm{y}$ & 0.4371 & 437.07 & 61.15 & 2.79 \\
\hline 62 & $2 \mathrm{~b}-4$ & $\mathrm{y}$ & 0.5250 & 525.03 & 66.96 & 2.98 \\
\hline 65 & $2 \mathrm{~b}-7$ & $\mathrm{y}$ & 0.6133 & 613.29 & 108.60 & 5.51 \\
\hline 66 & $2 \mathrm{~b}-8$ & $\mathrm{y}$ & 0.7926 & 792.65 & 259.74 & 11.10 \\
\hline 23 & $3 \mathrm{a}-1 \mathrm{~b}$ & $\mathrm{z}$ & 0.7079 & 707.93 & 127.07 & 4.81 \\
\hline 24 & $3 \mathrm{a}-2 \mathrm{~b}$ & $\mathrm{z}$ & 0.5936 & 593.61 & 121.76 & 4.59 \\
\hline 25 & $3 \mathrm{a}-3 \mathrm{~b}$ & $\mathrm{z}$ & 0.5668 & 566.77 & 114.26 & 3.99 \\
\hline 26 & $3 \mathrm{a}-4 \mathrm{~b}$ & $\mathrm{z}$ & 0.5501 & 550.09 & 82.66 & 3.36 \\
\hline 27 & $3 \mathrm{a}-5 \mathrm{~b}$ & $\mathrm{z}$ & 0.6053 & 605.30 & 91.70 & 4.56 \\
\hline 28 & $3 \mathrm{a}-6 \mathrm{~b}$ & $\mathrm{z}$ & 0.5863 & 586.35 & 85.67 & 2.75 \\
\hline 75 & $6 \mathrm{~b}-3$ & $\mathrm{z}$ & 0.3482 & 348.20 & 50.98 & 1.84 \\
\hline 45 & $6 \mathrm{a}-1$ & $\mathrm{z}$ & 0.3507 & 350.75 & 65.54 & 2.62 \\
\hline 46 & $6 \mathrm{a}-2$ & $\mathrm{z}$ & 0.3531 & 353.10 & 85.44 & 3.14 \\
\hline 47 & $6 \mathrm{a}-3$ & $\mathrm{z}$ & 0.3703 & 370.35 & 78.26 & 2.94 \\
\hline 48 & $6 \mathrm{a}-4$ & $\mathrm{z}$ & 0.3376 & 337.59 & 65.70 & 2.33 \\
\hline 49 & $6 \mathrm{a}-5$ & $\mathrm{z}$ & 0.3404 & 340.37 & 78.87 & 2.71 \\
\hline 50 & $6 \mathrm{a}-6$ & $\mathrm{z}$ & 0.3316 & 331.57 & 59.28 & 2.22 \\
\hline 80 & $6 \mathrm{~b}-2 \mathrm{~b}$ & $\mathrm{z}$ & 0.4005 & 400.54 & 136.27 & 3.95 \\
\hline
\end{tabular}

Table 4.4: Material properties of right whale cortical bone determined via uniaxial compression testing. Tissue density ( $\rho_{\text {tissue }}$ ), Young's modulus (E) and the ultimate compressive strength $\left(\sigma_{\mathrm{utt}}\right)$ are reported for all samples. The apparent density $\left(\rho_{\mathrm{app}}\right)$ was determined for a subset of samples. Average $\rho_{\text {app }}$ was $1.2370 \mathrm{~g} / \mathrm{cc}$

\begin{tabular}{|c|c|c|c|c|}
\hline Sample\# & $\rho_{\text {tissue }}(\mathrm{g} / \mathrm{cc})$ & $\rho_{\text {app }}(\mathrm{g} / \mathrm{cc})$ & $\mathrm{E}(\mathrm{MPa})$ & $\sigma(\mathrm{MPa})$ \\
\hline $\mathrm{C}-1$ & 1.5994 & 1.1942 & 658.34 & 14.83 \\
\hline C-2 & 1.6645 & 1.2715 & 802.71 & 18.03 \\
\hline C-3 & 1.6361 & 1.2739 & 557.86 & 13.51 \\
\hline C-4 & 1.6829 & 1.2805 & 1047.9 & 26.42 \\
\hline C-5 & 1.5596 & 1.1651 & 600.56 & 16.87 \\
\hline C-6 & 1.6626 & -- & 604.89 & 12.90 \\
\hline C-7 & 1.6194 & -- & 685.31 & 13.59 \\
\hline C-8 & 1.6344 & -- & 1093.5 & 23.60 \\
\hline C-9 & 1.6947 & -- & 998.36 & 32.05 \\
\hline C-10 & 1.6415 & -- & 986.56 & 28.69 \\
\hline C-11 & 1.8220 & -- & 1360.4 & 51.72 \\
\hline
\end{tabular}


Table 4.5: Average Young's modulus of elasticity and ultimate strength of trabecular and cortical bone from the right whale jaw bone are reported and accompanied by published values from other species (Currey, 2004, Currey, 1998, Giesen, et al., 2004, Kabel, et al., 1999a, Les, et al., 2002, Martin, et al., 1998, Yan, 2002, Zioupos, et al., 1997). Average values for trabecular bone from each axis are included, with standard deviations in parentheses. Values for cortical bone of undetermined orientation are organized as maximum (top value), average (middle value) and minimum (bottom value). Standard deviations for cortical bone are found in parentheses beneath average value.

\begin{tabular}{|c|c|c|c|c|}
\hline \multicolumn{1}{|c|}{ Bone Source } & \multicolumn{2}{|c|}{ Trabecular } & \multicolumn{2}{c|}{ Cortical } \\
\hline Right Whale Mandible & $\begin{array}{c}\text { Young's } \\
\text { Modulus } \\
(\mathrm{MPa})\end{array}$ & $\begin{array}{c}\text { Ultimate } \\
\text { Strength } \\
(\mathrm{MPa})\end{array}$ & $\begin{array}{c}\text { Young's } \\
\text { Modulus } \\
(\mathrm{MPa})^{*}\end{array}$ & $\begin{array}{c}\text { Ultimate } \\
\text { Strength } \\
(\mathrm{MPa})^{*}\end{array}$ \\
\hline \multicolumn{1}{|c|}{ X-axis $(\mathrm{n}=16)$} & $\begin{array}{c}357.2 \\
( \pm 36.85)\end{array}$ & $\begin{array}{c}15.6^{* *} \\
( \pm 3.296)\end{array}$ & $\begin{array}{c}1360.4 \\
(\max )\end{array}$ & $\begin{array}{c}51.7 \\
(\mathrm{max})\end{array}$ \\
\hline Y-axis $(\mathrm{n}=24)$ & $\begin{array}{c}106.4 \\
( \pm 49.96)\end{array}$ & $\begin{array}{c}4.3 \\
( \pm 1.991)\end{array}$ & $\begin{array}{c}854.2 \\
( \pm 259.45)\end{array}$ & $\begin{array}{c}22.9 \\
( \pm 11.66)\end{array}$ \\
\hline Z-axis $(\mathrm{n}=36)$ & $\begin{array}{c}30.3 \\
( \pm 23.87)\end{array}$ & $\begin{array}{c}3.2 \\
( \pm 0.734)\end{array}$ & $\begin{array}{c}557.9 \\
(\mathrm{~min})\end{array}$ & $\begin{array}{c}12.9 \\
(\mathrm{~min})\end{array}$ \\
\hline Human mandible*** & $373(290)$ & $3.3(2.4)$ & -- & -- \\
\hline Human femur & 424 & 5.6 & $16.7 \times 10^{3}$ & 166 \\
\hline Bovine femur & -- & -- & $24.5 \times 10^{3}$ & 141.9 \\
\hline Equine metacarpal & -- & -- & $14.1 \times 10^{3}$ & 178.8 \\
\hline Dugong scapula & -- & -- & $5.5 \times 10^{3}$ & -- \\
\hline Manatee rib & -- & -- & $18.1 \times 10^{3}$ & $\sim 175$ \\
\hline Canine vertebra & 231 & 9.6 & -- & -- \\
\hline Sperm Whale vertebra & $5.52 \times 10^{3}$ & -- & -- & -- \\
\hline Beaked Whale rostrum & -- & -- & $40 \times 10^{3}$ & 55 \\
\hline
\end{tabular}

*data represent max, min and average values

$* * \mathrm{n}=12$

***Human data include values for dentate and (edentate) mandibles

Figures 4.9 and 4.10 permit the comparison of relationships between trabecular bone apparent density and its material properties - Young's modulus (Figure 4.9) and the ultimate compressive strength (Figure 4.10) - in various species and skeletal components. Non-right whale data are from published studies indicated, as adapted by Gibson and Ashby (1997) (Behrens, et al., 1974, Bensusan, et al., 1983, Carter and Hayes, 1977, 
Carter, et al., 1980, Galante, et al., 1970, Hvid, et al., 1989, Linde, et al., 1991, Weaver and Chalmers, 1966). Data from published studies are represented by black symbols. Right whale trabecular bone data are plotted in color for clarity. Open red diamonds correspond to the $\mathrm{x}$-axis, open blue squares represent the $\mathrm{y}$-axis and solid green squares represent the z-axis.

Figures 4.11 and 4.12 permit the comparison of the apparent density of trabecular bone to corresponding values for Young's modulus and the ultimate compressive strength with respect to bone orientation. Data from Williams and Lewis ${ }^{9}$ (1982) are shown in black, while right whale data are again in color to clarify the axis orientation.

\subsubsection{QCT apparent density and estimated Young's modulus}

Apparent density values $(\mathrm{g} / \mathrm{cc})$ determined via QCT analysis of right whale jawbone segment B can be found in Table 4.7.

Observed variation in apparent density indicates a subtle trend of increasing apparent density moving from the caudal end toward the rostral region of the mandible. Results from one-way analysis of variance (ANOVA) conducted for a previous study demonstrated that the average values for each segment were statistically significantly different (Campbell-Malone, et al., 2007a). Trabecular bone from all five segments were significantly different from each of the other four segments respectively at a confidence level of $\alpha=0.05, \mathrm{p}<0.001$. Cortical bone also showed a similar trend of increasing density in the caudo-cranial direction.

\footnotetext{
${ }^{9}$ As adapted from Gibson and Ashby, 1997.
} 
Figure 4.9: Interspecies comparison of Young's modulus values vs. apparent density. Black symbols represent trabecular bone of unspecified orientation and are from (1) Carter and Hayes, 1977, (2) Carter et al., 1980, (3) Bensusan et al., 1983, (4) Hvid et al., 1989, and (5) Linde et al., 1991. Colored symbols (open red diamonds, open blue squares and green filled squares) represent mandibular bone specimens from this study and indicate the gross orientation (x-, y-, and z-axis respectively). Symbols represent specimens extracted from human $(\mathrm{H})$, bovine $(\mathrm{B})$ and right whale $(\mathrm{Eg})$ bone. Image adapted from Gibson and Ashby, 1997.

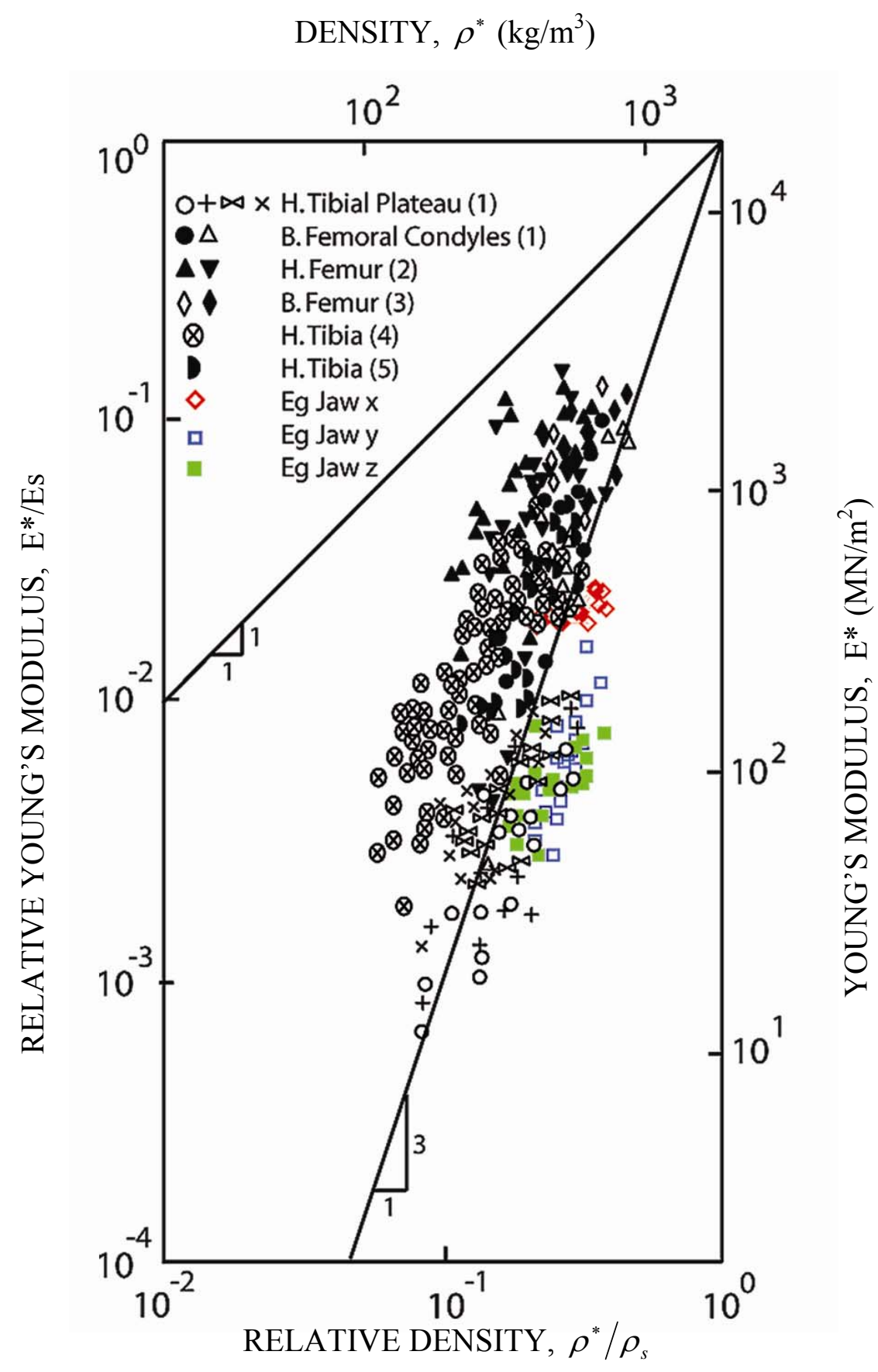


Figure 4.10: Interspecies comparison of ultimate compressive strength vs. apparent density. Black symbols represent trabecular bone of unspecified orientation and are from (1) Behrens, Walker and Shoji, 1974, (2) Carter and Hayes, 1977, (3) Galante, Rostoker and Ray, 1970, (4) Weaver and Chalmers, 1966, (5) Carter et al., 1980, and (6) Bensusan et al., 1983. As indicated in Figure 4.9, colored symbols represent mandibular bone specimens from this study and the gross orientation ( $\mathrm{x}-, \mathrm{y}-$, or $\mathrm{z}$-axis) of each specimen. Symbols represent specimens extracted from human $(\mathrm{H})$, bovine $(\mathrm{B})$ and right whale $(\mathrm{Eg})$ bone. Image adapted from Gibson and Ashby, 1997.

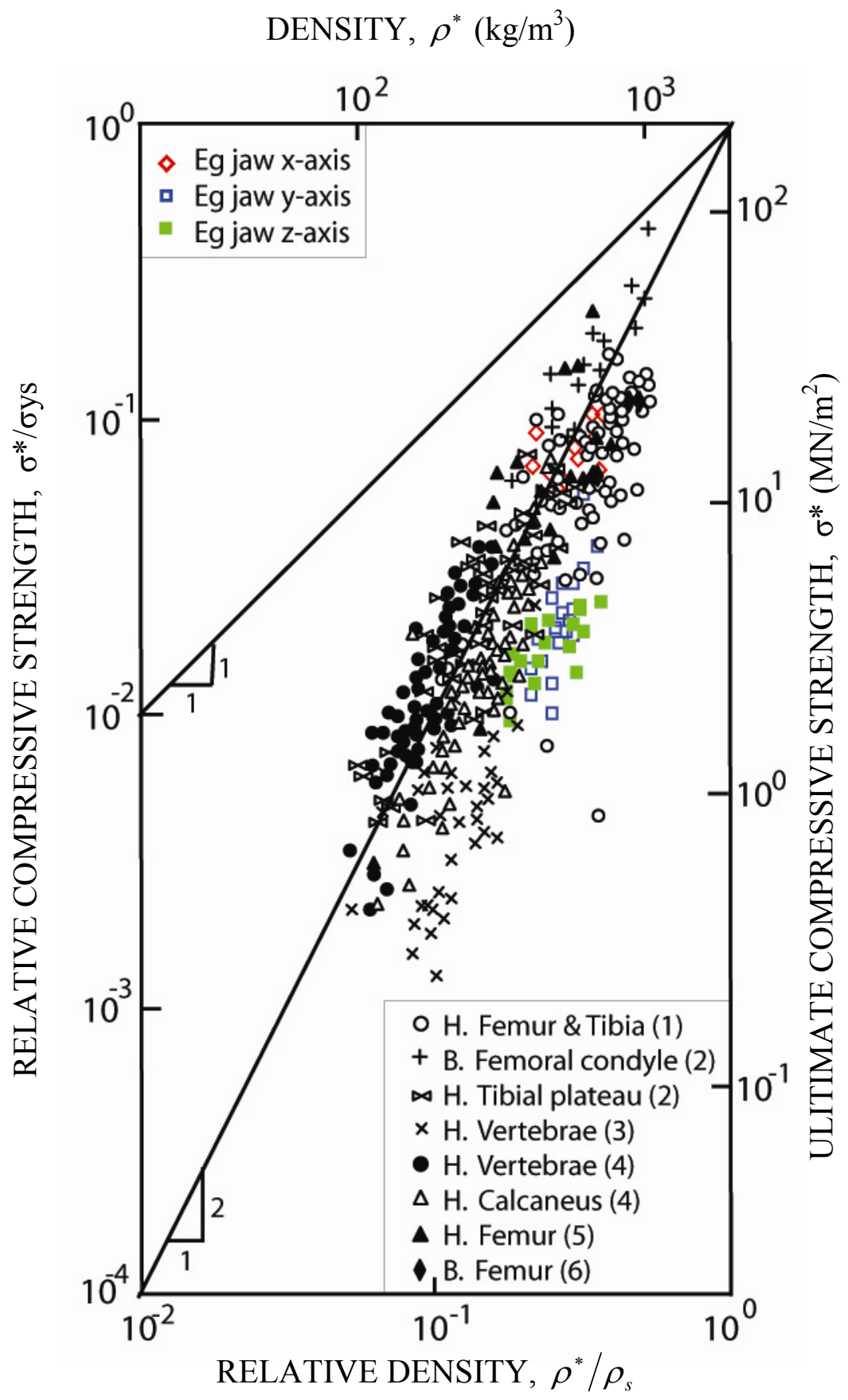


Figure 4.11: Apparent density vs. Young's modulus as a function of bone orientation. Black symbols represent trabecular bone specimens from the human tibia reported by Williams and Lewis, 1982. Colored symbols are consistent with Figure 4.9. For both datasets longitudinal loading places specimen on a line with a slope of 1 , while transverse loading finds specimens on a line with a slope of almost 3. Image adapted from Gibson and Ashby, 1997.

DENSITY, $\rho^{*}\left(\mathrm{~kg} / \mathrm{m}^{3}\right)$

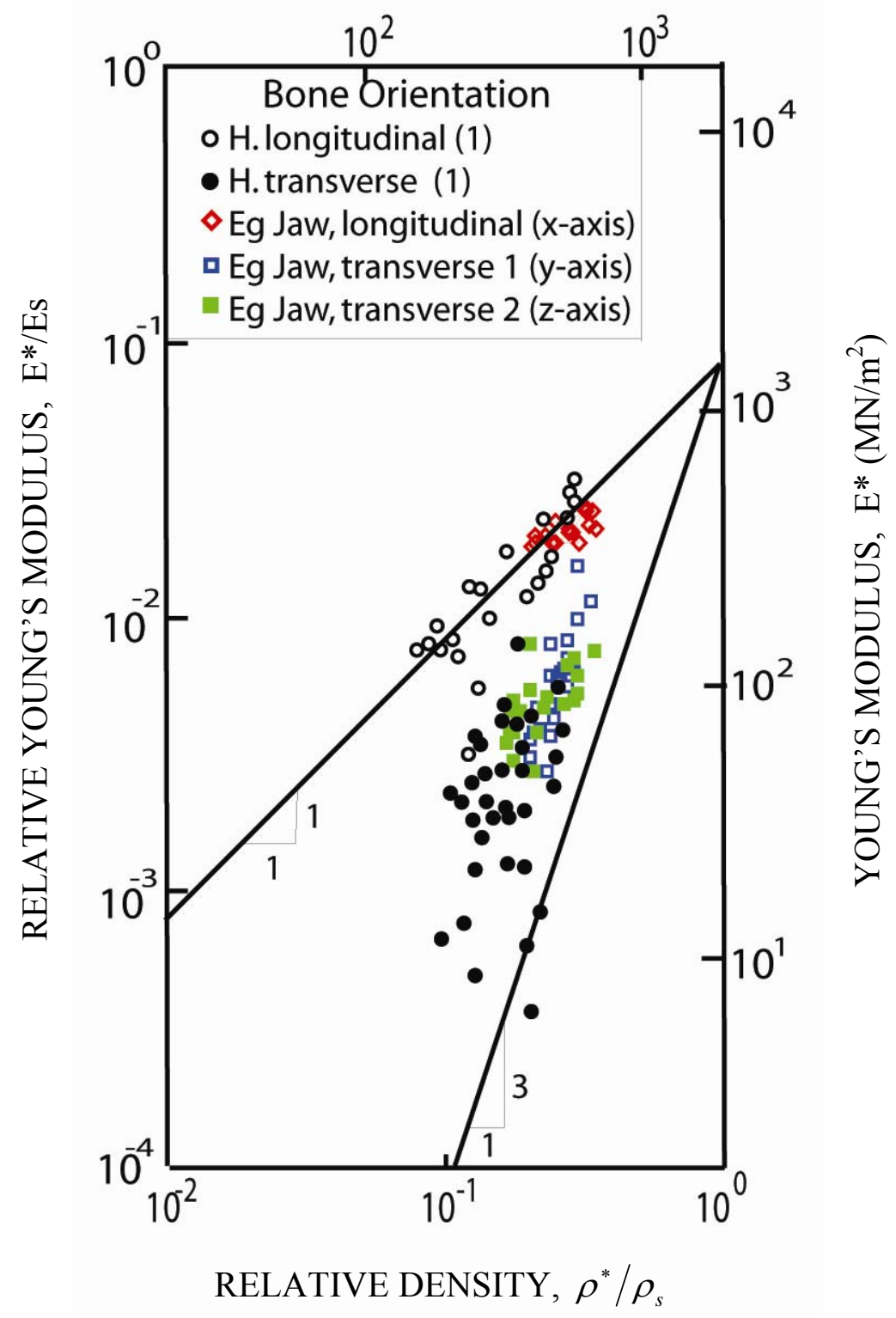


Figure 4.12: Apparent density vs. ultimate compressive strength as a function of bone orientation. Black symbols represent structurally prismatic trabecular bone specimens from the human tibia as reported by Williams and Lewis, 1982. Colored symbols are consistent with Figure 4.9. For prismatic specimens, longitudinal loading places specimen on a line with a slope of 1 , while transverse loading finds specimens on a line with a slope of almost 3 . While transverse right whale jawbone specimens fall in between this range, longitudinally loaded right whale specimens fall short of the general trend. Image adapted from Gibson and Ashby, 1997.

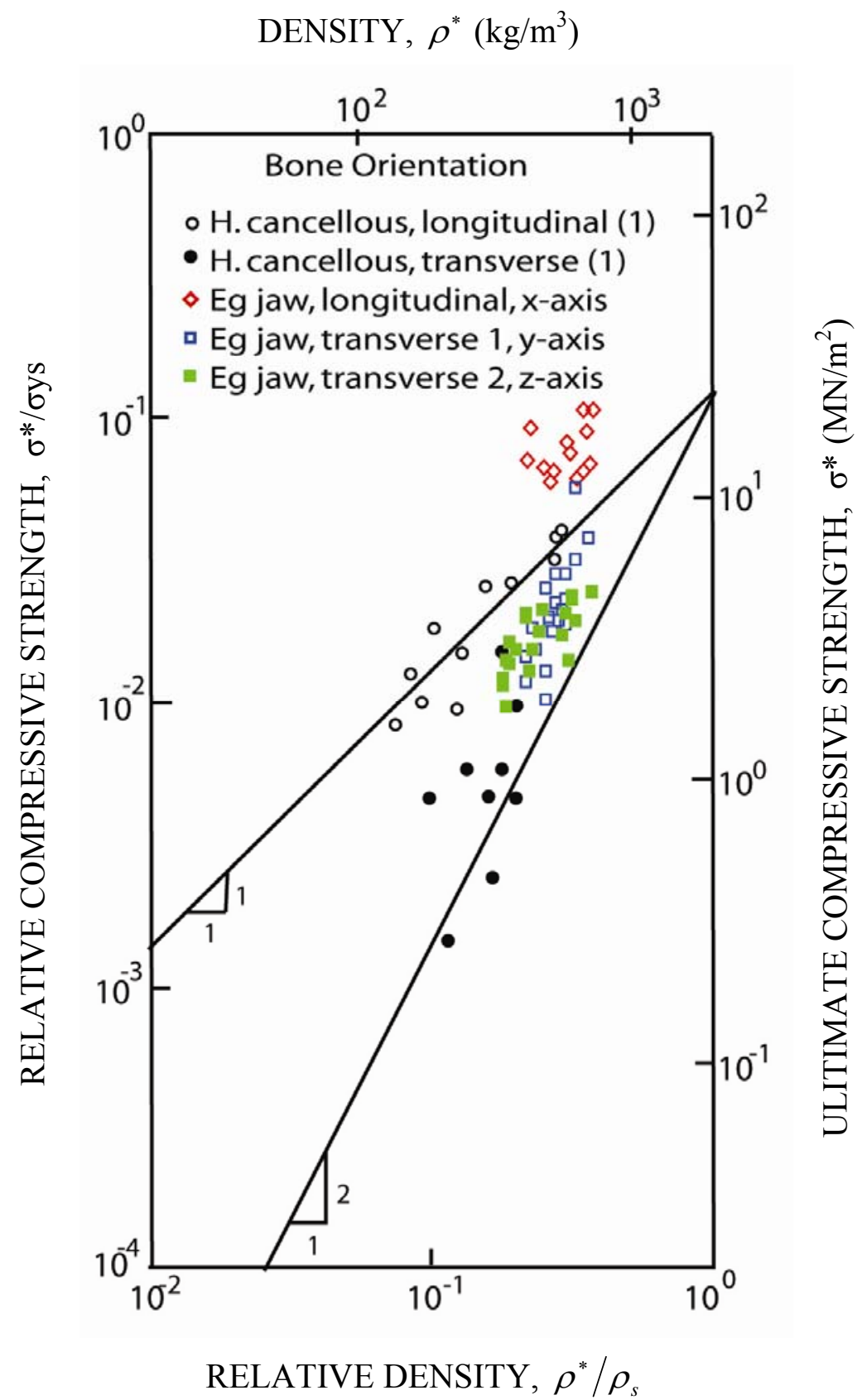


Percent differences calculated between average QCT apparent density and average measured apparent density can be seen in Table 4.6.

From these data, corresponding estimates of Young's modulus $\left(\mathrm{E}_{\text {est }}\right)$ were calculated using four regression equations from (Carter and Hayes, 1977, Ciarelli, et al., 1991, Hong, et al., 2004, Rice, et al., 1988). The resulting estimates for Young's modulus (in MPa) can be found in Table 4.7 and are displayed graphically in Figure 4.13. The curves (as displayed on the graph from top to bottom) are from equations 4.7, 4.8, 4.9 and 4.10 respectively.

The percent difference was also calculated between average QCT-estimated Young's modulus values and average experimentally derived Young's modulus. Results can be seen in Table 4.7.

Table 4.6: Percent difference between average QCT apparent density and the measured apparent density $\left(\rho_{\text {app }}\right)$ from segment B

\begin{tabular}{|c|c|c|}
\hline Parameter & Technique & $\begin{array}{c}\text { Avg. Apparent } \\
\text { Density }\end{array}$ \\
\hline QCT apparent density $(\mathrm{g} / \mathrm{cc})$ & QCT & 1.0963 \\
\hline Apparent density $(\mathrm{g} / \mathrm{cc})$ & $\begin{array}{c}\text { Manual } \\
\text { densitometry }\end{array}$ & 0.51402 \\
\hline & $\%$ difference $\left(\rho_{\mathrm{app}}\right)$ & $+113.3 \%$ \\
\hline
\end{tabular}


Table 4.7: Average QCT apparent density for right whale trabecular bone and corresponding values for estimated Young's modulus of elasticity $\left(\mathrm{E}_{\mathrm{est}}\right)$ as calculated from equations in Hong et al., 2004, Carter and Hayes, 1977, Ciarelli et al., 1991, Rice et al., 1988. All experimental data are averages for segment B as seen in Figure 4.1b.

\begin{tabular}{|c|c|c|c|c|}
\hline $\begin{array}{l}\text { Segment } \\
\text { ID }\end{array}$ & $\begin{array}{c}\text { Experimental } \\
\text { Data }\end{array}$ & $\begin{array}{c}\text { Avg. } E_{\text {est }} \\
\text { (equation 4.7) }\end{array}$ & $\begin{array}{c}\text { Avg. } \mathrm{E}_{\text {est }} \\
\text { (equation 4.8) }\end{array}$ & $\begin{array}{c}\text { Avg. } \mathrm{E}_{\text {est }} \\
\text { (equation 4.10) }\end{array}$ \\
\hline & $\begin{array}{l}\text { Avg. QCT App. } \\
\text { Density (g/cc) }\end{array}$ & \multicolumn{3}{|c|}{ Avg. QCT App. density $(\mathrm{g} / \mathrm{cc}) \rightarrow \mathrm{E}_{\text {est }}(\mathrm{MPa})$} \\
\hline \multirow[t]{2}{*}{$\mathrm{B}$} & $\begin{array}{c}1.096261 \\
( \pm 0.0834) \\
\end{array}$ & $5920.0( \pm 927.9)$ & $3852.6( \pm 848.1)$ & $\begin{array}{c}1061.1 \\
( \pm 147.8)\end{array}$ \\
\hline & Avg. $\mathrm{E}_{\exp }(\mathrm{MPa})$ & \multicolumn{3}{|c|}{ Percent Difference } \\
\hline \multirow[t]{3}{*}{$\mathrm{B}$} & 181.3 & $+3165.3 \%$ & $+2024.7 \%$ & $+485.2 \%$ \\
\hline & $\begin{array}{l}\text { Experimental } \\
\text { Data }\end{array}$ & $\begin{array}{c}\text { Avg. } \mathrm{E}_{\text {est }} \\
\text { (equation } 4.8 \text { ) }\end{array}$ & $\begin{array}{c}\text { Avg. } \mathrm{E}_{\mathrm{est}} \\
\text { (equation } 4.10 \text { ) }\end{array}$ & \\
\hline & Avg. $\rho_{a p p}(g / c c)$ & \multicolumn{2}{|c|}{ Avg. $\rho_{\text {app }}(\mathrm{g} / \mathrm{cc}) \rightarrow \mathrm{E}_{\mathrm{est}}(\mathrm{MPa})$} & \\
\hline \multirow[t]{2}{*}{ B } & $\begin{array}{c}0.51402 \\
( \pm 0.0970) \\
\end{array}$ & $390.5( \pm 3.2)$ & $286.7( \pm 78.9)$ & \\
\hline & Avg. $\mathrm{E}_{\exp }(\mathrm{MPa})$ & \multicolumn{2}{|c|}{ Percent Difference } & \\
\hline \multirow[t]{3}{*}{ B } & 181.3 & $+115.4 \%$ & $+58.1 \%$ & \\
\hline & $\begin{array}{c}\text { Experimental } \\
\text { Data } \\
\end{array}$ & \multicolumn{2}{|c|}{$\begin{array}{c}\text { Avg. } E_{\text {est }} \\
\text { (equation 4.9) }\end{array}$} & \\
\hline & $\begin{array}{c}\text { Avg. CT } \\
\text { Numbers (H.U.) }\end{array}$ & \multicolumn{2}{|c|}{ CT Numbers (H.U.) $\rightarrow \mathrm{E}_{\text {est }}(\mathrm{MPa})$} & \\
\hline \multirow[t]{2}{*}{$\mathrm{B}$} & $137.0( \pm 127.0)$ & \multicolumn{2}{|c|}{$148.6( \pm 173.5)$} & \\
\hline & Avg. $\mathrm{E}_{\exp }(\mathrm{MPa})$ & \multicolumn{2}{|c|}{ Percent Difference } & \\
\hline $\mathrm{B}$ & 181.3 & \multicolumn{2}{|c|}{$-18.0 \%$} & \\
\hline
\end{tabular}


Figure 4.13: Graph of apparent density $\left(\rho_{\mathrm{app}}, \mathrm{g} / \mathrm{cc}\right)$ vs. Young's modulus $\left(\mathrm{E}_{\mathrm{est}}, \mathrm{MPa}\right)$ predicted from published regression equations (Equations 4.7-4.10) from whale, human, and bovine bone. QCT apparent density values are plotted for the range observed in the right whale jawbone $0.827-1.331 \mathrm{~g} / \mathrm{cc}$ with an average of $1.096 \mathrm{~g} / \mathrm{cc}$ (Equations 4.7 and 4.10). $\rho_{\text {app }}$ for extracted right whale bone specimens (from manual densitometry) is represented by open yellow diamonds. Manual densitometry values for apparent density averaged $0.5140 \mathrm{~g} / \mathrm{cc}$, ranging from a minimum of $0.3316 \mathrm{~g} / \mathrm{cc}$ to a high of $0.7926 \mathrm{~g} / \mathrm{cc}$.

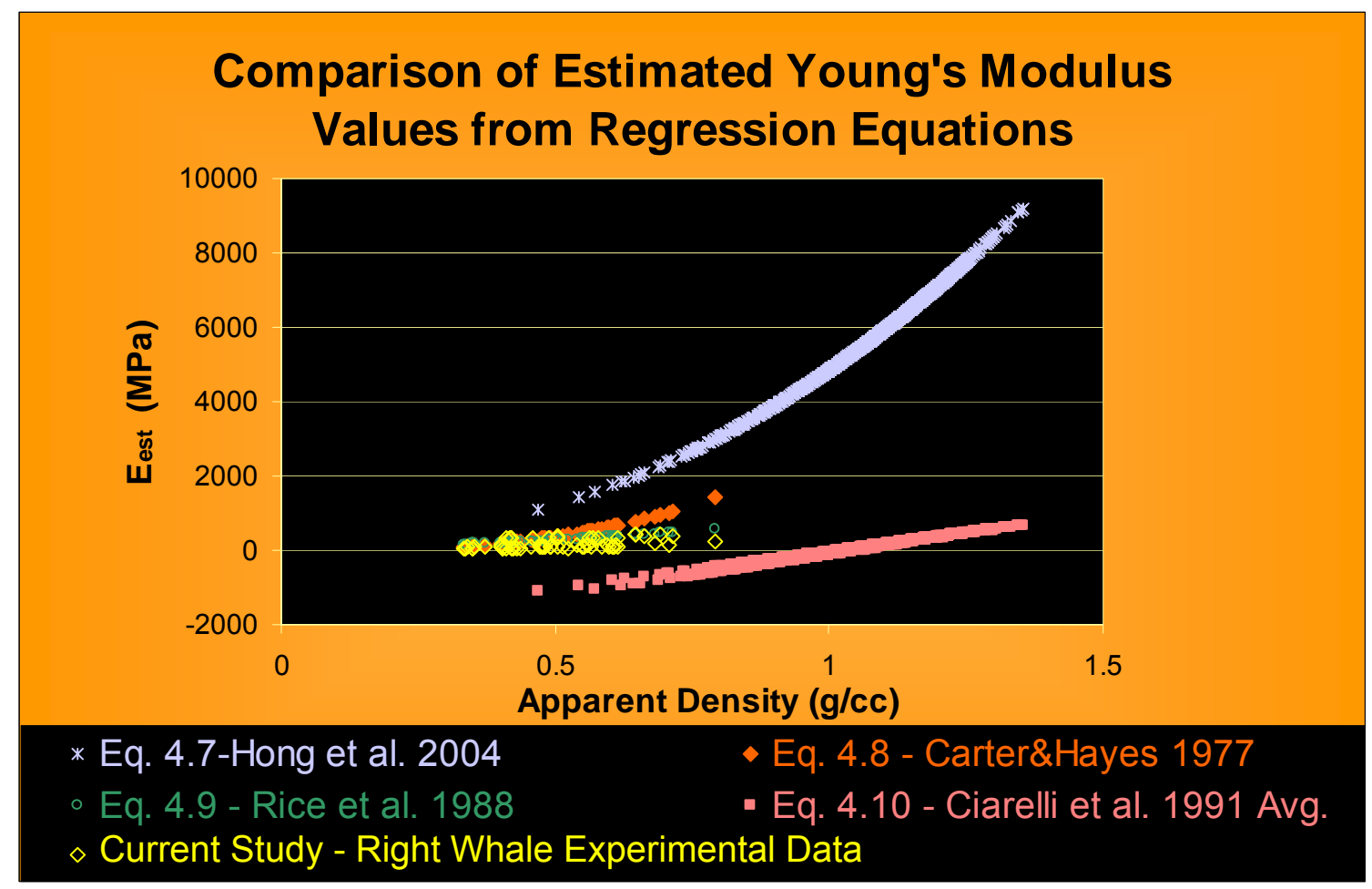

\subsection{DISCUSSION}

\subsubsection{Manual densitometry}

Manual densitometry revealed right whale trabecular bone average apparent density $(0.5140 \mathrm{~g} / \mathrm{cc})$ to be within the range of values observed in other species studied $(0.1-1.0 \mathrm{~g} / \mathrm{cc})$ (Huiskes and van Rietbergen, 2005). Cortical bone on the other hand had 
a relatively low apparent density $(1.24 \mathrm{~g} / \mathrm{cc})$ compared to standard values (typically 1.8 $\mathrm{g} / \mathrm{cc}$ ) (Huiskes and van Rietbergen, 2005).

Results from a prior study investigating right whale cortical bone using microscale computed tomography revealed that much of the bone was considered cortical bone based on its density, actually had intermediate characteristics of bone cortical and trabecular bone (Campbell-Malone, et al., 2007a). This bone type was classified as "transitional" bone because it was found in between the cortical shell and the trabecular medulla. Transitional bone was found in the right whale mandible in lieu of the sharp demarcation typically found between cortical and trabecular bone types. This descriptor was also used because the bone had a higher porosity than expected for compact bone and this was accompanied by trabeculae measuring up to a millimeter in thickness (Campbell-Malone, et al., 2007a). ${ }^{10}$

\subsubsection{Mechanical testing}

Mechanical testing was conducted to empirically determine the relationship between the material properties and apparent density of trabecular and cortical bone from the North Atlantic right whale mandible. Measurements of Young's modulus and the ultimate compressive strength represent novel data for comparison to other bones and various species.

Interspecific comparisons of stiffness and strength: When interspecific comparisons are made without regard for the specific bone analyzed it is apparent that the

\footnotetext{
${ }^{10}$ Normal trabecular bone has trabeculae that measure approximately $0.1 \mathrm{~mm}$ in thickness (Huiskes and van Rietbergen, 2005).
} 
right whale mandible behaves somewhat differently than other animals and other bone types. In Figure 4.9, Young's modulus is plotted against density for specimens tested in tension and compression without regard for bone orientation. There is a modest range of scatter - which may be due to differences in testing method (i.e. tension vs. compression, and varied strain rates), composition (i.e. water and inorganic content), the direction of loading, and structural differences (Gibson and Ashby, 1997). Despite this range, much of the dataset follows a trend with a slope below 3 (Gibson and Ashby, 1997). Only right whale mandibular bone and human tibial plateau samples are found slightly above the trend.

Both of these bone types exhibit material stiffness that is relatively low compared to the other bone types examined. In other words, right whale mandibular specimens are more compliant when compared to specimens of equal density (e.g. the equally dense bovine femur, which is 5 to 10 -fold stiffer than either the right whale mandible or the human tibial plateau). The trend is not perfectly established here (i.e. data from two additional studies of human tibia follow the trend of the majority), but a site-specific trend (e.g. human tibial plateau and right whale mandible) cannot be ruled out by this limited dataset.

Similarly, Figure 4.10 illustrates the relationship between density and the ultimate compressive strength for various human and bovine bones and the right whale mandible. Once more, there is moderate scatter to the data, but a majority of the data points fall upon a line with a slope of 2. Again, though not a significant outlier, right whale mandibular bone appears to be more compliant than its density would otherwise indicate. 
One minor caveat exists regarding the ultimate compressive strength in the trabecular bone dataset. As four of the trabecular specimens tested did not fail prior to reaching the load cell limit, they were left out of calculations of the ultimate strength. As such, the average value reported here for the ultimate compressive strength of right whale trabecular bone (7.7 MPa) is likely a slight underestimate of the value that would have been reported if a load cell with a higher capacity had been used. Thus, 7.7 MPa should be taken as a minimum value for the average ultimate compressive strength.

A thorough examination of these same trends in other mandibular specimens and in additional right whale bones (e.g. ribs and vertebrae) would provide much needed context for drawing conclusions regarding whether this may be a general trend in mandibles or in right whale bone.

Comparative values for the biomechanical properties of trabecular bone from nonhuman mandibular bone are scarce in the literature. However, there is marked similarity noted when comparing the Young's modulus of the stiffest axis of the right whale mandible (374.3 MPa) to the average values from the dentate human mandible (373 MPa) (Giesen, et al., 2004).

The stiffness of the human mandible, measured as Young's modulus of elasticity, was approximately 113 times the measured ultimate compressive strength (3.3 MPa), which is in line with a general trend from the literature where the ratio of Young's modulus to the ultimate compressive strength is 100:1 (Hodgskinson and Currey, 1990a, Hodgskinson and Currey, 1990b). The trend for the right whale mandible is strikingly different. The ratio between Young's modulus and the ultimate compressive strength 
ranges from 24:1-28.5:1, representing a 71.5-76\% reduction in stiffness in trabecular bone (or a 4-fold increase in compressive strength) as compared to trends from other species investigated.

This reduced stiffness was not accompanied by a loss of mineral as evaluated by ash content. Ash content for right whale bone averaged $64.4 \%$, well within the range of measurements from other mammals (60-80\%) (Currey, 2002). While it is beyond the scope of this study, it would be interesting to determine the potential factors (e.g. mineral composition, trabecular structure, etc.) that play a role in the reduced stiffness or increased strength observed.

The right whale mandible exhibits anisotropy: The experimental design of mechanical testing permitted the evaluation of anisotropy in right whale trabecular bone. It was determined that trabecular bone behaves anisotropically, with the longitudinal caudo-cranial axis (x-axis) having an average Young's modulus 3-4 times higher than the other orthogonal axes. Similarly, the x-axis also had a higher average ultimate strength (3.6 and 4.8 times greater) than the $y$ - and z-axes respectively.

Figures 4.11 and 4.12 illustrate the clear separation between material properties in longitudinally and transversely loaded specimens in the human tibia and right whale jawbone. Longitudinally loaded specimens are both stiffer and stronger than those loaded transversely in both species. ${ }^{11}$

\footnotetext{
${ }^{11}$ Though this second comparison between right whale and human tibia is coincidental, it would be interesting to evaluate similar data (with bone orientation preserved) in other species whose $\rho_{\text {app }}, E$, and $\sigma$ follow the general trend of the majority.
} 
Data from cylindrical cortical bone samples provided a wide range of values with an average Young's modulus of 854.2 MPa and an average ultimate strength of 22.9 MPa. When preparing these samples for mechanical testing, the orientation of the cortical bone (with respect to the $\mathrm{x}-, \mathrm{y}$ - and $\mathrm{z}$-axes) was not preserved. For this reason, questions regarding the anisotropic behavior of cortical whale bone could not be addressed with this sample set.

\subsubsection{Estimating apparent density and Young's modulus using QCT}

Estimating the material properties of bone using imaging techniques has been used previously as an important tool for determining fracture risk in live individuals in a non-invasive manner (Hong, et al., 2004). Here, the application of this tool permitted the non-destructive exploration of the internal bone structure of a museum quality baleen whale jaw bone specimen. Quantitative computed tomography (QCT) was used to generate detailed density maps of $3 \mathrm{~mm}$ resolution in a bone that measured $399.5 \mathrm{~cm}$ in length.

Estimating apparent density using QCT: Despite moderate use as a proxy for apparent density, the calculated values for QCT apparent density overestimated measured apparent density for the same region by over 2 -fold. There are a few possible reasons for this disparity.

The first may be in the sampling method employed. QCT scanning was performed on the entire bone segment prior to sampling. At the time, the bone was not marked in such a way that permitted direct correlation between the QCT point measurements and 
the location of sampling for densitometry. Sampling protocols have been redesigned such that the densitometry sample can be scanned either in situ prior to sampling or after it has been extracted. This will allow direct correlation of scanned and sampled regions and may reduce error based on comparison of two different regions of a complex tissue.

A second source of error is the high fat content which has been shown to introduce error in QCT measurements (Laval-Jeantet, et al., 1986). One possible contributing factor is the large contribution of fat to the mass of trabecular bone in the right whale mandible - ranging from $34.8-79.2 \%$ fat by mass (Campbell-Malone, et al., 2007a). The average value for fat content was $50.3 \%$ by mass. As whales lack bone marrow cavities, the high inter-trabecular fat content seems to compensate via widespread distribution of fat in an alternate skeletal reservoir. As fat has an apparent density of $0.960 \mathrm{~g} / \mathrm{cc}$ (roughly 70 H.U.) QCT apparent density values would systematically average in the lower grayscale values contributed by inter-trabecular fat and would thereby make bone with high fat content appear lower in density.

Human vertebral fat content has been shown to contain $13-28 \%$ fat, which has been shown to cause errors in QCT determinations of vertebral mineral density (LavalJeantet, et al., 1986). These errors can be reduced via the use of dual-energy CT scanning over the single-energy methods utilized to obtain QCT mineral (ash) density for right whale bone. ${ }^{12}$

\footnotetext{
${ }^{12}$ QCT mineral density and QCT apparent density are determined in the same manner using phantom standards of known mineral and apparent density. The first utilizes the known mineral density values to create regression curves for converting HU to mineral density. The second utilizes the known apparent density of the phantoms for regression.
} 
The human vertebrae study reported a mineral density "prediction error" on the order of $20 \mathrm{mg} / \mathrm{cc}$ (Laval-Jeantet, et al., 1986). With ash densities measuring from 175 $378 \mathrm{mg} / \mathrm{cc}$ (average $=273 \mathrm{mg} / \mathrm{cc}$ ) for trabecular bone from the right whale mandible this represents a potential average error of $7.3 \%$ for this species using this method to determine ash density. While methods of increasing the accuracy of QCT apparent density predictions will be explored, the degree of potential error noted was deemed reasonable for the purposes of this study.

Future studies involving wet, dry and defatted bone will help shed light on the contribution of fat content to the differences seen between QCT and physical measurements of density. These errors can also be reduced via the use of dual-energy CT scanning over the single-energy methods utilized in this study. While this knowledge will be used to refine QCT protocols to reduce error the potential error from this factor was low and as such it is not thought to have played a major role in the error noted.

Another possible source of error noted was the lack of ultra-low density standards to provide insight into the behavior of the calibration equation when little mineral is present. Preliminary studies used to calculate calibration equations between $\mathrm{CT}$ numbers and apparent density utilized calibration standards between $100 \mathrm{mg} / \mathrm{cc}$ and $1250 \mathrm{mg} / \mathrm{cc}$ calcium hydroxyapatite which corresponded to apparent densities between $1.091-1.83$ g/cc (Campbell-Malone, et al., 2007a). The calibration of CT numbers corresponding to lower density values was an extrapolation. Values in the low density range presumably follow the same trend and re-calibration is currently underway using standards of lower density $(0,25,50$ and $75 \mathrm{mg} / \mathrm{cc})$ to increase confidence in this range of values. 
At present it is unclear whether the percent difference between physical measurements of apparent density and QCT apparent density is a variable error or if it is constant that can be corrected for. Additional calibrations are underway to determine how consistent this error term is as well as possible methods of correction that may reduce it.

Estimating Young's modulus using QCT apparent density: While regression equations relating the apparent density of trabecular bone to Young's modulus were found in the literature for other species, including human and bovine bone, speciesspecific data were lacking. Ironically, an equation has been published which relates QCT apparent density to Young's modulus of elasticity $\left(\mathrm{E}_{\mathrm{est}}\right)$ for trabecular bone from other large whale species including the Sperm whale (Physeter macrocephalus), Bowhead whale (Balaena mysticetus), and Pygmy Sperm whale (Kogia breviceps) (Hong, et al., 2004). The equation showed early promise for comparison to the data presented in this study (QCT apparent density and experimentally derived E). When compared to right whale experimental data over the appropriate range of apparent density values the right whale data were not well represented by this power equation (Figure 4.13).

The average trabecular bone QCT apparent density for segment B was 1.0940 $\mathrm{g} / \mathrm{cc}$. This value and resulted in a predicted Young's modulus of $5920 \mathrm{MPa}$ for segment B. The experimentally determined average value for specimens from segment B was 181.3 MPa. While it is possible that the lack of specific units for this equation led to errors in interpretation, the data suggest that use of this equation would result in greater than 30-fold overestimation of the average Young's modulus for segment B! If 
interpreted properly, this function, despite being from taxonomically relevant species, was considered inappropriate.

Estimating Young's modulus using measured apparent density: Initially, this study sought to utilize regression equations 4.8 and 4.10 to convert QCT apparent density values directly into estimates of the average Young's modulus. However, this method resulted in over 2-fold overestimation of apparent density when QCT was used. As such, estimates of Young's modulus $\left(\mathrm{E}_{\text {est }}\right)$ calculated using equations 4.8 and 4.10 along with QCT apparent density resulted in unacceptably divergent values ranging from 6-fold to over 20-fold when compared to $\mathrm{E}_{\exp }$ (Table 4.7).

One reason for the near 30 fold difference in predicted values may stem from the fact that the range of apparent densities of the specimens used to determine equation 4.8 fell primarily between $0.15 \mathrm{~g} / \mathrm{cc}$ and less than $1 \mathrm{~g} / \mathrm{cc}$. The few outliers on the high end of the data set used by to create equation 4.8 were actually compact bone with an apparent density measuring roughly $2 \mathrm{~g} / \mathrm{cc}$ (Carter and Hayes, 1977). Differences in the methodology used to calculate apparent density (QCT vs. manual densitometry) likely introduced a factor confounding direct comparison, as many of the data points sampled via QCT measured over $1 \mathrm{~g} / \mathrm{cc}$.

As estimates from equations 4.8 and 4.10 were unsuccessful used with QCT apparent density, an alternate method of predicting Young's modulus was tested. Instead of using QCT apparent density values, the measured average apparent density was used with equations 4.8 and 4.10. Despite the fact that these equations were neither species- 
specific nor bone-specific, they resulted in far more reasonable estimates than the equation created using whale bone.

Equations 4.8 and 4.10 each overestimated Young's modulus by only a factor of roughly 2 (2.15 and 1.58 respectively). This is likely within the degree of error that may be introduced by utilizing different mechanical testing methods (e.g. tension instead of compression), bone with varied water content or trabecular orientation (Gibson, 1985). As such, these equations may be useful for calculating reasonable first order estimates of Young's modulus of elasticity for bone of unknown material properties. Finer estimates may require species- and bone-specific functions for estimating Young's modulus from measurements of apparent density.

Estimating Young's modulus using CT numbers: One of the primary goals of this study was to utilize CT scanning as a non-destructive means of indirectly determining the material properties of right whale bone on a fine spatial scale. Equation 4.9 was calculated based on the correlation of the average experimentally determined Young's modulus to CT numbers (in Hounsfield units) in human trabecular bone (Ciarelli, et al., 1991).

Here, using the average of CT numbers measured in segment B (137.0 H.U., S.D. \pm 127.0 ), an average value of $148.6 \mathrm{MPa}$ (S.D. \pm 173.5 ) was predicted. Equation 4.9 only slightly underestimated the measured value by just below $20 \%$. This was deemed suitable enough to provide reasonable estimate of Young's modulus - beyond the first order 
estimates determined by equations 4.8 and 4.10. A small degree of error such as this can be explained by various factors.

One difference may be attributed to the fact that the trabecular bone specimens used to determine the regression for equation 4.9 ranged from -25 to 714 H.U. While $82.4 \%$ of the H.U. values from whale bone the present study were within that range, the remaining $17.6 \%$ were below the range and thereby were extrapolated by default resulting in negative numbers for Young's modulus at the low end of the apparent density scale.

Aside from extrapolation, small differences between CT manufacturer specifications, individual scanners, beam hardening, and software processing result in slight differences in output (Mull, 1984).

Limitations and conclusions: The equations from the literature relating apparent density or Hounsfield units to Young's modulus are very different functions, ranging from linear regressions to second- and third-order exponential equations. QCT apparent density values were not a good predictor of Young's modulus (Figure 4.13). Apparent density values from manual densitometry on specimens extracted from the right whale jawbone showed much better agreement with the two power equations (Equations 4.8 and 4.10) than the linear regression (Equation 4.9) (Figure 4.13), particularly at values below $0.75 \mathrm{~g} / \mathrm{cc}$.

The small size of the sample set used for manual densitometry, its limited density range (compared to the range from QCT) and the fact that all samples were taken from 
the same region of bone (segment B) leaves the actual behavior of high density whale bone and bone in other regions of the mandible undetermined. Though samples from other segments of the mandible are no longer available, additional specimen processing is under way to increase the sample size from segment B in an effort to address outstanding questions regarding the behavior of right whale mandibular bone outside of the density range explored here.

In addition to the small sample size and limited density range, one additional factor to consider is the fact that regressions such as these rely upon a scalar factor (in this case apparent density) to predict a tensor (Williams and Lewis, 1982). This fact is particularly well-demonstrated when cubic samples used for anisotropy experiments are considered. For these samples, a single value for apparent density would be charged with predicting three different Young's moduli in a material that is truly anisotropic. Thus, the limitation of the current analysis restricts predictions of Young's modulus to the average Young's modulus in all directions. Axis-specific regressions could also be used to determine an individual modulus for each axis with increased confidence.

Despite this caveat, computed tomography combined with a regression equation (Equation 4.9) from a prior study provided valuable first order estimates of the material properties of right whale jawbone tissue on a larger spatial scale than could have otherwise been accomplished (Ciarelli, et al., 1991).

These data can later be merged with the spatial localization data to reveal the most compliant regions of the jawbone without the extensive and destructive sampling and mechanical testing required to obtain the same data experimentally. 
Regression equations could not be found in the literature for compact bone and in fact one study suggested that the apparent density of cortical bone may not be a good predictor of the mechanical properties of cortical bone (Snyder and Schneider, 1991).

The present study design attempted to address this issue directly via $\mu \mathrm{CT}$ scanning for apparent density and mechanical testing of cortical bone samples followed by physical measurements of apparent density.

Unfortunately, the protocol utilized for extracting fat was insufficient for cortical bone structure. This resulted in an overestimation of apparent density and severe underestimates of ash content upon ashing due to lower ash weight following the incineration of the remaining fat. An alternate method of fat extraction will be used in a subsequent study to provide a more reliable method of determining apparent density and correlating it with mechanical properties, thus providing an experimental dataset suitable for comparison to predicted values.

\subsection{CONCLUSIONS}

The primary goal of this study, defining the physical and material properties of right whale jawbone tissue, was accomplished using a combination of physical measurements and mechanical testing. Mechanical testing demonstrated that right whale trabecular and cortical bone Young's modulus averaged 181.3 MPa and 854.2 MPa, while their compressive strengths averaged 7.7 MPa and 22.9 MPa respectively. 
Results also indicate that right whale trabecular bone is anisotropic with the caudo-cranial "x-axis" having a higher average ultimate strength 3.6-4.8 times greater than each of the remaining orthogonal axes. Similarly, the same axis had a higher Young's modulus measuring 3-4 times greater than the other orthogonal axes. Cortical bone anisotropy was not determined for this study.

When put into context with other species that have been investigated the stiffness of trabecular bone was $75 \%$ less than expected (or the compressive strength was four times greater) based on the experimentally-derived Young's modulus. The decrease in stiffness was not explained by ash content, which was within the normal range for other mammalian species (Campbell-Malone, et al., 2007a). Trabecular structure and mineral composition are just two factors that may contribute to this and which could be explored by future studies.

As a trend for reduced strength in the human mandible is accompanied by reduced mastication function, the evolutionary questions raised by this trend in a filter-feeding whale are intriguing. Odontocetes (toothed whales) possess highly developed dentition used in a predatory context (pinch capture, prey preparation and consumption) without dedicated prey chewing (Heithaus and Dill, 2002). Mysticetes use baleen plates that hang from the upper jaw to strain their prey from seawater. Data regarding the biomechanical behavior of their toothed whale counterparts are essential to address whether development, stresses from feeding or other factors play a role in establishing this unexpected reduction in strength. 
While the use of QCT apparent density as an indirect predictor of Young's modulus for right whale trabecular bone was not successful, alternatives that may allow QCT apparent density to be translated into apparent density are being explored. In the meantime, a viable equation relating $\mathrm{CT}$ numbers to Young's modulus will indeed permit the development of a three-dimensional reconstruction of the internal and external structure of the mandible with its associated Young's modulus values.

Together, these data will contribute to a finite element model designed to simulate applied stress during a vessel-whale collision event. These studies provide parameters vital to making realistic assumptions such that model behavior predicts realistic outcomes, in terms of bone failure, to the extent possible. Additional parameters being explored include the behavior of the overlying soft tissue in response to applied stress and the contact area and contact time relevant to vessel collision scenarios.

Model outcomes will be used to analyze the relationship between vessel speed and the probability of whale fatality using jawbone failure as a fatal endpoint. This analysis will permit the evaluation of speed restrictions in right whale habitat as a management tool to reduce vessel-collision mortality - one of the primary measures being considered as a part of the strategic plan for the recovery of the North Atlantic right whale. The multidisciplinary, collaborative effort required to produce a vessel collision model speaks not only to the complexity of the problem, but also provides insight into the intricate nature of finding a solution that will reduce the most well-documented source of anthropogenic mortality faced by the right whale. 


\subsection{ACKNOWLEDGEMENTS}

The authors would like to thank the funding agencies whose support was vital to this body of work. These sources include: National Oceanic and Atmospheric Administration/National Marine Fisheries Service (Right Whale Grants Program - Grant No. NA04NMF4720402, RCM \& MJM), the National Science Foundation (Graduate

Research Fellowship Program, RCM), Woods Hole Oceanographic Institution (Ocean Life Institute Awards, RCM, MJM; WHOI SeaGrant, RCM)

In addition, our collective gratitude is extended to several individuals whose contributions were greatly appreciated - Ken Baldwin (UNH), Judson DeCew (UNH), Lorna Gibson (MIT), Jason Raymond (UNH), Brian Snyder (Beth Israel Deaconess Medical Center) and Vicke Starczak (WHOI). 


\subsection{LITERATURE CITED}

Ashby, M. F., 1983. The Mechanical Properties of Cellular Solids. Metallurgical and Materials Transactions A 14A, pp. 1755-1769.

Ashman, R. B., G. Rosinia, S. C. Cowin, M. G. Fontenot and J. C. Rice, 1985. The bone tissue of the canine mandible is elastically isotropic. Journal of Biomechanics 18 (9), pp. 717-721.

Ashman, R. B. and W. C. van Buskirk, 1987. The Elastic Properties of a Human Mandible. Adv Dent Res 1 (1), pp. 64-67.

Balsiger, J. W., 2006. Federal Register 50 CFR Part 224: Proposed Rule to Implement Speed Restrictions to Reduce the Threat of Ship Collisions with North Atlantic Right Whales. NOAA/NMFS. [Docket No. 040506143-6016-02. I.D.101205B] RIN 0648-AS36. 71, 122, 15 pages. http://www.nmfs.noaa.gov/pr/pdfs/fr/fr7136299.pdf

Behrens, J. C., P. S. Walker and H. Shoji, 1974. Variations in strength and structure of cancellous bone at the knee. Journal of Biomechanics 7 (3), pp. 201-207.

Bensusan, J. S., D. T. Davy, K. G. Heiple and P. J. Vertin, 1983. 19th Annual Orthopaedic Research Society Meeting.

Campbell-Malone, R., J. Arruda, D. R. Ketten and M. J. Moore, 2007a. Geometry, Internal Morphology and Densitometry of the Right Whale Mandible, in prep. 24.

Campbell-Malone, R., S. G. Barco, P.-Y. Daoust, A. R. Knowlton, W. A. McLellan, D. S. Rotstein and M. J. Moore, 2007b. Sharp and blunt trauma in North Atlantic right whales killed by vessels. Journal of Zoo and Wildlife Medicine, in press.

Carter, D. R., W. E. Caler, D. M. Spengler and V. H. Frankel, 1981. Uniaxial fatigue of human cortical bone. The influence of tissue physical characteristics. Journal of Biomechanics 14 (7), pp. 461-470.

Carter, D. R. and W. C. Hayes, 1977. The compressive behavior of bone as a two-phase porous structure. The Journal of Bone and Joint Surgery 59 (7), pp. 954-962.

Carter, D. R., Hayes, Wilson C., 1976. Bone Compressive Strength: The Influence of Density and Strain Rate. Science 194 (4270), pp. 1174-1176.

Carter, D. R., G. H. Schwab and D. M. Spengler, 1980. Tensile fracture of cancellous bone. Acta Orthopaedica Scandinavica 51 (5), pp. 733-741.

Ciarelli, M. J., S. A. Goldstein, J. L. Kuhn, D. D. Cody and M. B. Brown, 1991. Evaluation of orthogonal mechanical properties and density of human trabecular bone from the major metaphyseal regions with materials testing and computed tomography. Journal of Orthopaedic Research 9 (5), pp. 674-682.

Currey, J., 1988. The effects of porosity and mineral content on the Young's modulus of elasticity of compact bone. J. Biomechanics 21, pp. 131-139.

Currey, J., 2004. Tensile yield in compact bone is determined by strain, post-yield behaviour by mineral content. Journal of Biomechanics 37, pp. 549-556.

Currey, J. D., 1975. The effects of strain rate, reconstruction and mineral content on some mechanical properties of bovine bone. Journal of Biomechanics 8 (1), pp. 81-82. 
Currey, J. D., 1998. Mechanical properties of vertebrate hard tissues. Proceedings of the Institution of Mechanical Engineers. Part H, Journal of engineering in medicine 212, pp. 399-412.

Currey, J. D., 2002. Bones: structure and mechanics. Princeton University Press. Princeton, NJ. 436 pages.

Galante, J., W. Rostoker and R. D. Ray, 1970. Physical properties of trabecular bone. Calcified Tissue International V5 (1), pp. 236-246.

Gibson, L. J., 1985. The mechanical behaviour of cancellous bone. Journal of Biomechanics 18 (5), pp. 317-328.

Gibson, L. J. and M. F. Ashby, 1997. Chapter 11: Cancellous Bone. In. Cellular Solids: Structure and properties. Cambridge University Press. Cambridge. pp. 429-452.

Giesen, E., M. Ding, M. Dalstra and T. van Eijden, 2004. Changed Morphology and Mechanical Properties of Cancellous Bone in the Mandibular Condyles of Edentate People. Journal of Dental Research 83 (3), pp. 255-259.

Goldstein, S. A., 1987. The mechanical properties of trabecular bone: Dependence on anatomic location and function. Journal of Biomechanics 20 (11-12), pp. 10551061.

Goulet, R. W., S. A. Goldstein, M. J. Ciarelli, J. L. Kuhn, M. B. Brown and L. A. Feldkamp, 1994. The relationship between the structural and orthogonal compressive properties of trabecular bone. Journal of Biomechanics 27 (4), pp. 375-377.

Hamer, A. J., J. R. Strachan, M. M. Black, C. J. Ibbotson, I. Stockley and R. A. Elson, 1996. Biomechanical Properties of Cortical Allograft Bone Using a New Method of Bone Strength Measurement. The Journal of Bone and Joint Surgery 78-B, pp. 363-368.

Hayes, W. C. and M. L. Bouxsein, 1997. Chapter 3: Biomechanics of Cortical and Trabecular Bone: Implications for Assessment of Fracture Risk. In: Mow, V. C. and Hayes, W. C., Eds. Basic Orthopaedic Biomechanics. Lippincott-Raven Publishers. New York. pp. 69-112.

Heithaus, M. R. and L. M. Dill, 2002. Feeding Strategies and Tactics. In: Perrin, W., Wursig, B. and Thewissen, J. G. M., Eds. Encyclopedia of Marine Mammals. Academic Press. Boston. pp. 412-422.

Hernandez, C. J., G. S. Beaupre, T. S. Keller and D. R. Carter, 2001. The influence of bone volume fraction and ash fraction on bone strength and modulus. Bone 29 (1), pp. 74-78.

Hodgskinson, R. and J. Currey, 1990a. The effect of variation in structure on the Young's modulus of cancellous bone: a comparison of human and non-human material. Proceedings of the Institution of Mechanical Engineers, Part H: Journal of Engineering in Medicine 1989-1996 (vols 203-210) 204 (2), pp. 115-121.

Hodgskinson, R. and J. D. Currey, 1990b. Effects of structural variation on Young's modulus of non-human cancellous bone. ARCHIVE: Proceedings of the Institution of Mechanical Engineers, Part H: Journal of Engineering in Medicine 1989-1996 (vols 203-210) 204 (18), pp. 43-52. 
Hong, J., G. D. Cabe, J. R. Tedrow, J. A. Hipp and B. D. Snyder, 2004. Failure of trabecular bone with simulated lytic defects can be predicted non-invasively by structural analysis. Journal of Orthopaedic Research 22, pp. 479-486.

Huiskes, R. and B. van Rietbergen, 2005. Biomechanics of Bone. In: Mow, V. C. and Huiskes, R., Eds. Basic Orthopaedic Biomechanics and Mechano-Biology. Lippincott, Williams \& Wilkins. New York. pp. 123-179.

Hvid, I., S. Bentzen, F. Linde, L. Mosekilde and B. Pongsoipetch, 1989. X-ray quantitative computed tomography: the relations to physical properties of proximal tibial trabecular bone specimens. J. Biomechanics 22,

International Whaling Commission, 2001. Report of the Workshop on Status and Trends of Western North Atlantic Right Whales. Journal of Cetacean Research and Management Special Issue 2, pp. 61-87.

Kabel, J., B. van Rietbergen, M. Dalstra, A. Odgaard and R. Huiskes, 1999a. The role of an effective isotropic tissue modulus in the elastic properties of cancellous bone. Journal of Biomechanics 32 (7), pp. 673-680.

Kabel, J., B. van Rietbergen, A. Odgaard and R. Huiskes, 1999b. Constitutive relationships of fabric, density, and elastic properties in cancellous bone architecture. Bone 25 (4), pp. 481-486.

Keller, T. S., 1994. Predicting the compressive mechanical behavior of bone. Journal of Biomechanics 27 (9), pp. 1159-1168.

Laval-Jeantet, A. M., B. Roger, S. Bouysee, C. Bergot and R. B. Mazess, 1986. Influence of vertebral fat content on quantitative CT density. Radiology 159 (2), pp. 463466.

Les, C. M., S. M. Stover, J. H. Keyak, K. T. Taylor and A. J. Kaneps, 2002. Stiff and strong compressive properties are associated with brittle post-yield behavior in equine compact bone material. Journal of Orthopaedic Research 20 (3), pp. 607614.

Levi, C., J. E. Gray, E. C. McCullough and R. R. Hattery, 1982. The unreliability of CT numbers as absolute values. Am. J. Roentgenol. 139 (3), pp. 443-447.

Linde, F., P. Norgaard, I. Hvid, A. Odgaard and K. Soballe, 1991. Mechanical properties of trabecular bone. Dependency on strain rate. Journal of Biomechanics 24 (9), pp. 803-809.

Martin, R. B. and D. L. Boardman, 1993. The effects of collagen fiber orientation, porosity, density, and mineralization on bovine cortical bone bending properties. Journal of Biomechanics 26 (9), pp. 1047-1054.

Martin, R. B., D. B. Burr and N. A. Sharkey, 1998. Skeletal Tissue Mechanics. Springer. New York. 392 pages.

McLellan, W. A., S. Rommel, M. J. Moore and D. A. Pabst, 2004. Right Whale Necropsy Protocol. Final Report to NOAA Fisheries for contract \# 40AANF112525. U.S. Department of Commerce, National Oceanic and Atmospheric Administration, National Marine Fisheries Service, Office of Protected Resources. Silver Spring, MD. 51 pages.

Miller, M. E., G. C. Christensen and H. E. Evans, 1964. Anatomy of the Dog. W.B. Saunders Company. Philadelphia. 941 pages. 
Misch, C. E., Z. Qu and M. W. Bidez, 1999. Mechanical properties of trabecular bone in the human mandible: Implications for dental implant treatment planning and surgical placement. Journal of Oral and Maxillofacial Surgery 57 (6), pp. 700706.

Moore, M. J., A. R. Knowlton, S. D. Kraus, W. A. McLellan and R. K. Bonde, 2005. Morphometry, gross morphology and available histopathology in North Atlantic right whale (Eubalaena glacialis) mortalities (1970 to 2002). Journal of Cetacean Research and Management 6 (3), pp. 199-214.

Mull, R. T., 1984. Mass estimates by computed tomography: physical density from CT numbers. American Journal of Roentgenology 143 (5), pp. 1101-1104.

Ong, F. R. and K. Bouazza-Marouf, 2000. Evaluation of bone strength: correlation between measurements of bone mineral density and drilling force. Proceedings of the Institution of Mechanical Engineers 214 (Part H), pp. 385-399.

Rice, J. C., S. C. Cowin and J. A. Bowman, 1988. On the dependence of the elasticity and strength of cancellous bone on apparent density. Journal of Biomechanics 21 (2), pp. 155-168.

Right Whale Consortium, 2005. North Atlantic Right Whale Consortium Photo-ID, Sightings, Genetics, Contaminants and Necropsy Database. New England Aquarium, Boston, MA, USA.

Schaffler, M. B. and D. B. Burr, 1988. Stiffness of compact bone: Effects of porosity and density. Journal of Biomechanics 21 (1), pp. 13-16.

Snyder, S. M. and E. Schneider, 1991. Estimation of mechanical properties of cortical bone by computed tomography. Journal of Orthopaedic Research 9, pp. 422-431.

Uchiyama, T., T. Tanizawa, H. Muramatsu, N. Endo, H. E. Takahashi and T. Hara, 1999. Three-dimensional microstructural analysis of human trabecular bone in relation to its mechanical properties. Bone 25 (4), p. 487.

Wang, X., J. D. Mabrey and C. M. Agrawal, 1998. An interspecies comparison of bone fracture properties. Bio-Medical Material and Engineering 8, pp. 1-9.

Weaver, J. K. and J. Chalmers, 1966. Cancellous Bone: Its Strength and Changes with Aging and an Evaluation of Some Methods for Measuring its Mineral Content. Journal of bone and Joint Surgery 48 (2), pp. 289-299.

Williams, J. L. and J. L. Lewis, 1982. Properties of an Anisotropic Model of Cancellous Bone from the Proximal Tibial Epiphysis. Journal of Biomechanical Engineering 104, pp. 50-56.

Yan, J.-H., 2002. Biomechanical Properties of Manatee Rib Bone and Analytical Study Using Finite Element Analysis. Master's Thesis. University of Florida. Gainesville, FL. 115 pages.

Yan, J.-H., K. B. Clifton, R. L. Reep and J. J. Mecholsky, 2006. Application of Fracture Mechanics to Failure in Manatee Rib Bone. Journal of Biomechanical Engineering 128 (June), pp. 281-289.

Zioupos, P., J. D. Currey, A. Casinos and V. De Buffrenil, 1997. Mechanical properties of the rostrum of the whale Mesoplodon densirostris, a remarkably dense bony tissue. Journal of Zoology, London 241, pp. 725-737. 


\section{Chapter 5}

\section{Thesis Summary}

\subsection{INTRODUCTION}

In a 2005 policy forum entitled "North Atlantic Right Whales in Crisis," Kraus et al. appealed for immediate and aggressive action on the part of federal managers to address the human-induced mortality that threatens the critically endangered North Atlantic right whale (Kraus et al 2005). Vessel-whale collisions and entanglement in fishing gear were identified as the primary anthropogenic mortality factors facing the population and a call was made for emergency regulations requiring "changes in the operation of ships within right whale habitats and migratory corridors," including speed reductions (Kraus et al. 2005).

The National Oceanic and Atmospheric Administration/National Marine Fisheries Service, the federal agency charged with right whale protection and recovery in the United States, proposed speed restrictions as a part of its official recovery plan for the North Atlantic right whale (National Marine Fisheries Service, 2005). Speed restrictions were implemented as vessel speed advisories in 2005 and provide vessels with voluntary speed guidance at 12 knots or less in right whale critical habitat during time periods of whale occurrence (Silber and Bettridge, 2006).

Industries with a direct financial interest in efficient vessel operation, including commercial fishing, shipping and passenger vessels, are understandably resistant to 
management measures that result in increased travel time for a vessel. As with many commercial industries, profits are maximized when the cost of operations can be minimized. The added costs of operating a vessel at a lower speed in response to speed restrictions or routing around an area to avoid whales have been analyzed (Kite-Powell and Hoagland, 2002).

It is estimated that the annual costs of speed restriction measures to given ports on the eastern seaboard amount to between $\$ 300,000$ per year for smaller ports (i.e. Portland, ME and Wilmington, $\mathrm{NC}$ ) and approximately $\$ 4.8$ million per year for larger ports (i.e. New York and New Jersey) (Kite-Powell and Hoagland, 2002). While these costs would be much less of a burden on individual operators than this substantial figure would imply, the conflict between commercial interests and increasing protection for an endangered marine species is substantial. Due process in investigating and justifying potential measures that may result in added operating costs is vital to effective management and cooperative stewardship.

Proposed speed restrictions have been formulated on the basis of necropsy findings as well as accounts of reported vessel collisions involving large whales as compiled by Jensen and Silber, and Laist et al. (Jensen and Silber, 2003, Knowlton and Kraus, 2001, Laist, et al., 2001, National Marine Fisheries Service, 2006, Russell, 2001). While these datasets provide a comprehensive review and thorough analysis of reports for trends in vessel types involved, vessel speed at the time of collision, and collision outcomes, they are insufficient for addressing the direct effects of speed reduction on the 
outcome of a given collision scenario (i.e. trauma severity or fatality) (Jensen and Silber, 2003, Laist, et al., 2001).

Previously, data regarding the biomechanical effect of speed reductions in a vessel-whale collision scenario were lacking. The ultimate goal of an on-going collaborative project with the University of New Hampshire is to develop a model capable of predicting the stresses and indirectly the vessel mass and speed combinations sufficient to produce lethal blunt trauma in a right whale hit by a vessel. The preceding studies represent significant steps along the pathway toward analyzing the effect of reduced speed on the outcome of a blunt collision and recommending appropriate speed restrictions based on model results. As such, the studies composing this larger body of work accomplished three important tasks toward the development of a finite element model of vessel-whale collisions including:

1. Defining mandibular fracture as a fatal endpoint for vessel-whale collision models, based on necropsy data,

2. Characterizing the structure and physical properties of the right whale mandible, 3. Determining the material properties of the bone tissue to allow the prediction of the mechanical behavior of the bone in response to various loading conditions.

Here, the findings of these studies are summarized and preliminary findings of finite element modeling studies are presented and evaluated. Finally, the implications of this work and future studies are discussed. 


\subsection{SUMMARY OF FINDINGS}

5.2.1 Chapter 2 - Gross and histologic evidence of sharp and blunt trauma in North Atlantic right whales (Eubalaena glacialis) killed by vessels

In chapter two, gross and histologic evidence from post-mortem examination of right whale carcasses were evaluated based on the type of trauma observed to establish a standard for characterizing sharp and blunt trauma from vessel collisions. Accurate mortality statistics are a vital component to the management of endangered species and exemplifies the need for thorough examination and diagnosis of right whale mortality whenever possible. Here, four cases of vessel trauma were assessed and classified based on necropsy findings. The results provide an effective field standard for the appropriate diagnosis of cause of death for whales hit by vessels.

In addition, this study identified mandibular fracture as a common injury seen in whales that expired as a result of blunt vessel strike trauma. This justified the use of the mandible as a focal point for subsequent modeling studies.

5.2.2 Chapter 3 - Geometry, internal morphology and densitometry of the North Atlantic right whale mandible

In chapter three, the morphology and density of the mandible were explored to provide details regarding the internal structure and physical properties that influence the mechanical behavior of the whole bone. 
Morphometry: Standardized measurements of the mandible were taken and the gross structure was described in the context of other mammalian species. Empirical measurements of the physical properties of right whale bone tissue were also reported and compared to previously reported data for other species.

Internal structure: Computed tomography $(\mathrm{CT})$ was then used to perform a volumetric analysis of the various features of the jawbone, including the total bone volume, the mandibular canal and the relative contributions of components to the structure of the whole bone.

Cross-sectional and longitudinal variation in density: Calibration of computed tomography scans permitted quantitative computed tomography (QCT) analysis of the mineral density and apparent density in different regions of the right whale mandible. Results indicate that spatial trends in density variation exist. As seen in the bones of other species, the density of the right whale mandible decreases latero-medially from the cortical bone cortex to the porous trabecular core (Huiskes and van Rietbergen, 2005).

The details of this trend set the right whale mandible apart from others, as there is no marked delineation between cortical and trabecular bone as is typically seen in the bones of other species (Currey, 2002). Instead, axial CT cross-sectional images of the mandible reveal the cortical bone cortex grading medially, decreasing in density while increasing in porosity, into the trabecular medulla. This trend has been noted previously in unspecified whale species, but the evolutionary pressures that may have contributed to the development of this structural oddity are unknown (Currey, 2002). 
Longitudinal density variation was also investigated using QCT. Statistical analysis revealed a subtle, but statistically significant increase in QCT apparent density from the caudal end of the mandible to the rostral end in both cortical and trabecular bone. These findings correspond well with a similar trend in the human mandible, leaving outstanding questions regarding the relative roles of developmental processes vs. remodeling in response to loading in this non-masticating mammal (Misch, et al., 1999).

The influence of soft tissue on fracture risk: The longitudinal density trend also corresponds inversely to the thickness of the soft tissue surrounding the lower jaw which may function as a bumper to the mandible (Figure 3.5). Soft tissue thickness has been studied as a co-predictor of fracture force in the human pelvis (Etheridge, et al., 2005, Robinovitch, et al., 1991). Together with bone mineral density, soft tissue thickness has been positively correlated to the fracture force (Etheridge, et al., 2005). Soft tissue thickness is also inversely related to the peak impact force experienced at the hip during experimental falls (Robinovitch, et al., 1991). For instance, increasing in soft tissue overlying the trochanter by a factor of three has been shown to reduce the peak impact force measured at the hip by $34 \%$ (Robinovitch, et al., 1991). These results indicate that, in human subjects, soft tissue is capable of attenuating the peak impact force from blunt trauma.

The biomechanical behavior of right whale soft tissue is presently being investigated to determine the potential role that soft tissue plays in absorbing and distributing applied stress during a collision event. Characterizing the material properties 
of the visco-elastic soft tissue will provide a more complete picture of the dynamic collision event.

5.2.3 Chapter 4 - Material properties of the right whale mandible: a fatal endpoint for vessel-whale collision modeling

Finally, in chapter four, the material properties of right whale bone were determined using standard orthopedic biomechanics protocols. Uniaxial compression testing of bone specimens demonstrated that right whale trabecular bone had a Young's modulus $(E)$ to compressive strength $\left(\sigma_{\text {ult }}\right)$ ratio of about $25: 1(22.7: 1)$. This is much lower than the 100:1 ratio typical of other mammals (Currey, 1998). From this it follows that one of the following three conclusions is valid:

1) E is within the normal range of values observed for equally dense bone and $\sigma_{\text {ult }}$ is approximately 4 -fold greater than predicted by the apparent density (resulting in the 25:1 ratio),

2) $\sigma_{\text {ult }}$ is within the normal range of values observed for equally dense bone and $\mathrm{E}$ is 4-fold lower than predicted by the apparent density, 3) or neither variable falls within the typical range of values observed for equally dense bone, thus both variables are responsible for the atypical E: $\sigma_{\text {ult }}$ ratio observed.

Interspecific comparison of the apparent density vs. E and $\sigma_{\text {ult }}$ revealed that the stiffness of right whale bone was approximately 10 -fold lower than would be predicted by the apparent density (Figure 4.9). At the same time, the compressive strength was 
approximately one-fifth that seen in other bone sample of equal density (Figure 4.10). Together, these findings are consistent with the conclusion that both the Young's modulus and the compressive strength of right whale bone are lower than those reported for bones of similar density.

Mineral content and bone architecture are two factors known to have a direct influence on the biomechanical behavior of bone tissue (Currey, 1975, Gibson and Ashby, 1997, Hodgskinson and Currey, 1990, Uchiyama, et al., 1999). In chapter three, mineral (ash) content was determined for trabecular bone from the right whale mandible, and, at $64.4 \%$, it was found to be within the range of values reported for other species $(60-80 \%)$ and was thus insufficient to account for the measured reduction in strength.

While detailed examination of the microstructure of right whale bone is beyond the scope of this study, anisotropy was investigated to provide data regarding right whale jawbone structure. Mechanical testing revealed the anisotropic nature of right whale trabecular bone. The results of mechanical testing of trabecular bone indicated that the rostro-caudal axis is 3-4 times stiffer and 4-5 times stronger than the bucco-lingual and dorso-ventral axes. The Young's modulus for trabecular bone from the right whale mandible was strikingly similar to values from the human mandible (374.3 $\mathrm{MPa}$ and 373 MPa respectively). This finding indicates that the structural organization of right whale mandibular bone tissue plays an important role in determining the stiffness and strength of this bone tissue. 


\subsection{THE FINITE ELEMENT MODEL OF THE MANDIBLE}

\subsubsection{Considerations for a vessel-whale collision model}

The importance of determining the variation in bone density and the degree of anisotropy exhibited by the right whale mandible is apparent when considering the relative orientation of a whale to a vessel in various collision scenarios. The probability of stress applied during a collision being sufficient to fracture the jawbone is a combination of several key factors including (but not limited to) 1) the contact duration 2) the speed of the vessel, 3) the mass of the vessel, 4) the angle of incidence, 5) the material properties of bone along the axis of impact, 6) the surface area contacted, 7) detection ability and behavioral response of the whale, (Currey, 1975, Kite-Powell, et al., 2007, Knowlton, et al., 1995, Korsmeyer and Hynes, 1995, Laist, et al., 2001)

Contact duration: The contact duration is the amount of time over which energy is transferred from one object to another during a collision. The contact duration $(\Delta t)$ plays a large role in determining the change in momentum according to the equation:

$$
\text { External Forces }+\bar{F}_{\mathrm{vw}}+\bar{F}_{\mathrm{wv}}=\frac{\left(\mathrm{m}_{\mathrm{v}} \mathrm{v}_{\mathrm{vf}}+\mathrm{m}_{\mathrm{w}} \mathrm{v}_{\mathrm{wf}}\right)-\left(\mathrm{m}_{\mathrm{v}} \mathrm{v}_{\mathrm{vo}}+\mathrm{m}_{\mathrm{w}} \mathrm{v}_{\mathrm{wo}}\right)}{\Delta t}
$$

where $\bar{F}_{\mathrm{vw}}$ is the force applied to the whale from the vessel of mass $\mathrm{m}_{\mathrm{v}}$. Similarly, $\bar{F}_{\mathrm{wv}}$ is the force applied to the vessel from a whale of mass $\mathrm{m}_{\mathrm{w}}$. Final and initial velocities of the vessel $\left(\mathrm{v}_{\mathrm{vf}}\right.$ and $\left.\mathrm{v}_{\mathrm{vo}}\right)$ and the whale $\left(\mathrm{v}_{\mathrm{wf}}\right.$ and $\left.\mathrm{v}_{\mathrm{wo}}\right)$ are included (Cutnell and Johnson, 1998)

On land, external forces exerted on the objects include the weight of the colliding objects, but in a collision on the sea surface the force of gravity is accompanied by the 
buoyancy forces supporting both vessel and whale, as well as drag exerted by water. External forces were analyzed indirectly in several collision scenarios in a separate collision model in order to provide some insight into the effects of these parameters (Raymond, 2007). Preliminary modeling exercises concluded that fluid drag force was not significant (Raymond, 2007). ${ }^{1}$ As a result, the external forces were disregarded in subsequent modeling exercises. This leaves a simplified equation reflecting the conservation of linear momentum during a collision between a vessel and a whale (Equation 5.2).

$$
\bar{F}_{\mathrm{vw}}+\bar{F}_{\mathrm{wv}}=\frac{\left(\mathrm{m}_{\mathrm{v}} \mathrm{v}_{\mathrm{vf}}+\mathrm{m}_{\mathrm{w}} \mathrm{v}_{\mathrm{wf}}\right)-\left(\mathrm{m}_{\mathrm{v}} \mathrm{v}_{\mathrm{vo}}+\mathrm{m}_{\mathrm{w}} \mathrm{v}_{\mathrm{wo}}\right)}{\Delta t}
$$

While direct impact to the body plays a major role in the injuries resulting from blunt trauma, drastic changes in acceleration (and thereby momentum) also play a role (Galloway, 1999). From this equation it follows that a collision with minimal contact duration will result in a smaller change in the momentum of the object contacted thereby reducing the severity of trauma to some extent.

While the contact duration is at present an unknown value it can be constrained using estimates derived from the total impact duration, or time from initial contact to the time the impact force equals zero, from a finite element model of a vessel hitting a whole whale (Raymond, 2007). Values for total impact duration were found to range between 0.381 and 0.504 seconds for collisions with vessels moving 15 knots and 5 knots respectively (Raymond, 2007).

\footnotetext{
${ }^{1}$ Though considering fluid drag force in a vessel-whale collision model would likely result in more accurate predictions of collision outcomes.
} 
Vessel mass and speed: Vessels in right whale critical habitat range in size from small watercraft to large commercial container ships and very large crude carriers measuring over 1100 feet in length. Databases of known vessel-whale collisions detail the vessel types that have been involved in reported collisions with large whales (Jensen and Silber, 2003, Laist, et al., 2001). Another source of information regarding vessel size is the Mandatory Ship Reporting System (MSRS, discussed in chapter one). The MSRS is a mariner education and management tool requiring port-bound vessels entering right whale critical habitat to report their identity, course and other data while at the same time receiving the most recent location for right whales sighted in the area (National Marine Fisheries Service, 2006). Analysis of the MSRS data provides information regarding the use of coastal waters surrounding right whale critical habitat by commercial ships 300 gross tons and larger (Ward-Geiger and Silber, 2005).

Additional datasets indicate that, of the minority of reports detailing vessel size, vessels ranging from a 4-meter Boston whaler to a 259-meter cruise ship have been implicated in vessel-whale collisions (Jensen and Silber, 2003). The tonnage of a vessel involved in a collision is rarely reported (Jensen and Silber, 2003). Among the few reports where tonnage was included were a Navy ship (72 gross tons) and a tanker (46,100 gross tons). These two values, along with the MSRS minimum reporting size of 300 gross tons, are relevant to vessel-whale collisions by military and commercial vessels and are thus viable vessel mass inputs for a model of vessel collisions. 
Similarly, the speed of vessels traversing right whale critical habitat can be modeled as a range of realistic values from rule vessel ${ }^{2}$ traffic data and reports of collisions with whales (Jensen and Silber, 2003, Laist, et al., 2001, Ward-Geiger and Silber, 2005). A summary of MSRS data collected between July 1999 and June 2002 demonstrates that the reported speed of commercial ships equal to or greater than 300 gross tons ranged from 5-40 knots (Ward-Geiger and Silber, 2005). The speed data demonstrate that a majority of the reporting vessels were traveling at speeds between 12 and 16 knots with $59 \%$ of vessels reportedly traveling at or above 14 knots (Ward-Geiger and Silber, 2005).

In a comprehensive review of data reported for 292 cases of vessel collisions with large whales, the vessel speed was reported for 58 (19.8\%) of cases (Jensen and Silber, 2003). Using this partial dataset, it was determined that vessels involved in collisions were traveling at speeds ranging from 2-51 knots with an average speed of 18.1 knots ( \pm 9.14$)$ (Jensen and Silber, 2003). The average speed for vessels that struck a whale and resulted in fatal or non-fatal injury to the whale was 18.6 knots $( \pm 8.71)$ (Jensen and Silber, 2003). A majority of the vessels collisions involving injury to the whale were caused by vessels operating at speeds between 13-15 knots in this dataset (Jensen and Silber, 2003). Seventy-nine percent of the 292 vessel-whale collision events reported involved vessels operating at speeds of 13 knots or higher (National Marine Fisheries Service, 2006).

\footnotetext{
${ }^{2}$ Rule vessels are commercial vessels 300 gross tons or greater which are subject to the MSRS.
} 
An alternate review of reported collisions with whales resulted in similar findings (Laist, et al., 2001). In a 2001 review of collision reports, Laist et al. concluded that most reports of fatal and severe trauma resulted from collisions with vessels traveling at or above 14 knots (Laist, et al., 2001).

These studies detail the importance of considering ship speeds commonly traveled in right whale critical habitat (5-40 knots) and during reported collisions (2-51 knots) (Jensen and Silber, 2003, Laist, et al., 2001, Ward-Geiger and Silber, 2005). Additional focus on the range of speeds between the median and average speeds reported during fatal collisions with whales (14-18.6 knots) is also warranted (Jensen and Silber, 2003, Laist, et al., 2001).

The angle of incidence: The angle of incidence between a vessel and whale during a collision can range from slightly greater than 0 (for a glancing blow) to $90^{\circ}$ (for a perpendicular strike). Though this range of values could be explored, for simplicity, the load was applied normal to the whale, a condition that is considered the "worst-case scenario" for modeling purposes.

Behavioral response: Right whale response to vessel noise has been explored previously and is currently being investigated by others in an effort to predict the likelihood of vessel collision as a function of the approach distance and the speed of the approaching vessel (Kite-Powell, et al., 2007, Nowacek, et al., 2004, Parks, 2003) The behavioral response of right whales to approaching vessels will in part determine the surface area presented during a collision. 
The surface area contacted (A) is an important component in that it dictates to a large extent the applied stress $(\sigma)$ imposed upon the object struck according to the equation

$$
\sigma=\mathrm{F} / \mathrm{A}
$$

where $\mathrm{F}$ equals the force applied to the object of interest.

Forensic analysis of hemorrhage resulting from blunt trauma in humans reveals a lack of definitive correlation between the area of contact and the size of the resulting hemorrhage (DiMaio and DiMaio, 2001). In a realistic vessel-whale collision scenario, the surface area contacted is likely affected by the behavioral response of the whale to an approaching vessel. While behavioral response is currently being investigated, alternative assumptions can be made for the purposes of predictive modeling (e.g. on response condition and a range of realistic surface areas) (Kite-Powell, et al., 2007).

Finite element modeling of vessel-whale collisions relies upon the simplifying assumption of a "no-response" condition, thus simulating a collision with a stationary whale at the surface. This model scenario results in an equal likelihood of all the surfaces of the head being exposed during a collision. In that case, the probability that any given axis of the jaw is contacted by a vessel is proportional to the surface area that it presents.

Alternatively, preliminary evidence is available from a model of a collision between a vessel and a whole whale (Raymond, 2007). This model suggests values for the surface area of impact during a collision. These estimates were based on complex assumptions and are related to vessel speed. The model was designed by Jason Raymond and additional partners at the University of New Hampshire who are involved in the 
overarching collaborative modeling project. The specifics regarding the design and assumptions of the model are well known, increasing confidence in the appropriateness of the data for this study (Raymond, 2007). For the purposes of the model of mandibular failure, the estimated impact area $\mathrm{a}^{3}$ of $0.0915 \mathrm{~m}^{2}$ can be considered.

At present, further work is required to validate the assumptions and their impact on the model. With assumptions made regarding appropriate values for collision parameters, data can be input and the resulting model outcomes can be validated by fullscale mechanical testing on an intact jawbone. Once the behavior of the model is consistent with the results from mechanical testing, various collision parameters can be entered into the model and the model outcomes can be analyzed for relevant trends.

\subsubsection{Finite element model of mandibular failure: design and preliminary results}

A finite element model of the North Atlantic right whale mandible was created in collaboration with Judson DeCew and Igor Tsukrov of the University of New Hampshire (UNH). The model was designed to simulate the whole bone biomechanical response to applied stress from a vessel whale collision. The model predicts the distribution and magnitude of stress in individual mesh elements that compose the mandible. While the final products from this model are pending, preliminary data regarding the failure of the mandible in response to applied stress proved promising and are reported here. Detailed information regarding the development and assumptions of the model are available in a preliminary report, and are summarized briefly here (Tsukrov, et al., 2006).

\footnotetext{
${ }^{3}$ As calculated for the 15 knot condition.
} 
Finite element model design: A three-dimensional laser scan of the right whale mandible was used to create a Computer-aided design (CAD) compatible point cloud detailing its surface geometry (Figure 5.1). A finite element mesh was constructed using the transformed point cloud and was optimized to create the final model composed of 18,290 elements with 25,239 nodes (Figure 5.2) (Tsukrov, et al., 2006).

Material properties, including experimentally determined Young's modulus (E) and the ultimate compressive strength $\left(\sigma_{\mathrm{ult}}\right)$ of cortical and trabecular bone (see Chapter 4), and an estimate of Poisson's ratio were assigned to individual elements based on computed tomography (CT) data which linked QCT apparent density to 1440 points in X-, y-, z-coordinate space for the scanned mandible. This allowed elements of the mesh to be defined as cortical or trabecular bone in various regions of the mandible model coinciding with regions of cortical and trabecular bone types in the actual mandible (as determined by QCT apparent density).

Boundary conditions and loading: The boundary conditions for the mandible were designed such that the ends of the bone were fixed in three-dimensions while a load was applied over a chosen area at the midpoint of the bone. The resulting stresses were recorded during incremental loading to $155.7 \mathrm{kN}(35,000 \mathrm{lbf})$, with failure criteria for individual elements set by the ultimate compressive strength $\left(\sigma_{\text {ult }}\right)$ values determined from preliminary mechanical testing $(51.7 \mathrm{MPa})$. The load was distributed over a known area spanning 6 inches in the caudo-cranial direction and measuring $25 \%$ of the buccolingual width of the bone. 
Preliminary results: Preliminary results of loading indicate that the model is capable of providing stress output which was compared to the largest ultimate compressive strength value for cortical bone $(51.7 \mathrm{MPa})^{4}$ to predict localized failure. Localized failure is said to occur when internal stresses in a given element exceed this value. Figures 5.3, 5.4 and 5.5 are images of the model output for three loading scenarios (1400 lbf, 7,000 lbf, and 19,600 lbf) (Tsukrov, et al., 2006).

There are clear differences in the outcomes from varied loads. First, as predicted, there is a positive correlation between applied load and resulting stress. The crosssectional views of the finite element model output reveal that local stresses increase in magnitude and distribution as the load increases (Tsukrov, et al., 2006). At higher loads, localized failure is predicted across a larger area and penetrates deeper toward the center of the bone.

\footnotetext{
${ }^{4}$ As determined via uniaxial compression testing in Chapter 4.
} 
Figure 5.1: Three-dimensional laser scan of right whale mandible produces CADcompatible point cloud detailing the external geometry of the bone. a) Above, the bone was strung from a crane such that it was free to be scanned in its entirety. b) Below, the resulting point cloud image that was transformed into a finite element mesh. In both images, the caudal end is at left, while the rostral apex is at the right. The image gaps in $b$ designate the location of holding straps visible in a.
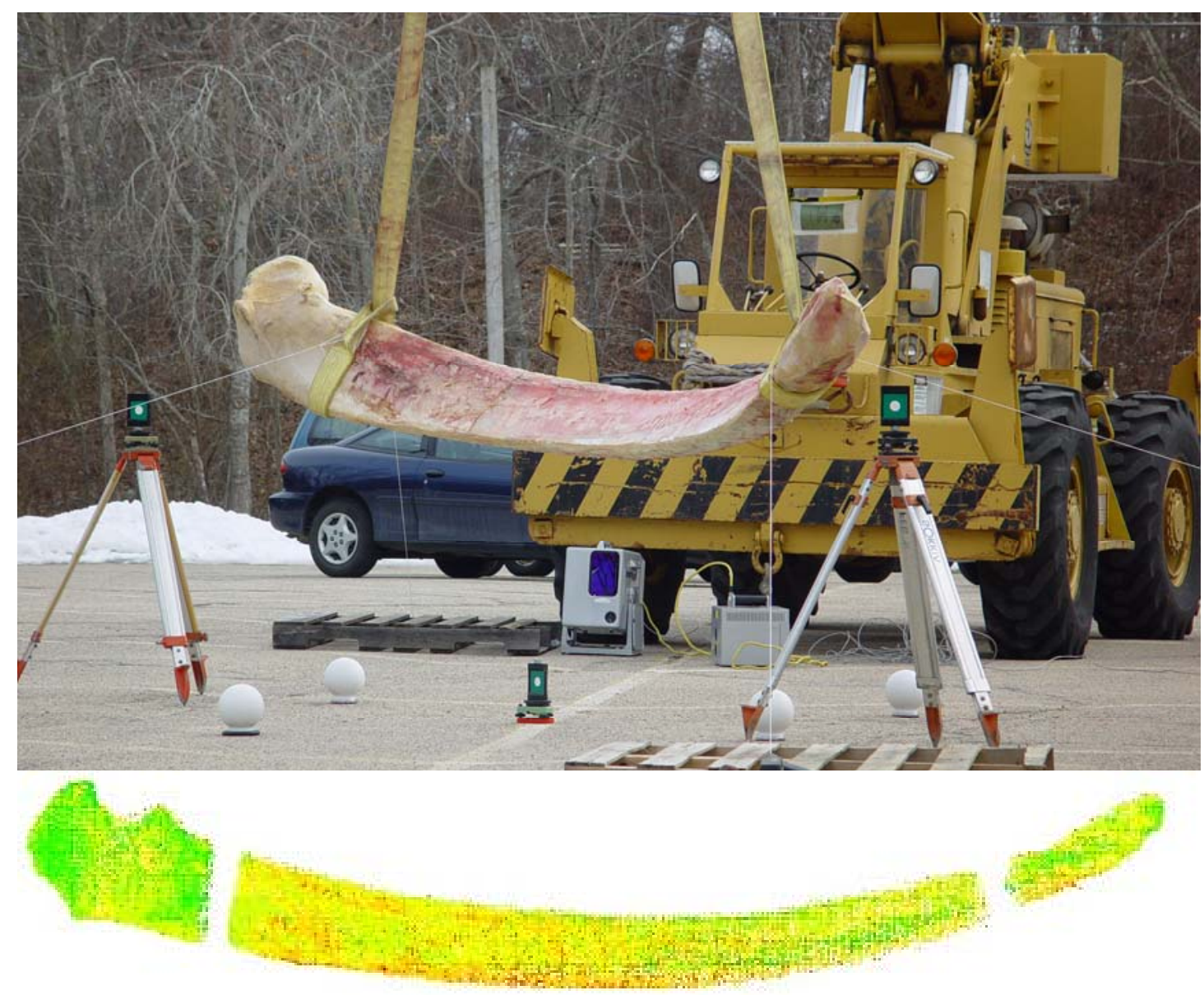
Figure 5.2: Preliminary Finite Element Model of right whale jaw bone. The bone is fixed at both ends and a load is applied over a known area. Image courtesy of J. DeCew, UNH.

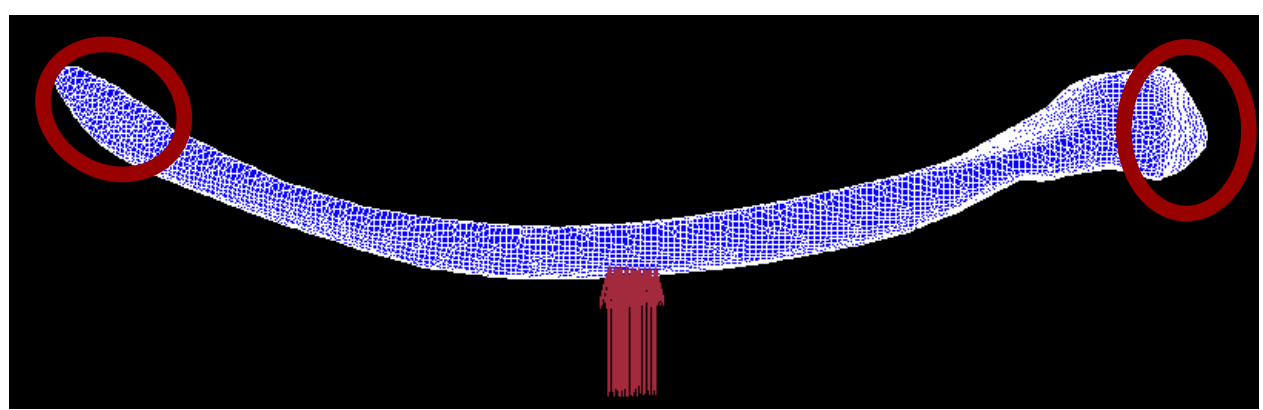

At low-level loading $(<10,500 \mathrm{lbf})$ it is notable that the internal elements are unaffected by the applied load (Figures 5.3 and 5.4). This is a scenario that would not likely result in transverse failure of the whole bone. However, when loads greater than $17,500 \mathrm{lbf}$ are applied stresses gradually penetrate to the interior. This is notable in the $19,600 \mathrm{lbf}$ scenario where a large portion of the interior reaches internal stresses sufficient to result in failure (Figure 5.5) (Tsukrov, et al., 2006).

Examining these loading scenarios with clear criteria regarding the degree of localized failure sufficient to result in bone failure is the key to evaluating the outcome of an applied load in the context of vessel-whale collisions. By varying the magnitude of the load and the area over which it is distributed, outcomes can be analyzed in the context of numerous vessel-whale collision scenarios. Additionally, by varying the location at which the load is applied, regions that are more prone (or more resistant) to bone failure may be identified. 
Figure 5.3: Finite element model simulating loading at 1,400 lbf. Color scale gives local stress in individual elements. Note that medial elements are unaffected at this loading level. Image courtesy of J. DeCew, UNH.

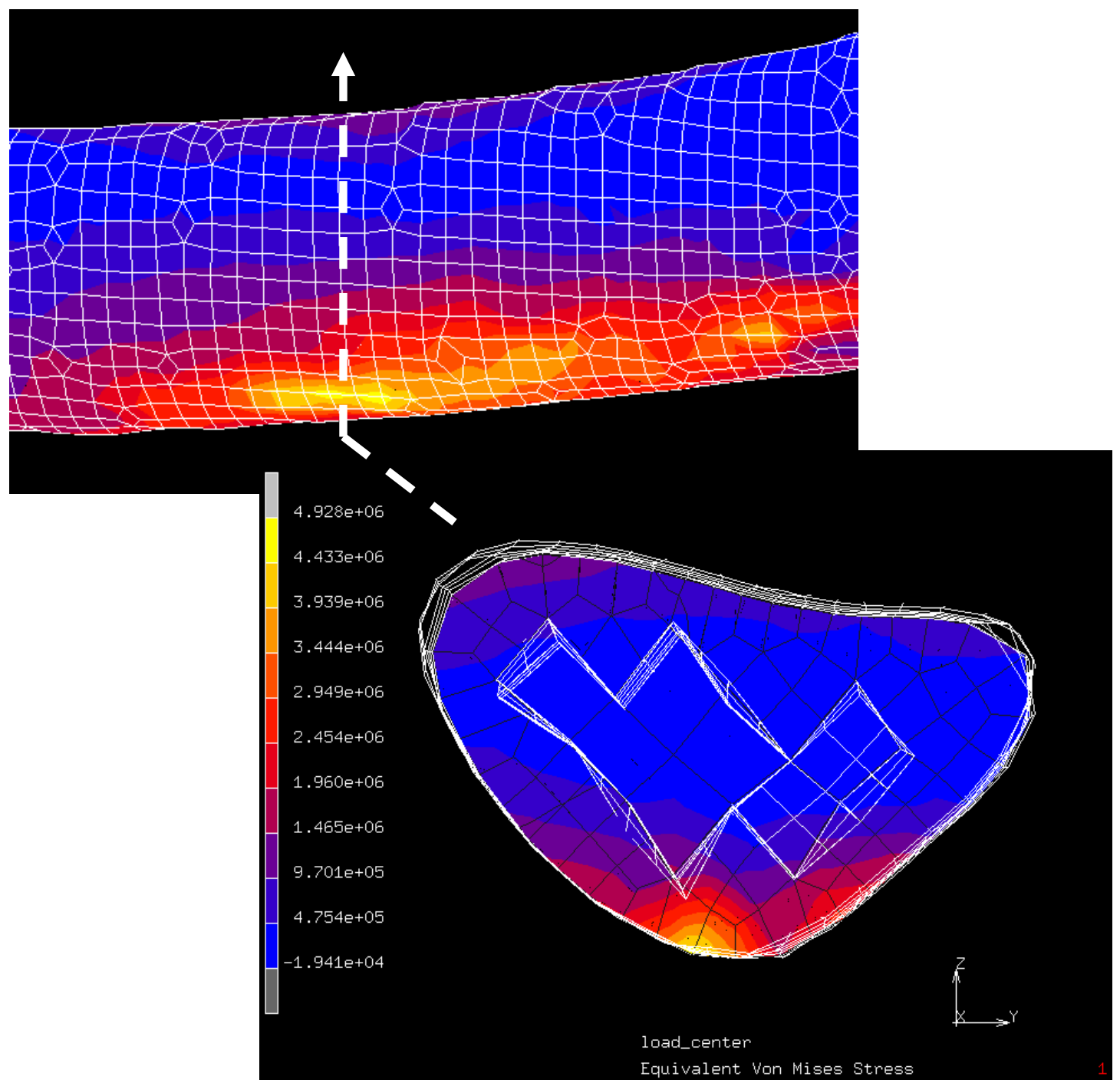

\section{0 lbs}


Figure 5.4: Finite element model simulating loading at 7,000 lbf. Color scale gives local stress in individual elements. Note that medial elements are relatively unaffected at this loading level, but stresses have increased in magnitude and distribution compared to those seen in the 1,400 lbf loading scenario. Image courtesy of J. DeCew, UNH.

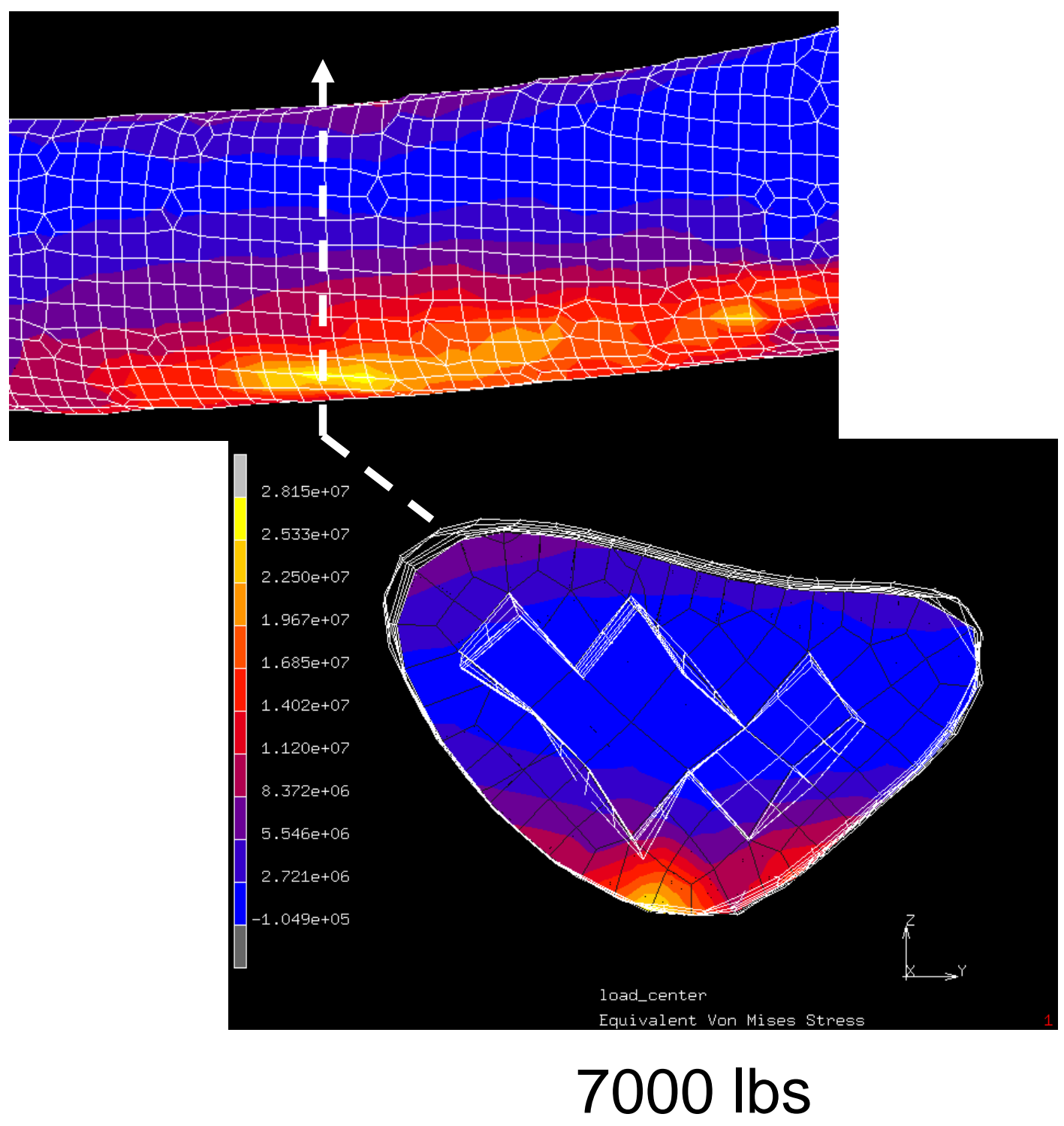


Figure 5.5: Finite element model simulating loading at 19,600 lbf. Color scale gives local stress in individual elements. Note that stresses have increased in magnitude and have started to infiltrate latero-medially compared to the 7,000 lbf scenario. Image courtesy of J. DeCew, UNH.

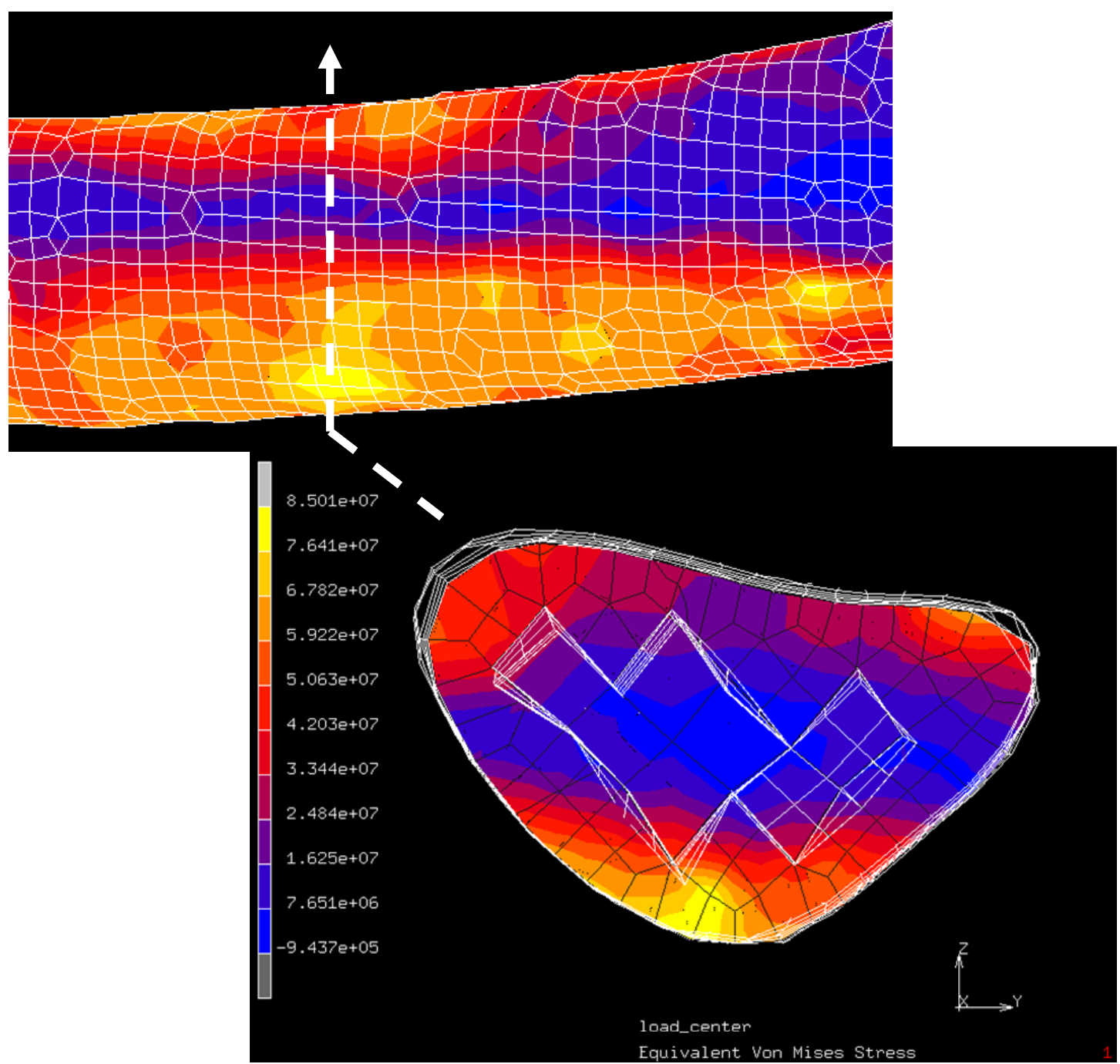

\section{$19,600 \mathrm{lbs}$}




\subsubsection{Model limitations}

While the model has its limitations, ${ }^{5}$ its utility in permitting the analysis of loading and the biomechanical response of right whale mandibular tissue is clear. It is anticipated that the refined model will provide valuable insights into the behavior of the right whale mandible and the mechanism of jawbone fracture as it relates to vessel-whale collisions. At present, however, the data reported in this volume do not provide predictions regarding the vessel size and vessel speed combinations that are sufficient to induce fractures in an intact North Atlantic right whale mandible in situ.

As noted in chapter three (section 3.3.4), several factors may limit the general application of the data presented in this volume. They include:

1) the limited sample size

2) gender bias of the sample set

3) spatial limitations of sampling

Limited sample size and gender bias: While morphometric data presented in chapter three were compiled from five individuals, ${ }^{6}$ the use of data from a larger number of individuals would increase confidence in the assumption that these values are representative of the population. Additionally, increasing the number of individuals from various life history categories (e.g. sex, age class and reproductive state) would contribute new knowledge regarding the effect of these factors on the morphometrics of the right whale mandible.

\footnotetext{
${ }^{5}$ Model limitations are discussed fully in the technical report (Tsukrov, et al., 2006)

${ }^{6}$ These included four adult females and a juvenile male.
} 
Spatial limitations of sampling: Quantitative computed tomography was used to examine the right mandible of a single mature female right whale for which no evidence of chronic health problems was noted in sighting records or upon post-mortem examination (Right Whale Consortium, 2007). As such the mandible of this animal is thought to be representative of mature adult females in this population. Additional considerations, including bone mineral loss with age as seen in human females (but not males), may contribute to adult female bone density not being representative of the entire population if this trend applies across taxa (Riggs, et al., 1981).

The overall pattern of decreased bone density (relative to other species) combined with the differences in the internal structure of cortical and trabecular bone (i.e. the presence of transitional bone rather than a definitive demarcation between cortical and trabecular bone) are likely more significant than small differences between mandibular tissue density and structure in aging females and males of the same species. As such, it is reasonable to assume that this individual is representative of the larger population of right whales and is thereby an appropriate specimen for this study (Right Whale Consortium, 2007).

Mechanical testing was conducted using samples extracted from a segment representing a portion ( $20 \%$ by length) of the mandible. The average QCT apparent density and QCT mineral density of the segment sampled represented an intermediate value compared to other regions. As the apparent and mineral densities of bone are known to be strong predictors of its stiffness and strength this segment was likewise expected to yield intermediate values for these material properties (Carter and Hayes, 
1977, Currey, 2004, Keller, 1994, Tabensky, et al., 1996). Multiple specimens

(subsamples) were tested to decrease the likelihood that spatial variation in structure resulted in random error or large standard deviations. Thus, despite spatially-limited sampling, the location from which samples were extracted was carefully chosen such that samples are likely representative of the material properties of the entire mandible.

\subsection{CONCLUSIONS}

Biomechanical studies of skeletal elements rely on the basic assumptions that bone fracture represents failure of a bone on two different scales - the tissue level and the structural or whole bone level (Hayes and Bouxsein, 1997).

At the tissue level, the data presented in this body of work demonstrate that, on average, cortical and trabecular bone tissue from a North Atlantic right whale mandible will fail when subjected to compressive stress levels as low as $51.7 \mathrm{MPa}$ and $15.6 \mathrm{MPa}$ respectively. However, these values do not take into account the ameliorating effects of soft tissue as a visco-elastic "bumper" capable of absorbing and distributing applied loads and reducing the impact force applied to the underlying bone (Etheridge, et al., 2005, Robinovitch, et al., 1991).

Furthermore, the geometry of the whole bone and of the whale as a whole cannot be ignored as factors contributing to the impact force required to fracture the mandible. Both factors should be considered along with the data reported in this volume. As such, the most appropriate methods for determining the fracture force required to fail the right 
whale mandible include 1) experimental loading of a whole specimen to failure or 2) finite element modeling validated by full-scale loading within the elastic range of the bone. The design of a controlled loading experiment was beyond the temporal and fiscal scope of the present study. However full-scale loading of the intact mandible was conducted and future work will focus on the completion of the finite element model and determination of the efficacy of proposed speed restrictions (Unrein, et al., 2005).

Additionally, it should be noted that this study only addressed blunt trauma resulting from vessel-whale collisions. The effects of speed on the outcomes of collisions involving sharp trauma in whales have been addressed by the aforementioned datasets which contain both sharp and blunt trauma cases (Jensen and Silber, 2003, Laist, et al., 2001). The conclusions of those studies, along with spatial probability models strongly suggest that slowing ships down in regions of high right whale density will reduce the likelihood of fatal encounters (Taggart and Vanderlaan, 2003, Vanderlaan and Taggart, 2007).

Further studies regarding behavioral response to approaching vessels have also contributed to a greater understanding of the potential effects of speed restrictions on the outcome of vessel-whale collisions (Kite-Powell, et al., 2007, Nowacek, et al., 2004).

Though controlled playback experiments of approach vessel noise failed to induce behavioral response in six right whales tested, in a separate study, behavioral observations indicate that whales respond to vessels as an inverse function of vesselwhale distance (Kite-Powell, et al., 2007, Nowacek, et al., 2004). It is thought that this inverse relationship between vessel distance and right whale response is based upon a 
combination of habituation to continuous stimuli and the limits of acoustic detection (Kite-Powell, et al., 2007, Nowacek, et al., 2004). Behavioral response data indicate that whales rarely commence avoidance response when an approaching vessel is over 500 meters away (Kite-Powell, et al., 2007). As such, increasing the amount of time between detection of an approaching vessel at 500 meters and the vessel intercepting the whale would provide additional time for a whale to initiate an avoidance response. The most effective way to increase the time to intercept would be to decrease the speed of the oncoming vessel. Through probabilistic modeling, Kite Powell et al. have demonstrated that reducing speed from 20-25 knots to $12-13$ knots will reduce the vessel-whale collision risk by $30 \%$.

Kite-Powell et al.'s conclusions, combined with results from this study which indicate a biomechanical advantage of reducing the load applied to the whale should a collision occur, suggest that there are compound benefits to implementing speed restrictions. Both studies predict a reduction of mortality to right whales as a result of decreasing the speed of vessels in right whale critical habitat.

The studies presented in the previous four chapters provided the means to model the biomechanics of vessel-whale collisions. Together, these studies offer unique insight into the problem that has not been addressed in previous models of vessel-whale collisions. While specific recommendations are not reported here regarding the precise speeds required to avoid vessel-whale collision mortality, further study is warranted to provide these values. Continued efforts will result in the evaluation of the impact of 
reduced speed on vessel-whale collision outcomes, thus providing valuable feedback to management agencies regarding the efficacy of programs implemented to aid the recovery of the North Atlantic right whale. 


\subsection{LITERATURE CITED}

Carter, D. R. and W. C. Hayes, 1977. The compressive behavior of bone as a two-phase porous structure. The Journal of Bone and Joint Surgery 59 (7), pp. 954-962.

Currey, J., 2004. Tensile yield in compact bone is determined by strain, post-yield behaviour by mineral content. Journal of Biomechanics 37, pp. 549-556.

Currey, J. D., 1975. The effects of strain rate, reconstruction and mineral content on some mechanical properties of bovine bone. Journal of Biomechanics 8 (1), pp. 81-82.

Currey, J. D., 1998. Mechanical properties of vertebrate hard tissues. Proceedings of the Institution of Mechanical Engineers. Part H, Journal of engineering in medicine 212, pp. 399-412.

Currey, J. D., 2002. Bones: structure and mechanics. Princeton University Press. Princeton, NJ. 436 pages.

Cutnell, J. D. and K. W. Johnson, 1998. Physics. John Wiley \& Sons, Inc. New York. pages.

DiMaio, V. J. M. and D. J. DiMaio, 2001. Forensic Pathology. CRC Press. New York. 565 pp pages.

Etheridge, B. S., D. P. Beason, R. R. Lopez, J. E. Alonso, G. McGwin and A. W. Eberhardt, 2005. Effects of Trochanteric Soft Tissues and Bone Density on Fracture of the Female Pelvis in Experimental Side Impacts. Annals of Biomedical Engineering 33 (2), pp. 248-254.

Galloway, A., 1999. Chapter 7: The Circumstances of Blunt Force Trauma. In: Galloway, A., Ed. Broken Bones: Anthropological Analysis of Blunt Force Trauma. Charles C Thomas. Springfield, Il. pp. 35-62.

Gibson, L. J. and M. F. Ashby, 1997. Chapter 11: Cancellous Bone. In. Cellular Solids: Structure and properties. Cambridge University Press. Cambridge. pp. 429-452.

Hayes, W. C. and M. L. Bouxsein, 1997. Chapter 3: Biomechanics of Cortical and Trabecular Bone: Implications for Assessment of Fracture Risk. In: Mow, V. C. and Hayes, W. C., Eds. Basic Orthopaedic Biomechanics. Lippincott-Raven Publishers. New York. pp. 69-112.

Hodgskinson, R. and J. D. Currey, 1990. Effects of structural variation on Young's modulus of non-human cancellous bone. ARCHIVE: Proceedings of the Institution of Mechanical Engineers, Part H: Journal of Engineering in Medicine 1989-1996 (vols 203-210) 204 (18), pp. 43-52.

Huiskes, R. and B. van Rietbergen, 2005. Biomechanics of Bone. In: Mow, V. C. and Huiskes, R., Eds. Basic Orthopaedic Biomechanics and Mechano-Biology. Lippincott, Williams \& Wilkins. New York. pp. 123-179.

Jensen, A. S. and G. K. Silber, 2003. Large Whale Ship Strike Database. U.S. Department of Commerce, National Oceanic and Atmospheric Administration. 37 pages.

Keller, T. S., 1994. Predicting the compressive mechanical behavior of bone. Journal of Biomechanics 27 (9), pp. 1159-1168. 
Kite-Powell, H. L. and P. Hoagland, 2002. Economic Aspects of Right Whale Ship Strike Management Measures. NOAA/National Marine Fisheries Service. Woods Hole, MA. 37 pages.

Kite-Powell, H. L., A. R. Knowlton and M. W. Brown, 2007. Modeling the effect of vessel speed on Right Whale ship strike risk. Report to NOAA/NMFS. WHOI Marine Policy Center. Woods Hole, Massachusetts.

Knowlton, A. R., F. T. Korsmeyer, J. E. Kerwin, H.-Y. Wu and B. Hynes, 1995. The Hydrodynamic Effects of Large Vessels on Right Whales. New England Aquarium \& Department of Ocean Engineering. Woods Hole, Ma. 93 pages.

Knowlton, A. R. and S. D. Kraus, 2001. Mortality and serious injury of northern right whales (Eubalaena glacialis) in the western North Atlantic Ocean. Journal of Cetacean Research and Management Special Issue 2, pp. 193-208.

Korsmeyer, F. T. and B. Hynes, 1995. Hydrodynamic Effects of Ships on Right Whales. MIT. 8 pages.

Laist, D. W., A. R. Knowlton, J. G. Mead, A. S. Collet and M. Podesta, 2001. Collisions between ships and whales. Marine Mammal Science 17 (1), pp. 35-75.

Misch, C. E., Z. Qu and M. W. Bidez, 1999. Mechanical properties of trabecular bone in the human mandible: Implications for dental implant treatment planning and surgical placement. Journal of Oral and Maxillofacial Surgery 57 (6), pp. 700706.

National Marine Fisheries Service, 2005. Recovery Plan for the Northern Right Whale (Eubalaena glacialis) Revision. National Marine Fisheries Service. 137 pages.

National Marine Fisheries Service, 2006. Proposed Rule to Implement Speed Restrictions to Reduce the Threat of Ship Collisions with North Atlantic Right Whales. Department of Commerce, 50 CFR Part 224. pages 36299-36313.

Nowacek, D. P., M. P. Johnson and P. L. Tyack, 2004. North Atlantic right whales (Eubalaena glacialis) ignore ships but respond to alerting stimuli. Proceedings of the Royal Society B: Biological Sciences 271 (1536), pp. 227-231.

Parks, S. E., 2003. Acoustic Communication in the North Atlantic right whale (Eubalaena glacialis). . Ph.D. Thesis. Massachusetts Institute of Technology. Woods Hole, MA.

Raymond, J. R., 2007. Development of a Numerical Model to Predict Impact Forces in a North Atlantic Right Whale During Collision with a Vessel. Master of Science. University of New Hampshire. Durham, NH. 100 pages.

Riggs, B. L., H. W. Wahner, W. L. Dunn, R. B. Mazess, K. P. Offord and L. J. Melton III, 1981. Differential changes in bone mineral density of the appendicular and axial skeleton with aging: relationship to spinal osteoporosis. The Journal of Clinical Investigation 67 (2), pp. 328-335.

Right Whale Consortium, 2007. North Atlantic Right Whale Consortium Photo-ID, Sightings, Genetics, Contaminants and Necropsy Database. New England Aquarium, Boston, MA, USA.

Robinovitch, S. N., W. C. Hayes and T. A. McMahon, 1991. Prediction of femoral impact forces in falls on the hip. Journal of Biomechanical Engineering 113: (4), pp. 366-74. 
Russell, B. A., 2001. Recommended measures to reduce ship strikes of North Atlantic right whales. National Marine Fisheries Service. 30 pages.

Silber, G. K. and S. Bettridge, 2006. United States' Actions to Reduce the Threat of Ship Collisions With North Atlantic Right Whales. International Whaling Commission's Conservation Committee, St. Kitts, National Oceanic and Atmospheric Administration/National Marine Fisheries Service.

Tabensky, A. D., J. Williams, V. DeLuca, E. Briganti and E. Seeman, 1996. Bone mass, areal, and volumetric bone density are equally accurate, sensitive, and specific surrogates of the breaking strength of the vertebral body: an in vitro study. Journal of Bone and Mineral Research 11 (12), pp. 1981-1988.

Taggart, C. T. and A. S. M. Vanderlaan, 2003. Regional Time/Space Conflicts in Vessel Traffic with Right Whales in the Bay of Fundy. Final Project Report, Habitat Stewardship Program for Species at Risk. Dalhousie University. Halifax, Nova Scotia, Canada. 16 pages.

Tsukrov, I., K. C. Baldwin, J. DeCew and J. J. Raymond, 2006. Finite Element Modeling of a Right Whale Mandible Strength and Ship-Whale Collision Dynamics. University of New Hampshire. Durham, NH. 55 pages.

Uchiyama, T., T. Tanizawa, H. Muramatsu, N. Endo, H. E. Takahashi and T. Hara, 1999. Three-dimensional microstructural analysis of human trabecular bone in relation to its mechanical properties. Bone 25 (4), p. 487.

Unrein, A., R. Marsella and M. Packard, 2005. Investigating the Effect of Loading on a North Atlantic Right Whale Mandible. Sea Grant, New Hampshire. Durham, NH. 62 pages.

Vanderlaan, A. S. M. and C. T. Taggart, 2007. Vessel Collisions with Whales: The probability of lethal injury based on vessel speed. Marine Mammal Science 23 (1), pp. 144-156.

Ward-Geiger, L. I. and G. K. Silber, 2005. Characterization of Ship Traffic in Right Whale Critical Habitat. Coastal Management 33, pp. 263-278. 